Aeroacústica computacional através de simulação numérica direta de escoamentos livres cisalhantes compressíveis

Jônatas Ferreira Lacerda 

Data de Depósito:

Assinatura:

Jônatas Ferreira Lacerda

\section{Aeroacústica computacional através de simulação numérica direta de escoamentos livres cisalhantes compressíveis}

\footnotetext{
Tese apresentada ao Instituto de Ciências Matemáticas e de Computação - ICMC-USP, como parte dos requisitos para obtenção do título de Doutor em Ciências - Ciências de Computação e Matemática Computacional. VERSÃO REVISADA

Área de Concentração: Ciências de Computação e Matemática Computacional

Orientador: Prof. Dr. Leandro Franco de Souza
} 
Ficha catalográ ${ }^{\mathrm{E}} \mathrm{c}$ elaborada pela Biblioteca Prof. Achille Bassi e Seção Técnica de Informática, ICMC/ USP,

com os dados fornecidos pelo(a) autor(a)

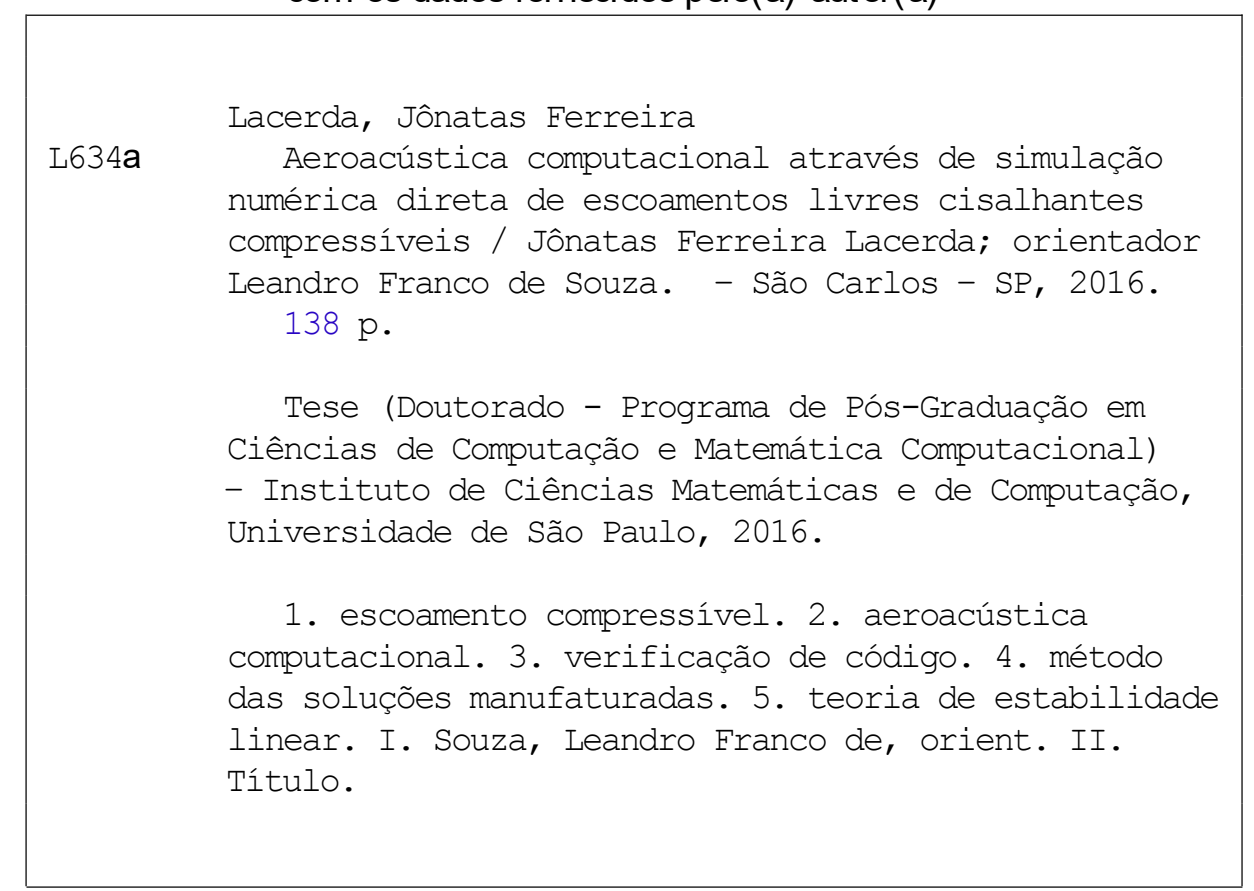


Jônatas Ferreira Lacerda

\section{Computational aeroacoustics through direct numerical simulation of free shear compressible flows}

Doctoral dissertation submitted to the Instituto de Ciências Matemáticas e de Computação - ICMC-USP, in partial fulfillment of the requirements for the degree of the Doctorate Program in Computer Science and Computational Mathematics. FINAL VERSION

Concentration Area: Computer Science and Computational Mathematics

Advisor: Prof. Dr. Leandro Franco de Souza

USP - São Carlos

July 2016 

À minha família. 

Diversas pessoas foram muito importantes durante essa etapa e sem a contribuição de cada uma eu não teria chegado até aqui .

À Tecumseh doBrasil Ltda. através de Enio Freitas eLuis Miguel por me proporcionarem essa oportunidade com total suporte.

Ao Prof. Leandro Franco de Souza, principalmente pela amizade e pelo trato fácil. Também, por aceitar um aluno de doutorado que não tinha dedicação exclusiva, mas sempre me recebendo com muita atenção, paciência e compreensão.

Aos col egas do LMAC, principal mente aos do Grupo de Estudos do Prof. Leandro por me receberem como um dos seus, e por não pouparem esforços em me auxiliar quando precisei.

Ao PhD. Andreas Babucke (IAG-Stuttgart) por fornecer os dados necessários para ini ciarmos as simul ações e responder prontamente todas as nossas questões.

Aos professores William Wolf (UNICAMP) e Márcio Mendonça (CTA) por todo suporte técnico e disponibilidade em nos atender.

Aos meus pais Élcio e Lúcia, minha irmã Raquel e seu esposo Luis, e avós por serem exemplos e porto seguro. Também aos familiares adqui ridos durante essa jornada dna. Lucimar, seu Edinal vo e Gabriel por todo carinho.

À minha companheira de caminhada, parceira de todas as horas (principal mente nas de ausência), minha linda esposa em todos os sentidos Naira. Se eu conquistei al go, não foi sozinho e não teria conseguido nada sem você. Te amo!

A Deus, princípio e fim de tudo. A Ele toda honra, glória elouvor! 

" Se dois homens vêm andando por uma estrada, cada um com um pão, e, ao se encontrarem, trocarem os pães, cada um vai embora com um. Se dois homens vêm andando por uma estrada, cada um com uma idéia, e, ao se encontrarem, trocarem as idéias, cada um vai embora com duas." 



\section{RESUMO}

LACERDA, J. F.. Aeroacústica computacional através de simulação numérica direta de escoamentos livres cisal hantes compressíveis. 2016. 138 f. Tese (Doutorado em Ciências Ciências de Computação e Matemática Computacional ) - Instituto de Ciências Matemáticas e de Computação (ICMC/USP), São Carlos-SP.

O som gerado por escoamentos, também conhecido como aeroacústica, tem se tornado cada vez mais importante em áreas industriais diversas desde aviação comercial até aparel hos eletrodomésticos, afetando diretamente os requisitos necessários para o desenvolvimento de novos produtos. Um caso particular é o ruído gerado por vál vulas de compressores herméticos de refrigeração, sendo o compressor a principal fonte de ruído em refrigeradores domésticos. O presente trabal ho tem por objetivo ini ciar o desenvolvimento de uma ferramenta confiável de simulação capaz de auxiliar engenheiros na predição de problemas de aeroacústica, especial mente um que possa no futuro ser utilizado para estudar o ruído gerado pelo escoamento em vál vul as de compressores herméticos. Para isso, foi desenvolvido um código para simulação numérica di reta de aeroacústica. Utilizou-se processamento paral elo com decomposição de domínio para usar Simul ação Numérica Direta em um tempo factível; esquemas de discretização espaciais e temporais de al ta ordem para minimizar ao máximo os fenômenos de dissi pação e dispersão do escoamento e das ondas acústicas e uma série de tratamentos no domínio como fil tragem e estiramento da mal ha como também condições de contorno características com o intuito de obter uma sol ução adequada para estudo de aeroacústica. Assim, são apresentadas todas as etapas desenvolvidas no equacionamento, implementação e verificação. A verificação foi realizada segundo um processo matemático formal (Método das Sol uções Manufaturadas) com o qual obteve-se que a ordem de precisão dos cál cul os era a mesma da ordem formal dos esquemas de discretização utilizados para todas as variáveis. Também obteve-se a mesma concordância para análise do divergente da vel oci dade, verificando o código para simul ação numérica direta de aeroacústica. Posteriormente, foram real izadas si mul ações de escoamentos compressíveis cisal hantes e seus resul tados comparados com dados apresentados em literatura. Também foram cal cul adas as taxas de amplificação de perturbações e comparadas com a Teoria de Estabilidade Linear. Novamente, foram obti dos resul tados sati sfatórios nessas etapas, mostrando que a implementação do código DNS está verificada.

Palavr as-chave: escoamento compressível, aeroacústica computacional, verificação de código, método das soluções manufaturadas, teoria de estabilidade linear. 



\section{ABSTRACT}

LACERDA, J. F.. Aeroacústica computacional através de simulação numérica direta de escoamentos livres cisal hantes compressíveis. 2016. 138 f. Tese (Doutorado em Ciências Ciências de Computação e Matemática Computacional ) - Instituto de Ciências Matemáticas e de Computação (ICMC/USP), São Carlos-SP.

Sound generated by flow, known as aeroacoustics, is becoming more important in several industrial areas from commercial aircraft to household appliances, affecting directly the requirements to the development of new products. A particular case is the noise generated by valves of refrigeration hermetic compressors, being the compressor the main noise source in household refrigerators. This work has the goal of initiate the development of a reliable tool able to help engineers to predict aeroacoustics problems, specially one that can be used in the future to study the noise generated by the flow in valves of hermetic compressors. To do so, it was developed a numerical code to perform direct numerical simulation of aeroacoustics. It was used parallel processing with domain decomposition to use Direct Numerical Simulation in a feasi ble time; high order temporal and spatial discretization schemes to minimize the most the dispersion and dissipation phenomena of the flow field and of the acoustics waves and a series of treatments in the domain as filtering and mesh stretching as well as characteristics boundary conditions aiming a proper solution to study aeroacoustics. Thus, here all the steps devel oped in the formulation, implementation and verification are presented. The verification was done according to a formal mathematical procedure (Method of Manufactured Solutions) with which was found that the precision order of the cal culations was the same of the formal order of the used discretization schemes for all variables. The same agreement was al so obtained to the analysis of the divergence of the velocity, verifying the code to direct numerical simulation of aeroacoustics. Posteriorly, it were simulated shear compressible flows and the results were compared to literature data. Also, it were calculated the amplification rates of the disturbances and compared to Linear

Stability Theory. Once more, it was obtained satisfactory results in these steps, showing that the implementation of the DNS code is verified.

Key-words: compressible flow, computational aeroacoustics, code verification, method of manufactured solutions, linear stability theory. 



\section{LISTA DE ILUSTRAÇÕES}

Figura 1 - Compressor hermético al ternativo (Cortesia da Tecumseh do Brasil Ltda). . 28

Figura 2 - Placa válvula contendo as lâminas de sucção e descarga (Cortesia da Tecumseh do Brasil Ltda). . . . . . . . . . . . . . . . . . . . . . . . . . . . . 29

Figura 3 - Caminhos de transmissão de ruído e vibração . . . . . . . . . . . . . . . . 29

Figura 4 - Esquema de um jato turbulento . . . . . . . . . . . . . . . . . . 32

Figura 5 - Difusor Radial . . . . . . . . . . . . . . . . . . . . . 33

Figura 6 - Dissi pação e dispersão de uma onda . . . . . . . . . . . . . . . . . . 36

Figura 7 - Esquema do domínio computacional tridimensional cartesiano para uma camada de mistura, destacando-se a região de interesse ea zona de amortecimento. 40

Figura 8 - Esquema do processo de simulação de um problema com o código numérico DNS. . . . . . . . . . . . . . . . . . . 50

Figura 9 - Esquema do funcionamento do código numérico DNS. . . . . . . . . . . . 51

Figura 10 - Mal ha computacional com esti ramento e divisão de domínios em cores preto e cinza. . . . . . . . . . . . . . . . . . . . . . . . 5 52

Figura 11 - Número de onda real por número de onda modificado para a $1^{a}$ derivada: (a) explíci ta centrada de $2^{\mathrm{a}}$ ordem; (b) compactas $6^{\mathrm{a}}$ ordem; (c) DRP $4^{\mathrm{a}}$ ordem; (d) valor exato; .

Figura 12 - Número de pontos por comprimento de onda por erro para a $1^{\mathrm{a}}$ derivada: (a) explícita centrada de $2^{\mathrm{a}}$ ordem; (b) compactas $6^{\mathrm{a}}$ ordem e (c) DRP $4^{\mathrm{a}}$ ordem.

Figura 13 - (esquerda) Número de onda real por número de onda modificado para a $2^{\mathrm{a}}$ derivada, e (direita) número de pontos por comprimento de onda por erro para a $2^{\mathrm{a}}$ derivada: (a) explícita centrada de $2^{\mathrm{a}}$ ordem; (b) compactas $6^{\mathrm{a}}$ ordem e (c) exato; . . . . . . . . . . . . . . . . . . . . . . . . . .

Figura 14 - Número de onda modi ficado para o cál cul o direto da segunda derivada versus aplicando a primei ra derivada duas vezes.

Figura 15 - Sobreposição do entre domínios adjacentes e processo de comunicação usando MPI . . . . . . . . . . . . . . . . . . . . . . . . . . . . 64

Figura 16 - Execução do al goritmo TDMA de forma sequencial e paral elizada. . . . . . . 64

Figura 17 - Esquema de di stribui ção dos el ementos de processamento e os índi ces utilizados. myrankx, myranky são apresentados em eixos coordenado e myrank é defi ni do no centro de cada el emento de processamento. . . . . . . . . . . . 65

Figura 18 - Esquema do funcionamento do código numérico LST. . . . . . . . . . . . . . 66

Figura 19 - Função s com transição suave . . . . . . . . . . . . . . . . . . . . . . . . . 69 
Figura 20 - (a) Erro e (b) ordem para a norma I 2 para o teste com condições de contorno prescritas para o código 2D . . . . . . . . . . . . . . . . . . . . 79

Figura 21 - (a) Erro e (b) ordem para a norma l. para o teste com condições de contorno prescritas para o código 2D . . . . . . . . . . . . . . . . . . . . 80

Figura 22 - Representação dos termos fontes para as mal has 1 e 2. . . . . . . . . . . . . 81

Figura 23 - Representação das variáveis para mal has 1 e 5. . . . . . . . . . . . . . . . . 82

Figura 24 - (a) Erro e (b) ordem para a norma I 2 para o teste com condições de contorno prescritas para o código 3D . . . . . . . . . . . . . . . . . . . . . . . . . . 84

Figura 25 - (a) Erro e (b) ordem para a norma l. para o teste com condições de contorno prescritas para o código 3D . . . . . . . . . . . . . . . . . . . 85

Figura 26 - Esquema de uma camada de mistura bi dimensi onal . . . . . . . . . . . . . . 86

Figura 27 - Esquema de uma sol ução similar para camada de mistura e condições de contorno. . . . . . . . . . . . . . . . . . . . . 87

Figura 28 - Perfis de vel ocidade u, densi dade e temperatura na entrada para o caso da camada de mistura bidimensional . . . . . . . . . . . . . . . . . . . . . . . 88

Figura 29 - Taxas de amplificação espaciais para camada de mistura bidimensional com máximo val or em $w=0 ; 6293 . \ldots \ldots$. . . . . . . . . . . . . 89

Figura 30 - (a) amplitude e (b) fase de perturbação para camada de mi stura bidimensional. 89

Figura 31 - Esquema da mal ha computacional utilizada, divisão de domínios em cores preto e cinza e condições de contorno. . . . . . . . . . . . . . . . . . . . . 90

Figura 32 - Vorticidade transversal ao final da simulação. Níveis de contorno de 0,26 até 0,02, com incremento de 0,04. (a) Colonius, Lele e Moin (1997); (b) Babucke, Kloker e Rist (2008) e (c) presente código. . . . . . . . . . . . . . 91

Figura 33 - Velocidade longitudinal média. Níveis de contorno de 0,50 até 1,00. (a) Colonius, Lele e Moin (1997); (b) Babucke, Kloker e Rist (2008) e (c) presente código. . . . . . . . . . . . . . . . . . . 92

Figura 34 - Comparação entre os resultados de Babucke, Kloker e Rist (2008) e do presente código da amplitude máxima da velocidade normal v. . . . . . . . 93

Figura 35 - Taxa de amplificação de v baseados na máxima ampl itude ao longo da di reção normal y. (a)Babucke, Kloker e Rist (2008) e (b) presente código. . . . . . . .

Figura 36 - Transformada de Fourier do campo de dilatação para a frequência (1/4). Níveis de contorno de $-10^{-5}$ a $10^{-5}$. (a) Colonius, Lele e Moin (1997) e (b) presente código. . . . . . . . . . . . . . . . . . . . . . . . . . 95

Figura 37 - Esquema de um jato planar bidimensional . . . . . . . . . . . . . . . . . . 96

Figura 38 - Perfis de (a) velocidade u, (b) temperatura e (c) densi dade para o caso Weder2D. 97

Figura 39 - Taxas de amplificação espaciais para os casos (a) sinuoso e (b) varicoso. . . 98

Figura 40 - Amplitude e distribuição de fase da perturbação para os casos (a) si nuoso e (b) varicoso. . . . . . . . . . . . . . . . . . . . . . . . . 
Figura 41 - Vorticidade transversal ao final da simulação para o modo sinuoso. Níveis de contorno de-2,4 até 2,4 com incremento de 0,2. Linhas sólidas correspondem a val ores positivos e tracejadas val ores negativos. . . . . . . . . . . . . 100

Figura 42 - Vorticidade transversal ao final da simulação para o modo varicoso. Níveis de contorno de-2,4 até2,4 com incremento de 0,2. Linhas sólidas correspondem a val ores positivos e tracejadas valores negativos. . . . . . . . . . . . . . . 100

Figura 43 - Perfil de veloci dade u para o caso ReichertBiringen2D. . . . . . . . . . . . 101

Figura 44 - Taxas de amplificação espaciais para os casos ReichertBiringen2D, modo sinuoso.

Figura 45 - Taxas de amplificação espaciais para os casos ReichertBiringen2D, modo varicoso.

Figura 46 - Vorticidade transversal ao final da simulação para o modo sinuoso. Níveis de contorno de -0,5 até 0,5. Linhas sól idas correspondem a valores positivose tracejadas val ores negativos. . . . . . . . . . . . . . . . . . . . . . . . 105

Figura 47 - Vorticidade transversal ao final da simulação para o modo varicoso. Níveis de contorno de -0,5 até 0,5. Linhas sólidas correspondem a valores positivos e tracejadas valores negativos. . . . . . . . . . . . . . . . . . . . 105

Figura 48 - Amplitude máxima da velocidade normal $v$ ao longo de y para o modo si nuoso. 107 Figura 49 - Amplitude máxima da vel ocidade normal v ao longo de y para o modo varicoso.107 Figura 50 - Máxima amplitude da vel ocidade normal v ao longo da direção y para cada posição x, para o modo sinuoso. Linhas sóli das: resul tados com o presente código e linhas tracejadas: resul tados obtidos com o código LST. . . . . . . . 108

Figura 51 - Máxima amplitude da vel ocidade normal v ao longo da direção y para cada posição x, para o modo varicoso. Linhas sólidas: resul tados com o presente código e linhas tracejadas: resul tados obtidos com o código LST.

Figura 52 - Divergente da velocidade dos casos sinuoso e varicoso com $\mathrm{Ma}_{\mathrm{j}}=0$; 25 para

(a) w; (b) w=2; (c) w=4 e (d) $w=8$.

Figura 53 - Divergente da velocidade dos casos sinuoso e varicoso com $\mathrm{Ma}_{\mathrm{j}}=1 ; 05$ para

(a) w; (b) w=2; (c) w=4 e (d) w=8.

Figura 54 - Divergente da velocidade dos casos sinuoso e varicoso com $\mathrm{Ma}_{\mathrm{j}}=1 ; 50$ para

(a) w; (b) w=2; (c) w=4 e (d) w=8.

Figura 55 - Divergente da velocidade dos casos sinuoso e varicoso com $\mathrm{Maj}_{\mathrm{j}}=2 ; 00$ para

(a) w; (b) w=2; (c) w=4 e (d) w=8.

Figura 56 - Divergente da velocidade dos casos sinuoso e varicoso com $\mathrm{Ma}_{\mathrm{j}}=2 ; 50$ para (a) w; (b) w=2; (c) w=4 e (d) w=8.

Figura 57 - Divergente da velocidade dos casos sinuoso e varicoso com $\mathrm{Maj}_{\mathrm{j}}=3 ; 00$ para

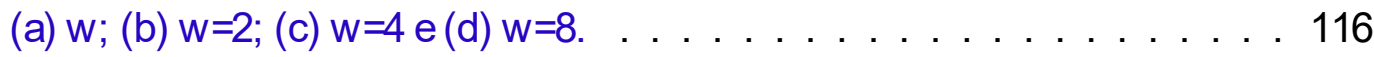

Figura 58 - Termo fonte para a variável $r$ - MMS 2D. . . . . . . . . . . . . . . . . . 131

Figura 59 - Termo fonte para a variável r u - MMS 2D . . . . . . . . . . . . . . . . . 131 
Figura 60 - Termo fonte para a variável $\mathrm{r} v$ - MMS 2D . . . . . . . . . . . . . . 132

Figura 61 - Termo fonte para a variável E - MMS 2D. . . . . . . . . . . . . 132

Figura 62 - Termo fonte para a variável $r$ - MMS 3D. . . . . . . . . . . . 132

Figura 63 - Termo fonte para a variável $\mathrm{r}$ u - MMS 3D . . . . . . . . . . . . . 132

Figura 64 - Termo fonte para a variável $r \mathrm{v}$ - MMS 3D . . . . . . . . . . . . 133

Figura 65 - Termo fonte para a variável $\mathrm{r} w$ - MMS 3D. . . . . . . . . . 133

Figura 66 - Termo fonte para a variável E - MMS3D. . . . . . . . . . . . . 134

Figura 67 - Speedup para os casos bidimensionais. . . . . . . . . . . . . 136

Figura 68 - Eficiência para os casos bidimensionais. . . . . . . . . . . . . 137

Figura 69 - Tempo adimensional para os casos bidimensionais. . . . . . . . . . 138 


\section{LISTA DE TABELAS}

Tabela 1 - Tipos de fontes aeroacústicas e características de radiação. . . . . . . . . . . . . . 32

Tabela 2 - Mal has utilizadas para o teste de condições de contorno prescritas. . . . . . . . . 77

Tabela 3 - Mal has utilizadas para o teste de condições de contorno prescritas. . . . . . . . . 83

Tabela 4 - Valore máximos de taxa de amplificação espacial para os casos sinuoso e varicoso. 97

Tabela 5 - Números de Mach e val ores máximos de taxa de amplificação espacial para os casos ReichertBiringen2D, modo sinuoso. . . . . . . . . . . . . . . . . . . . 102

Tabela 6 - Números de Mach e val ores máximos de taxa de amplificação espacial para os casos ReichertBiringen2D, modo varicoso. . . . . . . . . . . . . . . . . . . . 102

Tabela 7 - Parâmetros das simulações bi dimensionai s. . . . . . . . . . . . . . . . . . 137 

— Letras Latinas

a - velocidade do som no meio

$(a ; b ; c)$ - coeficientes dos esquemas de diferenças finitas

c - variável característica correspondente a onda acústica

$\left(c_{p} ; c_{v}\right)$ - cal or específico à pressão constante e cal or específico à volume constante

d — diâmetro do orifício de passagem do difusor radial

D — diâmetro do disco frontal do difusor radial

E - energia total

$E_{2 h} ; E_{h}$ - erros gl obais para a mal ha mais grosseira e para a mais refinada

E $f$ - eficiência

f — função genérica

$\hat{f}_{\mathrm{k}}$ - variável no espaço de Fourier

$(F ; G ; H)$ - vetores de fluxo nas direções $x$, y e z

$\mathrm{g}$ - função tangente hiperbólica para camada de mi stura bi dimensional

$\mathrm{h}$ - espaçamento entre pontos em uma mal ha uniforme

i — unidade imaginária ${ }^{\sqrt{ }} \overline{-1}$

$\mathrm{J}$ - determinante do Jacobiano da transformação de coordenadas

$\mathrm{K}$ - número de modos no espaço de Fourier

I - comprimento do assento do difusor radial

$\mathrm{L}$ — comprimento de referência e comprimento do domínio

$\mathrm{I}_{2}-$ normal $_{2}$

I. - normal.

Ma - número de Mach

$\mathrm{N}$ - número de pontos da mal ha na respectiva direção

$\mathrm{N}_{l}$ - número de pontos por comprimento de onda 
o — ordem de precisão

p - pressão

Pr — número de Prandtl

$\left(q x ; q_{y} ; q z\right)$ — fluxo de cal or nas direções $x$, y e z

$\mathrm{Q}$ - vetor sol ução com variáveis conservativas

$r$ - razão de refino entre 2 mal has consecutivas

$\mathrm{R}$ — metade do comprimento do jato planar

Re — número de Reynolds

s - al tura de afastamento do disco frontal do difusor radial e coordenada normal izada

S - termo fonte das sol uções manufaturadas

Sp - Speedup

$\mathrm{t}$ - tempo

Dt - incremento de tempo

$\mathrm{T}$ - temperatura

$\mathrm{T}_{1}$ - tempo computacional com um elemento de processamento

$\mathrm{T}_{\mathrm{N}}$ - tempo computacional com $\mathrm{N}$ elementos de processamento

$(u ; v, w)$ - componentes da velocidade nas direções x, y e z

$\mathrm{U}$ - velocidade da corrente livre

$(x ; y, z)$ - coordenadas na direção longitudinal, normal e transversal

(Dx; Dy, Dz) — incremento da mal ha regular nas direções $x$, y e z

- Letras Gregas

$a ; b$ - coeficientes das derivadas para os esquemas de diferenças finitas

b - número de onda

d - constante do esquema de diferenças finitas DRP

g - número de onda da frequência fundamental na di reção $z$

$e_{1} ; e_{2}$ - erro pela análise de Fourier para a $1^{\mathrm{a}}$ e $2^{\mathrm{a}}$ derivadas

$\mathrm{J}$ - condutividade térmica

k — razão de calores específicos

$\mathrm{m}$ — viscosi dade dinâmica

$\mathrm{I}_{z}$ - comprimento do domínio na direção z 
$\mathrm{x} ; \mathrm{h}$ - mal ha regular correspondente ao plano $(\mathrm{x} ; \mathrm{y})$

$D x ; D h$ —incremento da mal ha regular no plano $(x ; h)$

$r$ - densidade

$\mathrm{F}$ - estiramento da mal ha

s - função rampa suave

c — variável auxiliar para a função rampa

$\left(t_{x x} ; t_{y y} ; t_{z z}\right)$ - tensões normais

$\left(t_{x y} ; t_{x z} ; t_{y z}\right)$ - tensões cisal hantes

$q$ - defasagem de fase das autofunções e espessura da região de mistura do jato

Q - distribuição de fase das autofunções

$w_{0}$ - frequência fundamental da perturçaão

- Símbolos

— variáveis dimensionais

b— variáveis filtradas

— variáveis no espaço de Fourier

' - primeira derivada e flutuações de propriedade dos escoamento

" - segunda derivada

- Subíndices

an — solução anal ítica

num — solução numérica

D1 - termos relacionados à primeira derivada

D2 - termos relacionados à segunda derivada

i - ponto da mal ha

j - propriedades da corrente do jato para o caso de jato planar

k - variável no espaço de Fourier

0 - propriedades do escoamento base

1- propriedades da corrente livre mais rápi da para o caso da camada de mistura

2- propriedades da corrente livre mais I enta para o caso da camada de mistura

- - propriedades da corrente livre de referência 

INTRODUÇÃO . . . . . . . . . . . . . . . . . . . 27

1.1 Ruído em Compressores Herméticos Alternativos . . . . . . . . . 28

1.2 Ruído Gerado por Escoamento - Aeroacústica . . . . . . . . . . . 30

$1.3 \quad$ Aeroacústica Computacional . . . . . . . . . . . . . . 33

$1.4 \quad$ Objetivo Principal e Escopo do Trabalho . . . . . . . . . . . 37

2 FORMULAÇÃO MATEMÁTICA . . . . . . . . . . . . 39

$2.1 \quad$ Notação . . . . . . . . . . . . . . . . . . . . . . . . . 39

2.2 Equações Governantes . . . . . . . . . . . . . . . . . 41

$2.3 \quad$ Teoria de Estabilidade Linear . . . . . . . . . . . . . . . 43

3 MÉTODO NUMÉRICO . . . . . . . . . . . . . . . . . 49

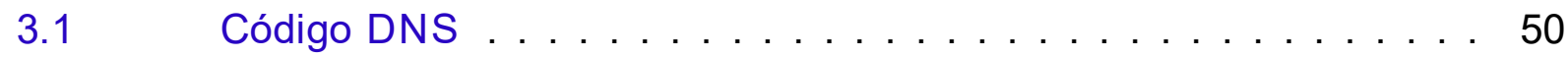

3.2 Decomposição do Domínio e Transformação de Coordenadas . . . 51

3.3 Discretização Numérica . . . . . . . . . . . . . . . . . . . . 54

3.3.1 Esquema de Discretização Espacial . . . . . . . . . . . . . . . . . 54

3.3.2 Esquema de Discretização Temporal . . . . . . . . . . . . . . 58

$3.4 \quad$ Análise de Fourier das Derivadas Espaciais . . . . . . . . . . 58

3.5 TDMA Paralelizado . . . . . . . . . . . . . . . 63

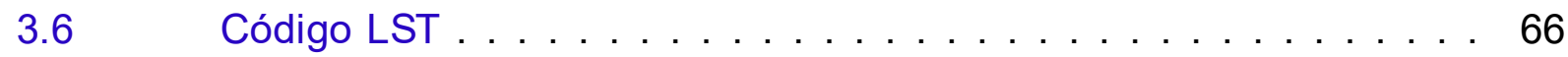

$3.7 \quad$ Condições de Contorno . . . . . . . . . . . . . . . . . . . 67

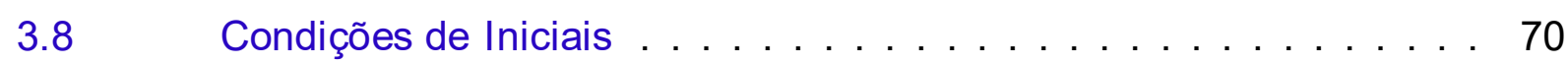

$4 \quad$ RESULTADOS . . . . . . . . . . . . . . 73

4.1 Veri ⿷匚⿱⺊⿴囗㐅㐅⿺乚一匕ação e Validação de Códigos Numéricos . . . . . . . . . . . . 74

4.1.1 Método das Soluções M anufaturadas . . . . . . . . . . . . . . 75

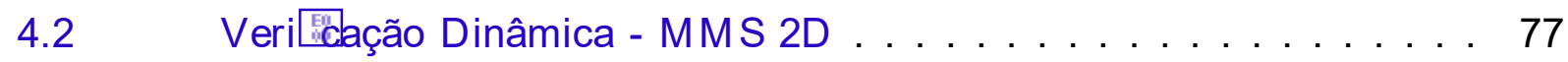

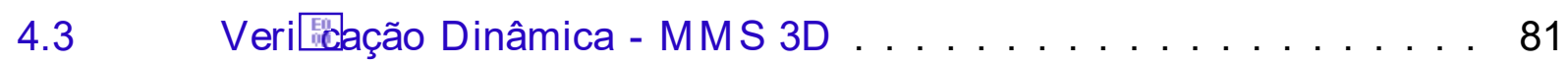

$4.4 \quad$ Camada de Mistura Bidimensional . . . . . . . . . . . . . . . 86

4.5 Jatos Planares Bidimensionais . . . . . . . . . . . . . . . . . 95

4.5.1 Jatos Planares Bidimensionais - caso apresentado por Weder (2012) 96

4.5.2 Jatos Planares Bidimensionais - caso apresentado por Reichert e Biringen (2007) . . . . . . . . . . . . . . . . . . 101 
REFERÊNCIAS . . . . . . . . . . . . . . . . . . . . 119

APÊNDICE A TERMOS ADICIONAIS NAS EQUAÇÕES GOVER-

NANTES . . . . . . . . . . . . . . 125

APÊNDICE B TERMOS FONTES DO MMS . . . . . . . . . 131

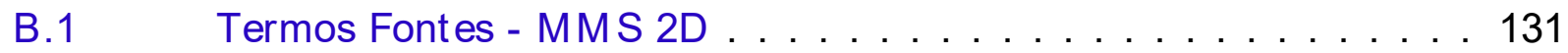

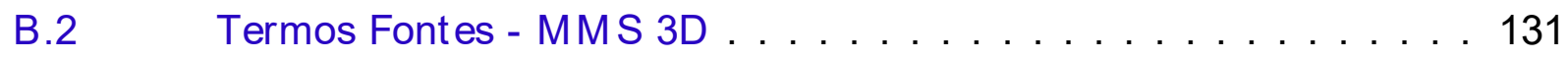

APÊNDICE C SPEEDUP E EFICIÊNCIA . . . . . . . . . 135 
CAPÍTULO
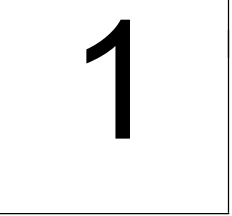

\section{INTRODUÇÃO}

Faz parte da vida do ser humano ouvir o que ocorre no mundo a sua vol ta e interagir com esse estímulo. O som pode ser agradável ou até imperceptível em muitas ocasiões, porém também pode ser incômodo em outras, ao que se dá o nome de ruído. O ruído nada mais é do que um som excessivo ou desconfortável e sua redução tem se tornado um importante aspecto para o aumento do conforto e bem-estar do ser humano.

Tal preocupação tem provocado, por exemplo, um aumento no nível de exigência de regulamentações quanto a níveis de ruídos em regiões próximas a aeroportos (BABUCKE, 2009). Também se observa um aumento da pressão de consumi dores e órgãos governamentais por diminuição de ruído de bens de consumo domiciliares, motivando fabricantes a of erecer produtos menos ruidosos que atendam exigências legi sl ativas ou padrões de acei tação melhores estabel ecidos pela concorrência (NUNES, 2005). Segundo a norma NBR10152 (1987), os níveis de ruído recomendados para conforto acústico em dormitórios e salas de estar devem estar entre $35-45 \mathrm{~dB}(\mathrm{~A}){ }^{1}$ e 40 - $50 \mathrm{~dB}(\mathrm{~A})$, respectivamente, que se equival em a níveis de ruídos observados em bibliotecas. Daí surge o termo "controle de ruído" e a ideia de que para projetar equi pamentos menos rui dosos é necessário entender os mecani smos bási cos de geração e propagação de ruído.

Dentre esses produtos, podem-se destacar os refrigeradores e freezers domésticos, onde a principal fonte de ruído são os compressores instal ados para comprimir o fluido de trabal ho responsável por promover a retirada de cal or do ambiente refrigerado. Geral mente, um compres sor do tipo hermético al ternativo é utilizado nessas aplicações. A redução do ruído gerado por escoamento dentro de um compressor hermético é a principal motivação do presente trabal ho

$1 \mathrm{~dB}(\mathrm{~A})$ : nível de pressão sonora em escal a decibel e ponderada por uma curva de correção $\mathrm{A}$ que representa melhor a resposta da audição humana a certas frequências 


\subsection{Ruído em Compressores Herméticos Alternativos}

Um compressor hermético alternativo utilizado em refrigeradores é apresentado em mais detal hes na Figura 1. O processo de compressão do gás refrigerante é realizado pelo deslocamento linear e al ternado de um pistão no interior de um cilindro de compressão. Vál vulas de sucção e de descarga são responsáveis pela retenção e passagem do flui do de trabal ho de uma da câmara de sucção para o cilindro e do cilindro para uma câmara de descarga, respectivamente. As diferenças de pressão entre o cilindro e a câmara de sucção e a câmara de descarga comandam inicial mente a abertura e o fechamento das vál vulas. Uma vez abertas, o movimento das vál vulas é controlado pel a força resul tante da ação conjunta do campo de pressão do próprio escoamento e da força de reação devido às características dinâmicas das vál vulas. Como as vál vulas não possuem um mecani smo auxiliar de acionamento, são denominadas automáticas (LACERDA, 2009), e podem ser vistas com mais detal hes na Figura 2. Além dos componentes destacados anteriormente, também pode se observar na Figura 1 que o cilindro de compressão é uma região destacada em um corpo fundido apoi ado sobre molas fixas na base da carcaça. Também é possível notar um motor elétrico que, através do movimento rotativo, é responsável pelo acionamento do mecanismo que impõe o movimento linear ao pistão.

Figura 1 - Compressor hermético al ternativo (Cortesia da Tecumseh do Brasil Ltda).

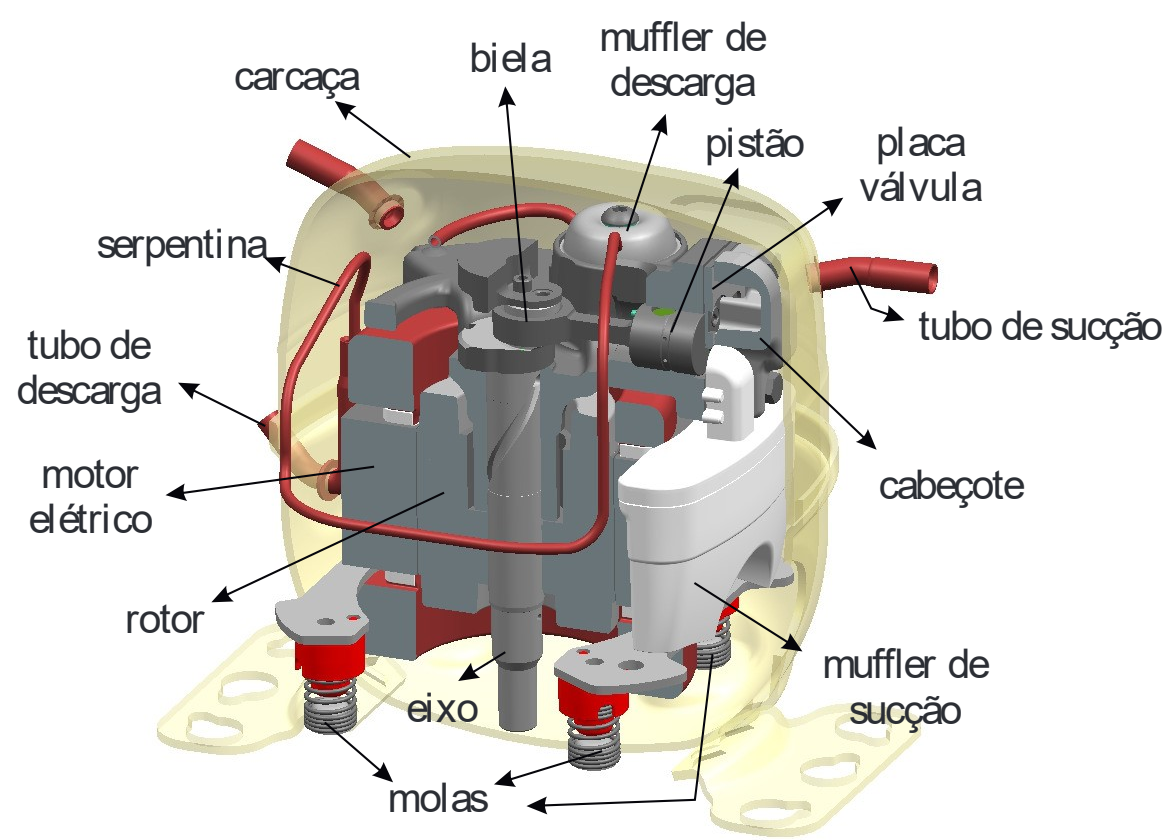

Fonte: Elaborada pelo autor.

A partir das fontes sonoras no interior do compressor, o ruído percorre caminhos de transmissão até chegar a carcaça e ser irradiado para o ambiente, ou pode ai nda excitar a tubulação do refrigerador através da vibração do compressor. Os princi pais caminhos de transmissão são a vibração estrutural das partes sólidas transmitidas pelas molas ou serpentina à carcaça ou através da excitação do gás presente na cavidade acústica interna, que, por sua vez, também excita 
Figura 2 - Placa vál vula contendo as lâminas de sucção e descarga (Cortesia da Tecumseh do Brasil Ltda).
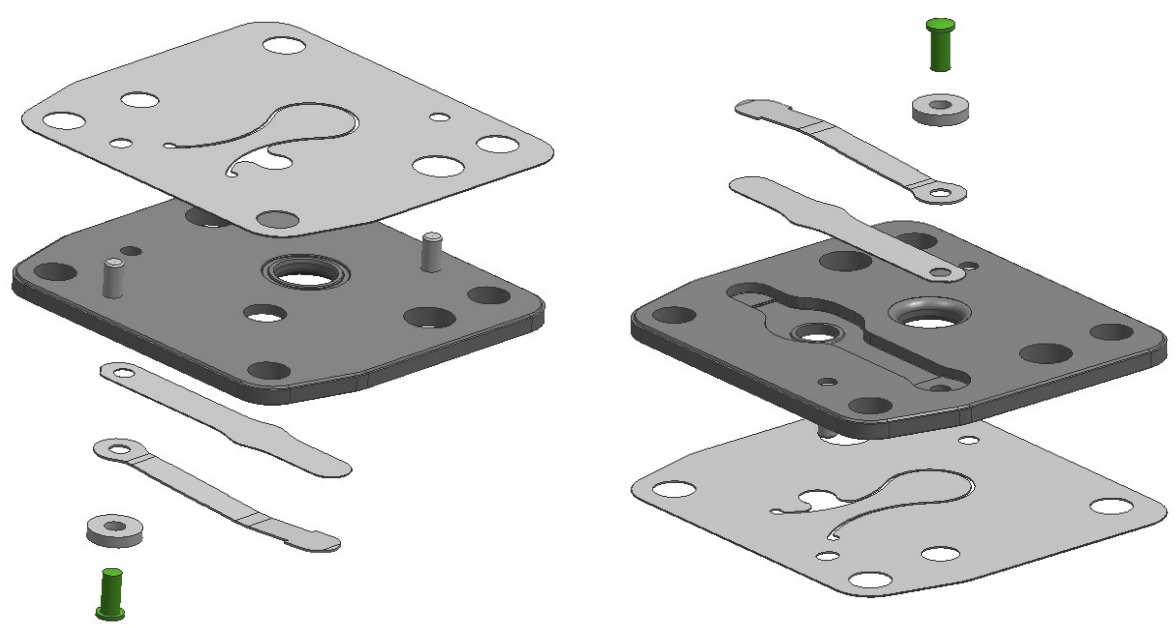

Fonte: Elaborada pelo autor.

a carcaça e irradia pela carcaça, conforme Figura 3 (NUNES, 2005). Efeitos de ressonância (momento em que há acoplamento entre frequências de excitação com as frequências naturais de componentes mecânicos ou cavidades acústicas) tendem a aumentar a intensidade sonora irradiada pel o compressor.

Figura 3 - Caminhos de transmissão de ruído e vibração

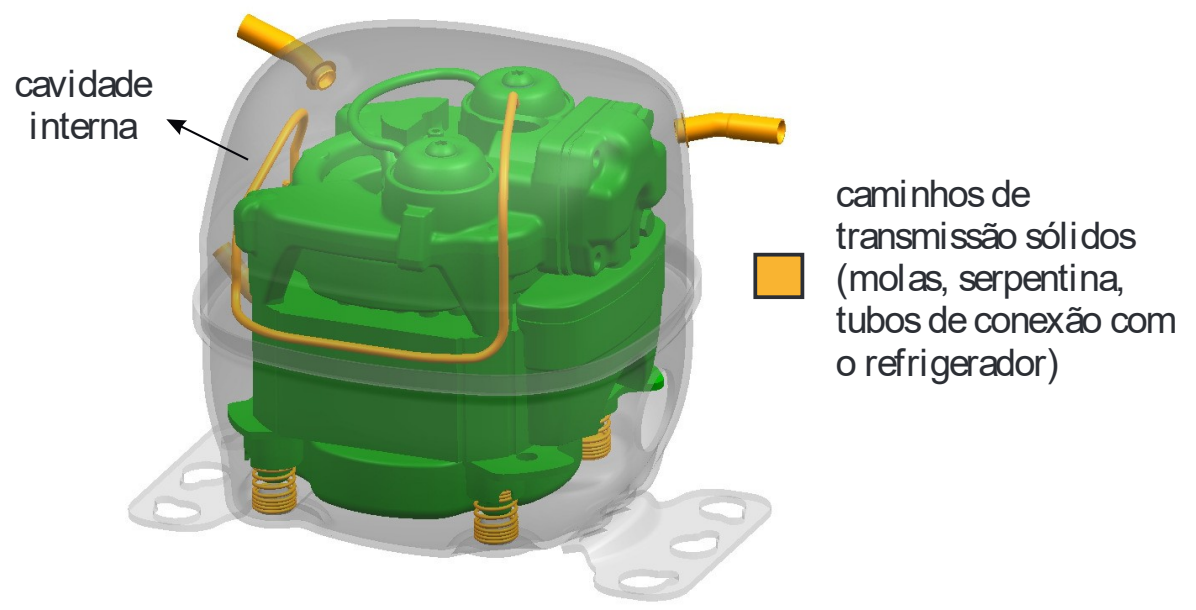

Fonte: Elaborada pelo autor.

O compressor possui dois tipos principais de fontes de ruído: mecânicas e não mecânicas. Soedel (2006) apresenta diversas fontes de ruído em compressores de deslocamento positivo, que é o caso dos compressores herméticos al ternativos. De forma sucinta, destacam-se entre as fontes do tipo mecânicas as forças vibratórias decorrentes do movimento dos componentes móveis e transmitidas através das molas ou tubulações internas. As fontes do tipo não mecâni cas são causadas principal mente pelas pul sações do fluido de trabal ho nas linhas de sucção e descarga, 
podendo excitar cavidades acústicas presentes no interior do compressor. Santos (2003) também destaca a associação entre as grandes variações de pressão e a inércia das partes móveis que causam vibrações geradas pel os impactos nas folgas existentes.

Os mecanismos de geração e propagação de ruído descritos até então já foram bastante investigados. Alguns exemplos são os trabal hos de Silveira (2004) que investigou as fontes e caminhos de transmissão de ruído e vibração em compressores utilizados em apl icações comerciais destacando quais componentes contribuíam mais em determinadas faixas de frequência e propondo modificações que reduziram os níveis sonoros de um modelo antigo; e também Silva, Lenzi e Baars (2004) que utilizaram al goritmos genéticos para avaliar diversas formas de serpentina buscando minimizar a energia vibratória transmitida à carcaça.

Diversas soluções construtivas são utilizadas para reduzir o ruído irradiado de compressores destacando-se, princi pal mente, a instal ação de filtros acústicos (mufflers) nos sistemas de sucção e descarga para atenuar o ruído gerado pelas pul sações do gás; mi nimização da energia transmitida pel os caminhos de transmissão como projetos oti mizados de molas e serpentina por meio do control e de forma e propriedades dos materiais utilizados; e, por final, o desacoplamento entre frequências de excitação e as frequências naturais de componentes sól idos e de cavidades acústicas, principal mente da carcaça do compressor.

Outro mecanismo de geração de ruído em válvulas de compressores herméticos de refrigeração é aquele produzido pelo próprio escoamento através do desprendimento de vórtices. Se o regime de geração de vórtices é periódico, um ruído tonal sobreposto com a frequência próxima da frequência de vibração da vál vul a é observado, entretanto, se o regi me de geração de vórtices é turbulento, uma ampla faixa de modos é excitada, gerando um ruído de banda larga (FAHY, 2003). Tal fenômeno é ainda pouco investigado e éa principal motivação para real ização do presente trabal ho.

O objetivo principal do presente trabal ho é real izar um estudo numérico da geração e propagação de ruído gerado por um jato planar, semel hante ao escoamento obtido em vál vulas de compressores herméticos.

\subsection{Ruído Gerado por Escoamento - Aeroacústica}

O som pode ser descrito como flutuações de pressão, geral mente em torno da pressão atmosférica, que se propagam por um meio a uma determinada velocidade, chamada de vel ocidade do som no meio. O som gerado por escoamentos transientes e pela interação de escoamentos de gases com superfícies sólidas é chamado de "som aerodinâmico" e Aeroacústica é a disci plina responsável por estudar esses fenômenos. O nível de pressão sonora (Soud Pressure Level - SPL) 
é uma medi da em deci béis $(\mathrm{dB})$ da pressão sonora em relação a um valor de referência:

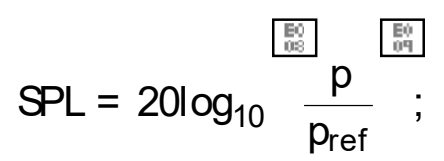

onde p é a pressão sonora e o valor geralmente usado para ar é pref $=20 \mathrm{mPa}$.

O som aerodinâmico pode ser atribuído a três tipos bási cos de fontes: monopolo, di polo e quadrupolo. Fontes do tipo monopolo são geradas pelo deslocamento de fluido de maneira transi ente, como o provocado por autofal antes ou sirenes, pela injeção intermitente de massa como a saída de escapamentos, ou pela variação brusca de temperatura também de forma intermitente, como por exemplo um laser pul sando (FAHY, 2003). A radi ação de um monopolo aerodinâmico em um meio parado ocorre de forma igual em todas as direções, assumindo um padrão esférico simétrico, conforme Tabela 1.

Já fontes do tipo dipolo aerodinâmicos ocorrem quando escoamentos transi entes interagem com superfícies gerando forças transientes onde parte da energia é convertida em som. Alguns exemplos desse tipo de som são os assobios do ar passando por cabos de energia ou aerofól ios de carros. A radiação de um di pol o aerodi nâmico é equival ente a um par de monopolos defasados em $180^{\circ}$, criando uma interferência destrutiva de radiação. Assim surge uma direção preferencial de radiação, conforme Tabela 1.

Por fim as fontes do tipo quadrupol os aerodi nâmi cos são produzidos pel os tensores de Reynolds em escoamentos turbul entos na ausência de obstáculos, como a partir da geração de vórtices turbul entos em escoamentos cisal hantes (jatos ou camadas de misturas). A radi ação de um quadrupolo é equival ente a um par de dipolos, defasados em $180^{\circ}$ tendo assim duas direções preferênciais (Tabela 1).

De acordo com Beranek e Vér (1992), existe uma rel ação entre a potência sonora radiada por cada tipo de fonte com a velocidade e o número de Mach do escoamento em questão. Segundo o autor, esses val ores são os apresentados na Tabela 1. Para escoamentos subsôni cos ( $\mathrm{Ma}<1 ; 0)$, as fontes com maior potência sonora são as do tipo monopolos, seguidas das do tipo dipolo e então das do tipo quadrupolo. Entretanto, para escoamentos supersônicos $(\mathrm{Ma}>1 ; 0)$ há uma inversão desse comportamento, sendo que fontes do ti po quadrupolo passam a ter uma mai or potência sonora. No presente trabal ho tem-se o objetivo de estudar a geração de ruído em escoamentos turbul entos cisal hantes, portanto principal mente fontes do tipo quadrupolo.

Um caso bastante estudado em aeroacústica é o ruído gerado por jatos turbulentos, devido a grande aplicação em ruído de aeronaves: Freund (2001), Boersma (2004), Bailly e Bogey (2004), Bogey e Bailly (2006), Babucke (2009). A Figura 4 apresenta um esquema desse caso onde são mostrados: o núcleo potencial , uma região de transição e uma região desenvolvida. $A$ fonte de energia do ruído do jato é a turbulência provocada pela mistura do núcleo potencial com escoamento ao seu redor (TAM, 1998). Como pode ser observado, o perfil de vel ocidade se torna infl exional na região limítrofe entre o núcleo potencial e o ambiente ao seu redor, o 
Tabela 1 - Tipos de fontes aeroacústicas e características de radiação.

\begin{tabular}{|c|c|c|c|}
\hline Tipo & $\begin{array}{l}\text { Car acter ística de } \\
\text { Radiação }\end{array}$ & Caso & $\begin{array}{c}\text { Potência de } \\
\text { Radiação }\end{array}$ \\
\hline Monopolo & 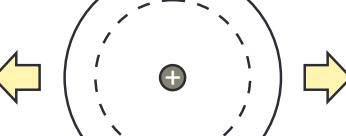 & $\begin{array}{l}\text {. injeção de fluido } \\
\text {. fontes térmicas }\end{array}$ & $\mu r L^{2} U^{3} M a$ \\
\hline Dipolo & & $\begin{array}{l}\text { forças decorren- } \\
\text { tes da interação } \\
\text { com superfícies } \\
\text { sólidas }\end{array}$ & $\mu r L^{2} U^{3} M a^{3}$ \\
\hline Quadrupolo & & $\begin{array}{l}\text { devido a fontes } \\
\text { não-linerares pro- } \\
\text { duzidas em re- } \\
\text { giões com flutu- } \\
\text { ações de tensões } \\
\text { de Reynolds (tur- } \\
\text { bulência) }\end{array}$ & $\mu r L^{2} U^{3} M a^{5}$ \\
\hline
\end{tabular}

qual apresenta condições de escoamento próximas das estacionárias se comparadas com as magnitudes de vel ocidade do núcleo potencial. Nesse caso, instabilidades hidrodi nâmi cas são originadas fazendo com que o escoamento transi cione para um regime de emissão de vórtices (SOUZA; SOUZA, 2006).

Figura 4 - Esquema de um jato turbul ento

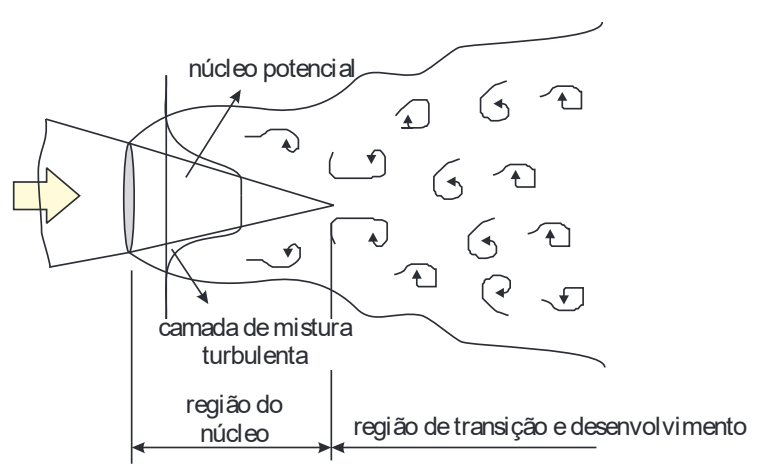

Fonte: Elaborada pelo autor.

O escoamento em jatos, apresentado anteriormente, tem grandes semelhanças com o 
escoamento observado na saída de difusores radiais (Figura 5). Esse tipo de geometria tem sido vastamente utilizada para representar o escoamento através de vál vul as de compressores, principalmente com relação ao cál culo de coeficientes a serem utilizados para representar válvulas em simuladores de compressores: Rovaris e Deschamps (2006), Lacerda (2009) e Mariani, Prata e Deschamps (2010). O fluido entra através do orifício de passagem de diâmetro d, sendo defletido pelo disco frontal de diâmetro $D$, escoando posteriormente entre as superfícies dos dois discos (difusor). Para mai ores val ores de relação de di âmetros $D=d$ e baixos val ores de afastamento s, ocorre a relaminarização do escoamento na região do difusor, e o perfil de velocidades na saída do difusor apresenta-se como um jato planar circunferencial.

Figura 5-Difusor Radial

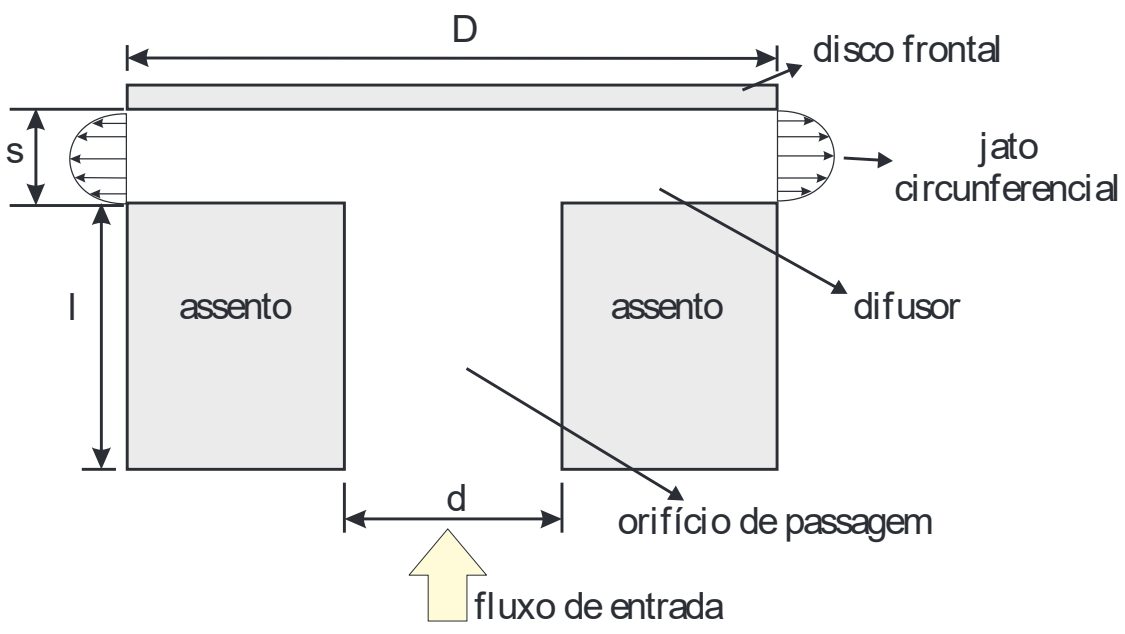

Fonte: Elaborada pelo autor.

Uma pesquisa bi bliográfica revela que o ruído aeroacústico do escoamento através das vál vulas de compressores herméticos ainda é um tema pouco investigado e os poucos trabal hos encontrados ainda são baseados em um processo de tentativa e erro para mel horia do ruído gerado pelo sistema de vál vulas, como os trabal hos apresentados por Trella e Soedel (1972) e Erol e Gurdogan (2000). No presente trabal ho o tema aeroacústica de jatos planares em vál vulas de compressores herméticos é utilizado como motivador, entretanto tal tema ainda não foi abordado no presente trabal ho, sendo uma sugestão para trabal hos futuros.

\subsection{Aeroacústica Computacional}

Os primeiros estudos no campo da aeroacústica foram desenvolvidos por Sir James Lighthill: Lighthill (1952) e Lighthill (1954). O objetivo era realizar o estudo do som gerado pelo escoamento turbulento em jatos. $O$ autor propôs uma anal ogia acústica onde é feita a di stinção entre o campo do escoamento, onde o som é gerado, e o campo acústico onde as ondas acústicas se propagam. A ideia básica foi expressar as equações governantes para o escoamento de fluidos compressíveis na forma de uma equação de onda para o cál culo de flutuações acústicas da 
densidade do fluido sujeitas a certas fontes acústicas. As fontes acústicas descritas pelo tensor de Lighthill são compostas pel os tensores de Reynolds e por ef eitos de entropia. Assim, uma vez cal culadas as fontes sonoras, é possível cal cul ar a propagação de ruído através da sol ução da equação de onda não-homogênea proposta. Entretanto, a anal ogia acústica de Lighthill não considera o efeito da presença de superfícies sól idas no escoamento, o que foi incluído posteriormente em outras anal ogias por Curle (1955) e FfowcsWilliams e Hawkings (1969). De forma resumi da a equação de onda não-homogênea é dada por (KINSLER et al ., 2000):

$$
-2 p-\frac{1}{a^{2}} \frac{\partial^{2} p}{\partial t^{2}}=-\frac{\partial M}{\partial t}+-f-\frac{\partial^{2}}{\partial x_{i} \partial x_{j}} \stackrel{\text { 撕 }}{r} u_{i j} u_{j}
$$

onde o termo - $\frac{\partial \mathrm{M}}{\partial \mathrm{t}}$ representa injeção de massa no domínio, correpondendo a fontes do tipo monopolo. O termo $f$ representa forças decorrentes da interação com superfícies sólida e corresponde a fontes do tipo dipolo. O termo $-\frac{\partial^{2}}{\partial x_{i} \partial x_{j}} \quad r \quad u_{i} u_{j}$ representa variações espaciais do fluxo de quantidade de movimento dentro do fluido que são geradas em regiões onde há presença de turbulência. El as são cal cul adas a partir de flutuações das tensões de Reynolds e correspondem a fontes do tipo quadrupolo.

A simulação numérica dos fenômenos de geração e propagação do ruído aeroacústico pode ser dividida basi camente em duas categorias: através do cál cul o direto ou usando metodologias híbridas. Na abordagem direta o som é cal culado em conjunto com o campo do escoamento através da solução das equações governantes compressíveis. Nesse caso pode ser usada tanto a Si mul ação Numérica Direta (Direct Numerical Smulation - DNS), que resolve todas as escal as do escoamento, como também a Si mul ação de Grande Escal as (Large Edge Si mulation - LES) que resolve as princi pais escal as e modela o efeito dissipativo das menores escal as. A principal vantagem de DNS é a ausência de modelagens no cál culo da geração do ruído, fornecendo uma ferramenta capaz de cal cular os mecani smos de geração de som e, também, avaliar outras metodol ogias. Por outro lado, como o domínio deve incl uir a região da fonte sonora e parte do campo acústico próximo, esta metodologia apresenta el evado custo computacional, limitando seu uso a casos mai s simples com moderados números de Reynolds (WANG; FREUND; LELE, 2006).

As metodol ogias híbridas são baseadas nas anal ogias acústicas descritas anteriormente onde o cál culo do escoamento é desacoplado do cál cul o da propagação do som. Uma solução temporal do escoamento pode ser obtida usando DNS, LES ou U-RANS (Unsteady Reynoldsaveraged Navier-Stokes - Navier-Stokes por média de Reynol ds transiente) de onde as fontes acústicas são extraídas. O som no campo distante é obtido através de soluções numéricas ou integrais das equações de onda não-homogêneas semelhantes à Equação 1.2, como um procedimento de pós-processamento da solução do escoamento (WANG; FREUND; LELE, 2006).

Ambas abordagens apresentadas para o cál culo numérico de aeroacústica fazem parte 
de uma área denominada Aeroacústica Computacional ( Computational Aeroacoustics - CAA). CAA é uma área recente comparada com o estágio atual da di nâmi ca dos fluidos computacional ( Computational Fluid Dynamics - CFD). Segundo Tam (2004), CAA vem se constituindo uma área distinta de CFD porque problemas de aeroacústica são diferentes dos problemas comuns de escoamento de fluidos, principal mente pela natureza transiente dos fenômenos aeroacústicose que não são de grande importância em al guns casos tradi cionais de escoamento de flui dos. Tais diferenças impõem maiores desafios ao método numérico, os quais o autor destaca como sendo:

- Vasta faixa de frequências espaciais e temporais envolvidas, exigindo resolução numérica das al tas frequências que possuem pequenos comprimentos de onda;

- Multiplicidade de escalas, pois ondas acústicas geralmente tem baixas amplitudes comparadas com as grandezas aerodinâmicas. Isso exige que o método numérico possua uma di ssi pação numérica extremamente baixa. Também há diferença de escal as entre as regiões próximas à fonte e regiões distantes;

- Em muitos casos é de interesse conhecer a intensi dade sonora a uma grande di stância da fonte sonora;

- O domínio computacional é finito e, devido ao baixo decaimento das grandezas acústicas, ondas acústicas atingem os contornos. Para evitar a reflexão dessas ondas de volta ao domínio, contaminando a solução, um tratamento especial deve ser dado aos contornos para permitir que tais ondas deixem o domínio de forma suave.

Portanto, via de regra, métodos numéricos desenvolvidos para CAA devem possuir características que os diferem de metodologias tradicionais usadas em CFD. Tais características são (TAM, 2004):

- um esquema numérico de avanço temporal com al ta ordem de preci são e baixa dissi pação e dispersão numéricas;

uma mal ha computacional adequada;

- um procedimento de amortecimento sel etivo ou filtragem para eliminar ondas numéricas espúrias que podem contaminar a solução numérica. Tal procedimento também pode ajudar a estabilizar a sol ução numérica em contornos ou descontinui dades como paredes ou mudanças nos espaçamentos da mal ha computacional;

- um conjunto de tratamentos numéricos nos contornos do domínio computacional para evitar que reflexão de ondas acústicas contamine a sol ução do domínio, ou permitir a entrada de ondas acústicas ou de vortici dade que estejam chegando ao domínio. 
Dois efei tos importantes são a dissi pação e a di sper são numéricas. Conforme pode ser observado na Figura 6, o fenômeno de dissi pação numérica tende a diminuir a amplitude das ondas transportadas, enquanto que a di spersão numérica tende a mudar a fase em que uma onda é transportada. Ambos os efeitos estão relacionados aos métodos de discretização espacial e temporal . O grande desafio está em desenvolver métodos apropriados para resolver problemas de aeroacústica que, após longos períodos de tempo e a longas distâncias, não degradem as característi cas físi cas da onda acústica através da di ssi pação e da dispersão (WELLS; RENAUT, 1997).

Um aprofundamento mai or sobre o estági o atual das várias vertentes da aeroacústica computacional, os desafios encontrados e os esforços envolvidos para superálos, bem como al gumas aplicações da metodol ogia a problemas de engenharia podem ser encontrados em Wells e Renaut (1997), Tam (2004), Colonius e Lele (2004) e Wang, Freund e Lele (2006).

Figura 6 - Dissi pação e dispersão de uma onda

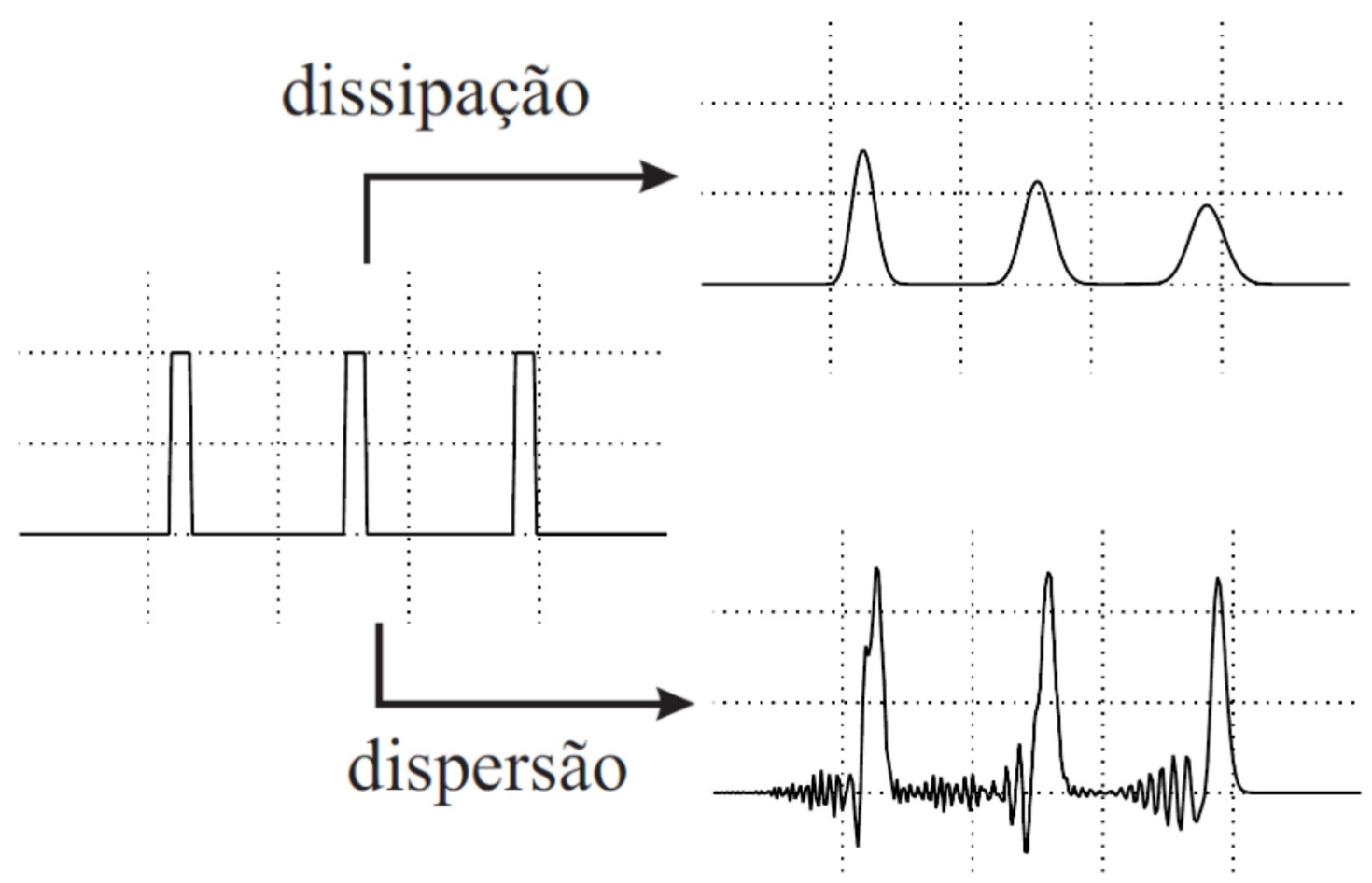

Fonte: Elaborada pelo autor. 


\subsection{Objetivo Principal e Escopo do Trabalho}

\section{Objetivo Principal}

O motivador principal do presentetrabal ho éiniciar o desenvolvimento de umaferramenta confiável de simulação capaz de auxiliar engenhei ros na predição de problemas de aeroacústica, especial mente um que possa no futuro ser utilizado para estudar o ruído gerado pel o escoamento em vál vul as de compressores de refrigeração. Para isso foi desenvol vido um código com uma versão bidimensional e outra tridimensional para simulação numérica direta de aeroacústica. Utilizou-se processamento paral el o com decomposição de domínio para poder simular usando DNS em um tempo factível; esquemas de di scretização espaciais e temporais de al ta ordem para mi nimizar ao máximo os fenômenos de dissi pação e di spersão das ondas acústicas; e uma série de tratamentos no domínio como filtragem e esti ramento da mal ha como também condi ções de contorno não-refl exivas como intuito de obter uma solução adequada para estudo de aeroacústica.

Assim, o objetivo principal do presente trabal ho é apresentar todas as etapas desenvolvidas no equacionamento, implementação e verificação, tanto segundo um processo matemático formal quanto por comparação com resultados obtidos de literatura, de um código numérico para simulação numérica direta de aeroacústica.

\section{Escopo do Trabalho}

A divisão do trabal ho se dá da seguinte forma: no Capítul o 2 são apresentadas as equações que regem os probl emas a serem estudados e as equações da Teoria de Estabilidade Linear utilizados para obter as autof unções necessárias para perturbar o escoamento. Em seguida, são apresentados no Capítul o 3 detal hes do presente código, o processo de decomposi ção de domínio para a paral elização do código, os métodos de di scretização numérica com anál ises discutindo sobre a acurácia esperada, detal hes do código para geração das perturbações, condi ções de contorno e condições ini ciais. Posteriormente, no Capítul o 4 é apresentado o Método das Soluções Manufaturadas utilizado para verificação do presente código e os resultados dessas análises. Ainda nesse capítulo também são apresentadas comparações de sol uções de escoamentos cisal hantes (camada de mistura bidimensional e jatos planares bidimensionais) com resultados obtidos por outros autores e com a Teoria de Estabilidade Linear. Por fim, são descritas no Capítulo 5 as concl usões finais e propostas de trabal hos futuros. 

CAPÍTULO
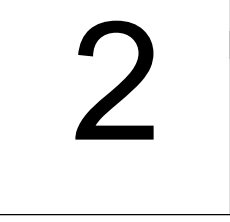

\section{FORM ULAÇÃO MATEMÁTICA}

Como destacado anteriormente no fim da seção 1.3, no presente trabal ho, simulações aeroacústicas baseadas nas equações de Navier-Stokes compressíveis em regime transiente foram realizadas para investigar o ruído gerado pelo escoamento de camadas de misturas e jatos planares. A seguir são apresentadas as equações governantes que foram implementadas no código computacional DNS. Também são apresentadas as bases teóricas para as análises de Teoria de Estabilidade Linear utilizadas para obter as perturbações para o escoamento base.

\subsection{Notação}

O sistema cartesiano $(x ; y, z)$ de referência é apresentado na Figura 7. Tomando como exemplo o caso de uma camada de mistura, tem-se que a camada superior tem velocidade $\mathrm{U}_{1}$ e a corrente inferior tem velocidade $\mathrm{U}_{2}$.

O eixo x se encontra al inhado com a direção longitudinal do escoamento, o eixo y com a direção normal e o eixo $z$ com a direção transversal. As respectivas componentes da vel ocidade são u, v ew. Todos os cál cul os serão real izados na forma adimensional, sendo que as veloci dades são normalizadas por Ũ. , a temperatura por T̃. e a densidade por $\tilde{r}$. . O subscrito . indica condições de corrente livre e o símbolo grandezas na forma dimensional. As escal as de grandeza são adimensional izadas por um comprimento de referência Ĺ. e as de tempo f̃ por L. $=$ Ũ. :

$$
x=\frac{\tilde{X}}{\tilde{L} .} ; \quad y=\frac{\tilde{y}}{\tilde{L} .} ; \quad r=\frac{\tilde{r}}{\tilde{r} .} ; \quad u=\frac{\tilde{U}}{\tilde{U} .} ; \quad v=\frac{\tilde{V}}{\tilde{U} .} ; \quad w=\frac{\tilde{W}}{\tilde{U} .} ; \quad T=\frac{\tilde{T}}{\tilde{T} .} ; \quad t=\frac{\tilde{t} \cdot \tilde{U} .}{\tilde{L} .}:
$$

Com as quantidades descritas acima, obtemos a pressão e os cal ores específicos normali- 
Figura 7 - Esquema do domínio computacional tridimensional cartesiano para uma camada de mistura, destacandose a região de interesse e a zona de amortecimento.

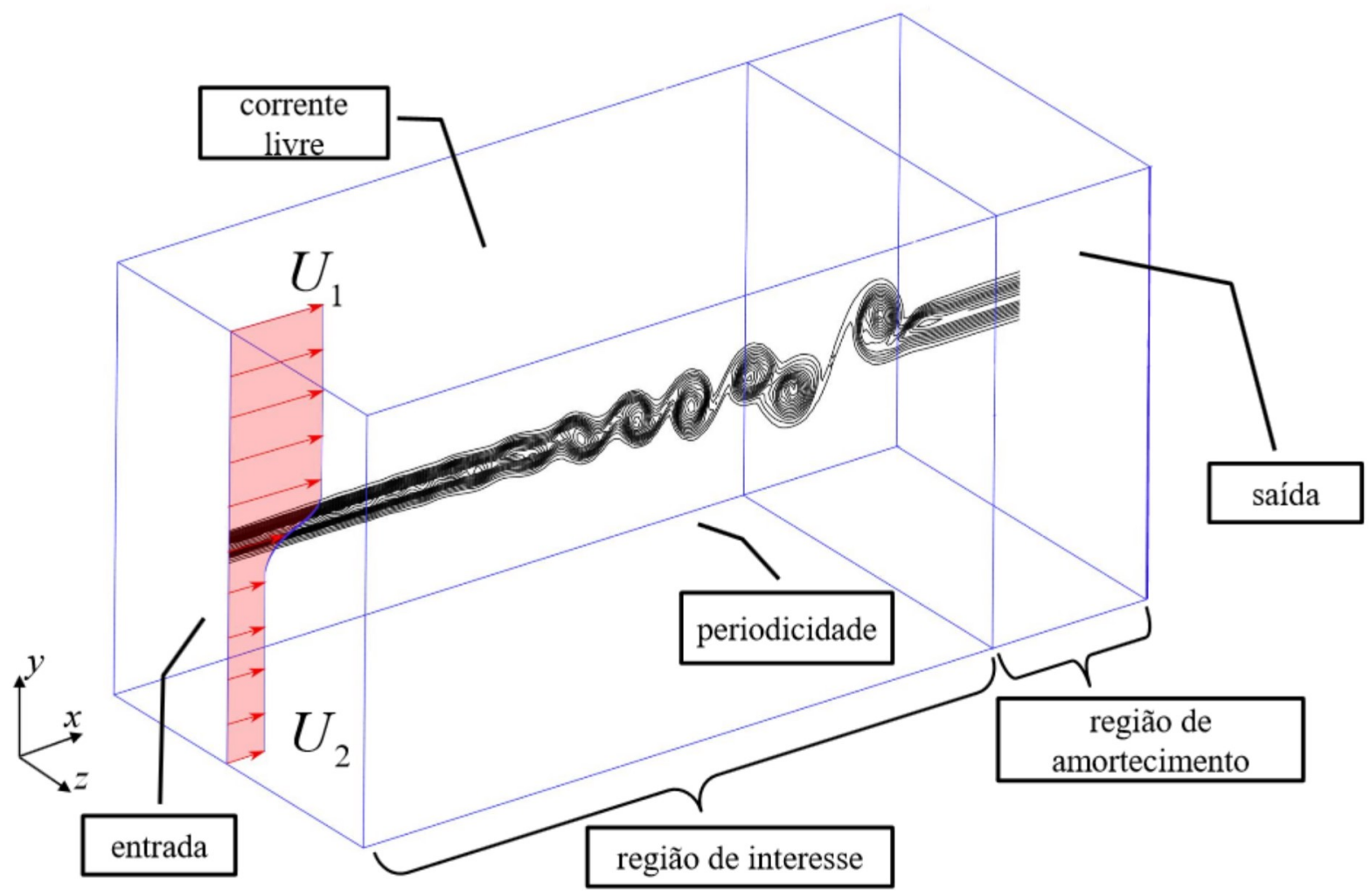

Fonte: Elaborada pelo autor.

zados:

$$
p=\frac{\tilde{p}}{\tilde{r} \cdot \tilde{U}_{0}^{2}} ; \quad c_{p}=\tilde{c}_{p} \cdot \frac{\tilde{T}_{0}}{\tilde{U}_{0}^{2}} ; \quad c_{v}=\tilde{c}_{v} \cdot \frac{\tilde{T}_{.}}{\tilde{U}_{0}^{2}}:
$$

Também é possível definirmos o número de Reynolds, o número de Mach e o número de Prandtl como:

$$
\begin{aligned}
& \operatorname{Re}=\frac{\tilde{r} \cdot \tilde{U} \cdot \tilde{L} \cdot}{\tilde{m}} ; \\
& M a=\frac{\tilde{U} .}{\tilde{a}_{\bullet}} ; \\
& \operatorname{Pr}=\frac{\tilde{\mathrm{C}}_{p} \tilde{m}}{\tilde{J} .} ;
\end{aligned}
$$

onde ã. corresponde à vel ocidade do som no meio na região de corrente livre. 


\subsection{Equações Governantes}

A solução é obtida através da solução da equação da continuidade, das equações de Navier-Stokes e da energia. Considerando um escoamento tridimensional em coordenadas cartesianas, compressível, não isotérmico e em regime transiente, o vetor sol ução na formulação conservativa é dado por:

$$
Q=(r ; r u ; r v, r w, E)^{T}
$$

contendo a densidade, os fluxos de massa nas di reções $x$, y e z, respectivamente e a energia total por uni dade de volume $E$, o qual é definida como:

$$
E=r^{Z} \quad C_{v} d T+\frac{r}{2} u^{2}+v^{2}+w^{2}:
$$

As equações de Navier-Stokes compressíveis podem ser escritas em notação vetorial como:

$$
\frac{\partial Q}{\partial t}+\frac{\partial F}{\partial x}+\frac{\partial G}{\partial y}+\frac{\partial H}{\partial z}=0
$$

onde os vetores de fluxo são:

$$
\begin{aligned}
& F=\begin{array}{ccc}
2 & r u & 3 \\
\vdots & r u^{2}+p-t_{x x} & 7 \\
8 & r u v-t_{x y} & 3 \\
r u w-t_{x z} & 5 \\
u(E+p)+q_{x}-u t_{x x}-v t_{x y}-w t_{x z}
\end{array} \\
& \left.G=\begin{array}{ccc}
2 & r v & 3 \\
6 & r u v-t_{x y}
\end{array}\right\} \\
& \mathrm{H}=\begin{array}{ccc}
2 & r w & 3 \\
6 & r u w-t_{x z} & z \\
8 & r v w-t_{y z} & \xi \\
& r w^{2}+p-t_{z z} & 5 \\
w(E+p)+q_{z}-u t_{x z}-v t_{y z}-w t_{z z}
\end{array}
\end{aligned}
$$

contendo as tensões normais

$$
t_{x x}=\frac{m}{\operatorname{Re}} \frac{4}{3} \frac{\partial u}{\partial x}-\frac{2}{3} \frac{\partial v}{\partial y}-\frac{2}{3} \frac{\partial w^{5}}{\partial z}
$$




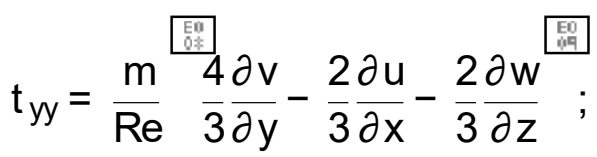

$$
\begin{aligned}
& \mathrm{t}_{\mathrm{yy}}=\frac{\mathrm{m}}{\operatorname{Re}} \frac{4}{3} \frac{\partial \mathrm{w}}{\partial \mathrm{z}}-\frac{2}{3} \frac{\partial \mathrm{u}}{\partial \mathrm{x}}-\frac{2}{3} \frac{\partial \mathrm{v}}{\partial \mathrm{y}} \text {; }
\end{aligned}
$$

as tensões cisal hantes

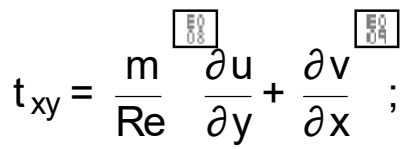

$$
\begin{aligned}
& t_{x z}=\frac{m}{\operatorname{Re}} \frac{\partial u}{\partial z}+\frac{\partial w^{\text {鹿 }}}{\partial x} \text {; }
\end{aligned}
$$

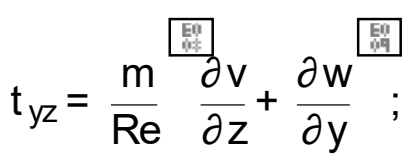

e os fluxos de calor

$$
\begin{aligned}
& q_{x}=-\frac{J}{(k-1) \operatorname{RePrMa}_{*}^{2}} \cdot \frac{\partial T}{\partial x} ; \\
& q_{y}=-\frac{J}{(k-1) \operatorname{RePrMa}_{\bullet}^{2}} \cdot \frac{\partial T}{\partial y} ; \\
& q_{z}=-\frac{J}{(k-1) \operatorname{RePrMa}_{\bullet}^{2}} \cdot \frac{\partial T}{\partial z}:
\end{aligned}
$$

Propriedades do Fluido

Para o fechamento do si stema de equações governantes é necessária uma equação de estado para a pressão que, considerando um gás ideal perfeito, é dada por:

$$
p=\frac{r T}{\mathrm{kMa}^{2}}
$$

A velocidade do som adimensional é dada por:

$$
a=\frac{V_{\bar{T}}}{M a_{\bullet}} \text { : }
$$

Os cal ores específicos para pressão constante e volume constante são consi derados constantes dados por:

$$
c_{p}=\frac{1}{(k-1) M a^{2}} ; \quad c_{v}=\frac{1}{k(k-1) M a^{2}}
$$


onde o produto adiabático $k=c_{p}=c_{v}$ é fixo fazendo com que a integral ${ }^{R} c_{v} d T$ da Equação 2.7 possa ser simplificada pelo produto $c_{v} T$. No presente trabal ho, o fluido utilizado val ores típicos para o ar com uma razão de cal ores específicos $\mathrm{k}=1 ; 4$ e o número de Prandtl igual a $\operatorname{Pr}=0 ; 71$.

Para aval iação da viscosidade, esta é modelada como sendo dependente da temperatura de acordo com a lei de Sutherland (WHITE, 2005) para temperaturas acima da temperatura de Sutherland $\tilde{\mathrm{T}}_{\mathrm{S}}=110,4 \mathrm{~K}$ :

$$
\tilde{m}(T)=\tilde{m}\left(T_{0}\right) T^{3 / 2} \frac{1+T_{s}}{T+T_{s}}
$$

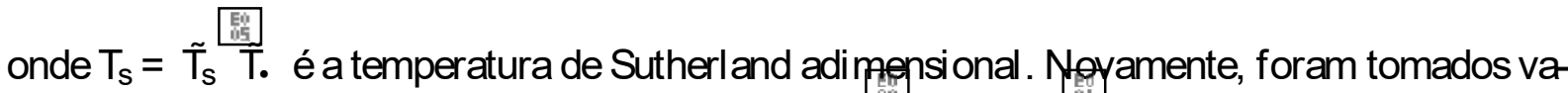
lores típicos do ar com a viscosidade dinâmica $\tilde{\mathrm{m}}_{0} \mathrm{~T}_{0}=280 \mathrm{~K} \stackrel{\text { ii }}{=} 1 ; 735 \cdot 10^{-5} \mathrm{~kg}=(\mathrm{m} \cdot \mathrm{s})$ e a condutividade térmica $\tilde{J}=0 ; 03 \mathrm{~W}=(\mathrm{m} \cdot \mathrm{K})$, val ores que foram utilizados nas adimensional iza ções.

\subsection{Teoria de Estabilidade Linear}

O concei to de instabilidade de um escoamento em regi me permanente está associado a como el e se comporta quando submetido a pequenas e moderadas perturbações, que podem ser introduzi das na forma de uma onda (ROGENSKI, 2015). Se há um decaimento espacial dessas ondas e o escoamento retorna ao seu estado inicial diz-se que o escoamento é estável. Porém, se há um crescimento dessas perturbações fazendo com que o escoamento transi cione para um regime diferente do seu estado inicial, diz-se que o escoamento é instável (QUIRINO, 2006).

Geral mente, esse é o comportamento de um escoamento que transiciona para os mais diversos regimes turbul entos presentes em casos reais. Segundo teorema de Rayleigh um perfil de velocidade que possui um ponto de inflexão é instável a perturbações (KUNDU; COHEN, 2002). Perturbações recebi das pelo escoamento (rugosi dades de parede, injeção ou sucção de fluido, ruído, turbulência de escoamentos próximos) se amplificam linearmente segundo uma taxa de ampl ificação até surgi rem estruturas não lineares e a transi ção para regime turbulento de escoamento.

A Teoria de Estabilidade Linear (Linear Stability Theory - LST) é um método para se obter informações sobre perturbações e suas taxas de amplificações. Assim, esta se torna uma importante ferramenta para fornecer os dados de perturbação para o presente código e para aval iar os resul tados obtidos de acordo com essa metodologia formal. Para essa anál ise, divide-se o escoamento em um escoamento base em regime permanente (0) e uma flutuação('):

$$
f=f_{0}+f^{\prime}
$$

onde $f$ representa tanto as variáveis primitivas $(u ; v, w, r ; T ; p)$ quanto a viscosidade $m$ e a 
condutividade térmica J . Considerase também que a perturbação f' se propaga como uma onda:

$$
f^{\prime}=\hat{f}(y) \cdot e^{i \cdot(a x+g z-w t)}
$$

onde a e g são os números de onda nas di reções longitudinal e transversal, respectivamente, e w é a frequência temporal da onda. A varíavel complexa $\hat{f}=\hat{f}_{\mathrm{r}}+\mathrm{i} \cdot \hat{f}_{\mathrm{i}}$ é a autofunção da onda. A amplitude a distribuição de fase da flutuação são dadas por Equação 2.27 e Equação 2.28, respectivamente.

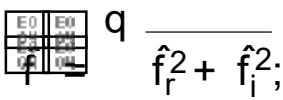

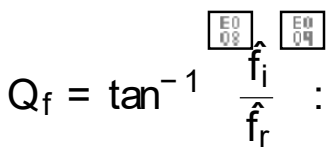

Assumindo periodicidade na direção z, o número de onda g é real , não permitindo que perturbações cresçam na direção transversal. Sendo w ea números complexos, estes dão origem a um problema temporal ou espacial. No problema temporal acompanha-se a perturbação, enquanto que no problema espacial permite-se que a perturbação seja advectada pelo escoamento, e que representa os casos si mulados no presente trabal ho. Nesse caso, impõe-se $w_{i}=0$. Assim, a Equação 2.26 pode ser reescrita como:

$$
f^{\prime}=\hat{f}(y) \cdot e^{i \cdot\left(a_{r} x+g z-w_{r} t\right)} \cdot e^{\left(-a_{i} x\right)}
$$

O termo $a_{i}$ é a taxa de amplificação espacial e indica o quão rápido uma perturbação se amplifica ou a onda se tranforma em vórtice ou se estingue no domínio. Este é cal culado para um referencial fixo no domínio e a onda move-se com relação a este referêncial. Este tipo de análise é conhecida como análise espacial da instabilidade e val ores negativos da taxa de amplificação $a_{i}$ correspondem a amplificação das perturbações enquanto que valores positivos denotam amortecimento.

Para obtenção das autofunções pode-se recorrer às equações da estabilidade. O desenvolvimento dessas equaçães pode ser encontrado com mais detal hes em Sal emi (2006) e não é escopo do presente trabal ho. Porém al gumas consi deraçães dessa análise são apresentadas para auxiliar o entendimento teórico. A primeira já apresentada pela Equação 2.25 é a de que o escoamento pode ser separado em um escoamento base e uma perturbação e substitui-se as variáveis nas equações governantes do escoamento (Equação 2.8). Outra hipótese da LST é a de que o escoamento base é uma solução em regime permanente das equações de Navier-Stokes, fazendo com que todos os termos contendo somente quantidades do escoamento base sejam desprezados. Outras hipóteses são as de que considera-se o escoamento base como paral elo 
e de que a anál ise se dá local mente, desprezando-se assim o espal hamento do escoamento e o produto de perturbações, por assumi-las pequenas. Assim a análise se torna linear de um conjunto de perturbações. Por fim, também assume-se uma sol ução por modos normais conforme Equação 2.26.

Assumindo o conjunto dessas hi póteses com al guma ál gebra apresentada por Salemi (2006), temos que as equações das perturbações se reduzem a:

$$
\begin{gathered}
(a U-w) \frac{d \hat{v}}{d y}-a \hat{v} \frac{d U}{d y}=\frac{i a^{2} g \hat{p}}{k M a^{2}} ; \\
r i(a U-w)=-\frac{1}{k M a^{2}} \frac{d \hat{p}}{d y}
\end{gathered}
$$

onde g é a equação de Gropengiesser, dada por:

$$
g=\frac{a^{2}+g^{2}}{r a^{2}}-M a^{2} \frac{(a U-w)^{2}}{a^{2}}
$$

Definindo uma transformação de coordenadas proposta por Gropengi esser (GROPENGIESSER, 1970):

$$
c=\frac{\text { ia } \hat{p}}{\mathrm{kMa}^{2} \hat{\mathrm{v}}}
$$

temos que,

$$
\frac{-i a}{k M a^{2}} \frac{d \hat{p}}{d y}=\frac{c}{d y} \hat{v}+c \frac{d \hat{v}}{d y}
$$

Combinando a Equação 2.30 e a Equação 2.31 com a Equação 2.34, dividindo por v̂ e usando a definição de c (Equação 2.33) temos que,

$$
\frac{d c}{d y}=r a(a U-w)-\frac{a c}{a U-w} g c-\frac{d U}{d y} \text { : }
$$

Como descrito por Salemi (2006), as condições de contorno para a equação Equação 2.35 são derivadas do fato de que para $\mathrm{y} \rightarrow \pm \cdot$ temos que $c$ é uma constante e dc $=\mathrm{dy}=0$. Assim, para $\mathrm{y} \rightarrow \pm \cdot$ :

$$
c= \pm \frac{\mathrm{g}}{\mathrm{r}} \frac{1}{\mathrm{aU}-\mathrm{w}}
$$


Ao resolver a Equação 2.35, a função c e a função g são cal culadas juntamente com os autovalores a e w do problema. Alguma manipulação pode ser real izada na Equação 2.30 e na Equação 2.31, fornecendo:

$$
\begin{gathered}
\frac{d \hat{v}}{d y}=\frac{i a g \hat{p}}{k M a^{2}(a U-w)}+\frac{a \hat{v}}{(a U-w)} \frac{d U}{d y} ; \\
\frac{d \hat{p}}{d y}=-k M a^{2} r i(a U-w) \hat{v} ;
\end{gathered}
$$

As autofunções para a veloci dade normal v̂ e para a pressão p̂ são dadas pela integração da Equação 2.37 e Equação 2.38 (SALEMI, 2006). As condi ções de contorno para integração são:

$$
\begin{gathered}
\hat{v}(0)=1+i 0: \\
\hat{p}(0)=\frac{c(0) \mathrm{kMa}^{2}}{i a}
\end{gathered}
$$

A partir do cál culo de v̂ e p̂, cal cula-se as autofunções para a densidade $\hat{r}$, vel ocidade longitudinal û, vel ocidade transversal $\hat{\mathrm{w}}$ e temperatura $\hat{T}$ respectivamente pela Equação 2.41 , Equação 2.42, Equação 2.43 e Equação 2.44:

$$
\begin{gathered}
\hat{r}=-\frac{\hat{v}}{i(a U-w)} \frac{d r}{d y}-\frac{r a \hat{u}}{(a U-w)}-\frac{r g \hat{w}}{(a U-w)}-\frac{r}{i(a U-w)} \frac{d \hat{v}}{d y} ; \\
\hat{u}=\frac{-a \hat{p}}{k M a^{2} r(a U-w)}-\frac{\hat{v}}{i(a U-w)} \frac{d U}{d y} ; \\
\hat{w}=\frac{-g \hat{p}}{k M a^{2} r(a U-w)} ; \\
\hat{T}=\frac{\hat{p}-\hat{r} T}{r}:
\end{gathered}
$$

O estudo de instabilidade de jatos revela a presença de dois modos instáveis: um modo sinuoso e um modo varicoso. O modo varicoso é tal que a perturbação v̂ e sua derivada d̂̂=dy vão para zero no centro do jato. A definição original da transformação de Gropengiesser (Equação 2.33) vai para infinito no centro do jato. Para se capturar o modo varicoso utiliza-se o inverso da transformação de Gropengi esser para evitar singularidade, originando uma nova equação para transformação de Gropengiesser:

$$
c=\frac{k M a^{2}}{i a} \frac{\hat{v}}{\hat{p}}
$$


tal que,

$$
\frac{\mathrm{kMa}}{2} \frac{\mathrm{d} \hat{v}}{\mathrm{ia}}=\frac{\mathrm{dc}}{\mathrm{dy}} \hat{\mathrm{p}}+\mathrm{c} \frac{\mathrm{d} \hat{\mathrm{p}}}{\mathrm{dy}}
$$

Substituindo Equação 2.30 e Equação 2.31 na Equação 2.46, dividindo por p̂ e usando a nova defini ção de c (Equação 2.45) temos que,

$$
\frac{d c}{d y}=a g+a \frac{d U}{d y} c \frac{1}{a U-w}-r a(a U-w) c^{2} \text {. }
$$

Da mesma maneira que para a versão original da equação de Gropengiesser, as condições de contorno para a integração são dadas pela Equação 2.36. As autofunções também podem ser cal culadas da mesma manei ra que anteriormente resol vendo-se da Equação 2.37 à Equação 2.44. 

CAPÍTULO
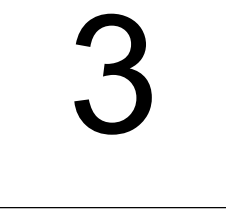

MÉTODO NUMÉRICO

O presente trabal ho envolve o desenvolvimento de um programa de computador que permita resolver as equações que governam escoamentos compressíveis, apresentadas no capítulo anterior, usando DNS. Neste capítulo é apresentado inicial mente um breve delineamento do funcionamento do código e, posteriormente, maiores detal hes sobre os esquemas de discretização espacial e temporal são apresentados. Em seguida, análises de Fourier dos esquemas de discretização espacial são real izadas, ressal tando os cuidados tomados para se obter esquemas numéricos de bai xas dissipação e dispersão numéricos. Os processos de geração de mal ha e de transformação de coordenadas utilizados são apresentados posteriormente, e também foi real izada a paral el ização do código com decomposição do domínio nas di reções longitudi nal e normal para o cál cul o das derivadas espaciais. Dando prosseguimento, é brevemente apresentado o esquema do funcionamento do código gentilmente fornecido pelo Prof. Márcio T. de Mendonça (MENDONçA, 2015) para cál culo das auto-funções segundo a Teoria de Estabilidade Linear apresentada na seção 2.3 e que foram utilizadas para gerar as perturbações que são introduzidas na entrada do domínio do escoamento. Por fim, são apresentados o processo de obtenção das condi ções de contorno e das condições iniciais util izadas para a sol ução dos problemas propostos.

Todas as simulações foram real izados no recém adquirido cl uster Euler e instal ado nas dependências do Instituto de Ciências Matemáticas e de Computação (ICMC) da USP de São Carlos. O cluster Euler possui 104 lâminas computacionais IP113, cada uma com 2 Processadores Intel Xeon E5-2680v2 de $2.8 \mathrm{GHz}$ com dez núcl eos cada, total izando 2080 núcleos de processamento e 13TB de memória disponíveis. Os trabal hos são submetidos através de jobs que são gerenciados de forma a se ter o mel hor desempenho possível (CEMEAI-ICMC-USP, 2016). 


\subsection{Código DNS}

Um código numérico foi desenvol vido para a real ização do presente trabal ho. Para esse desenvolvimento, Fortran Free Format foi usada como linguagem de programação. A estratégia de paral el ização de decomposição do domínio foi utilizada através da linguagem independente de protocolo de comunicações Message-Passing Interface - MPI (LUSK; DOSS; SKJELLUM, 1996), permitindo que os cál cul os sejam fei tos de forma simul tânea em diversos elementos de processamento de uma mesma máquina ou cluster.

Figura 8 - Esquema do processo de simulação de um problema com o código numérico DNS.

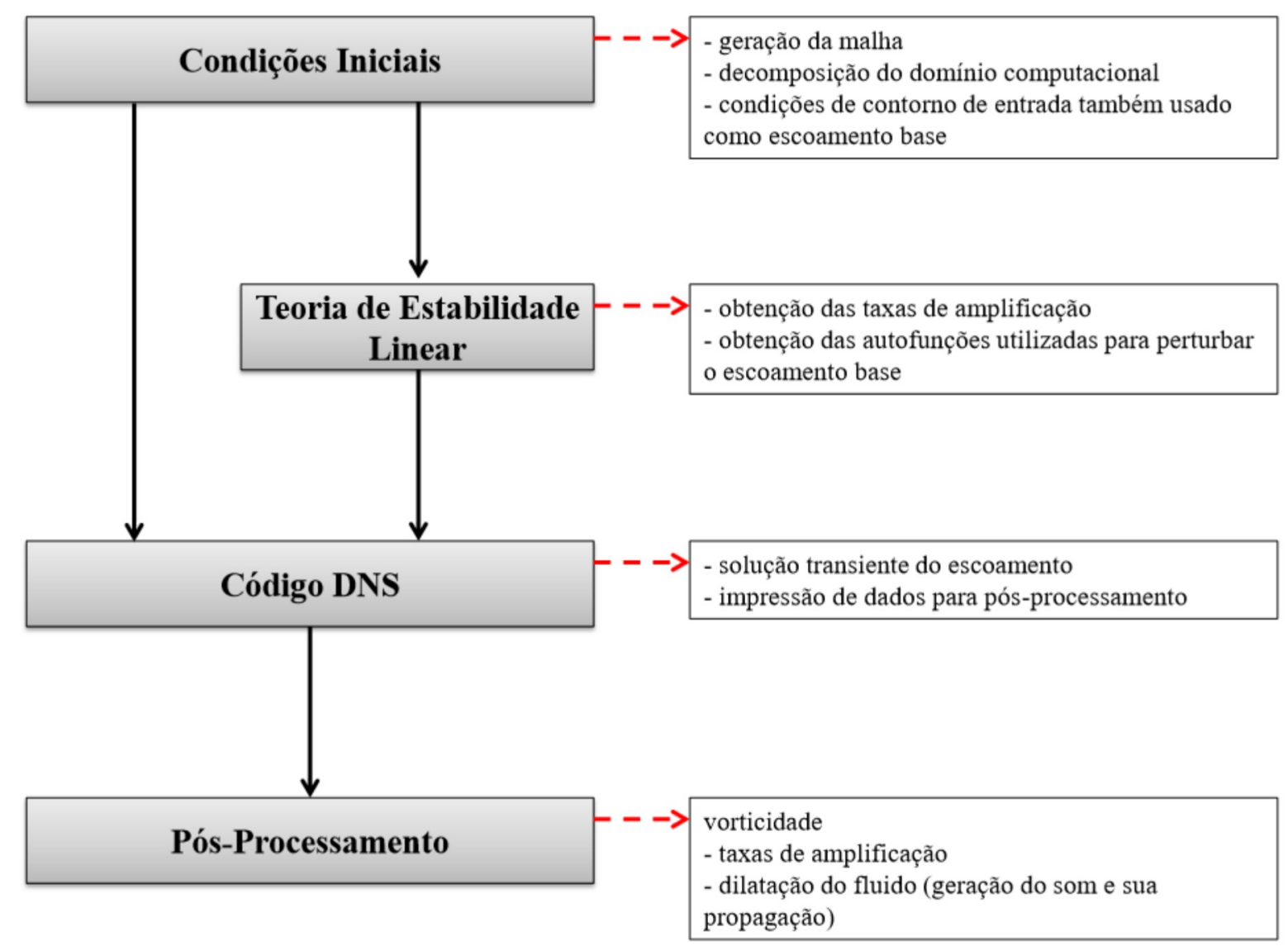

Fonte: Elaborada pelo autor.

A Figura 8 apresenta em linhas gerais a sequência de etapas para a si mul ação de um problema usando o presente código DNS. Usou-se como referência o procedimento adotado por Babucke (2009). Maiores detal hes de cada etapa serão apresentadas posteriormente nesse capítulo, mas suci ntamente segue-se as segui nte etapas: defini do o problema em questão, constróise uma mal ha computacional adequada para si mulação do problema e obtém-se as condições iniciais para o escoamento base, as quais podem ser obti das a partir de soluções anal íti cas para problemas mais simples, como no caso das sol uções de si milaridade das equações de camada limite (SCHLICHTING, 1979). Posteriormente, realiza-se uma análise usando a Teoria de Estabilidade Linear (Linear Stability Theory - LST) onde são obtidas as taxas de amplificações e 
autofunções, que são utilizadas para gerar perturbações na simulação DNS em regime transiente. Assim, definidas a mal ha, as condi ções iniciais e as perturbações (al ém de parâmetros numéricos necessários) o presente código é executado. Durante sua execução há a impressão de resul tados para real izar as anál ises de pós-processamento e obter informações rel evantes do probl ema como, no presente caso, o som gerado pel o escoamento e sua propagação pelo domínio através do cál culo do divergente do campo de velocidades, que corresponde a dilatação do fluido. Um fluxograma do funcionamento do presente código é apresentado na Figura 9.

Figura 9 - Esquema do funcionamento do código numérico DNS.

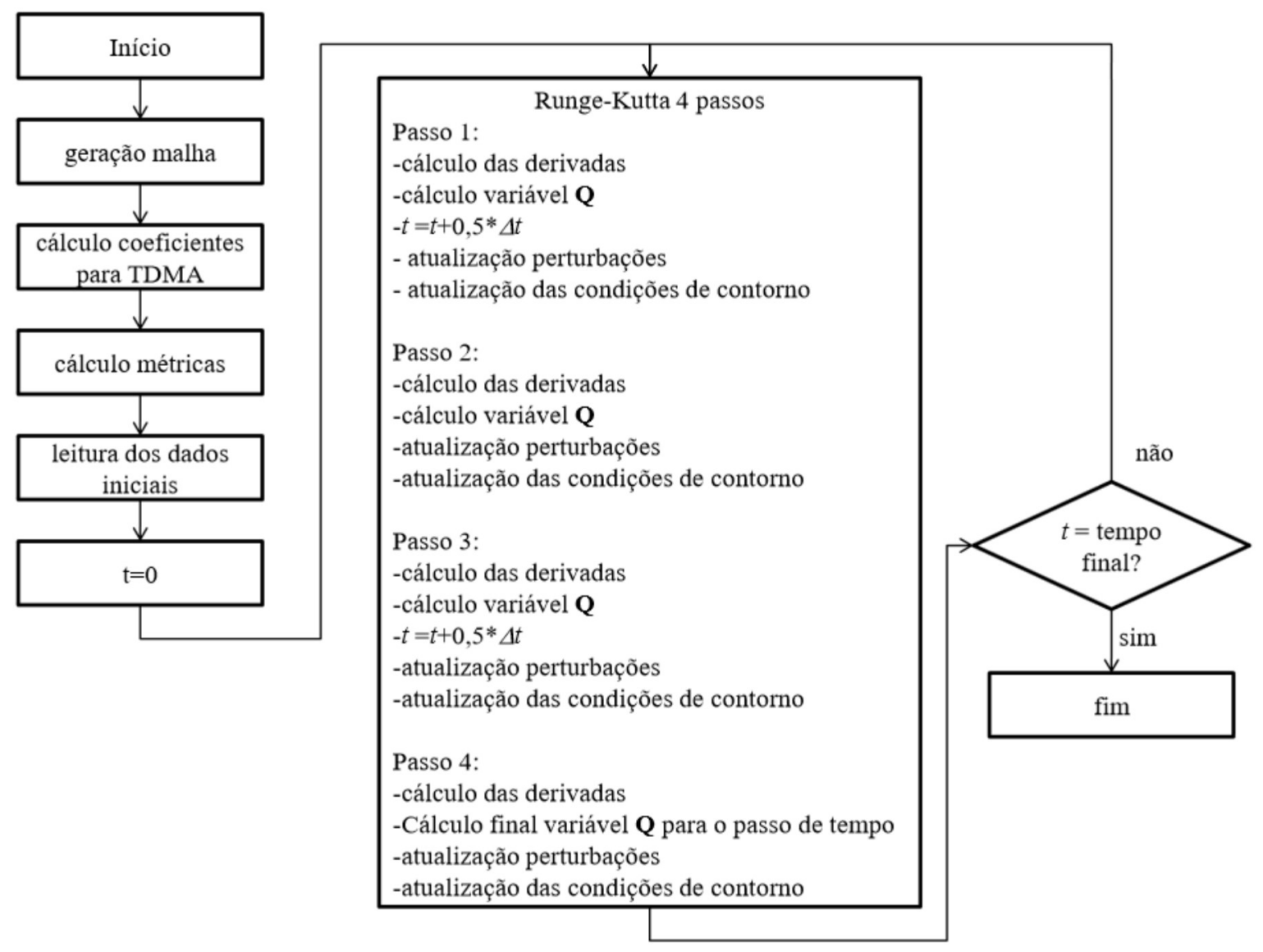

Fonte: Elaborada pelo autor.

\subsection{Decomposição do Domínio e Transformação de Co- ordenadas}

Em todas as simulações de escoamento definiu-se uma regi ão de interesse na di reção longitudinal x e uma região de amortecimento, conforme detacado na Figura 7. A região de amortecimento na direção longitudinal é obtida com a combinação de estiramento de mal ha com uso de um filtro espacial na direção x, como utilizado por Colonius, Lele e Moin (1997) e Babucke, Kloker e Rist (2008) para que as flutuações sejam al tamente atenuadas antes de 
atingirem o contorno. Na direção normal y também definiu-se uma região de interesse e outra de amortecimento com estiramento da mal ha computacional e filtro espacial, conforme o utilizado para a direção x. Mais detal hes são apresentados na seção 3.7

Para se resolver grandes simulações em super-computadores usando DNS, é essencial utilizar uma estratégia de paral elização que aumente a eficiência do processo de cál culo. No presente código desenvolvido, como estratégia de paral elização dos cálculos, optou-se pela decomposi ção do domínio de cál cul o. Nesse procedimento um único código é executado por cada elemento de processamento sobre um conjunto separado de dados (Single Program Multiple Data - SPMD), havendo a necessidade de se comunicar informações e sincronizar atividades entre os elementos de processamento durante a sol ução. Para isso foram utilizadas diretivas do protocolo de comunicação MPI. Assim, tem-se a vantagem de ocorrerem cál culos simultaneamente, reduzindo-se o tempo de cál culo. A Figura 10 ilustra um exemplo de mal ha com estiramento nas di reções $x$ e y e também as partições de domínio.

Figura 10 - Mal ha computacional com estiramento e divisão de domínios em cores preto e cinza.

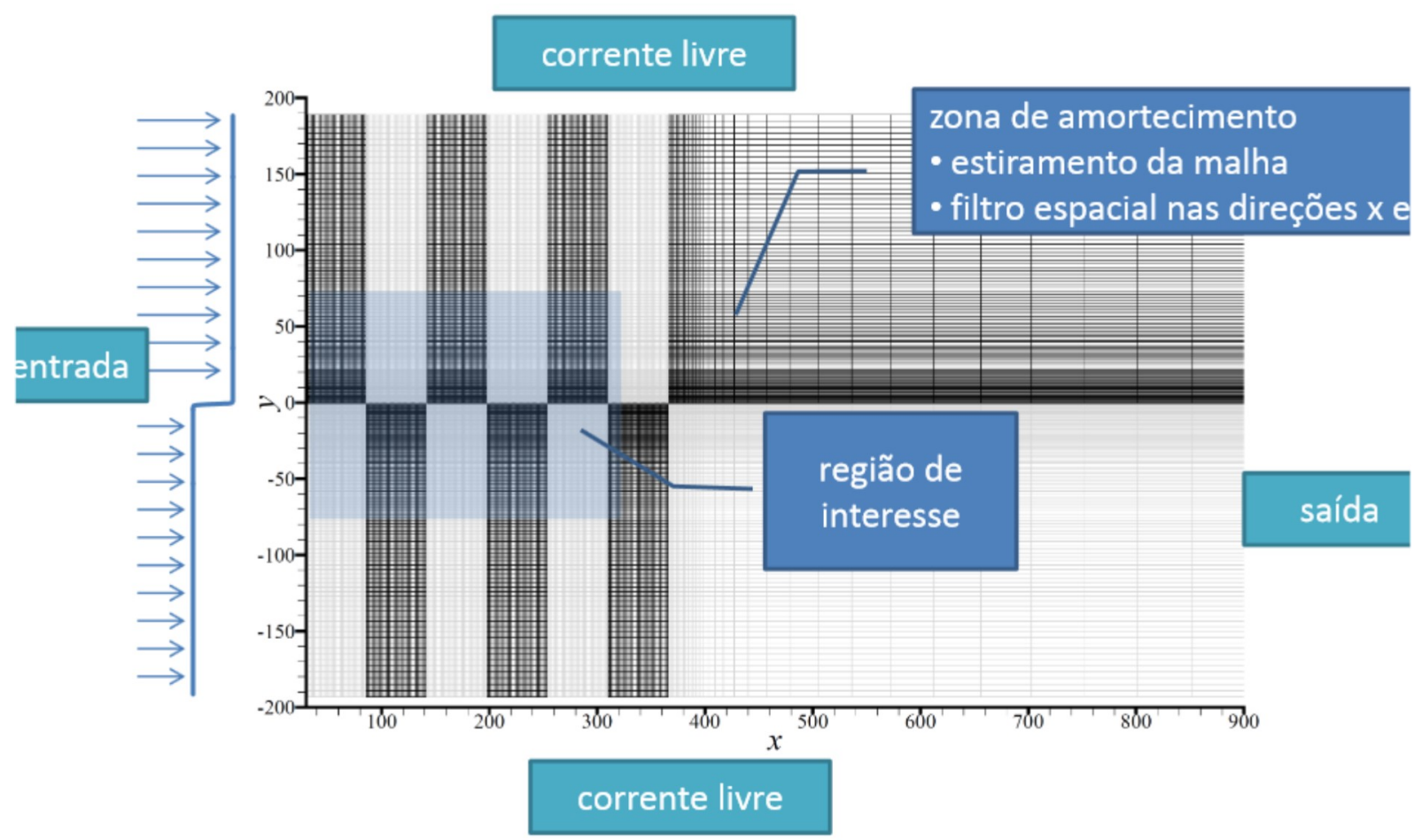

Fonte: Elaborada pelo autor.

Os esquemas de discretização espacial apresentados na subseção 3.3.1 são definidos para mal has regul ares enquanto que a mal ha proposta possui regiões com estiramento, tornando 
os espaçamentos não-uniformes. Portanto, transformações de coordenadas são implementadas através do mapeamento de uma mal ha não-uniforme $x$ - y para uma mal ha uniforme $x-h$, com espaçamentos uniformes Dx e Dh. De acordo com Anderson (1995), as primeiras derivadas espaciais no espaço físico são dadas por:

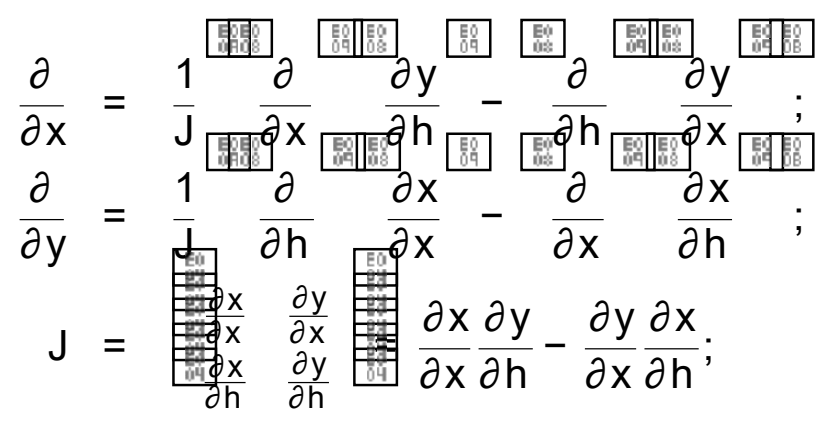

onde $\mathrm{J}$ é o determinante Jacobiano e os coeficientes $\partial \mathrm{x}=\partial \mathrm{x}, \partial \mathrm{x}=\partial \mathrm{h}, \partial \mathrm{y}=\partial \mathrm{x}$ e $\partial \mathrm{y}=\partial \mathrm{h}$ são as métricas da transformação. Ao invés de se aplicar derivação anal ítica para se obter as métricas, os próprios métodos de discretização espacial são utilizados para obtê-los. Segundo Babucke (2009), o cál culo numérico das métricas é mai s preciso se a mesma discretização é usada tanto para as métricas como para as quantidades do escoamento. Dessa forma, temos que:

$$
\begin{aligned}
& \frac{\partial h}{\partial x}=\frac{\partial x}{\partial y}=0 \\
& \frac{\partial x}{\partial x}=\frac{1}{\frac{\partial x}{\partial x}} \\
& \frac{\partial h}{\partial y}=\frac{1}{\frac{\partial y}{\partial h}}
\end{aligned}
$$

e as derivadas primeiras podem ser cal cul adas por:

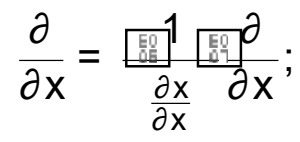

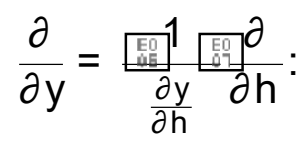

As derivadas segundas e cruzadas são obti das aplicando-se as equações Equação 3.1 e Equação 3.2 duas vezes. Dessa forma as derivadas segundas de uma função são dadas por: 


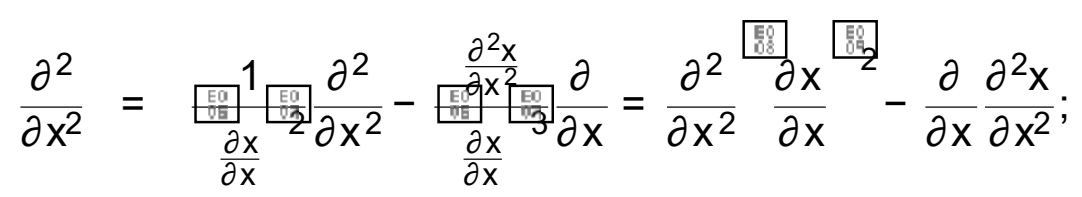

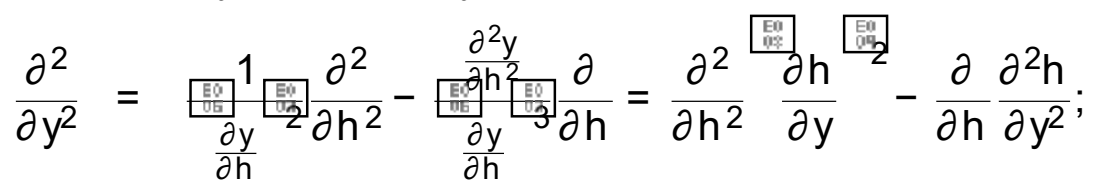

sendo que as métricas são dadas por:

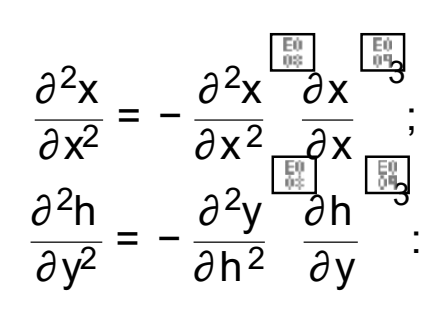

\subsection{Discretização Numérica}

A seguir são apresentados os esquemas de discretização espacial e temporal implementados no código numérico, e posteriormente na seção 3.4, uma discussão sobre problemas de dissi pação e dispersão numéricas e suas implicações para simul ações numéricas de aeroacústica.

\subsubsection{Esquema de Discretização Espacial}

Como destacado na seção 1.3, o método numérico utilizado para resolver problemas de aeroacústica deve possuir baixo ruído numérico para não contaminar a sol ução do escoamento, como também deve permitir que as ondas acústicas sejam propagadas a grandes distâncias e longos interval os de tempo sem sofrer com efeitos de dissipação e dispersão numéricas. Com base nessas restrições, tem crescido o desenvolvimento de métodos numéricos de al ta-ordem buscando minimizar tais efeitos. Para esquemas de diferenças finitas, os princi pais exemplos são as classes de esquemas baseados nos:

- esquemas de diferenças finitas expl ícitos construídos por Tam e Webb (1993) para preservar a rel ação de dispersão: esquemas de diferenças finitas DRP (Dipersion-RelationPreserving);

- esquemas de diferenças finitas implícitos compactos apresentados por Lele (1992), onde é necessário resolver um sistema de equações al gébricas para obtenção das derivadas espaciais. 
No presente trabal ho, os cál culos das derivadas foram real izados através do esquema de diferenças finitas compactas, o qual já foi estudado e otimizado por vários autores que mostram as vantagens em utilizálo (Adam (1977), Hirsh (1975), Lele (1992), Mahesh (1998), Souza, Mendonça e Medeiros (2005)). No código numérico foram adotados esquemas de $5^{\mathrm{a}}$ e $6^{\mathrm{a}}$ ordens de precisão. Aproximações de $6^{a}$ ordem são usadas para o ponto próximo ao contorno e no centro do domínio, e aproximações de $5^{\mathrm{a}}$ ordem para o ponto no contorno, desenvolvidas por (SOUZA; MENDONçA; MEDEIROS, 2005), e será daqui em diante descrito como esquema de diferenças finitas compactas.

Como mencionado anteriormente, esquemas de diferenças finitas compactas geram um si stema de equações al gébricas a ser resolvido. Neste trabal ho, si stemas tridiagonais são obtidos e resolvidos através do al goritmo de Thomas TDMA (Tridiagonal Matrix Algorithm) (PRESS et al ., 1992) e o auxílio de computação paral el a com decomposi ção do domínio. Detal hes desse procedimento são apresentados na seção 3.5.

A seguir, são apresentados os sistemas de equações al gébricas adotados para os cál culos da primei ra e segunda derivadas para uma mal ha uniforme de espaçamento entre pontos $h$.

\section{Cálculo da Primeira Derivada}

No cál culo da primeira derivada para o ponto no contorno inferior ou de entrada, $\mathrm{i}=1$, adotou-se a aproximação descentrada de $5^{\mathrm{a}}$ ordem

$$
f_{1}^{\prime}+4 f_{2}^{\prime}=\frac{1}{24 h}\left(-74 f_{1}+16 f_{2}+72 f_{3}-16 f_{4}+2 f_{5}\right)+O\left(h^{5}\right)
$$

Para o ponto próximo a parede, $\mathrm{i}=2$, adotou-se a aproximação descentrada de $6^{\mathrm{a}}$ ordem

$$
f_{1}^{\prime}+6 f_{2}^{\prime}+2 f_{3}^{\prime}=\frac{1}{120 h}\left(-406 f_{1}-300 f_{2}+760 f_{3}-80 f_{4}+30 f_{5}-4 f_{6}\right)+O\left(h^{6}\right):
$$

Para os pontos centrais adotou-se a seguinte aproximação

$$
f_{i-1}^{\prime}+3 f_{i}^{\prime}+f_{i+1}^{\prime}=\frac{1}{12 h}\left(-f_{i-2}-28 f_{i-1}+28 f_{i+1}+f_{i+2}\right)+O\left(h^{6}\right):
$$

Já, para os pontos $\mathrm{i}=\mathrm{N}$ e $\mathrm{i}=\mathrm{N}-1$ as aproximações são anál ogas às utilizadas para os pontos $\mathrm{i}=1$ e $\mathrm{i}=2$, com inversão do sinal. O sistema de equações al gébricas a ser resolvido segundo o al goritmo de Thomas é dado por: 

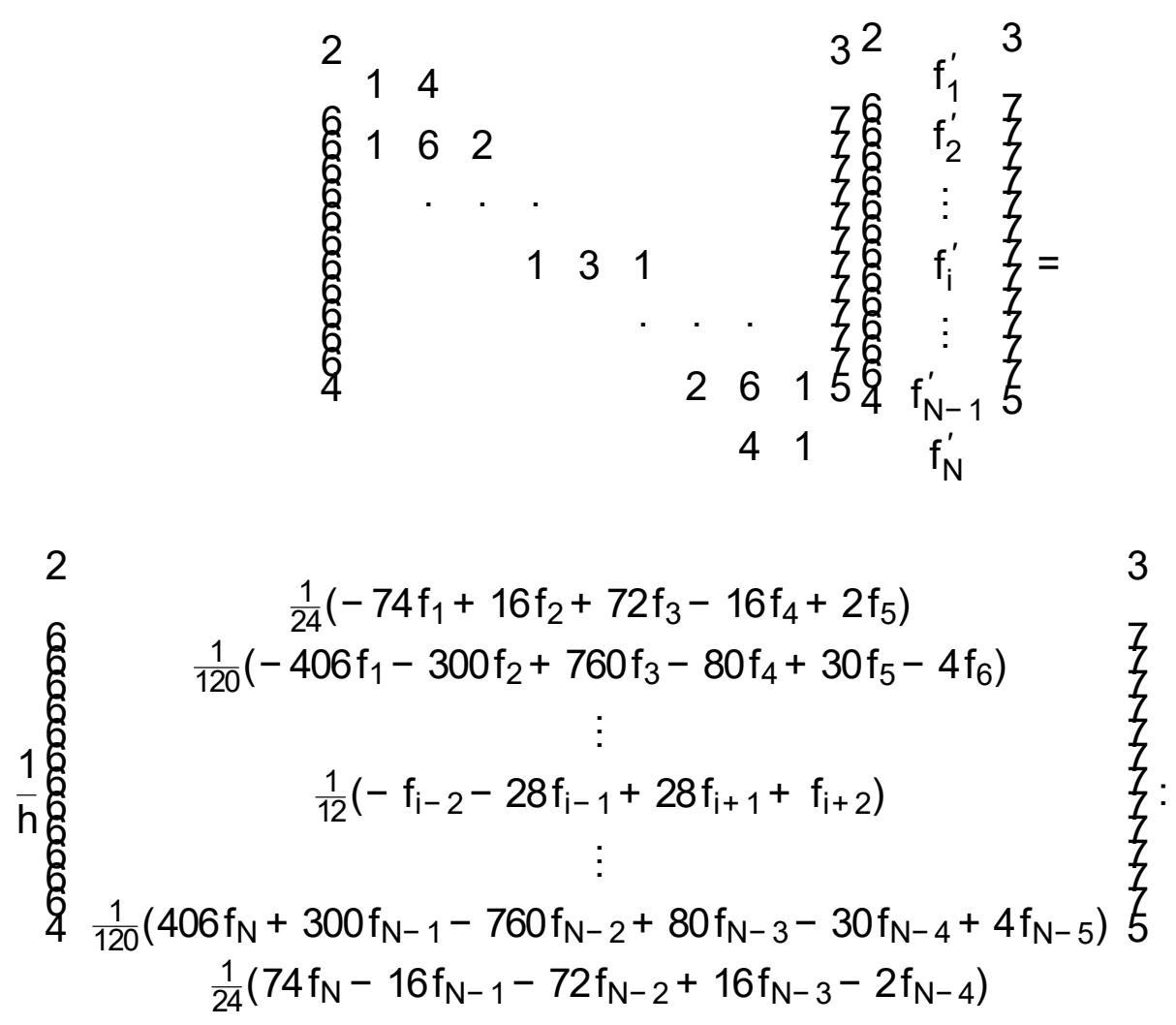

Cálculo da Segunda Derivada

No cál cul o da segunda derivada, para o ponto no contorno, i = 1, adotou-se a aproximação descentrada de $5^{\mathrm{a}}$ ordem

$$
13 f_{1}^{\prime \prime}+137 f_{2}^{\prime \prime}=\frac{1}{120 h^{2}}\left(9775 f_{1}-20285 f_{2}+11170 f_{3}-550 f_{4}-145 f_{5}+36 f_{6}\right)+O\left(h^{5}\right):
$$

Para o ponto próximo a parede, i = 2, adotou-se a aproximação descentrada de 6 a ordem, dada por

$$
f_{1}^{\prime \prime}+12 f_{2}^{\prime \prime}+3 f_{3}^{\prime \prime}=\frac{1}{360 h^{2}}\left(4834 f_{1}-8424 f_{2}+1890 f_{3}+2320 f_{4}-810 f_{5}+216 f_{6}-26 f_{7}\right)+O\left(h^{6}\right):
$$

Para os pontos centrais utilizou-se a seguinte aproximação

$$
2 f_{i-1}^{\prime \prime}+11 f_{i}^{\prime \prime}+2 f_{i+1}^{\prime \prime}=\frac{1}{4 h^{2}}\left(3 f_{i-2}+48 f_{i-1}-102 f_{i}+48 f_{i+1}+3 f_{i+2}\right)+O\left(h^{6}\right):
$$

Para os pontos $\mathrm{i}=\mathrm{N}$ e $\mathrm{i}=\mathrm{N}-1$ as aproximações são anál ogas às obtidas para os pontos $\mathrm{i}=1 \mathrm{e} \mathrm{i}=2$. Dessa forma, o sistema de equações al gébricas tridiagonais a ser resolvido é dado por 

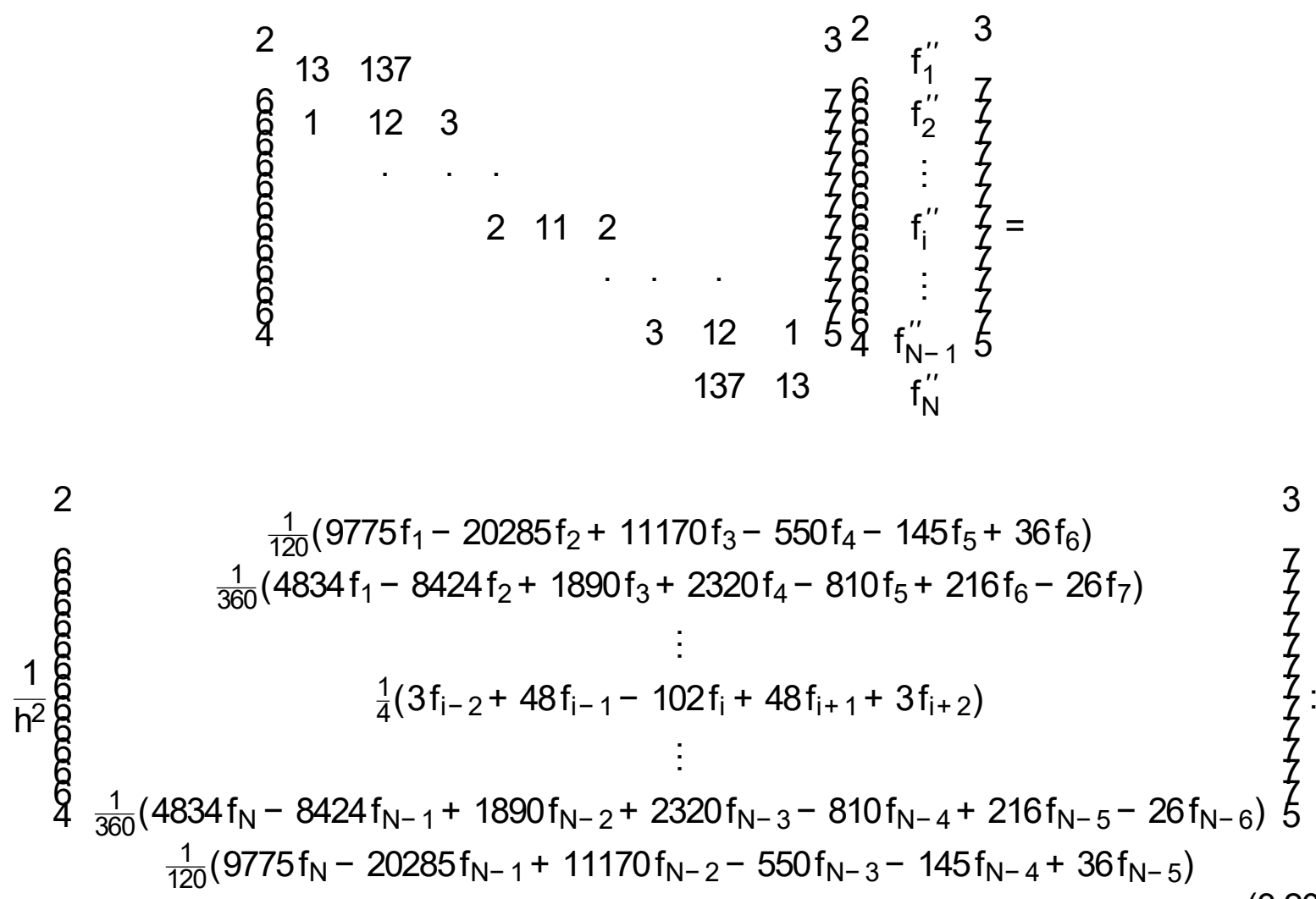

\section{Discretização Espectral na direção z}

Nos casos das simulações tridimensionais é utilizada uma discretização espectral na direção z devido à condi ção de periodi ci dade na di reção transversal , onde cál culos são feitos no espaço de Fourier. A transformação de uma variável no espaço físi co para sua correspondente no espaço de Fourier é dada por:

$$
f(x ; y, z ; t)=\underset{k=0}{\hat{A}} \hat{f}_{k}(x ; y, t) \cdot e^{i(k g z)}
$$

com $f$ sendo qual quer variável no espaço físico e f a variável complexa no espaço de Fourier. $\mathrm{O}$ número de onda fundamental na direção transversal g é dado pelo comprimento transversal do domínio de integração I z:

$$
g=\frac{2 p}{I_{z}}
$$

Com o intui to de se evitar transformaç̃es desnecessárias, todos os cál cul os das variáveis do escoamento são real izados no espaço físico, enquanto que somente as derivadas primeira e segundas na direção z são cál culadas no espaço de Fourier. Para isso, a variável que se deseja cal cular-se a derivada na direção zé transformada para o espaço de Fourier (PRESS et al., 1992). Uma vez no espaço de Fourier as derivadas são cal culadas, tendo a vantagem de serem exatas e 
não possuírem erros de truncamento. Por fim, os val ores das derivadas é que são transformadas de vol ta para o espaço físi co onde os demais cál cul os são real izados.

$$
\begin{aligned}
\frac{\partial \hat{f}_{k}}{\partial z} & =\hat{A}_{k=1}^{2 K=3}-i k g \hat{f}_{k}: \\
\frac{\partial^{2} \hat{f}_{k}}{\partial z^{2}} & =\hat{A}_{k=1}^{2 K=3}-k^{2} g \hat{f}_{k}:
\end{aligned}
$$

Para se evitar problemas de "alias", que são oscilações não físicas de al ta frequência que aparecem devido a produtos não lineares dos modos, somente os primeiros 2=3 do número máximo de modos permitidos são utilizados (DAINEZI, 2012).

\subsubsection{Esquema de Discretização Temporal}

Souza (2005) realizou diversos testes para aval iar diferentes esquemas de discretização temporal. O resultado destes testes mostrou que, apesar de al guns métodos obterem vantagens, como baixo armazenamento (WILLIAMSON, 1980), o tempo total de simulação para o método Runge-Kutta de $4^{a}$ ordem é mel hor, pois pode-se trabal har com passos de tempo mai ores. Desta forma, no código numérico foi implementado um método explícito do tipo Runge-Kutta de quatro estágios, com $4^{\mathrm{a}}$ ordem de precisão. A partir da solução do escoamento em um tempo n, a solução no tempo n+ 1 após um avanço de tempo Dt é obtido a partir dos seguintes passos:

$$
\begin{aligned}
& \mathrm{Q}_{0}=\mathrm{Q}^{\mathrm{n}} \text {; } \\
& Q_{1}=Q^{n}+\frac{1}{2} D t \cdot \frac{\partial Q}{\partial t} \\
& Q_{2}=Q^{n}+\frac{1}{2} D t \cdot \frac{\partial Q}{\partial t} \\
& Q_{3}=Q^{n}+D t \cdot \frac{\partial Q}{\partial t}
\end{aligned}
$$

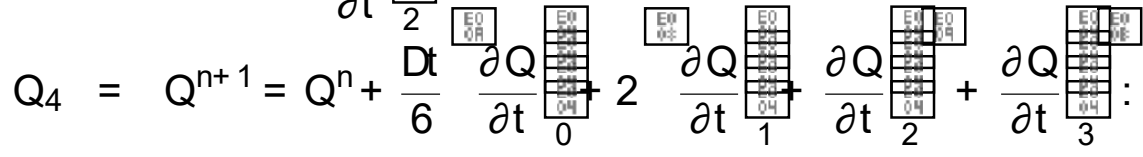

Inicial mente armazena-se a solução do tempo n em $Q_{0}$. Posteriormente, a cada passo intermediário no tempo (dado pelos subíndices 1, 2, 3 e 4), a derivada no tempo $\partial \mathrm{Q}=\partial \mathrm{t}$ e, portanto, as derivadas espaciais devem ser recal culadas.

\subsection{Análise de Fourier das Derivadas Espaciais}

Esquemas de di scretização como os apresentados nas seções anteriores são aproximações para a solução das equações diferenciais parciais (EDP's) que governam o problema a ser 
estudado. Uma análise de Fourier do método numérico é um modo efetivo de avaliar equantificar os erros de di scretização envolvidos nessas aproximações (LELE, 1992). Tam (2004) real izou análises de Fourier de esquemas de diferenças finitas explícitas DRP, enquanto que Lele (1992) real izou tais anál ises para esquemas de diferenças finitas compactas. Nesta seção, é apresentada a análise de Fourier para os esquemas de discretização de diferenças finitas compactas para o cál cul o das derivadas primeira e segunda a serem utilizados nas direções $x$ e y no presente trabal ho.

Para a realização da análise de Fourier, assume-se que as variáveis são constantes e periódicas em um domínio [0; L] e que o número de modos de Fourier $\mathrm{N}$ utilizados para representar uma função no espaço físico $f(x)$ é igual a $N=L=h$, sendo $h$ espaçamentos no espaço físico. Assim, uma variável $f(x)$ pode ser descrita no espaço de Fourier $\hat{f}_{k}$ por:

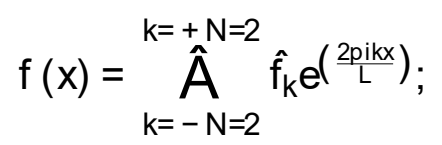

onde $\mathrm{i}={ }^{\sqrt{-1}}$. Introduzindo o número de onda normal izado $\mathrm{b}=2 \mathrm{pkh}=\mathrm{L}=2 \mathrm{pk}=\mathrm{N}$ e a coorde nada normalizadas $=x=h$, a Equação 3.30 pode ser reescrita como:

$$
f(s)=\hat{A}_{k=-N=2}^{k=+N=2} \hat{f}_{k} e^{i b s}
$$

Assim, o domínio do número de onda normalizado é [0; $p]$ e a primeira derivada da Equação 3.31 gera uma função com coeficientes de Fourier $\hat{f}_{k}{ }^{\prime}=i b \hat{f}_{k}$, logo:

$$
f^{\prime}(s)=\hat{A}_{k=-N=2}^{k=+N=2} i b \hat{f}_{k} e^{i b s}
$$

A análise de Fourier da primeira derivada consiste em comparar os coeficientes de Fourier obtidos a partir do esquema de discretização com os coeficientes exatos (Equação 3.32). Aplicando-se a transformação para o espaço de Fourier (Equação 3.31) a um esquema de discretização, é possível então descrever uma relação da seguinte forma:

$$
i \bar{b}^{\prime} \hat{f}_{k} \cong i b \hat{f}_{k} ;
$$

onde $\overline{b^{\prime}}$ é o número de onda modificado referente ao esquema de di scretização utilizado.

Cada esquema de diferenças finitas possui uma função particular $\bar{b}^{\prime}(b)$, sendo que diferenciações exatas fornecem $\overline{b^{\prime}}=b$ e métodos espectrais também, exceto para $b /=$. Lele 
(1992) fornece essa relação para diferentes esquemas de diferenças finitas compactas:

$$
\bar{b}^{\prime}(b)=\frac{a \operatorname{sen}(b)+(b=2) \operatorname{sen}(2 b)+(c=3) \operatorname{sen}(3 b)}{1+2 a \cos (b)+2 b \cos (2 b)}
$$

onde, para o esquema de diferenças finitas compactas do presente trabal ho, $a=1=3 ; b=c=0$; $a=14=9$ e $b=1=9$. Coloni us e Lele (2004) apresentam também os coeficientes para diversos esquemas, entre el es o esquema explícito de $2^{a} \operatorname{ordem}(a=b=b=c=0 ; a=1)$, e o esquema DRP de Tam e Webb (1993) $(a=b=0 ; a=(992-30 p)=42 d, b=(6900 p-22528)=84 d e$ $c=(1632-510 p)=14 d$, sendo $d=45 p-128)$.

A Figura 11 apresenta um gráfico do número de onda real por número de onda modificado onde são pl otados os esquemas citados. Os val ores de número de onda para os quais a curva do esquema de discretização mais se aproxima da curva exata correspondem àquel as ondas que são bem resolvidas pelo método aplicado. A medi da que há um distanciamento entre elas, o método numérico começa a inserir ef eitos de di spersão à metodol ogia. Pode se observar também que o esquema de diferenças finitas compactas de $6^{\mathrm{a}}$ ordem fornece mel hor resol ução que o método explícito DRP, que é de $4^{\mathrm{a}}$ ordem (COLONIUS; LELE, 2004).

Figura 11 - Número de onda real por número de onda modificado para a $1^{\mathrm{a}}$ derivada: (a) explícita centrada de $2^{\mathrm{a}}$ ordem; (b) compactas 6 a ordem; (c) DRP $4^{\mathrm{a}}$ ordem; (d) val or exato; .

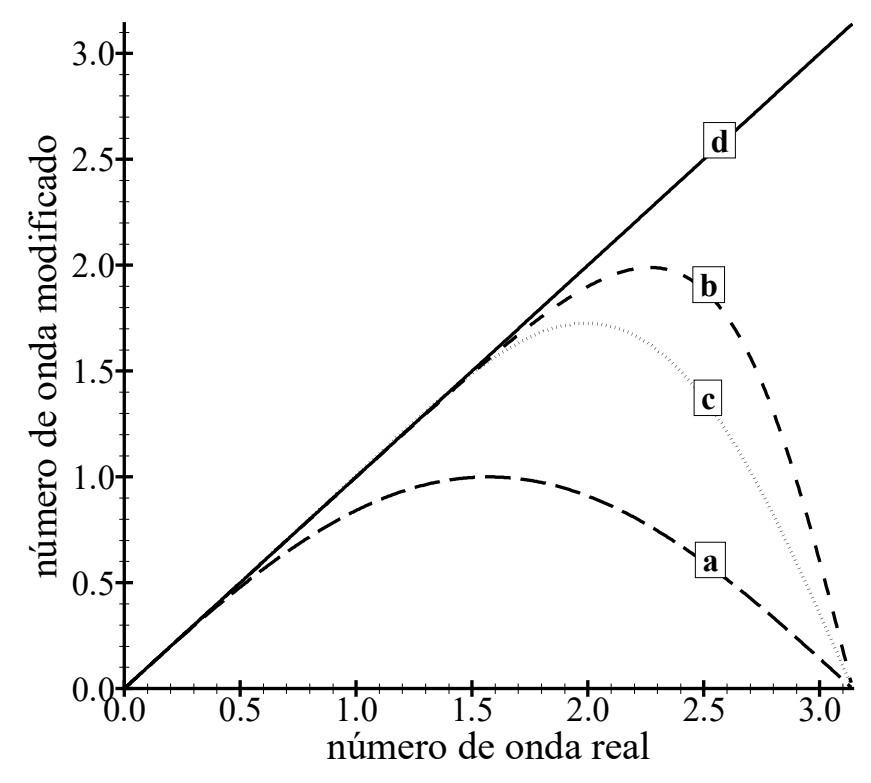

Fonte: Elaborada pelo autor.

O número de pontos por comprimento de onda é igual $a N_{l}=2 p=b$ e o erro da discretização pode ser avaliado conforme:

$$
e_{1}=\frac{\sqrt{5}(b)-b^{50}}{b}
$$


Dessa forma, é possível verificar através da Figura 12 que o esquema compacto apresenta menor erro e necessita de menos pontos por comprimento de onda do que os demais, tornando-o mais atrativo. Por exemplo, para se ter um nível de erro de discretização da ordem de $10^{-3}$, o esquema compacto necessita de aproximadamente 6 pontos por comprimento de onda enquanto que os esquemas DRP e expl ícito centrado de $2^{\mathrm{a}}$ ordem necessitam de aproximadamente 12 e 80 pontos, respectivamente. A desvantagem é a necessi dade de se resolver si stemas de equações al gébricas tridiagonais para o cál culo das derivadas.

Figura 12 - Número de pontos por comprimento de onda por erro para a $1^{\mathrm{a}}$ derivada: (a) explícita centrada de $2^{\mathrm{a}}$ ordem; (b) compactas 6 a ordem e (c) DRP $4^{a}$ ordem.

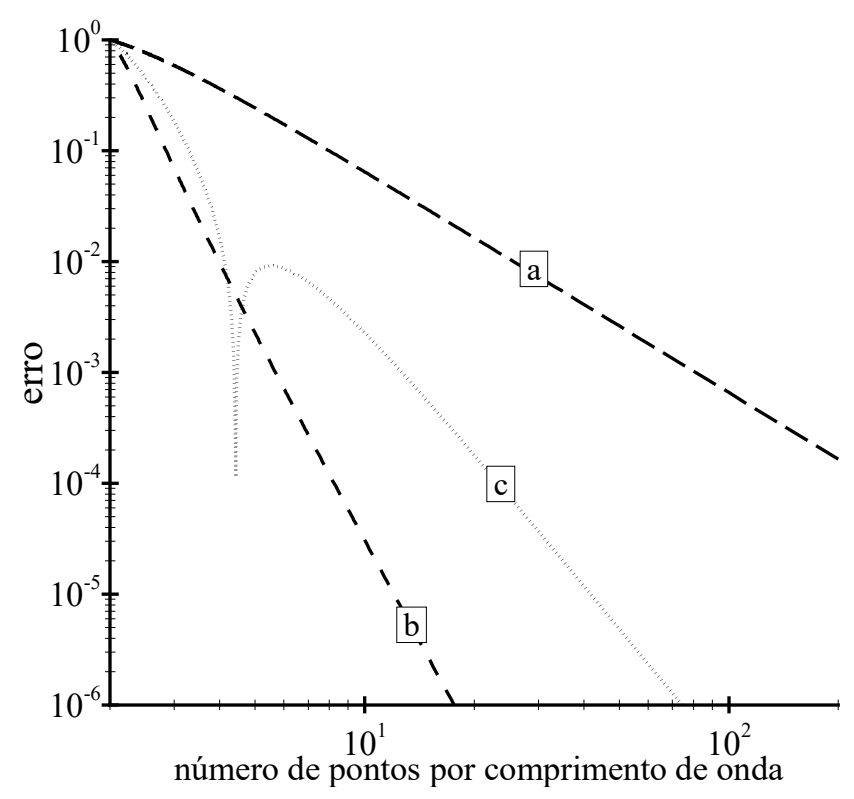

Fonte: Elaborada pelo autor.

A nál ise semel hante pode ser real izada para o cál culo da segunda derivada. A segunda derivada exata da Equação 3.31 é dada por:

$$
f^{\prime \prime}(s)=\hat{A}_{k=-N=2}^{k=+N=2}-b^{2} \hat{f}(k) e^{i b s}
$$

Lele (1992) também fornece uma relação entre o número de onda modificado para segunda derivada e o número de onda real:

$$
\bar{b}(b)=\frac{2 a[1-\cos (b)]+(b=2)[1-\cos (2 b)]+(2 c=9)[1-\cos (3 b)]}{1+2 a \cos (b)+2 b \cos (b)}
$$

Para o esquema de diferenças finitas centradas de $2^{a}$ ordem $a=1$ e $b=c=a=b=0$, e para o esquema de diferenças finitas compactas de $6^{a}$ ordem utilizada no presente trabal ho $a=3=11, b=48=11, a=2=11$ e $c=b=0$. A Figura 13 apresenta um gráfico de número 
de onda real por número de onda modificado comparando os dois métodos, e também uma comparação do erro, dado pela Equação 3.38, em relação ao valor exato em função do número de pontos por onda, onde é evidenciado a vantagem do método compacto.

$$
e_{2}=\frac{\sqrt{y^{\prime}}(b)-b^{2}}{b^{2}}
$$

Efeitos de dispersão numérica estão relacionados ao esquema utilizado e tendem a al terar a fase com que as ondas estão sendo transportadas, quando os comprimentos dessas ondas não são bem resolvidas pelo esquema numérico. Tal verificação foi apresentada anteriormente e consiste em comparar a parte real da rel ação dada pela Equação 3.33. Por outro lado, os efei tos de dissi pação numérica, que tendem a diminuir as amplitudes das ondas sendo transportadas, são aval iados comparando-se a parte imagi nária da rel ação dada pela Equação 3.33. Tal diferença de fase ocorre quando esquemas de discretização espaciais utilizados não são centrados. Neste trabal ho, o uso de um esquema de diferenças finitas compactas centrado garante que os efeitos de dissi pação devido à di scretização espacial são nul os (LELE, 1992).

Figura 13 - (esquerda) Número de onda real por número de onda modificado para a $2^{\mathrm{a}}$ derivada, e (direita) número de pontos por comprimento de onda por erro para a $2^{\mathrm{a}}$ derivada: (a) explícita centrada de $2^{\mathrm{a}}$ ordem; (b) compactas $6^{\mathrm{a}}$ ordem e (c) exato; .
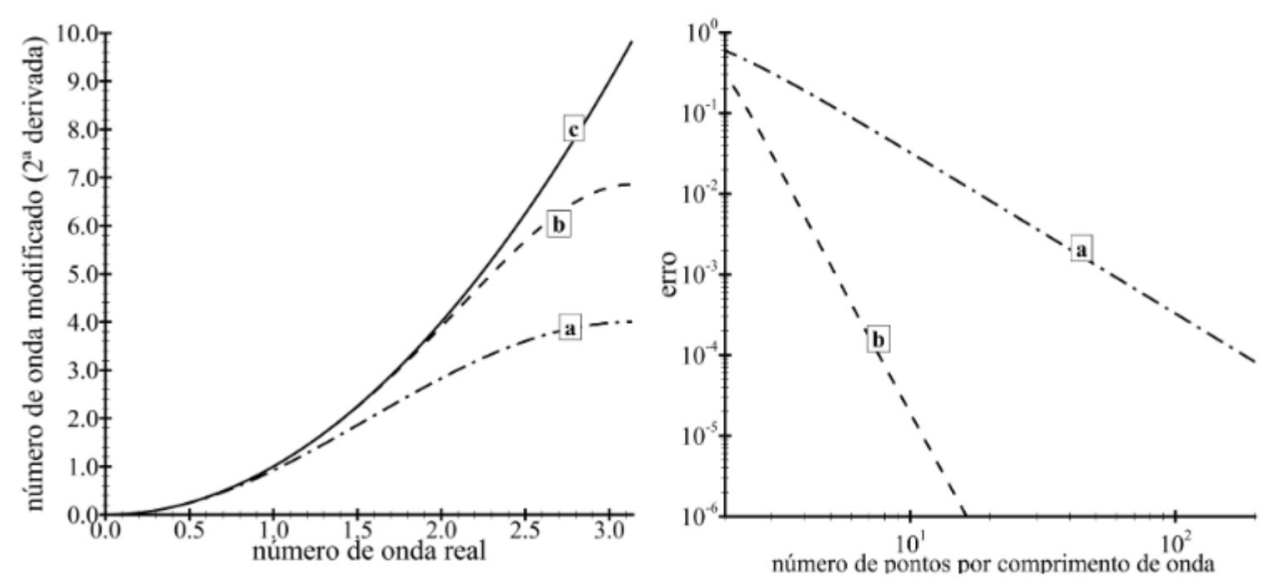

Fonte: Elaborada pelo autor.

De acordo com Babucke (2009) o cál cul o da $2^{\mathrm{a}}$ derivada de uma variável realizando dois cál cul os consecutivos de $1^{\text {a }}$ derivada causa uma perda de resolução para mai ores val ores de números de onda (Figura 14). Sendo assim, termos dos vetores de fl uxo da Equação 2.8 foram separados entre $2^{a}$ derivadas di retas em uma di reção específica e termos que geraram derivadas cruzadas. A $2^{\mathrm{a}}$ derivada das variáveis foram realizadas conforme procedimento descrito anteriormente, enquanto que as derivadas cruzadas foram cal culadas com dois cál cul os consecutivos de $1^{a}$ derivada. Tal procedimento de separação faz com que surjam termos adi cionais às equações e é apresentado no Apêndice $A$. 


\subsection{TDMA Paralelizado}

Os sistemas al gébricos tridiagonais obtidos são resolvidos através do algoritmo de Thomas TDMA (PRESS et al., 1992). Para os cál cul os da primei ra e segunda derivadas através do esquema de diferenças finitas compactas de $5^{a}$ e $6^{a}$ ordem define-se uma molécula de cál cul o com o número de pontos necessários para a real ização das operações. Para os pontos intermediários (a partir do terceiro ponto até o ponto $\mathrm{N}$ - 3) a molécul a de cál cul o é de 5 pontos.

Entretanto, quando o domínio é particionado conforme ilustrado anteriormente (Figura 10), em cada elemento de processamento o domíni o não possui os pontos necessários para se cal cular as derivadas de forma correta nas interfaces entre domínios adjacentes. Dessa forma, para se garantir que o cál cul o seja feito de forma correta, é necessário haver uma sobreposi ção entre domínios adjacentes. A Figura 15 mostra um exemplo de dois domínios, indicando em cada um, quais os pontos em que é possível cal cular as derivadas usando somente pontos do seu próprio domínio, e quais pontos em que isso não é possível. Logo, os val ores das derivadas para os pontos em que não se pode cal cul ar são obti dos através da comunicação do val or correto obtido do domínio adjacente. Computacional mente isso é feito usando di retivas de paral elização MPI, como já discutido anteriormente e indi cado na Figura 15.

Além do procedimento de comunicação do val or da derivada, também é necessária a comunicação entre el ementos de processamento adjacentes durante a execução do algoritmo TDMA. Este al goritmo se divide em dois processos de varredura no domínio para obtenção da solução: um de ida onde coefi cientes são cal culados, e outro de volta onde o val or da sol ução é obti do. Quando o domíni o é decomposto, informações durante as duas varreduras devem ser comunicados entre domínios adjacentes. A Figura 16 mostra o procedimento de ida e vol ta para o TDMA quando real izado de forma sequencial e de forma paral elizada.

Figura 14 - Número de onda modificado para o cál culo direto da segunda derivada versus aplicando a primeira derivada duas vezes.

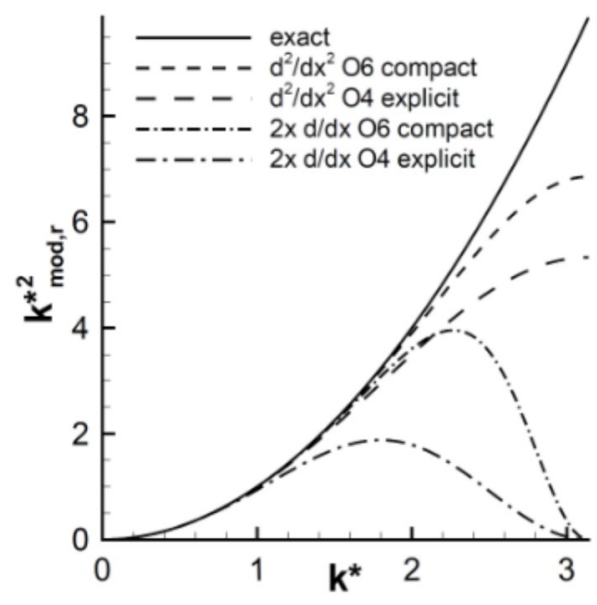

Fonte: Babucke (2009). 
Figura 15 - Sobreposição do entre domínios adjacentes e processo de comuni cação usando MPI.

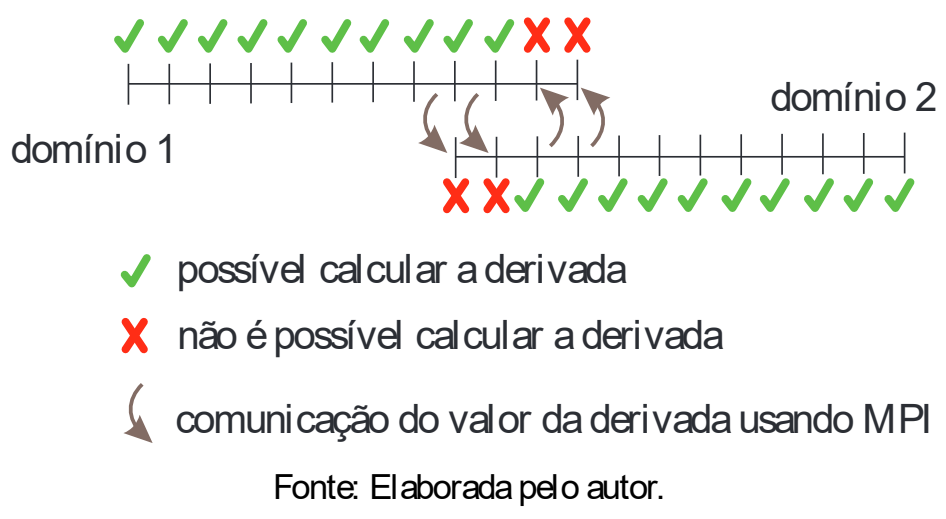

Figura 16 - Execução do al goritmo TDMA de forma sequencial e paral elizada.
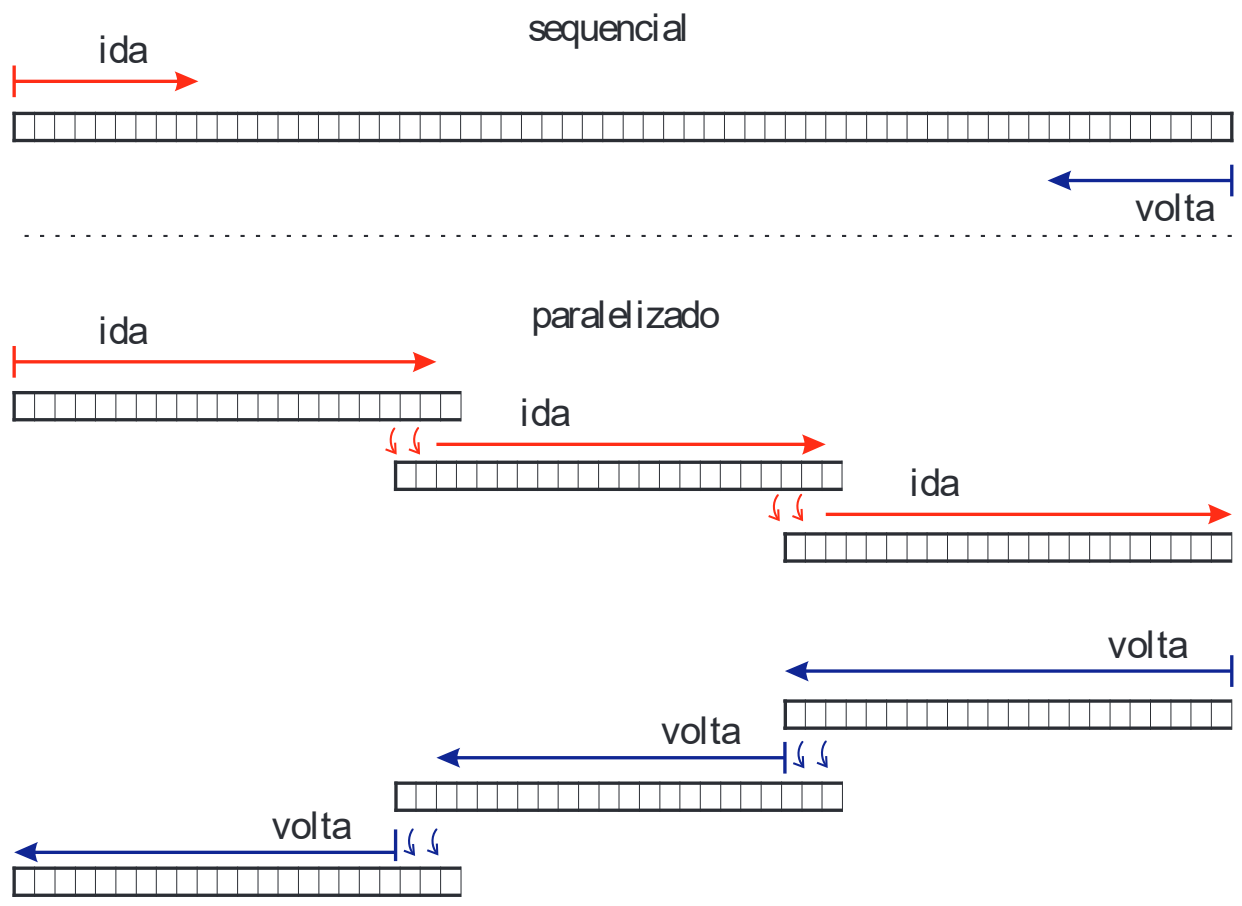

Para evitar uma "serial ização" dessa parte do código utiliza-se um procedi mento chamado pipeline. Por exemplo, para o cál culo na direção x o processo segue as seguintes etapas: o elemento de processamento do primeiro domínio inicia os cál culos da ida para a primeira linha da direção y. Chegando ao fim do primeiro el emento de processamento, informação é comuni cada para o próximo el emento de processamento. Enquanto o próximo elemento inicia os cál cul os da primeira linha da direção y, o anterior já pode iniciar os cál cul os da segunda linha na direção y. O segundo elemento continua até o tercei ro e assi m consequentemente. Esse processo se repete até que todos os el ementos de processamento tenham feito o processo de ida para todas as linhas em y de seus respectivos domínio. Uma vez que o el emento de processamento do úl timo domínio termi na o processo de ida para a primeira linha em y, ele já pode iniciar o processo de volta que funciona de forma reversa. Os cál cul os são feitos de trás pra frente até chegar à interface com o 
domínio anterior. Informação é passada para o cál culo da vol ta no domínio anterior e o último el emento já pode iniciar os cál cul os para a segunda linha na direção y. Esse processo se repete até que todos os el ementos de processamento tenham feito o processo de volta de todas as linhas em y de seus respectivos domínio.

Para auxiliar a identificação dos elementos de processamento durante a execução do código, definiu-se 3 variáveis: myrankx, myranky e myrank:

myrankx: índice de posição do elemento de processamento na direção x;

- myranky: índice de posição do elemento de processamento na direção y;

- myrank: índice do elemento de processamento no domínio.

A Figura 17 apresenta um esquema dos índices dos el ementos de processamento. Em todas as si mul ações utilizou-se dois el ementos de processamento na direção y e número variado de elementos de processamento na direção $x$.

Figura 17 - Esquema de distribui ção dos elementos de processamento e os índices utilizados. myrankx, myranky são apresentados em eixos coordenado e myrank é definido no centro de cada el emento de processamento.

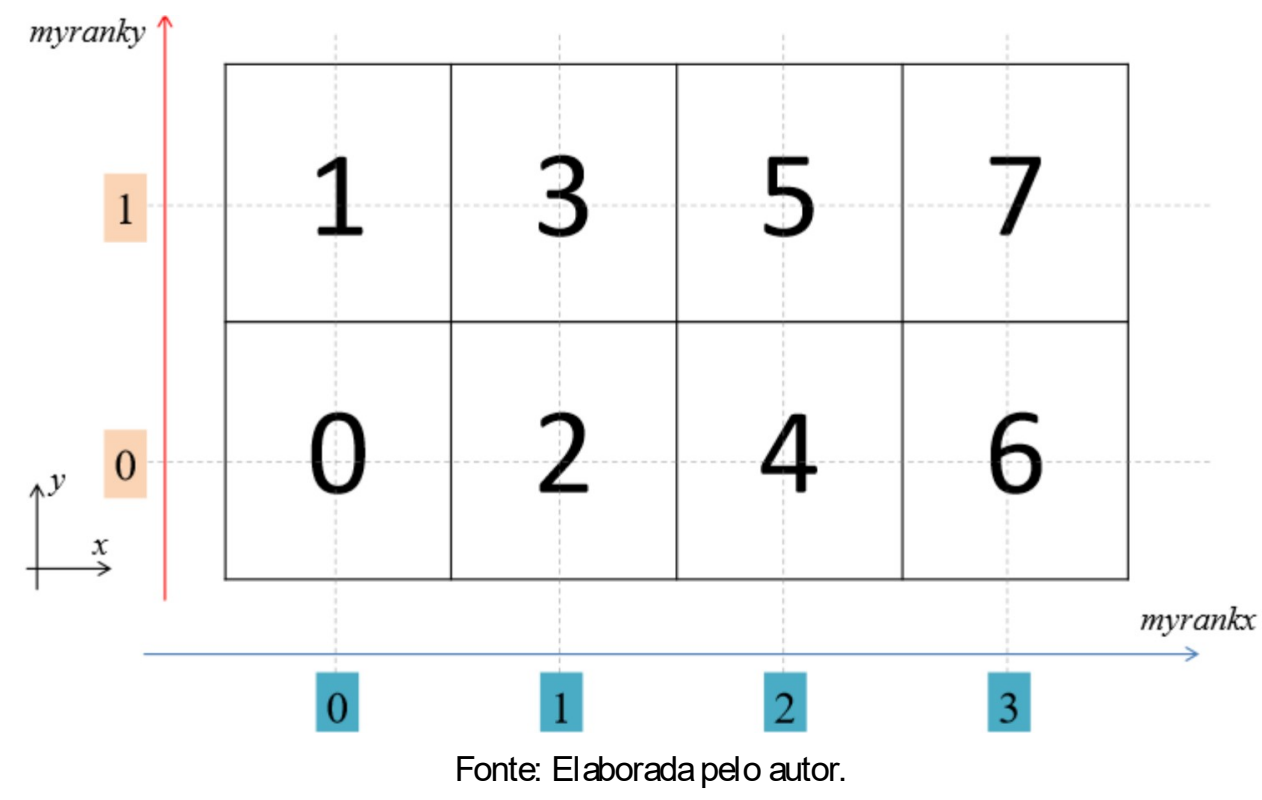




\subsection{Código LST}

Um código numérico foi gentilmente fornecido pelo Prof. Márcio T. de Mendonça (MENDONçA, 2015) para resolver o conjunto de equações descritas na seção 2.3 e obter-se as taxa de amplificação espacial e as autofunções utilizadas para introduzir as perturbações no contorno de entrada do escoamento. O procedimento de sol ução dessas equações é apresentada por Salemi (2006).

Integra-se numericamente a Equação 2.35 (ou Equação 2.47 para o caso de jato varicoso) das bordas para o meio utilizando as condições de contorno apresentadas. No centro a solução para c obtida pela integração da parte superior ao centro, $\mathrm{c}\left(0^{+}\right)$, e obtida pela integração da parte inferior, c $\left(0^{-}\right)$, tem de ser iguais. Caso não sejam, varia-se a até que isso ocorra. Encontrado o val or de a que satisfaz a condição descrita acima, pode-se calcul ar as autofunções das variáveis. A Figura 18 apresenta em linhas gerais a sequência de etapas para a simul ação.

Figura 18 - Esquema do funcionamento do código numérico LST.

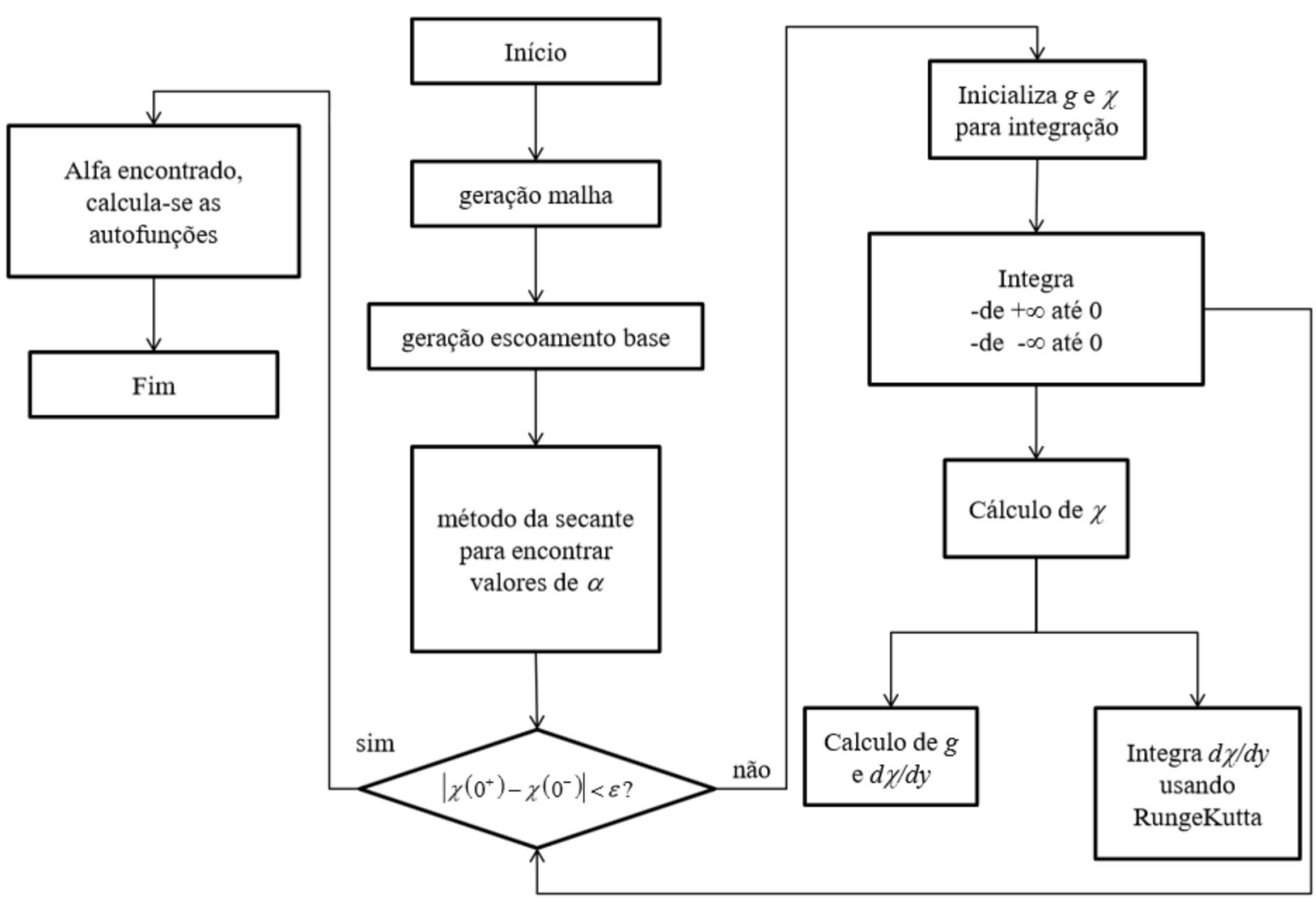

Fonte: Elaborada pelo autor. 


\subsection{Condições de Cont orno}

As condições de contorno para os problemas estudados são apresentadas na Figura 7: entrada, saída, corrente livre e periodi cidade.

\section{Entrada}

Na região da entrada são utilizadas as varíaveis defini das como condição inicial conforme descrita na seção 3.8. Entretanto, al ém desses val ores prescritos, duas informações nas condições de entrada: flutuações a partir das características e perturbações com autofunções obti das pelo LST.

A introdução da flutuações a partir das características ocorre porque um tratamento diferenciado deve ser feito na entrada para permitir que ondas acústicas, originadas no interior do domínio computacional e que viajam na direção contrária a do escoamento quando este é subsônico, deixem o domínio através da entrada sem que haja reflexões que contaminem a solução em seu interior.

Para se introduzir o efeito de tais ondas acústicas na condi ção de contorno de entrada, é possível escrever as perturbações do escoamento base em função de variáveis características que correspondem às perturbações de entropia, fl utuações de vortici dade do escoamento e às ondas acústicas que viajam contra e a favor do escoamento. A variável característica c que corresponde a onda acústica que viaja na direção contrária a do escoamento pode ser obtida a partir das flutuações do escoamento como:

$$
c=-u^{\prime} r_{0} a_{0}+p^{\prime}
$$

onde o subscrito 0 indica val ores do escoamento base e o superescrito ' flutuações em torno do escoamento base. Cal culados os val ores de c próximo à entrada, é possível extrapolar para o contorno, por exemplo com uma aproximação de $2^{\mathrm{a}}$ ordem:

$$
c_{(j=1)}=3 \cdot c_{(j=2)}-3 \cdot c_{(j=3)}+c_{(j=4)}:
$$

Uma vez cal culados o val or da característica no contorno, é possível obter o val or das flutuações através de:

$$
\begin{aligned}
& r^{\prime}=\frac{c}{2 a_{0}^{2}} \\
& u^{\prime}=\frac{c}{2 r_{0} a_{0}^{2}} \\
& v^{\prime}=0 \\
& p^{\prime}=\frac{c}{2}
\end{aligned}
$$

O processo de cál culo das perturbações com autofunções obtidas pelo LST é apresentado na seção 2.3. Concluindo, a condição de contorno de entrada se constitui de um val or prescrito 
obtido da condição inicial somada a perturbações com autofunções do LST e somada a flutuações obti das das características para evitar reflexões de ondas acústi cas geradas no interior do escoamento em escoamentos subsônicos.

\section{Saída}

No contorno de saída é utilizada uma condição de contorno não-refl exiva na direção $x$ da seguinte maneira:

$$
Q_{i=N}=Q_{i=N-1}
$$

Entretanto, em simulações de aeroacústica, principalmente no caso de escoamento subsôni co, as perturbações são pouco dissi padas ao longo domínio. Dessa forma, elas chegam ao contorno de saída mas não podem ser refletidas. De acordo com Colonius, Lele e Moin (1992), condições de contorno não-reflexivas não são sufi cientes para evitar refl exões em condições de contorno de saída pois vórtices produzem grandes reflexões devido a efeitos não lineares.

O procedimento utilizado para tratar dessa situação apresentada consiste em el iminar o máximo possível as flutuações antes que elas atinjam a saída domínio. Col onius, Lele e Moin (1992) propuseram o uso de estiramento da mal ha e um processo de filtragem do domínio para que as flutuações sejam al tamente atenuadas, o qual é utilizado no presente trabal ho. $O$ esti ramento da mal ha faz com que as flutuações se tornem mal resolvidas e sofram um processo de dissipação numérica. O uso do filtro continua o processo de dissi pação sobre as flutuações antes que elas cheguem ao contorno de saída. No presente trabal ho, um filtro compacto de $6^{a}$ ordem é utilizado (LELE, 1992):

$$
B f_{1-1}+p_{1}+B f_{1-1}=c f_{i-2}+b f_{i-1}+a f_{i}+b f_{i+1}+c f_{i+2}
$$

onde o superescritobrepresenta o valor da variável filtrada. Os coeficientes são dados por:

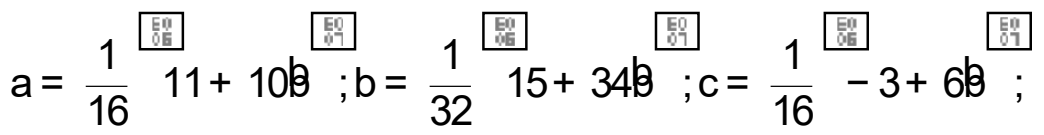

$\operatorname{com} B=0 ; 48$.

A transi ção da mal ha entre região com estiramento (Figura 10) é dada por:

$$
F=(1-s) F_{r i}+s F_{r a}
$$

onde $F_{r i}=1 ; 0$ é o estiramento da região de interesse e $F_{r a}=1 ; 009$ é o estiramento utilizado na região de amortecimento. 


$$
\begin{aligned}
s & =1-6 x^{* 5}+15 x^{* 4}-10 x^{* 3} \\
x^{*} & =\frac{x^{*}-x_{0}^{*}}{D x_{\text {rampa }}^{*}}
\end{aligned}
$$

A variável s é um polinômio de $5^{\mathrm{a}}$ ordem que transiciona de forma suave da região não amortecida para a região amortecida e sendo $x^{*}$ a direção em que o polinômio será aplicado, $x_{0}^{*} 0$ ponto de início e x rampa sua extensão, conforme observa-se na Figura 19.

Figura 19 - Função s com transição suave.

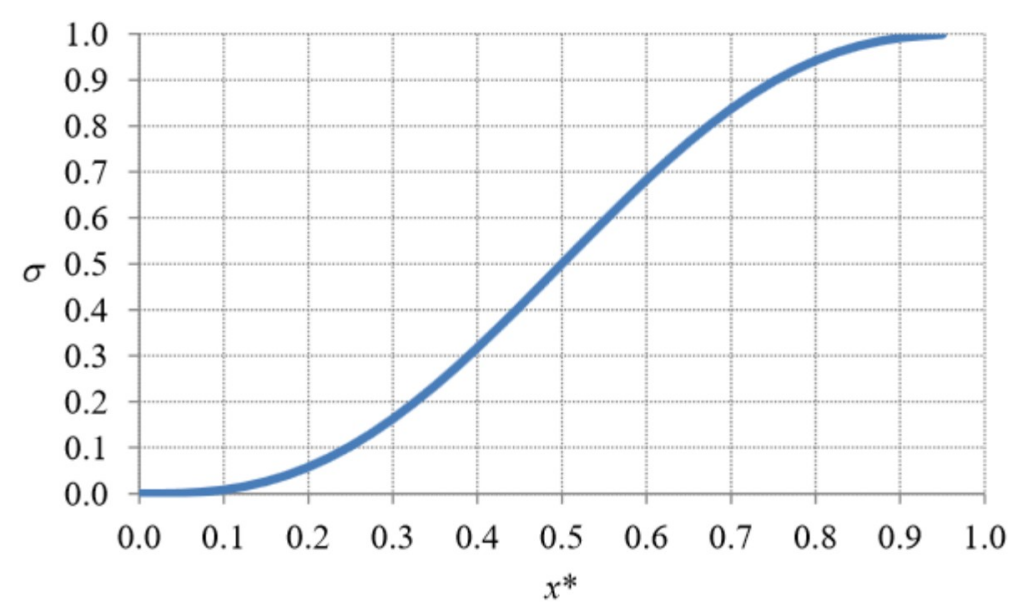

Fonte: Elaborada pelo autor.

\section{Corrente Livre}

Um tratamento semelhante à condição de contorno da saída é utilizada na direção y, com o uso de estiramento da mal ha em conjunto com filtro espacial para el iminar as flutuações para impedir que estas contaminem o domínio computacional. Nos contornos da di reção y são utilizados:

$$
\begin{aligned}
& Q_{j=1}=Q_{j=2} ; \\
& Q_{j=N}=Q_{j=N-1}
\end{aligned}
$$

\section{Periodicidade}

Na direção transversal z é utilizada condição de contorno de periodicidade, em que as variáveis do úl timo ponto são tomadas iguais as varíaveis do primeiro ponto, e no interior do domínio as derivadas espaciais são cál culadas no espaço de Fourier conforme descrito na seção 3.3 .

$$
Q_{k=N+1}=Q_{k=1}:
$$




\subsection{Condições de Iniciais}

Em conjunto com a geração da mal ha, a imposição das condições iniciais constituem uma parte primordial do processo de configuração do problema a ser si mul ado. Porém, os casos simulados podem diferenciar consideravelmente entre si (um problema de camada de mistura ou um problema de jato planar, por exemplo). Assim, em cada caso simul ado no presente trabal ho foi utilizada uma mal ha computacional específica.

Para o domínio do escoamento, utilizou-se como condição inicial o perfil de velocidades, temperatura e densidade utilizadas como condição de contorno de entrada e simulou-se um período suficente para que a inacurácia dessa sol ução inicial fosse transportada e convectada para fora do domínio, sem haver prejuízo da sol ução final.

O programa também contém uma subrotina que grava arquivos de reserva (backup) com todos os dados do campo de escoamento. Estes arquivos podem ser utilizados para reiniciar uma simulação interrompida, o que é uma boa prática do ponto de vista de continuidade e produtividade.

\section{Resumo}

No presente capítul o foram apresentados detal hes do código computacional e as etapas necessárias para real izar as si mul ações. Foi abordada a necessidade de se ter uma mal ha nãouni forme para se definir regiões de interesse do escoamento e regiões de amortecimento. Portanto, um processo de geração de mal ha não-uni forme em conjunto com transformaçães de coordenadas são necessárias para se realizar o cál culo das derivadas. Além do mais, devido ao grande número de pontos computacionais, foi apresentado o processo de decomposição do domínio para utilização de processamento paral elizado através de diretivas MPI.

Detal hes do esquema de diferenças finitas compactas de $5^{\mathrm{a}}$ e $6^{\mathrm{a}}$ ordem de precisão para o cál culo das derivadas espaciais nas direções $x$ e y, respectivamente e a discretização espectral para o cál culo das derivadas na direção $z$ foram apresentados e discutidos. Também foi apresentada o esquema de discretização temporal através do método Runge-Kutta de quatro passos e $4^{\mathrm{a}}$ ordem de precisão. Uma análise de Fourier mostrou que o esquema compacto oferece um menor erro que o esquema explícito DRP apresentado, diminuindo efeitos de dissipação numérica, além de evitar efeitos de dispersão por se tratar de um esquema centrado. Devido à decomposição de domínio, o al goritmo de Thomas utilizado para a sol ução dos sistemas de equações al gébricas obti dos para os cál cul os da primeira e segunda derivadas foi al terado e tal abordagem foi apresentada.

Posteriormente, foi apresentado de forma sucinta o esquema de funcionamento do código computacional gentilmente fornecido pelo Prof. Márcio Mendonça para os cál cul os das autofunções para introdução das perturbações. 
Por fim, o conjunto de condições ini ciais e de contorno foram apresentados com mais detal hes. 

CAPÍTULO

\section{4}

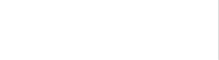

\section{RESULTADOS}

Neste trabal ho um código computacional foi desenvolvido onde foram implementados os métodos apresentados no capítulo anterior. As equações governantes deste problema foram apresentadas no Capítulo 2. As derivadas espaciais são calculadas usando um esquema de diferenças finitas compactas de $5^{\mathrm{a}}$ e $6^{\mathrm{a}}$ ordem, e a discretização temporal usando um esquema Runge-Kutta de $4^{\mathrm{a}}$ ordem e quatro passos, apresentados no Capítul o 3.

Entretanto, há a necessidade de confirmar se o código computacional foi implementado de forma correta, estando livre de erros de programação ou modelagem. Esse procedimento é chamado de verificação e validação de um código numérico, e os resultados de tal procedimento serão apresentados nesse capítul o. Inicial mente, segue-se uma breve discussão sobre conceitos de verificação e val idação de códigos numéricos e então é apresentado o método das soluções manufaturadas (Method of Manufactured Solutions - MMS). Os resultados obtidos usando MMS são então apresentados e discutidos (seção 4.1).

A maneira mais adequada para realização da validação de resultados numéricos é comparálos com resultados experimentais confiáveis. Uma vez que a comparação é satisfatória, diz-se que o modelo matemático representa a física simul ada. Porém, a disponibilidade de dados experimentais é escassa em muitos casos, sendo então dados numéricos publicados em literatura vigente uma fonte al ternativa confiável de dados para comparação, mas ainda sendo mais um procedimento de verificação. Esse foi o procedimento utilizado nesse trabal ho, também tomando um comparativo em rel ação a resultados obtidos por meio do uso da Teoria de Estabilidade Linear.

Posteriormente, foram então sel ecionados al guns problemas de escoamentos de fluidos com resultados publicados na literatura para serem simulados com o presente código, e seus resultados comparados. O primeiro caso de escoamento de fluido simul ado foi o do escoamento bidimensional de uma camada de mistura, cujos resultados são apresentados por Colonius, Lele e Moin (1997) e Babucke, Kloker e Rist (2008). Os resultados das comparações são 
apresentados na seção 4.4. Depois foram simulados dois casos de escoamentos de jatos planares bidimensionais: jatos planares com modos varicoso e sinuoso apresentados por Weder (2012) e por fim, jatos planares para diversos números de Mach apresentados por Reichert e Biringen (2007). Os resultados obtidos para os casos de jato são apresentados na seção 4.5.

\subsection{VeriE⿷匚⿳亠口冋ação e Validação de Códigos Numéricos}

Segundo Silva e Villar (2010), resul tados obtidos por simul ações numéricas devem ter boa representação do problema em estudo, e para tanto, os códigos computacionai sutilizados para obtê-los devem passar por um processo de verificação e val idação.

A verificação consiste em analisar se o código está resolvendo corretamente as equações implementadas (ROACHE, 1998). Nessa etapa, erros de implementação são procurados e o erro numérico envolvido é quantificado. Segundo o autor, um código pode ser considerado verificado se for demonstrado que as equaç̃es são resol vidas com a ordem de precisão teórica dos métodos de discretização. Isso se constitui um exercício puramente matemático e que não requer a priori nenhum rigor com a física do problema a ser solucionado.

Por outro lado, o processo de val idação é uma etapa posterior e consiste em, uma vez verificado o código, comparar os resultados da si mul ação numérica com resul tados experimentais (ROACHE, 1998). Nesse caso sim, rigor físico é al tamente necessário, e um resultado aceitável indica que o modelo matemático utilizado é adequado para modelar o problema físico em questão.

Um código numérico verificado e val idado então produz resultados coerentes com o problema físico a que se propõe si mular, com ordem numérica conhecida e de forma segura no que se diz respeito à erros de implementação (OBERKAMPF; TRUCANO, 2002). Portanto, essa etapa é primordial no desenvol vimento de novos códigos, como éo caso do presente trabal ho.

Em engenharia de software, a área que trata procedimentos formais para testes de qual idade e confiabilidade de códi gos é chamada garanti a de qual idade de software (Software Quality Assurance- SQA). Sal ari eKnupp (2000) apresentam estes procedimentos, que consistem basicamente de três partes:

- ver ificação estática: verificar se o programa está livre de erros de compilação, não sendo necessário executar o programa;

- verificação dinâmica: o programa é executado e avaliado se não há problemas com índices, erros de al ocação de memória para variáveis e erros de programação, entre outros problemas;

verificação formal: algum problema restante. 
Dentre esses procedimentos, o mais importante é o de verificação di nâmica, pois erros encontrados nessa etapa podem afetar a convergência, a eficiência e a precisão do código. Vários métodos de teste dinâmicos são possíveis, desde os menos rigorosos como uma análise de tendências dos resultados obtidos, como outros mais exigentes em que se destaca o método das sol uções manufaturadas. Da mesma forma como se classi ficam a rigorosidade dos tipos de testes, pode-se classificar os critérios de acei tação, indo de uma análise subjetiva de um especial ista até a utilização de métodos formais de aval iação de ordem de precisão. Segundo Sal ari e Knupp (2000), um método de aval iação mai s completo e rigoroso consiste naquele em que o método das soluções manufaturadas é util izado em conjunto com aval iação da ordem de precisão como critério de aceitação. Tal procedimento será utilizado no presente trabalho.

\subsubsection{Método das Soluções Manufaturadas}

Uma boa manei ra de se aval iar resul tados numéricos obtidos com um código é compará Ios com resul tados exatos. O uso do MMS é uma maneira fácil de se obter sol uções exatas para um determinado conjunto de equações diferenciais parciais (EDP's). Para isso, primeiro são construídas sol uções para as variáveis a serem resolvidas. Posteriormente, essas sol uções são então aplicadas ao conj unto de equações diferenciais que modelam o problema, obtendo-se assim termos fontes. O método de verificação envolve a introdução dos termos fontes nas equações diferenciais, criando um problema sem real ismo físico, mas que possui solução anal ítica que pode ser comparada com os resul tados numéricos e um teste de convergência de mal ha pode fornecer a ordem de precisão da metodologia (SILVA; VILLAR, 2010). Uma vez verificado o código, basta se retirar os termos fontes adi cionados do MMS.

Sal ari e Knupp (2000) apresentam al gumas recomendações para a construção de soluções manufaturadas:

- utilizar funções suaves como pol inômios, funções trigonométricas ou exponenciais, de modo que sejam facilmente cal culadas;

deve ser mais general izada possível, de modo a garantir que a solução seja dependente das variáveis corretas (principalmente do espaço e tempo);

deve possuir número adequado de derivadas para que não sejam obtidas constantes ou val ores nul os quando estas são cal culadas;

- as derivadas das sol uções manufaturadas devem ser limitadas por constantes pequenas, garantindo que a solução não varie bruscamente com espaço ou tempo (ou seja, solução não deve possuir singularidades);

- não necessita ter rigor físico, mas precisa ter al gum cuidado de modo que as equaçõesa serem resolvidas façam sentido e o código funcione de forma robusta. 
Sal ari e Knupp (2000) também apresentam recomendações semel hantes para o cál culo dos coeficientes das equações diferenciais que, de forma general izada, devem ser constituídos de funções suaves, serem genéricas de modo a não limitar o teste a casos simples, e possuir mínimo significado físico de modo a manter a robustez da solução, pois verificação de robustez não é o objetivo do uso de MMS.

De posse das soluções manufaturadas, essas são aplicadas ao conjunto de EDP's para obtenção dos termos fontes. Entretanto, a manipulação matemática desses termos pode ser trabal hosa. Para contornar esse problema, é possível fazer o uso de códigos de manipulação simbólicas, como o Wblfram Mathematica, que tratam dessas manipulações com grande sucesso. Além do mais, tai s códi gos conseguem exportar os resul tados em formatos prontos para serem implementados como expressões em códigos Fortran, por exemplo. Tal procedimento foi utilizado no presente trabal ho para a obtenção dos termos fontes.

O passo seguinte consi ste em testar o código. Um processo formal consi ste em executar o programa usando diversas mal has com refinamentos progressivos entre elas. Assim, realiza-se um teste de conver gência de mal ha (SALARI; KNUPP, 2000), onde são avaliados os erros de discretização e a ordem de precisão da solução.

O erro de discretização é a diferença entre a sol ução numérica e a solução analítica, $\left(Q_{\text {num }}-Q_{a n}\right)$ e pode ser obtida ponto a ponto. Por outro lado, uma medida global do erro pode ser obtida a partir da normal 2 :

$$
I_{2}=\frac{\stackrel{v}{u}}{\hat{A}\left(Q_{n u m}-Q_{a n}\right)_{n}{ }^{2}} ;
$$

ou através do máximo erro dentro do domínio a partir da norma l. :

$$
\text { I. }=\max _{\mathrm{n}}\left|\left(\mathrm{Q}_{\mathrm{num}}-\mathrm{Q}_{\mathrm{an}}\right)_{\mathrm{n}}\right| \text {; }
$$

onde $\mathrm{N}$ é o número total de pontos e os subíndices num e an, correspondem a solução numérica e analítica, respectivamente.

O código é então executado usando uma série de mal has com diferentes tamanhos de maIha $h$, cal cul ando-se o erro gl obal para cada uma através das normas $\mathrm{I}_{2}$ el. . A ordem de precisão o é obtida comparando-se esses val ores para duas mal has com refinamentos consecutivos:

$$
\mathrm{O}=\frac{\log \frac{E_{2 h}}{E_{h}}}{\log (r)}
$$

onde $E_{2 h}$ e $E_{h}$ são os erros globais para a mal ha mais grosseira e para a mais refinada, respectivamente, e r é a razão de refino entre as duas malhas, cujo valor geralmente usado é 2. 


\subsection{Veri區ação Dinâmica - MMS 2D}

O processo de verificação da impl ementação das equações governantes (Capítulo 2) no código computacional é apresentado a seguir. Para se fazer o uso do MMS, a Equação 2.8 pode ser reescrita da seguinte forma:

$$
\frac{\partial Q}{\partial t}+\frac{\partial F}{\partial x}+\frac{\partial G}{\partial y}=S
$$

onde $S$ representa o termo fonte obtido das soluções manufaturadas.

No presente caso, foi utilizado o seguinte conjunto de sol uções manufaturadas:

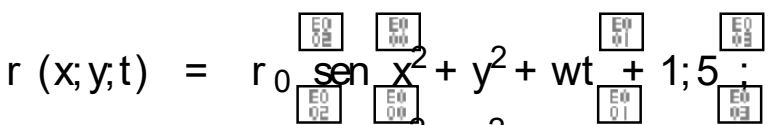

$$
\begin{aligned}
& u(x ; y, t)=u_{0} \operatorname{sen} x^{2}+y^{2}+w t+0 ; 5
\end{aligned}
$$

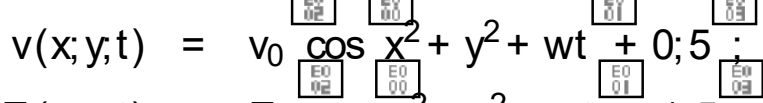

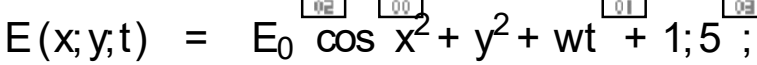

onde as constantes foram definidas como: $r_{0}=1 ; 0, u_{0}=0 ; 1, v_{0}=1 ; 0$ e,$E_{0}=0 ; 5$ para a real ização dos cál cul os. Os termos fontes são construídos através da substituição das sol uções manufaturadas nas equações governantes (Equação 4.4). Tal processo foi real izado usando o software de mani pul ação si mbólica Wbl fram Mathematica e estes são apresentados no apêndice A pêndice B. Foi utilizado um domínio computacional com $x \in[-p+p=16 ; p+p=16]$ e y $\in$ $[-p+p=16 ; p+p=16]$ para se evitar simetria da solução. As condições de contorno prescritas utilizadas são dadas por Equação 4.5 - Equação 4.8 aplicadas a cada subinterval o do Runge-Kutta.

O código foi executado e os resul tados numéricos comparados com os resultados analíticos dados por Equação 4.5 - Equação 4.8. Assim, sete mal has diferentes foram utilizadas, conforme Tabela 2 e obtidos o erro e a ordem de preci são considerando as normas $I_{2}$ el. .

Tabela 2 - Mal has utilizadas para o teste de condições de contorno prescritas.

\begin{tabular}{|c|c|c|c|}
\hline Mal ha & $N_{x}=N_{y}$ & Dx = Dy & $r$ \\
\hline 1 & 16 & $4,19 \mathrm{E}-01$ & \\
\hline 2 & 31 & $2,09 \mathrm{E}-01$ & 2,00 \\
\hline 3 & 61 & $1,05 \mathrm{E}-01$ & 2,00 \\
\hline 4 & 121 & $5,25 \mathrm{E}-02$ & 2,00 \\
\hline 5 & 241 & $2,62 \mathrm{E}-02$ & 2,00 \\
\hline 6 & 481 & $1,31 \mathrm{E}-02$ & 2,00 \\
\hline 7 & 961 & $6,54 \mathrm{E}-03$ & 2,00 \\
\hline
\end{tabular}

Um incremento de tempo $\mathrm{Dt}=1 \cdot 10^{-8}$ foi utilizado e 500 passos de tempo simulados. A escol ha de um val or bem baixo para o incremento de tempo foi necessária para minimizar 
os efeitos dos erros de discreti zação temporal sobre os resultados, avaliando assim somente a ordem das derivadas espaciais. Foram utilizados também $\operatorname{Re}=1000 ; 0, \operatorname{Pr}=100 ; 0, M a=0 ; 1$, $c_{V}=0 ; 1, J=1 ; 0, m=1 ; 0$ ek $=1 ; 0$.

A Figura 20 e Figura 21 apresentam os erros obtidos e a ordem de precisão observados, consi derando ambas as normas $\mathrm{I}_{2} \mathrm{e} \mathrm{l}$. , respectivamente.

Como pode se observar, o erro observado para a variável $r$ é menor do que para as demais variáveis, enquanto que as demai s variáveis apresentam um nível de erro semelhantes entre si , ocorrendo tanto para a norma ${ }_{2}$ como para a norma I. . A ordem de precisão atingiu um ponto praticamente assi ntótico entre as mal has 3 e 7, apresentando valores de aproximadamente $5^{\mathrm{a}}$ e $6^{\mathrm{a}}$ ordem para as variáveis $r, r u, r v$ e $\mathrm{E}$, exceto por um decréscimo da ordem para a váriavel $r$ na mal ha 7 onde já pode atribui $r$-se a erros de arredondamento de máquina. Podemos também destacar o bom comportamento da ordem de precisão para o divergente da velocidade - $\mathrm{u}$, desde as mal has mais grossas.

Observando com cuidado a Figura 20 identifica-se que a ordem de precisão é menor entre as mal has $2 / 1$ e $3 / 2$, indi cando de que pode haver al gum erro de programação af etando os resultados. Entretanto, isso ocorreu porque as mal has 1, 2 e 3 não possuem resol ução de mal ha suficiente para representar ondas de al tas frequências. A Figura 22 mostra uma comparação do termo fonte para cada variável conservativa para as mal has 1 e 5, respectivamente. É possível verificar que nem todos os pontos são capturados com a mal ha mais grossa, afetando, em um certo grau, a solução numérica, que é apresentada na Figura 23

Portanto, de acordo com os testes apresentados nesta seção é possível dizer que o código está verificado através de um procedimento dinâmico de veri ficação elivre de erros de programação que possam afetar sua ordem de precisão numérica para o caso bidimensional . Também é importante destacar o bom comportamento obtido para o divergente da vel ocidade, isto é, propagações acústicas também estão sendo bem cal culados. 
Figura 20 - (a) Erro e (b) ordem para a norma $\mathrm{I}_{2}$ para o teste com condições de contorno prescritas para o código 2D.

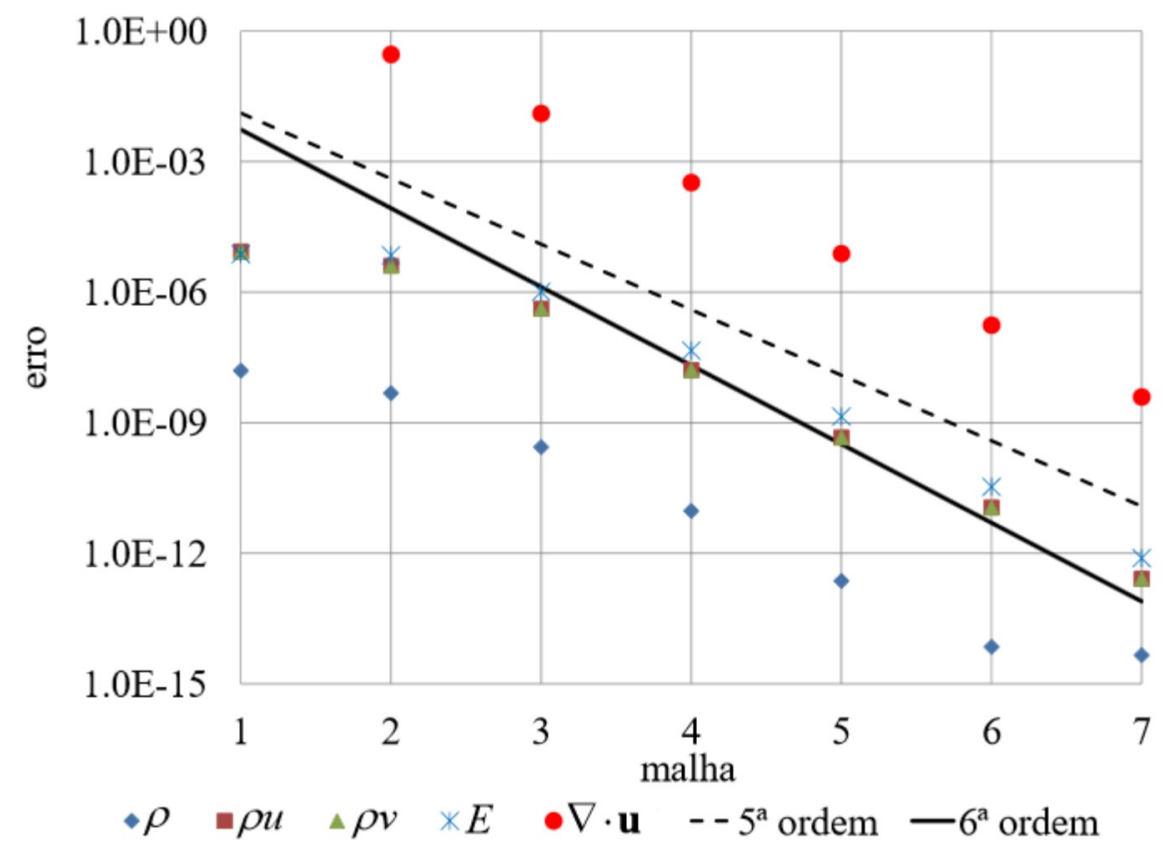

(a)

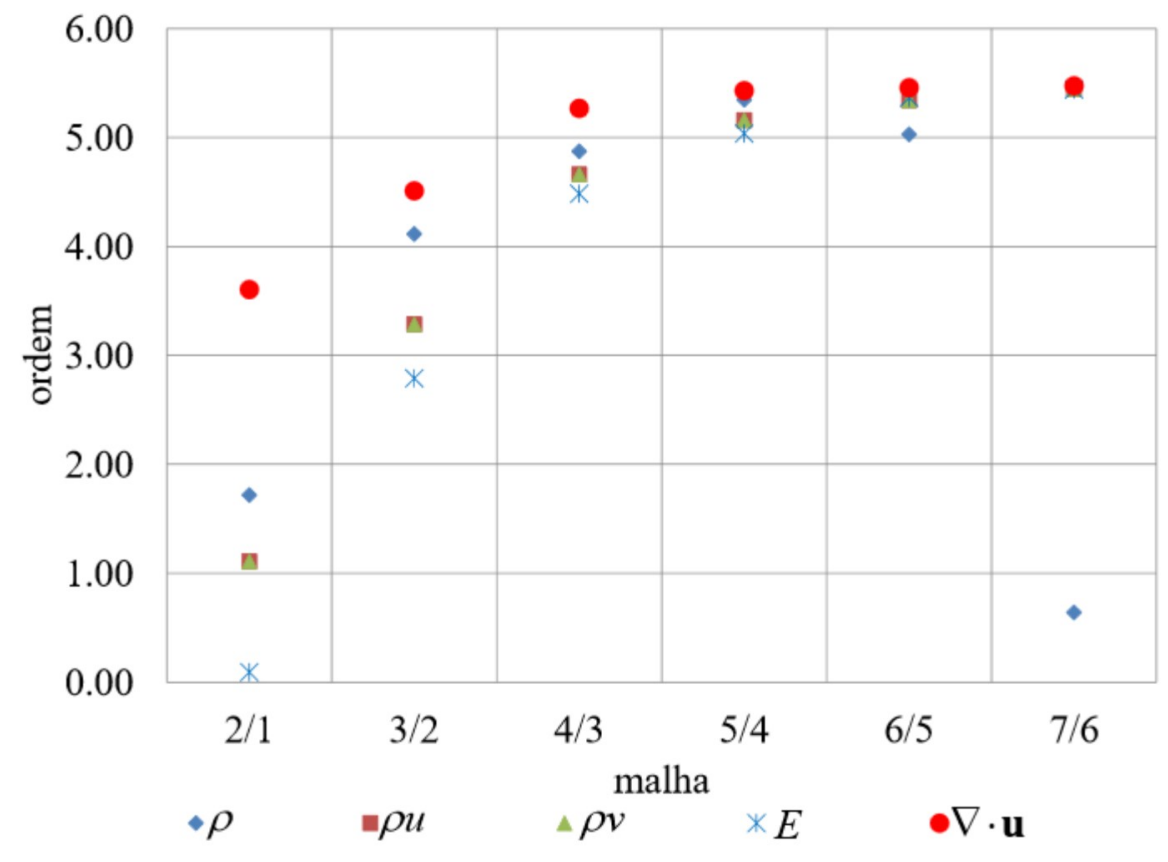

(b)

Fonte: Elaborada pelo autor. 
Figura 21 - (a) Erro e (b) ordem para a norma I. para o teste com condições de contorno prescritas para o código $2 \mathrm{D}$.

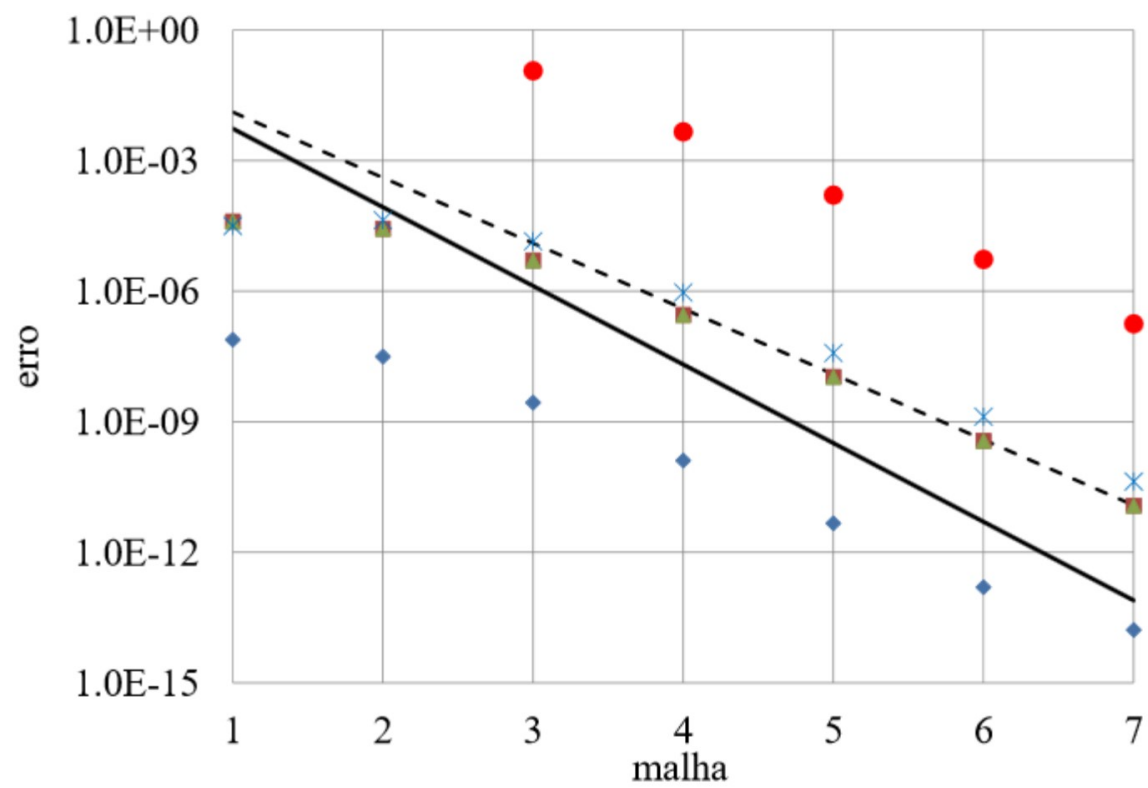

$\bullet \rho \quad \bullet u \quad \Delta \rho v \quad * E \quad \bullet \nabla \cdot \mathbf{u} \quad--5^{\mathrm{a}}$ ordem $\quad-6^{\mathrm{a}}$ ordem

(a)

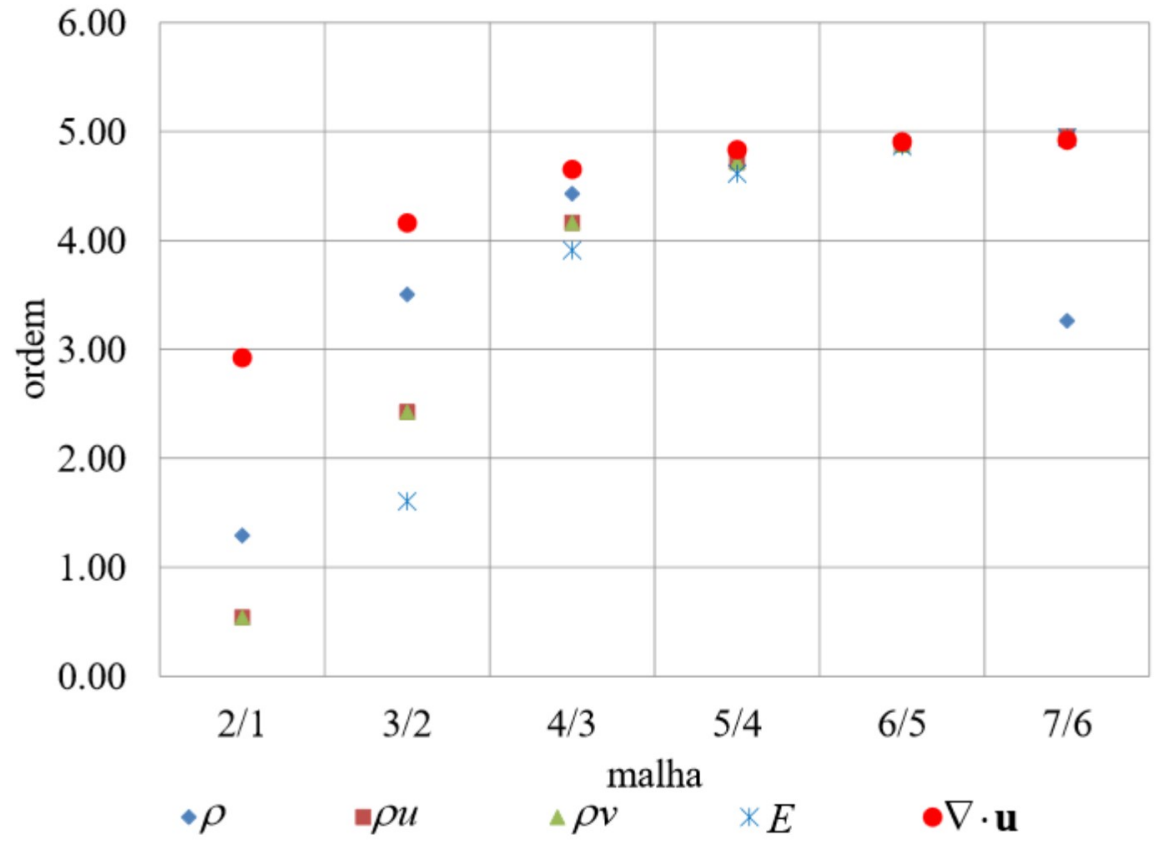

(b)

Fonte: Elaborada pelo autor. 


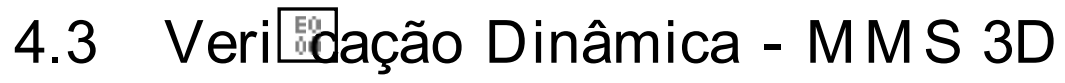

Uma versão do presente código também foi escrito para si mular problemas tridimensionais. Nesse caso, as derivadas na direção transversal z são cal culadas usando método espectral, que como mencionado anteriormente só apresentam erro de arredondamento. O processo de verificação da implementação das equações governantes no código computacional é semelhante ao apresentado para o código bidimensional na seção 4.2, e é apresentado a seguir. Novamente reescreve-se a Equação 2.8 da seguinte forma:

$$
\frac{\partial Q}{\partial t}+\frac{\partial F}{\partial x}+\frac{\partial G}{\partial y}+\frac{\partial H}{\partial z}=S ;
$$

onde S representa o termo fonte obtido das soluções manufaturadas.

Para o caso tridimensional, foi utilizado o seguinte conjunto de sol uções manufaturadas:

Figura 22 - Representação dos termos fontes para as mal has 1 e 2.

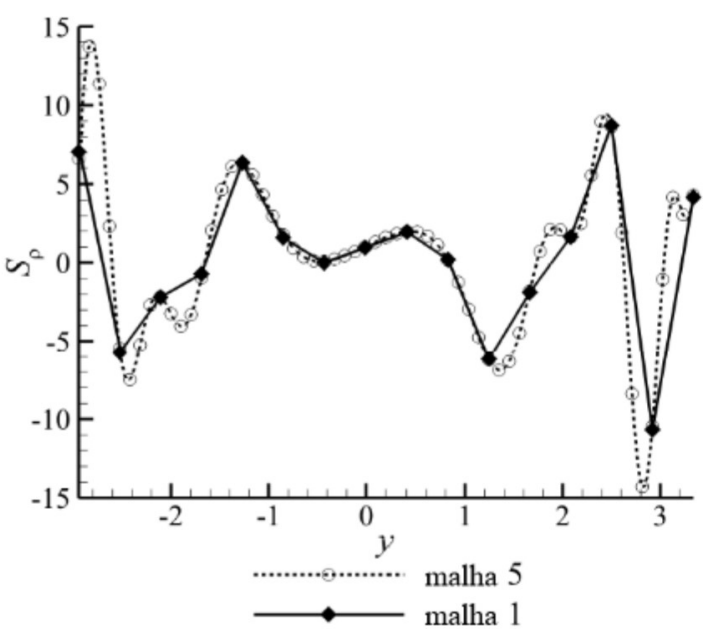

(a)

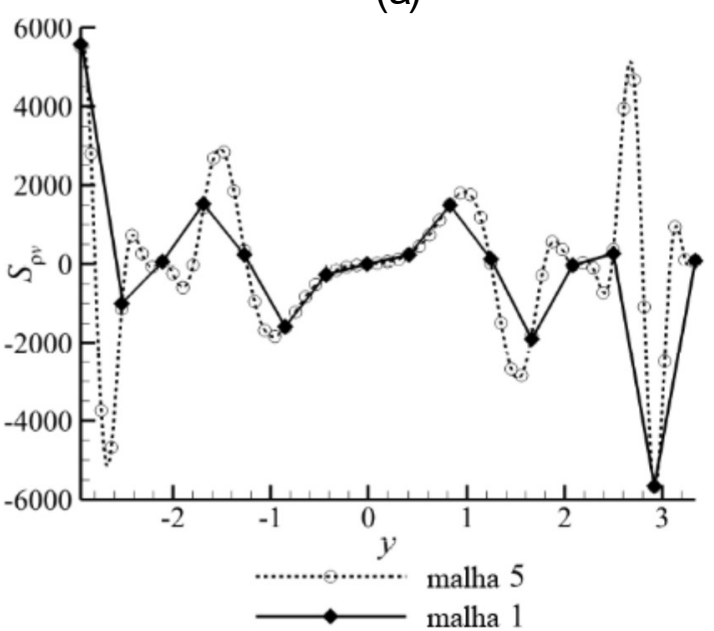

(c)

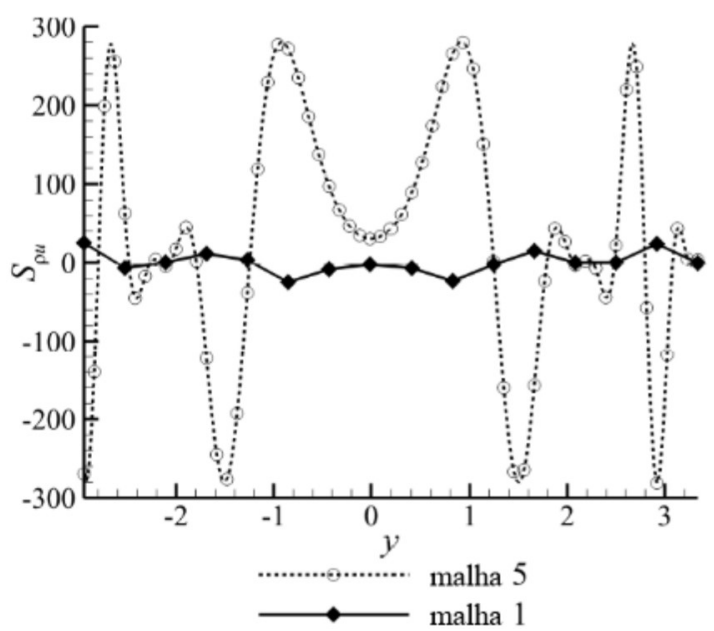

(b)

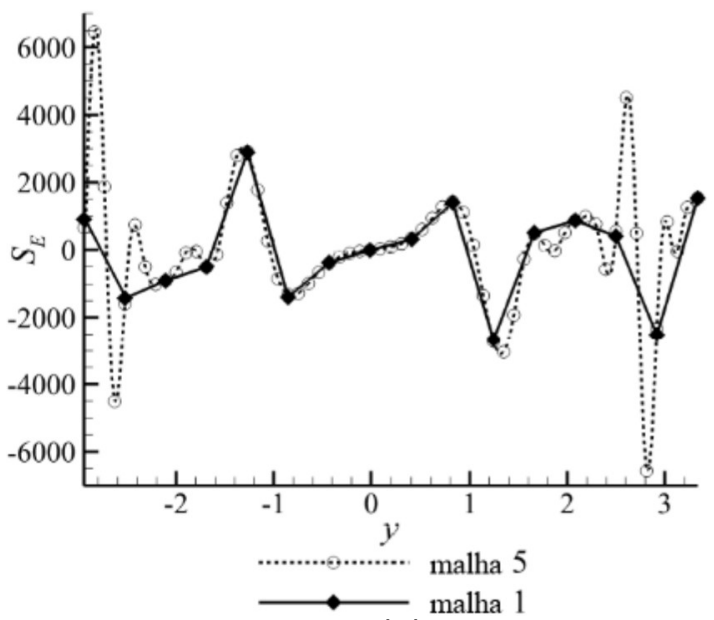

(d)

Fonte: Elaborada pelo autor. 
Figura 23 - Representação das variáveis para mal has 1 e 5.

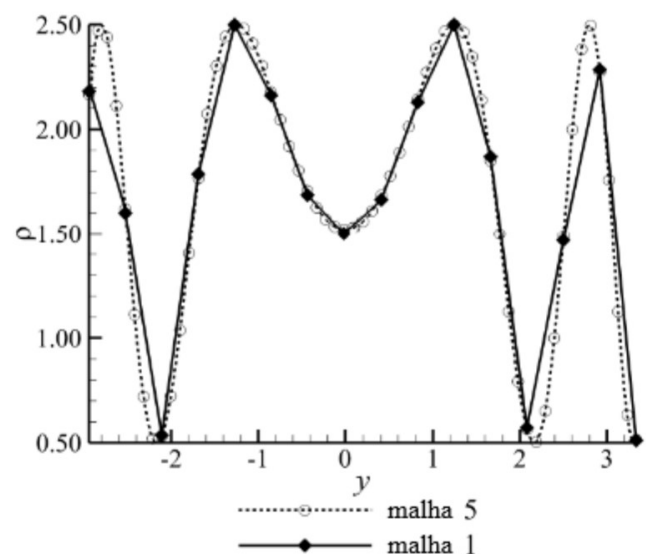

(a)

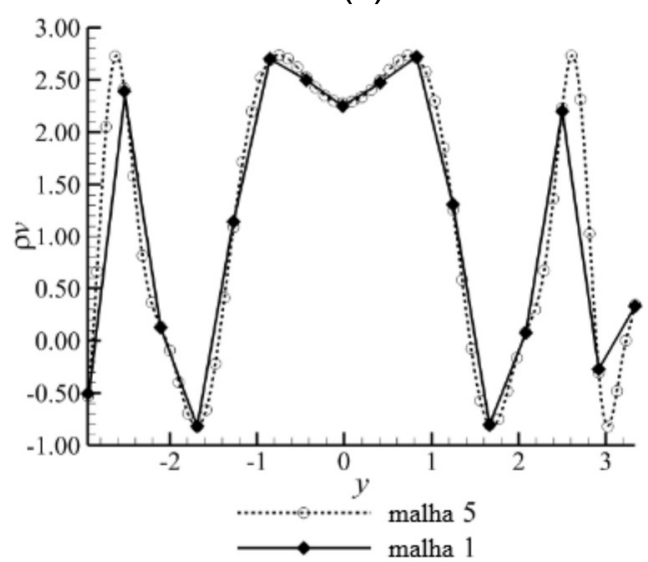

(c)

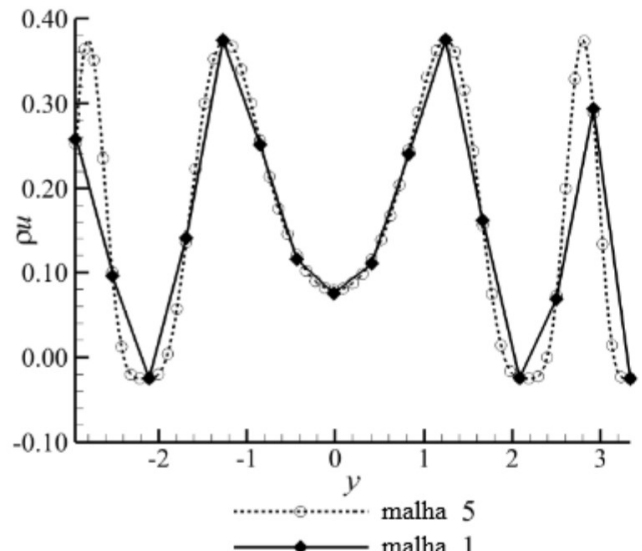

(b)

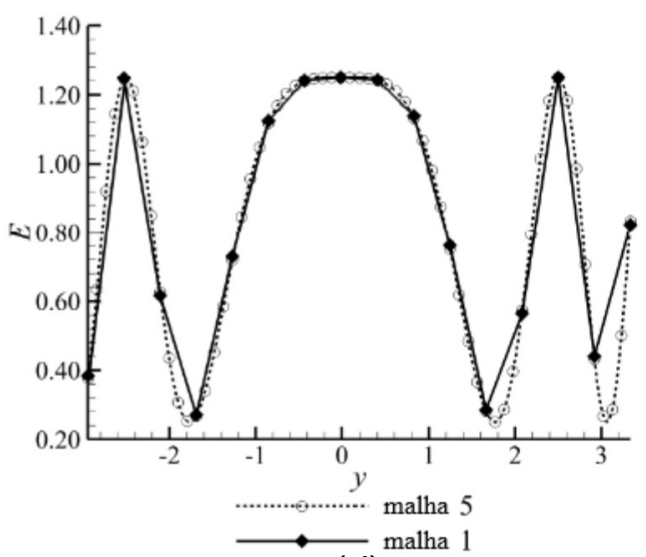

(d)

Fonte: Elaborada pelo autor.

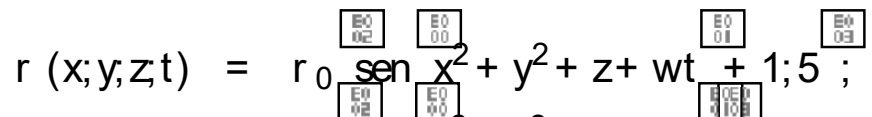

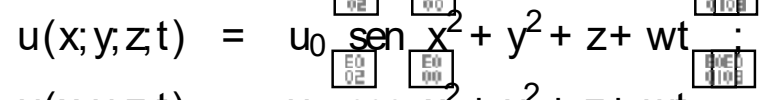

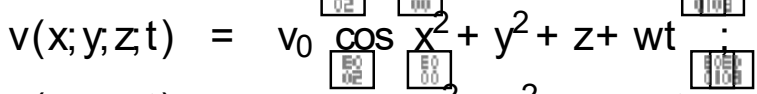

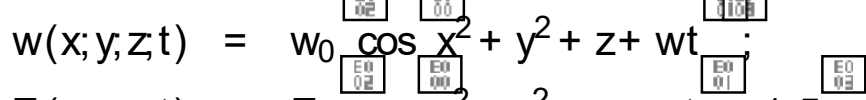

$$
\begin{aligned}
& E(x ; y, z ; t)=E_{0} \cos x^{2}+y^{2}+z+w t+1 ; 5 ;
\end{aligned}
$$

onde as constantes foram defini das como: $r_{0}=1 ; 0, u_{0}=0 ; 1, v_{0}=1 ; 0, w_{0}=0 ; 5 e, E_{0}=0 ; 5$ para a real ização dos cál culos. Os termos fontes são construídos através da substituição das sol uções manufaturadas nas equações governantes (Equação 4.9) e estes são apresentados no Apêndice $B$. Foi utilizado um domínio computacional com $x \in[-1+p=16 ; 3+p=16], y \in$ [ $1+p=16 ; 3+p=16]$ e $z \in[0 ; 2 p]$ para se evitar simetria da solução. As condições de contorno prescritas utilizadas são dadas por Equação 4.10 - Equação 4.14 apl icadas a cada subintervalo do Runge-Kutta. 
O código foi executado e os resul tados numéricos comparados com os resultados analíticos dados por Equação 4.5 - Equação 4.8. Assim, sete mal has diferentes foram utilizadas, conforme Tabela 3 e obtidos o erro e a ordem de preci são considerando as normas $\mathrm{I}_{2}$ el. .

Tabela 3 - Mal has utilizadas para o teste de condições de contorno prescritas.

\begin{tabular}{|c|c|c|c|}
\hline Malha & $\mathrm{N}_{\mathrm{x}}=\mathrm{N}_{\mathrm{y}}$ & Dx $=$ Dy & $\mathrm{r}$ \\
\hline 1 & 16 & $2,67 \mathrm{E}-01$ & \\
\hline 2 & 31 & $1,33 \mathrm{E}-01$ & 2,00 \\
\hline 3 & 61 & $6,67 \mathrm{E}-02$ & 2,00 \\
\hline 4 & 121 & $3,33 \mathrm{E}-02$ & 2,00 \\
\hline 5 & 241 & $1,67 \mathrm{E}-02$ & 2,00 \\
\hline
\end{tabular}

Na direção $z$ foi utilizado um incremento espacial $D z=2 p=16$ para todos os casos. Um incremento de tempo $\mathrm{Dt}=1 \cdot 10^{-10}$ foi utilizado e 150 passos de tempo simulados. A escolha de um val or bem baixo para o incremento de tempo foi necessária para minimizar os efeitos dos erros de discretização temporal sobre os resultados, avaliando assim somente a ordem das derivadas espaciais. Foram utilizados também $\operatorname{Re}=1000 ; 0, \operatorname{Pr}=100 ; 0, \mathrm{Ma}=0 ; 1, \mathrm{c}_{\mathrm{v}}=0 ; 1$, $\mathrm{J}=1 ; 0, \mathrm{~m}=0 ; 3 \mathrm{ek}=1 ; 4$.

A Figura 24 e Figura 25 apresentam os erros obtidos e a ordem de preci são observados, considerando ambas as normas $\mathrm{I}_{2}$ el. , respectivamente. Como pode se observar, o erro observado para a variável $r$ e $r$ w são menores do que para as demais variáveis. A ordem de precisão atingiu um ponto praticamente assintótico entre as mal has 4 e 5, apresentando valores de aproximadamente $5^{\mathrm{a}}$ e $6^{\mathrm{a}}$ ordem para todas as variáveis. Novamente, $-\mathrm{u}$ apresentou um bom comportamento para a ordem de preci são desde as mal has com mai ores espaçamentos de discretização.

Como no caso bidimensional (seção 4.2), baixa resolução de malha para representar ondas de al ta frequência para as mal has 1, 2 e 3 parecem estar af etando os resultados. Assim sendo, e de acordo com os resul tados apresentados na presente seção, é possível dizer que o código está verificado através de um procedimento dinâmico de verificação e livre de erros de programação que possam afetar sua ordem de precisão numérica também para a versão tridimensional. Os cál cul os acústicos representados pel o divergente da velocidade não foram af etados na implementação tridimensional . 
Figura 24 - (a) Erro e (b) ordem para a norma $\mathrm{I}_{2}$ para o teste com condições de contorno prescritas para o código 3D.

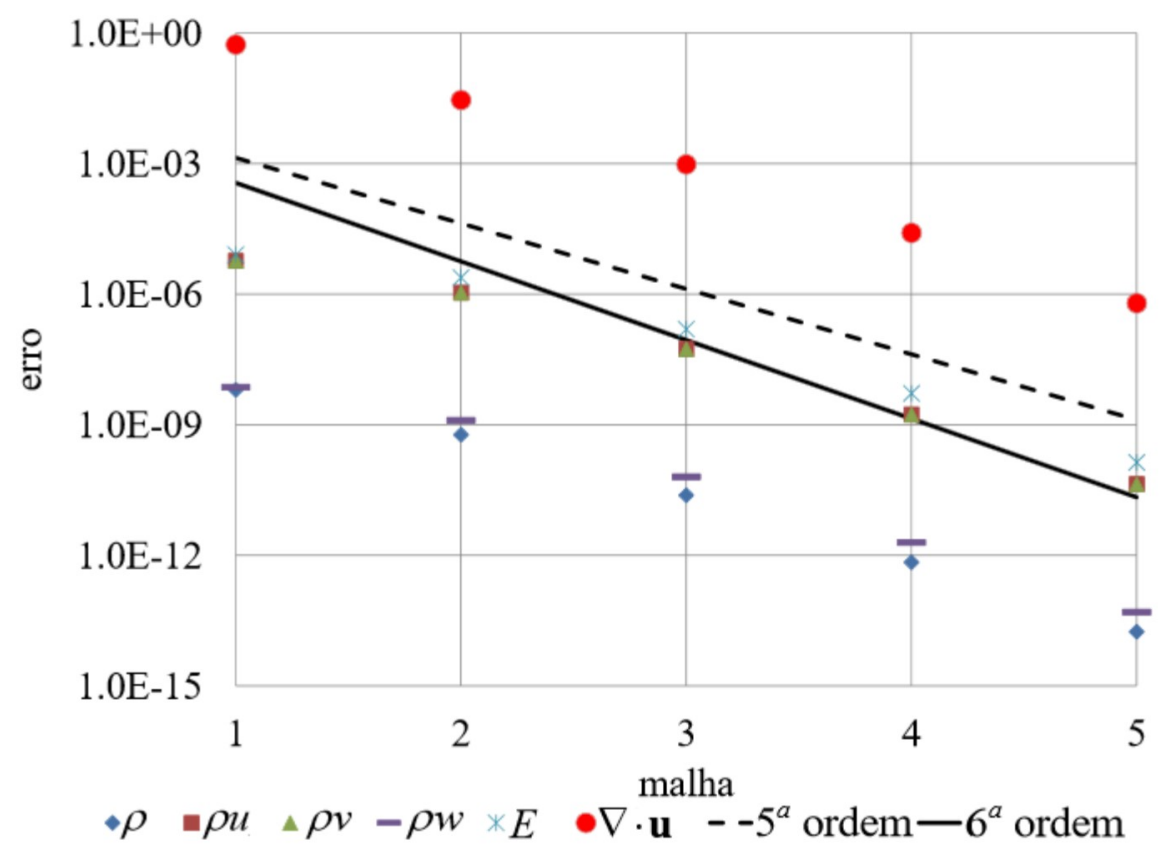

(a)

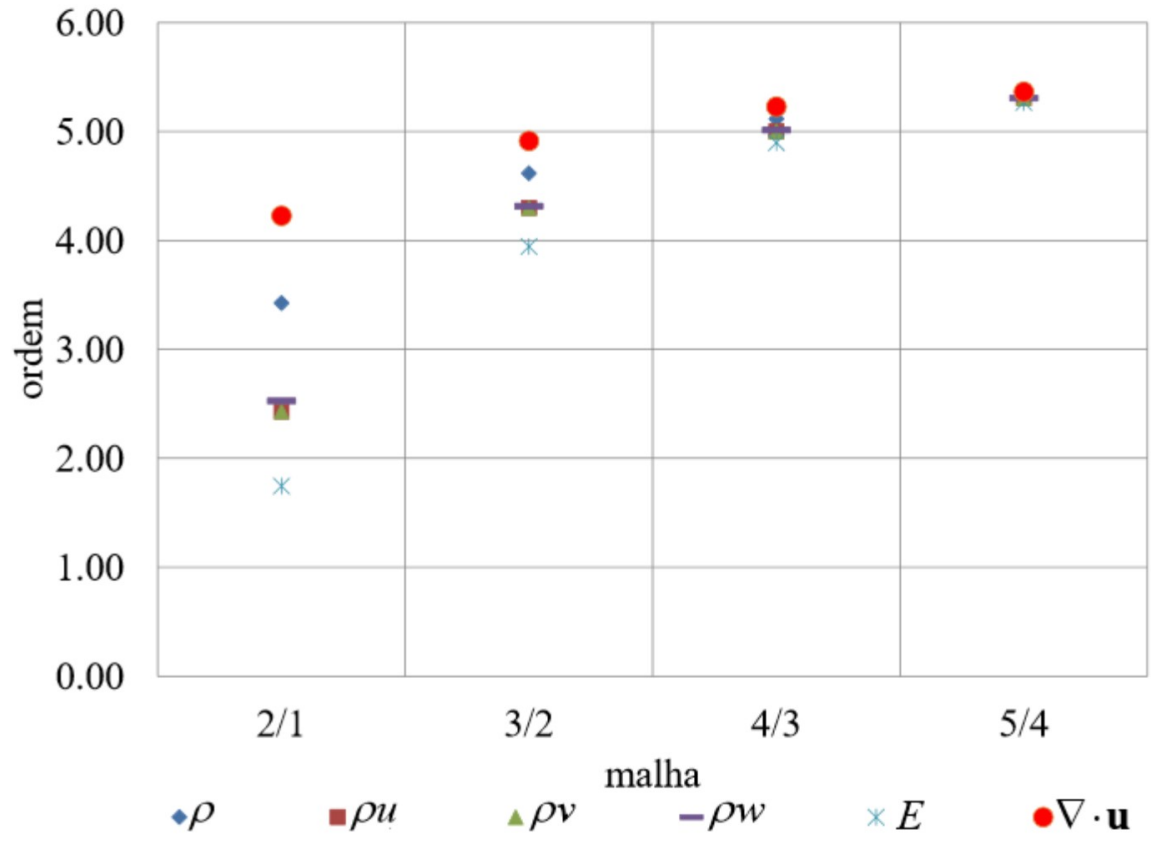

(b)

Fonte: Elaborada pelo autor. 
Figura 25 - (a) Erro e (b) ordem para a norma I. para o teste com condições de contorno prescritas para o código 3D.

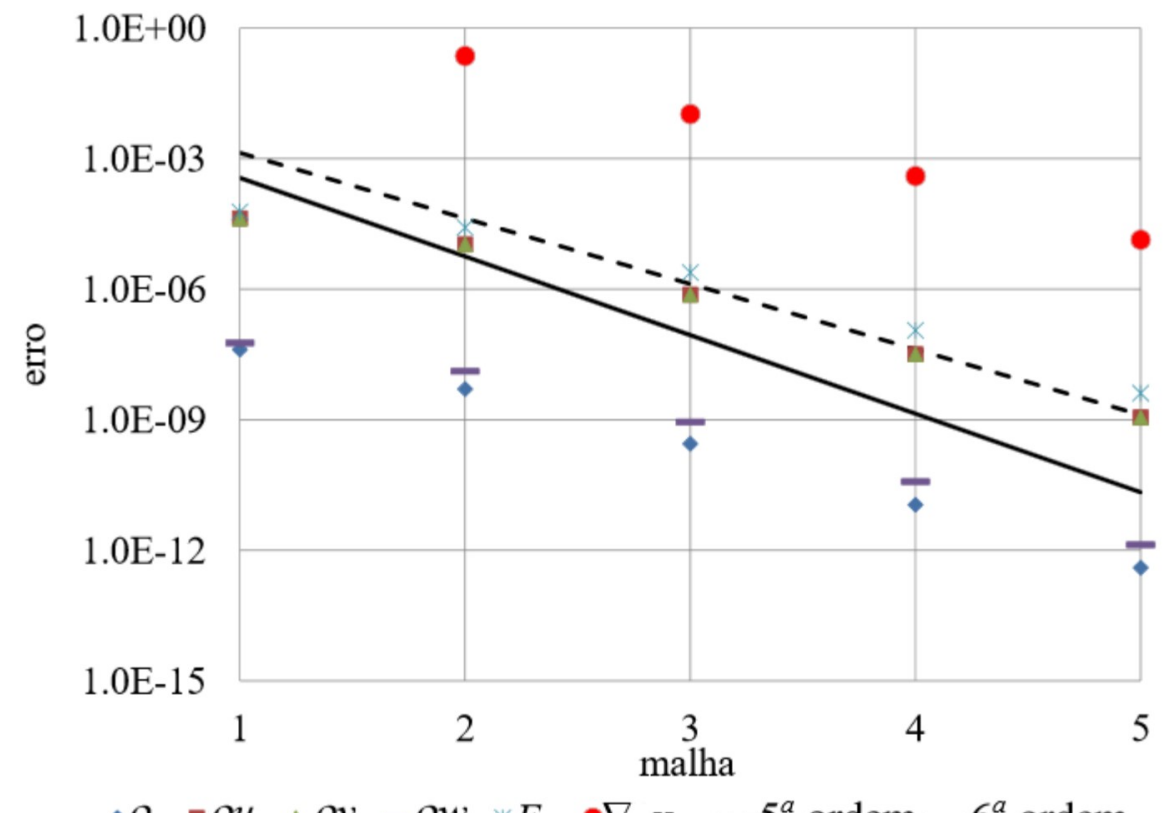

$\bullet \rho \quad \nabla u \quad \Delta \rho v-\rho w * E \quad \bullet \nabla \cdot \mathbf{u} \quad-\quad-5^{a}$ ordem $-6^{a}$ ordem

(a)

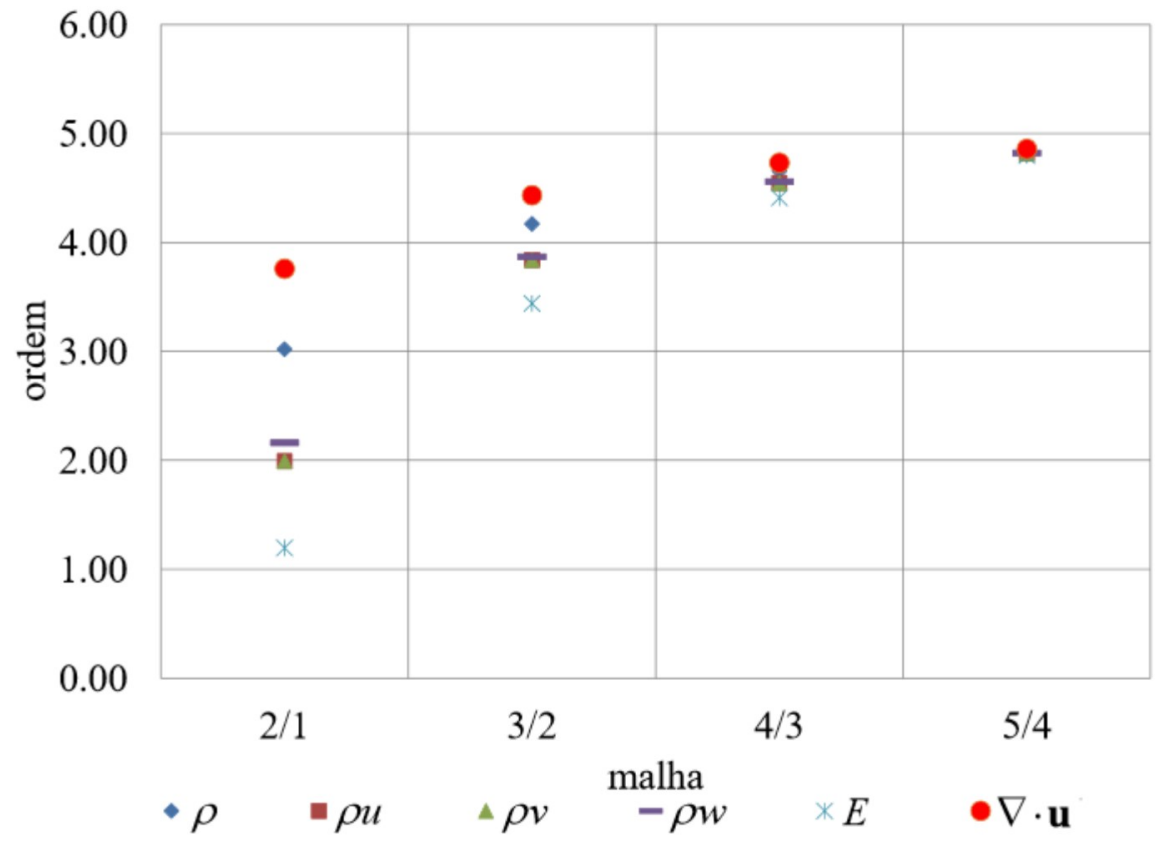

(b)

Fonte: Elaborada pelo autor. 


\subsection{Camada de Mistura Bidimensional}

O escoamento de uma camada de mistura consiste de duas correntes de fluido escoando paral el amente com vel ocidades diferentes inicial mente separadas por uma barrei ra física (placa separadora) que se encontram no bordo de fuga dessa barreira, formando uma interface em formato de S nessa região. Essa interface se forma devido aos gradientes das propriedades entres as duas camadas (SALEMI, 2006). Mesmo sendo um tipo de escoamento simples, os principais mecâni smos de geração de som por pareamento de vórtices podem ser investigados com essa configuração.

Um exemplo de ruído gerado por camadas de mistura é aquel e gerado por motores a jato de aeronaves comerciais. Na parte inicial do jato, a geração de som é causada pela camada de mistura entre o escoamento primário e o escoamento de bypass, e entre o escoamento de bypass e o escoamento livre. Para jatos de grandes diâmetros, a camada de mistura é conhecida por ser a responsável pelos ruídos de al ta frequência mais audíveis, com frequencia na faixa de $1 \mathrm{kHz}$ a 4kHz (BABUCKE, 2009).

A Figura 26 apresenta um esquema de uma camada de mistura com suas principais características. A corrente superior tem velocidade $U_{1}$ maior do que a velocidade $U_{2}$ da corrente inferior. Pequenas perturbações geradas nessa região se amplifi cam em uma região de transição, causando o surgimento de vórtices.

Figura 26 - Esquema de uma camada de mistura bidimensional .

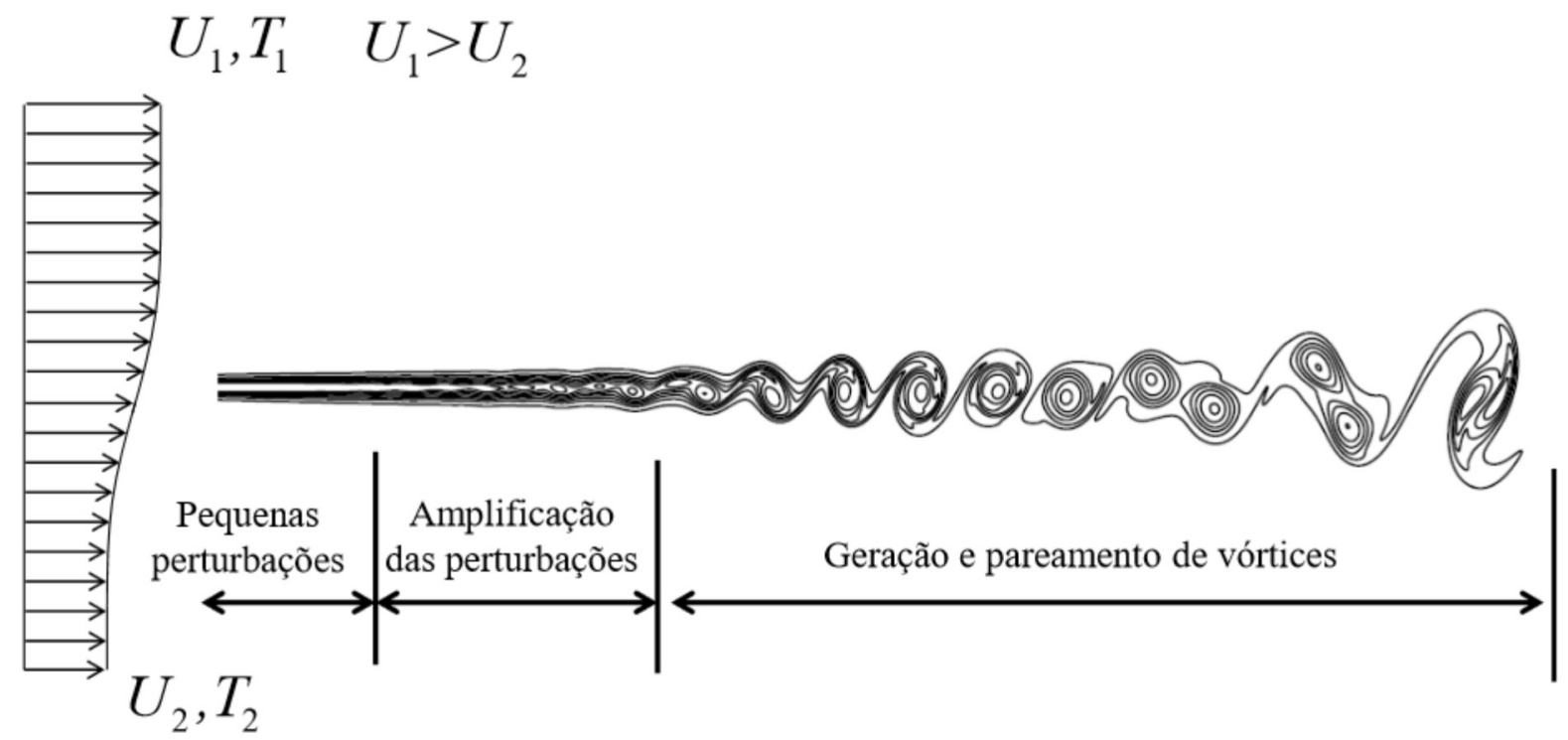

Fonte: Elaborada pelo autor. 


\section{Parâmetros do Escoamento}

Com o objetivo de verificar o código, utilizou-se o caso da camada de mistura apresentado por Colonius, Lele e Moin (1997) e posteriormente por Babucke, Kloker e Rist (2008). Os números de Mach das correntes superior e inferior são $\mathrm{Ma}_{1}=0 ; 50$ e $\mathrm{Ma}_{2}=0 ; 25$, respectivamente; as temperaturas adimensionais das duas correntes são $T_{1}=T_{2}=1 ; 0$ e a razão de vel ocidades $\mathrm{U}_{1}=\mathrm{U}_{2}=2 ; 0$. O número de Prandtl $\mathrm{Pr}=0 ; 71$ e o número de Reynolds $\mathrm{Re}=500$ é baseado na espessura de vorticidade da entrada, dada por:

$$
\mathrm{d}\left(\mathrm{x}_{0}\right)={\frac{\text { 國 }}{|\partial \mathrm{u}=\partial \mathrm{y}|_{\max }}}_{\mathrm{x}=\mathrm{x}_{0}}^{\text {嶇 }} ;
$$

onde $D U=U_{1}-U_{2}$.

A condição inicial da camada de mistura é obtida como um caso particular da solução de similaridade para camada limite bidimensional compressivel sobre uma placa plana em regime permanente. Essa sol ução é obtida a partir da simplificação das equações de Navier-Stokes para o escoamento sobre uma placa plana e é conhecida como equação de Blasius (SALEMI, 2006). Para obtenção desse perfil resolve-se duas sol uções similares ligadas entre si onde estaria a placa plana, formando uma "parede virtual" em $\mathrm{y}=0$, e as velocidades das correntes livres são as velocidades acima e abaixo da camada de mistura (Figura 27).

Figura 27 - Esquema de uma solução si milar para camada de mistura e condições de contorno.

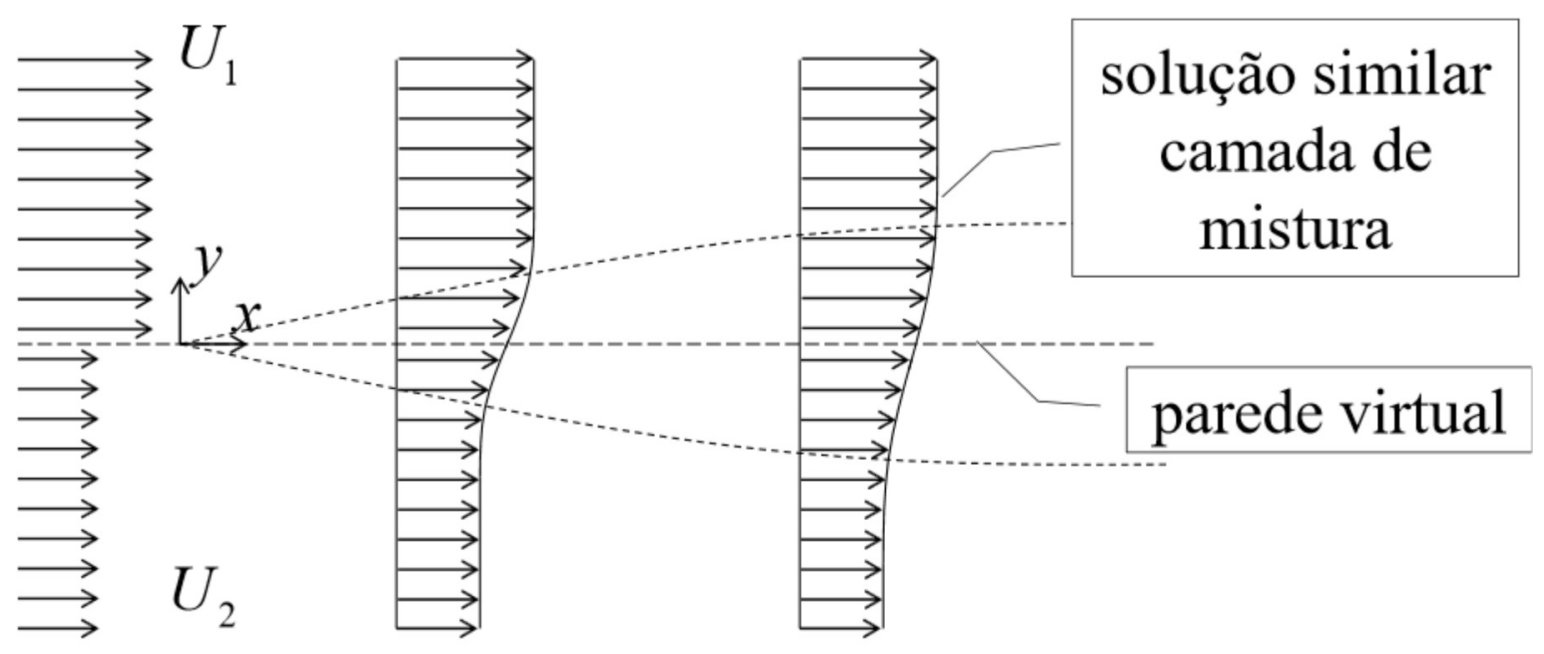

Fonte: Elaborada pelo autor.

No presente trabal ho utilizou-se perfis de vel ocidade, densidade e temperatura gentilmente forneci dos por Andreas Babucke eutilizados por ele em suatese de doutorado (BABUCKE, 2009). O perfil de vel ocidade u se assemel ha a uma tangente hi perbólica (Equação 4.16) e uma aproximação para o perfil de temperatura pode ser obtido da relação Crocco-Busemann (Equa- 
ção 4.18) aplicado a uma camada de mistura (Equação 4.18). A densidade é obtida como o inverso da temperatura.

$$
u=g+U_{2}(1-g)
$$

onde no presente caso

$$
\begin{aligned}
& g=0 ; 5+0 ; 5 \cdot \tanh (1 ; 945 y)
\end{aligned}
$$

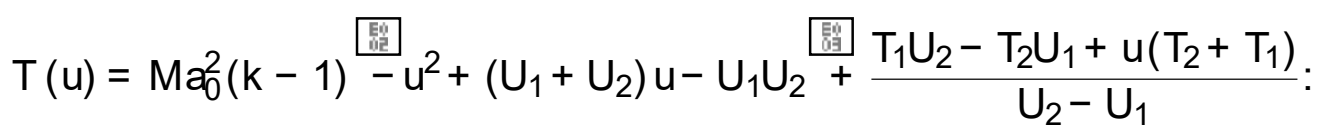

A coordenada inicial escol hida foi $x_{0}=30$ de tal forma que a espessura de vorticidade seja 1,0 na entrada. Os perfis da velocidade $u$, temperatura e densidade obtidos segundo o procedimento descrito anteriormente para esta posição $\mathrm{x}_{0}$ está apresentada na Figura 28.

Figura 28 - Perfis de vel ocidade u, densi dade e temperatura na entrada para o caso da camada de mistura bidimensional.
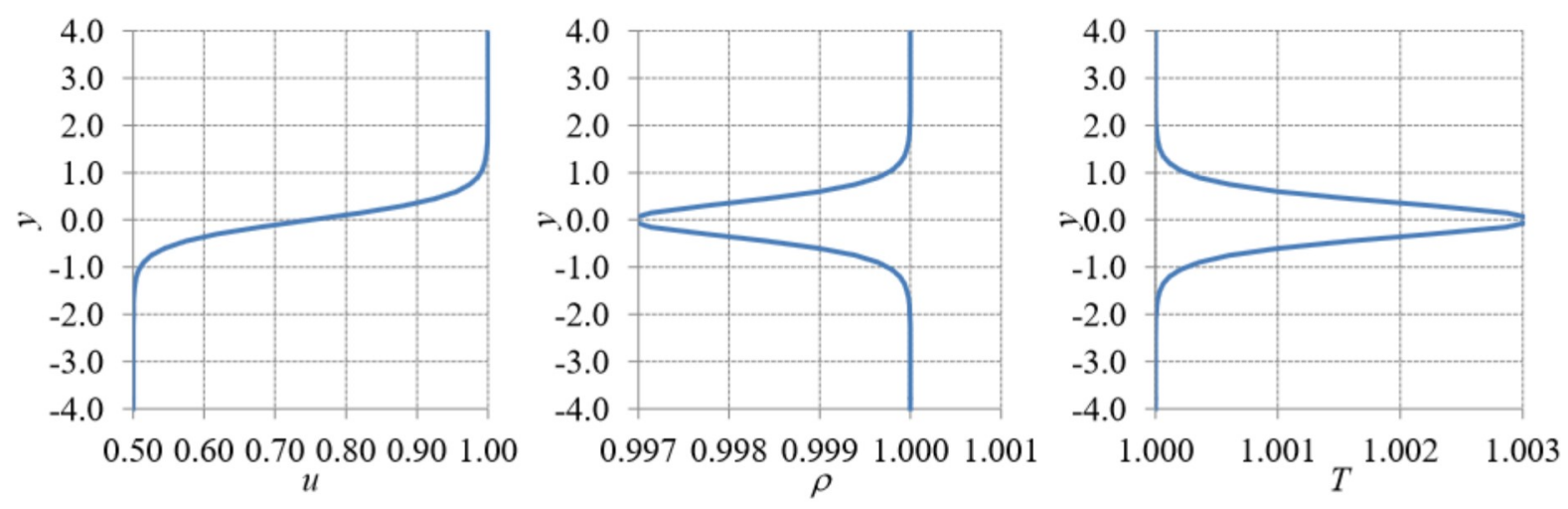

Fonte: Elaborada pelo autor.

Para que o escoamento desenvol va um regime de emissão de vórtices foram introduzidas perturbações na entrada utilizando as autofunções obtidos através da LST, conforme descrito na seção 2.3. Para o caso da camada de mi stura bi di mensional , a taxa de amplificação espacial é apresentada na Figura 29, onde observa-se que a frequência fundamental é $w_{0}=0 ; 6293$. Da mesma forma que Babucke, Kloker e Rist (2008), essa frequência e suas três subharmônicas foram utilizadas para perturbar o escoamento na entrada com uma ampl itude máxima de 0,001 para todas as perturbações, conforme a Equação 4.19. Também foi introduzi da uma defasagem $D q=-0 ; 028$ para a primeira subharmonica, $D q=0 ; 141$ para a segunda $e$ Dq $=0 ; 391$ para a terceira. A amplitude e distribuição de fase das autof unções para essa frequência fundamental são apresentadas na Figura 30.

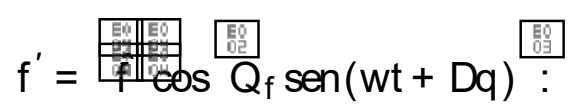


Figura 29 - Taxas de amplificação espaciais para camada de mistura bidimensional com máximo val or em w = $0 ; 6293$.
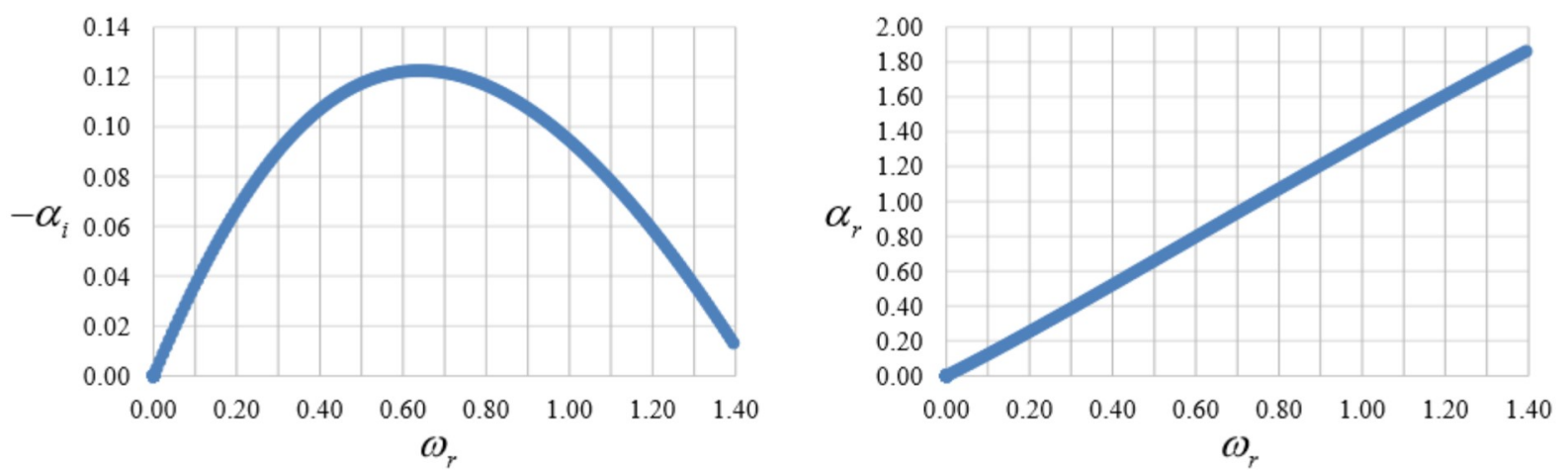

Fonte: Elaborada pelo autor.

Figura 30 - (a) amplitude e (b) fase de perturbação para camada de mi stura bidimensional .

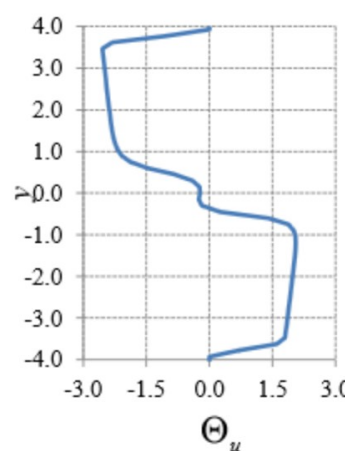

$\Theta_{u}$

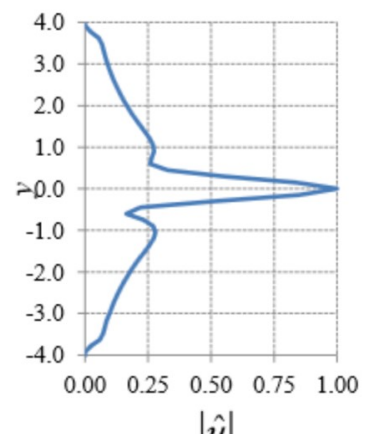

$|\hat{u}|$

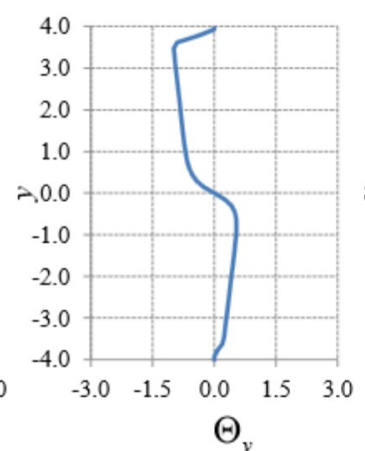

$\Theta_{v}$

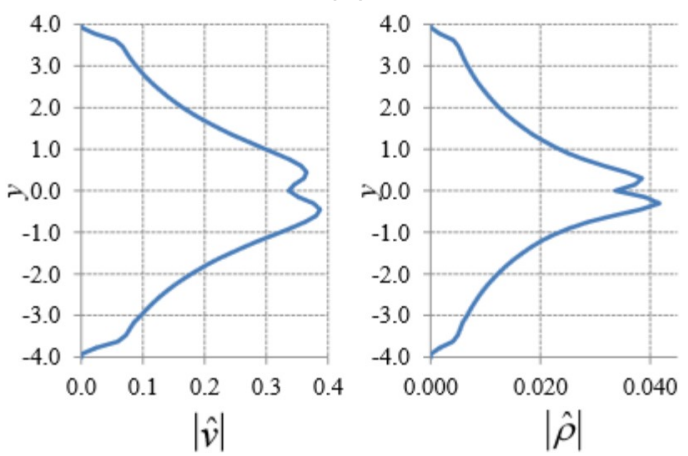

(b)

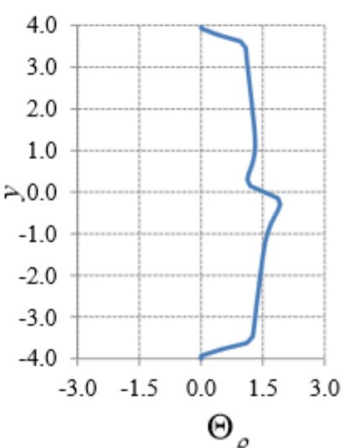

(a)

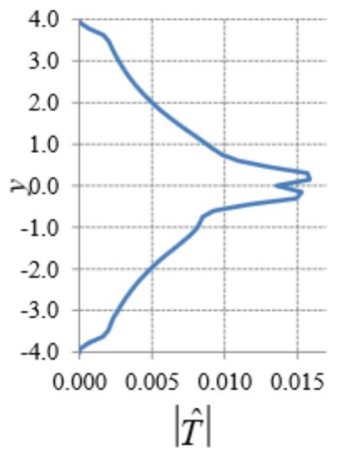

Fonte: Elaborada pelo autor.

\section{Parâmet ros da Simulação}

Para a simulação da camada de mistura bidimensional foi utilizada uma mal ha computacional cartesiana semel hante a utilizada por Babucke, Kloker e Rist (2008), com 2500 x 850 pontos nas direções x e y, respectivamente. Na direção longitudinal a mal ha possui uma 
região de espaçamento uniforme com $\mathrm{Dx}=0$; 157 até $\mathrm{x}=300$ e depois a mal ha é estirada com a uma taxa de aproximadamente 1,0\%, formando a zona de amorteci mento. Na di reção normal a mal ha é estirada do centro até os contornos, com menor espaçamento Dy $=0$; 15 e o mai or espaçamento $D y=1 ; 06$. Além do mais, utilizou-se de decomposição de domínio para solução através de processamento paral elo. A mal ha computacional, a decomposição de domínios e as condi ções de contorno utilizadas são apresentadas na Figura 31. Foram utilizados 7 elementos de processamento na di reção x e 2 na direção y, totalizando 14 el ementos de processamento de acordo com o estudo de Speed-up apresentado no A pêndice C.

Figura 31 - Esquema da mal ha computacional utilizada, divisão de domínios em cores preto e cinza e condições de contorno.

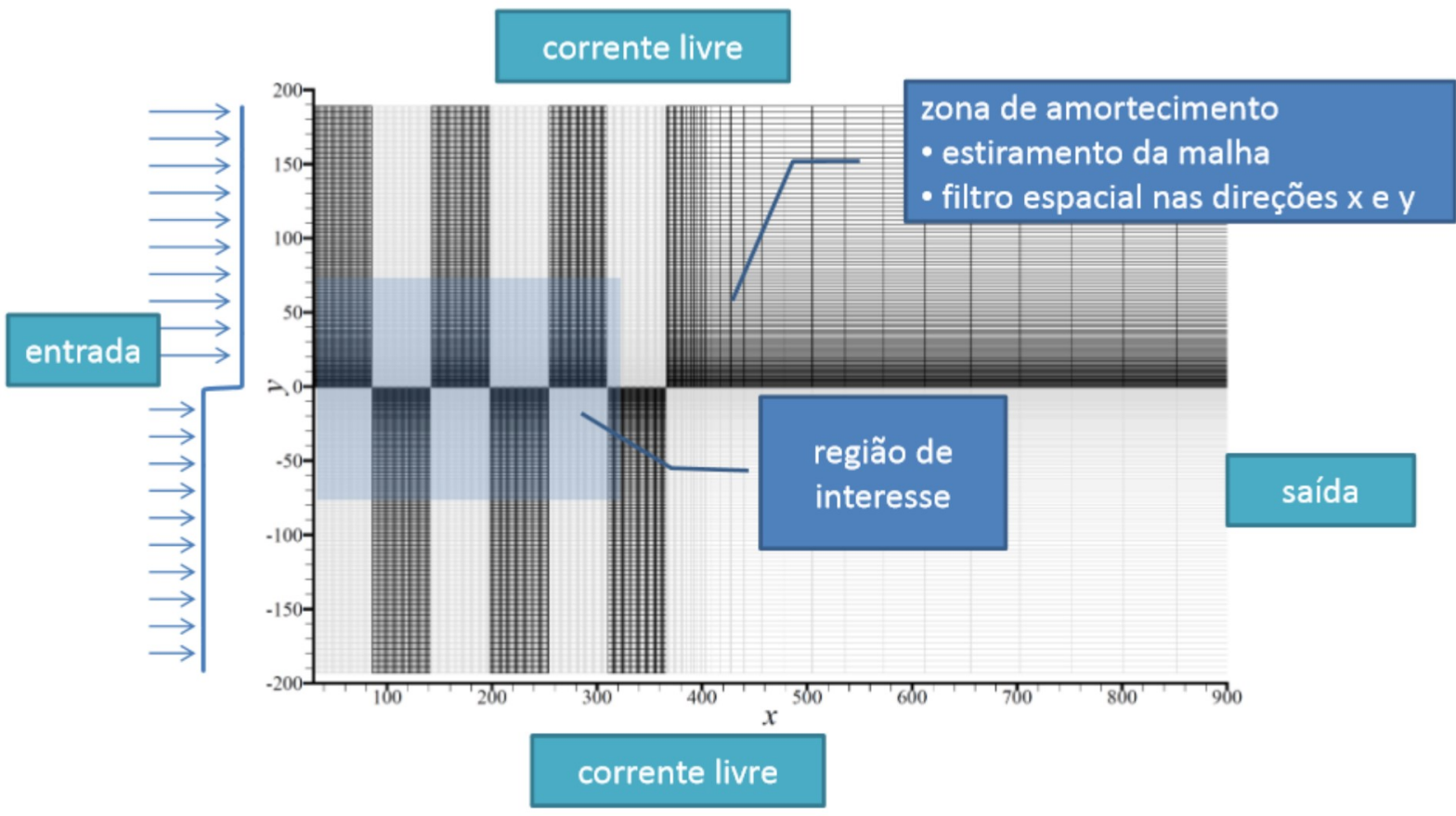

Fonte: Elaborada pelo autor.

O passo de tempo escolhido foi $\mathrm{Dt}=\frac{2 \mathrm{p}}{\mathrm{w} \cdot \mathrm{n}_{\text {passos }}}$, onde $\mathrm{n}_{\text {passos }}$ é o número de pontos por onda da frequencia fundamental que serão utilizados. Nesse caso utilizou-se $n_{\text {passos }}=752$, o que corresponde a um passo de tempo $\mathrm{Dt}=0$; 0133. Foram simulados um total de 76 períodos da frequência fundamental, onde os últimos 8 períodos foram utilizados para análise de dados.

Como condições de contorno, na entrada foram utilizados os perfis de velocidade u, temperatura e densidade apresentados na Figura 28 e introduzidas as perturbações a cada passo do Runge-Kutta, conforme descrito anteriormente. Ainda na entrada utilizou-se de condições de contorno características para evitar reflexões na entrada do domínio. Nos contornos superior e inferior foi utilizado uma região de amortecimento ao longo de 40 pontos próximos às fronteiras com um fator de amortecimento de 0,01 , seguindo o procedimento descrito na seção 3.7. No contorno final da direção longitudinal é usada uma combinação de estiramento da mal ha com 
filtro espacial para atenuar as perturbações.

\section{Resultados e Discussões}

A vorticidade transversal $W_{z}$ ao final da simulação é apresentada na Figura 32. Nesse gráfico os resul tados são comparados com os apresentados por Colonius, Lel e e Moin (1997) e Babucke, Kloker e Rist (2008), apresentando uma boa concordância. Nessa figura é possível ver a formação dos primeiros vórtices de Kelvin-Helmol tz pareando entre si e formando novas estruturas ajusante do escoamento.

Figura 32 - Vorticidade transversal ao final da simulação. Níveis de contorno de 0,26 até 0,02, com incremento de 0,04. (a) Colonius, Lele e Moin (1997); (b) Babucke, Kloker e Rist (2008) e (c) presente código.
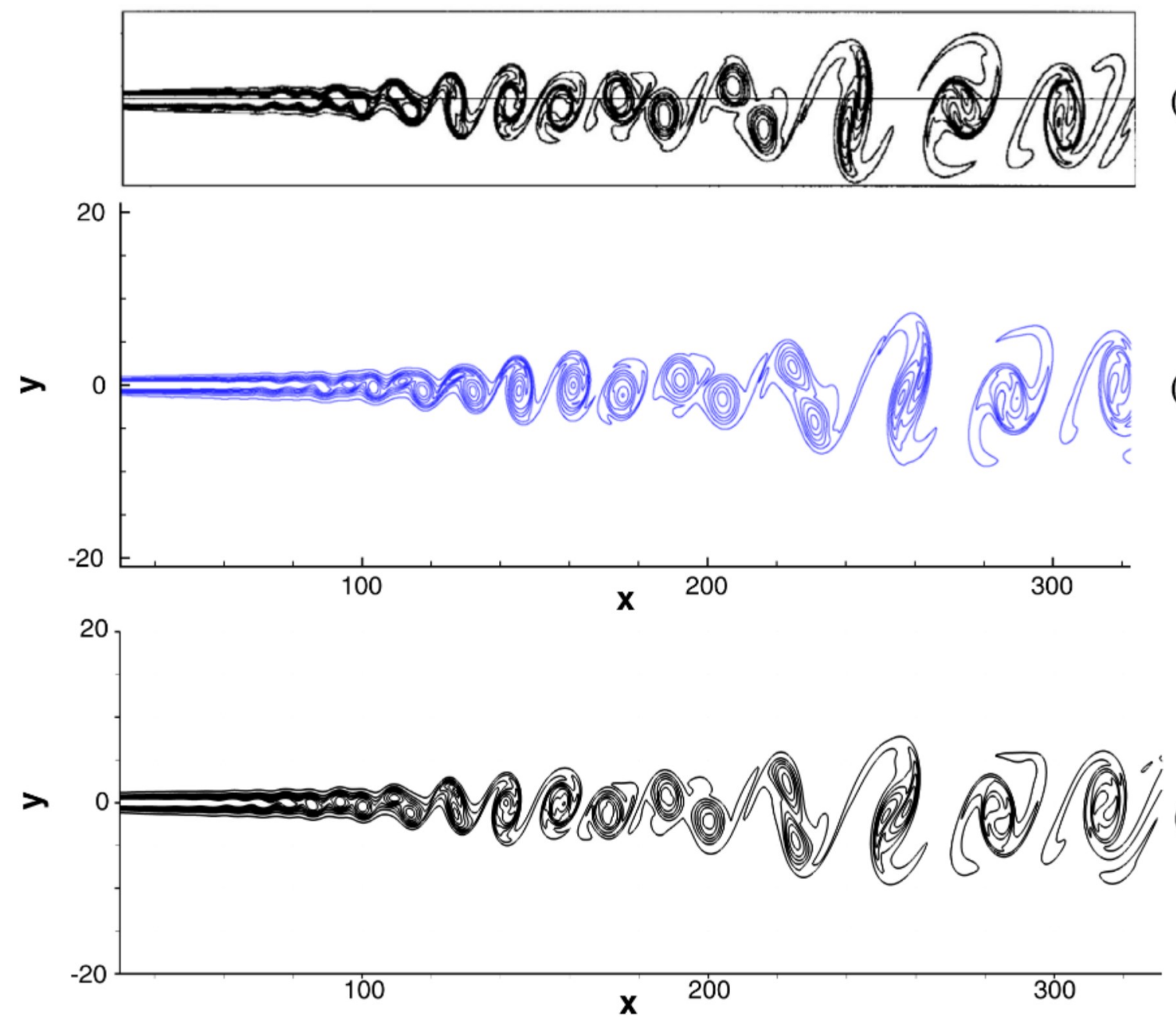

Fonte: Elaborada pelo autor.

A velocidade longitudinal média é dada por:

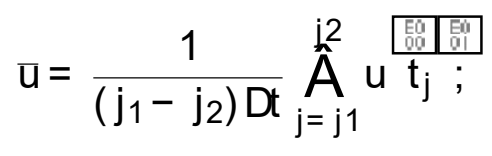


onde $\left(\mathrm{j}_{1}-\mathrm{j}_{2}\right)=8 \cdot \mathrm{n}_{\text {passos, }}$ correspondendo aos 8 últimos períodos simulados, usados para fazer a análise. A Figura 33 apresenta a comparação da velocidade longitudinal média com os resultados apresentados por Colonius, Lele e Moin (1997) e Babucke, Kloker e Rist (2008). Novamente há uma boa concordância com os resultados apresentados, e é possível verificar um forte crescimento da espessura da camada de mistura em $x=130$ e $x=240$, regiões onde 0 ocorrem pareamento de vórtices.

Figura 33 - Velocidade longitudinal média. Níveis de contorno de 0,50 até 1,00. (a) Colonius, Lele e Moin (1997); (b) Babucke, Kloker e Rist (2008) e (c) presente código.

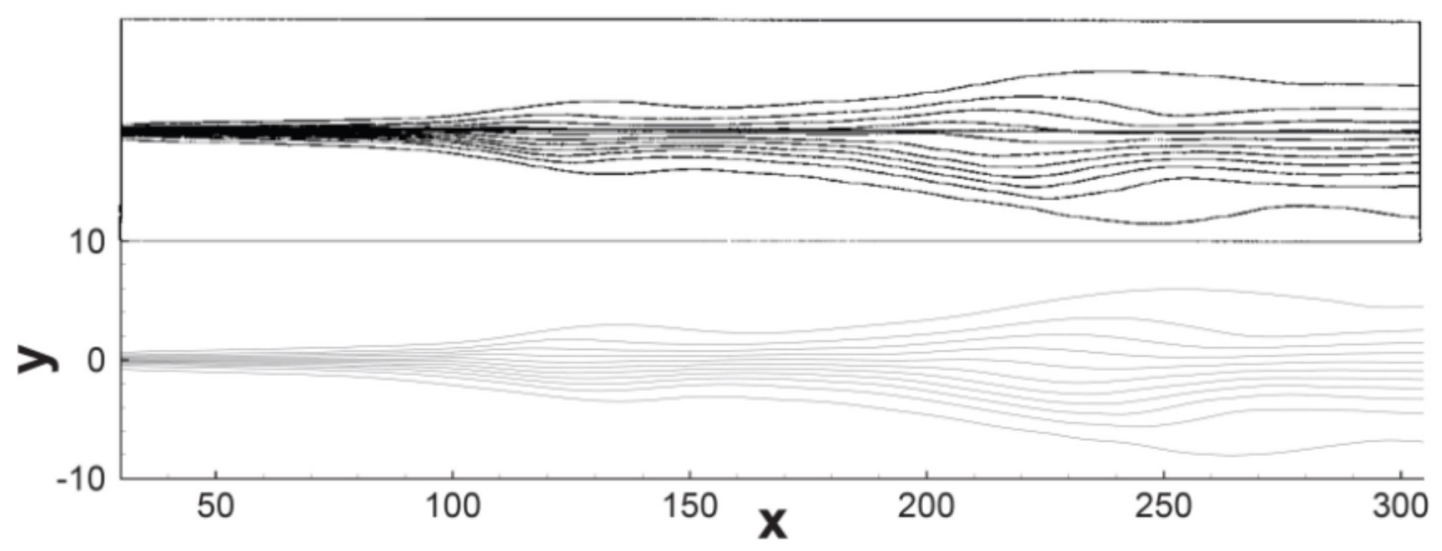

(a)

(b)

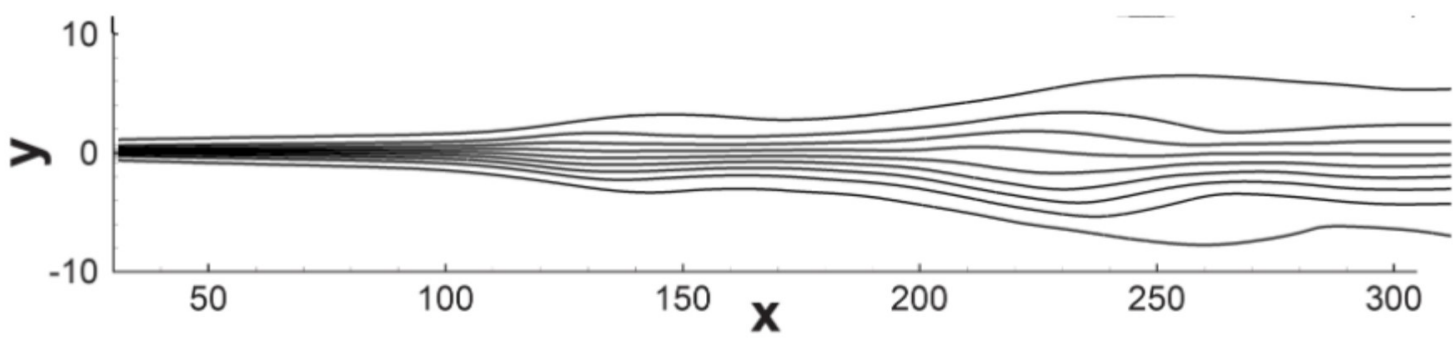

(c)

Fonte: Elaborada pelo autor.

Também é possível comparar as taxas de amplificação ao longo da di reção longitudinal . Para essa anál ise, o máximo val or na direção normal y da vel ocidade $v$ foi tomada a cada ponto ao longo da direção longitudinal x, pois ela está mai s associada com a formação e pareamento de vórtices na direção transversal . As taxas de amplificação podem ser dadas por:

$$
a_{i}=-\frac{\partial}{\partial x}\left[\ln \left(|v|_{\max }\right)\right]
$$

onde $|\mathrm{V}|$ max correspende ao máximo val or na direção normal y da vel ocidade $v$ a cada ponto de $x$, e que é apresentada na Figura 34. Já na Figura 35 são comparadas as taxas de ampl ificação para os modos $(1 ; 0) ;(1=2 ; 0)$ e $(1=4 ; 0)$. Conforme pode se obervar, há boa concordância com os resultados apresentados por Babucke, Kloker e Rist (2008) e também com as correspondentes taxas de ampl ificação da teoria de estabilidade linear. Através da Figura 34 nota-se que os modos $(1 ; 0) ;(1=2 ; 0)$ e $(1=4 ; 0)$ atingem seus valores máximos em torno das posições $x=90, x=130$ e 
$x=240$, respectivamente. Do ponto de vista físico, estas posições correspondem a posições onde estruturas vorticais associadas com cada modo se formam ao longo do escoamento, conforme Figura 32. Vale destacar que para se obter os resultados apresentados na Figura 35, é necessario fazer uma transformada de Fourier dos val ores máximos de v. Para essa anál ise há a necessi dade de aquisi tar dados da si mulação a uma taxa específica, como será esclarecido posteriormente.

Figura 34 - Comparação entre os resultados de Babucke, Kloker e Rist (2008) e do presente código da amplitude máxima da velocidade normal $\mathrm{v}$.

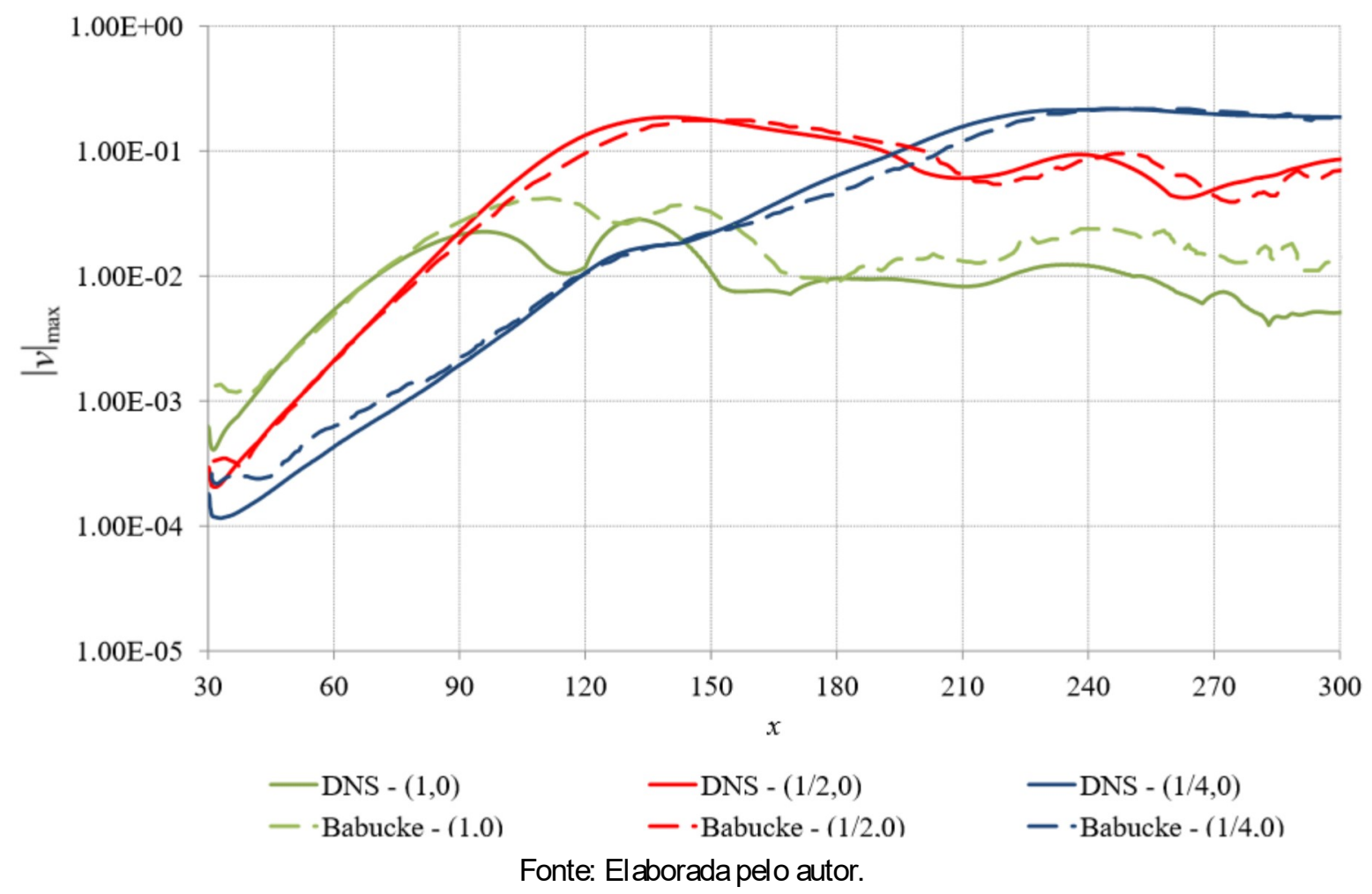

Uma maneira de observar o campo acústico é através da dilatação do escoamento, sendo o divergente do campo de velocidades - u. Na região de corrente livre a solução em regime permanente corresponderia a um escoamento incompressível, onde $-u=0$. Porém, flutuações de pressão e densidade geradas pel o escoamento propagam através da corrente livre, al terando o campo de di latação. Dessa forma, val ores diferentes de zero do campo de di latação na região de corrente livre representam o som emitido.

Para facilitar a visual ização, foram sel ecionadas frequências através da parte real da transformada de Fourier do campo de dilatação. Para isso, é necessário gravar resultados do campo de dilatação a uma taxa que permita real izar a análise Fourier temporal até uma dada frequência. No presente trabal ho essa frequência correspondia a terceira subharmônica da perturbação, ou seja $w=8$. Assim, 8 pontos por frequência fundamental foram aquisitados ao longo dos 8 últimos períodos simulados, correspondendo a um total 64 pontos disponíveis para fazer a análise de Fourier. Uma subrotina de transformada rápi da de Fourier foi adaptada para realizar essa anál ise. Tal procedimento também foi utilizado para obter os resultados apresentados 
Figura 35 - Taxa de ampl ificação de $v$ baseados na máxima amplitude ao longo da direção normal y. (a)Babucke, Kloker e Rist (2008) e (b) presente código.

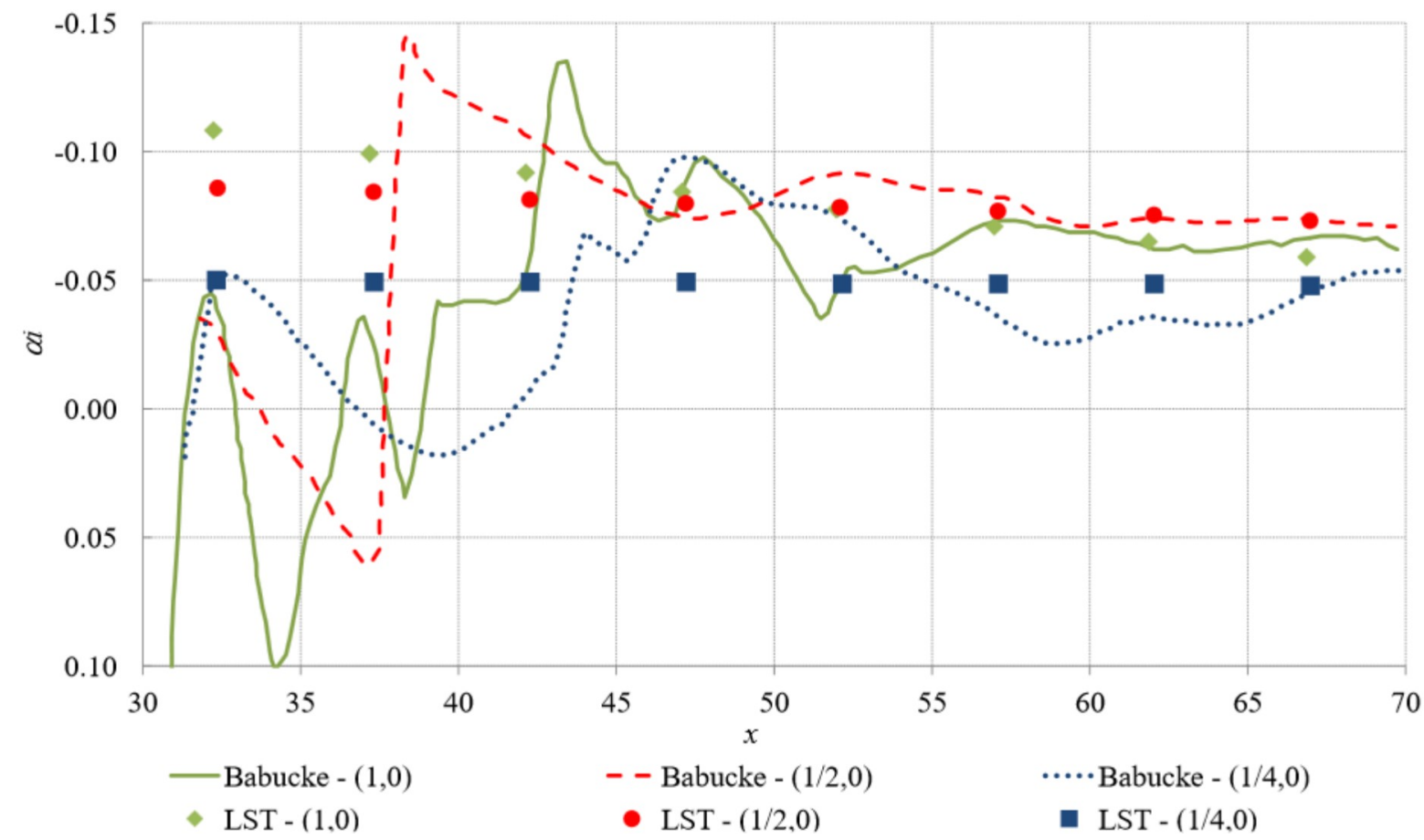

(a)

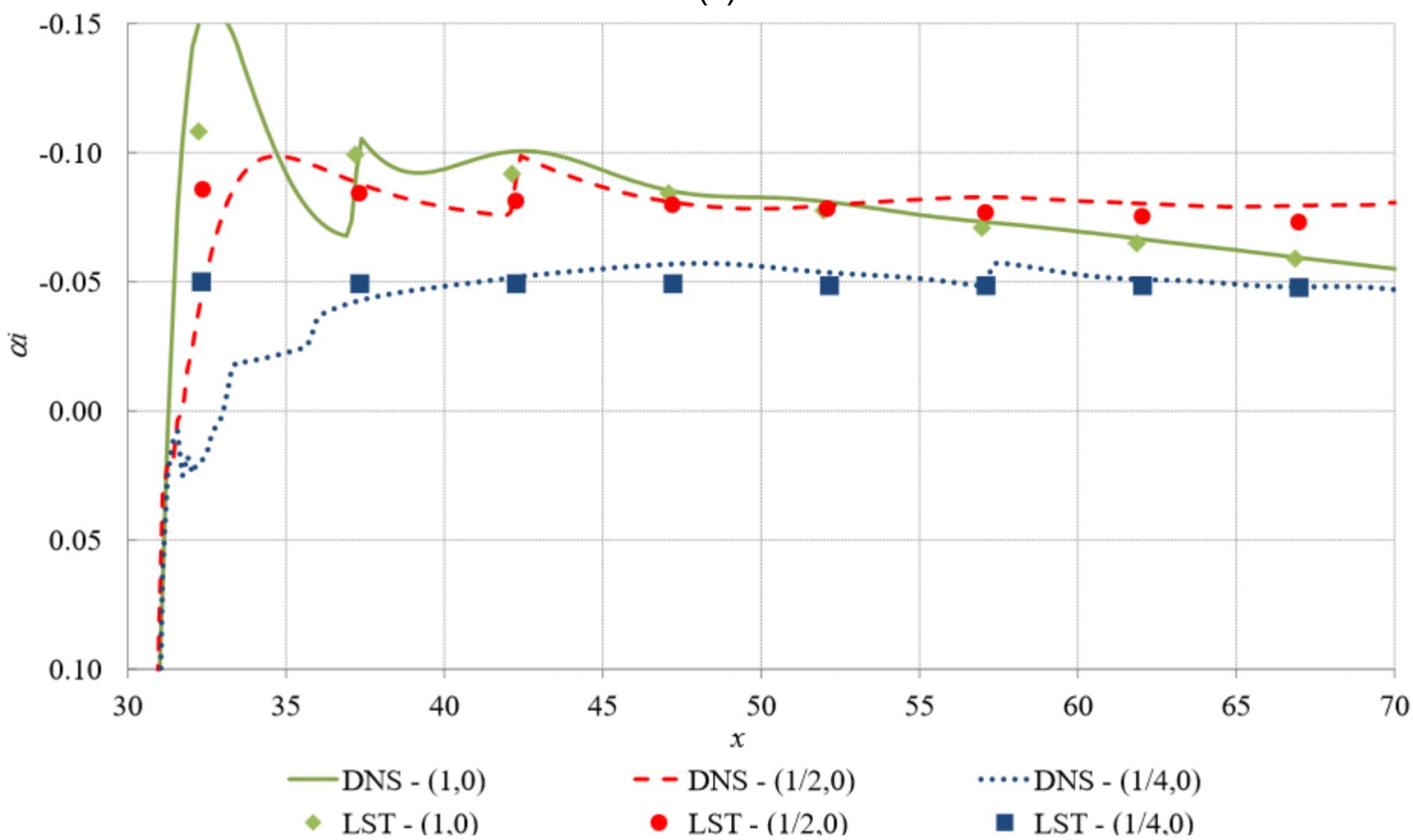

(b)

Fonte: Elaborada pelo autor. 
na Figura 35 para vários modos.

A Figura 36 mostra o campo de dilatação para $w=4$. Pode-se verificar uma fonte acústica dominante localizada em $x \approx 240$, onde os vórtices se unem e o som emitido se propaga principal mente à jusante. Observa-se uma boa comparação com os resul tados apresentados por Babucke, Kloker e Rist (2008), assim podendo dizer que o código está também verificado para simulações di retas de acústica.

Figura 36 - Transformada de Fourier do campo de dilatação para a frequência (1/4). Níveis de contorno de $-10^{-5}$ a $10^{-5}$. (a) Colonius, Lele e Moin (1997) e (b) presente código.

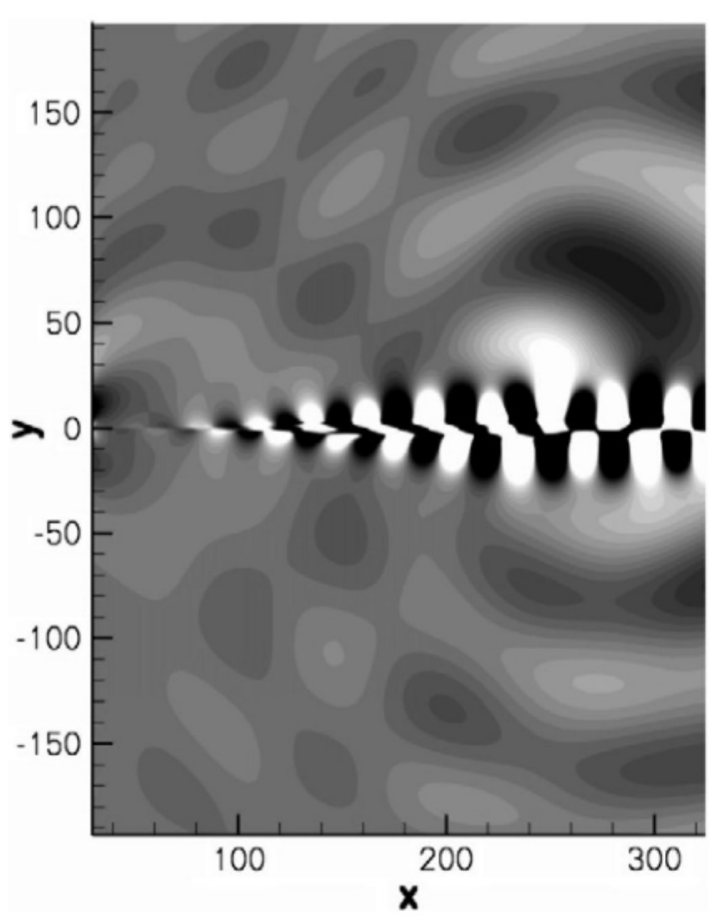

(a)

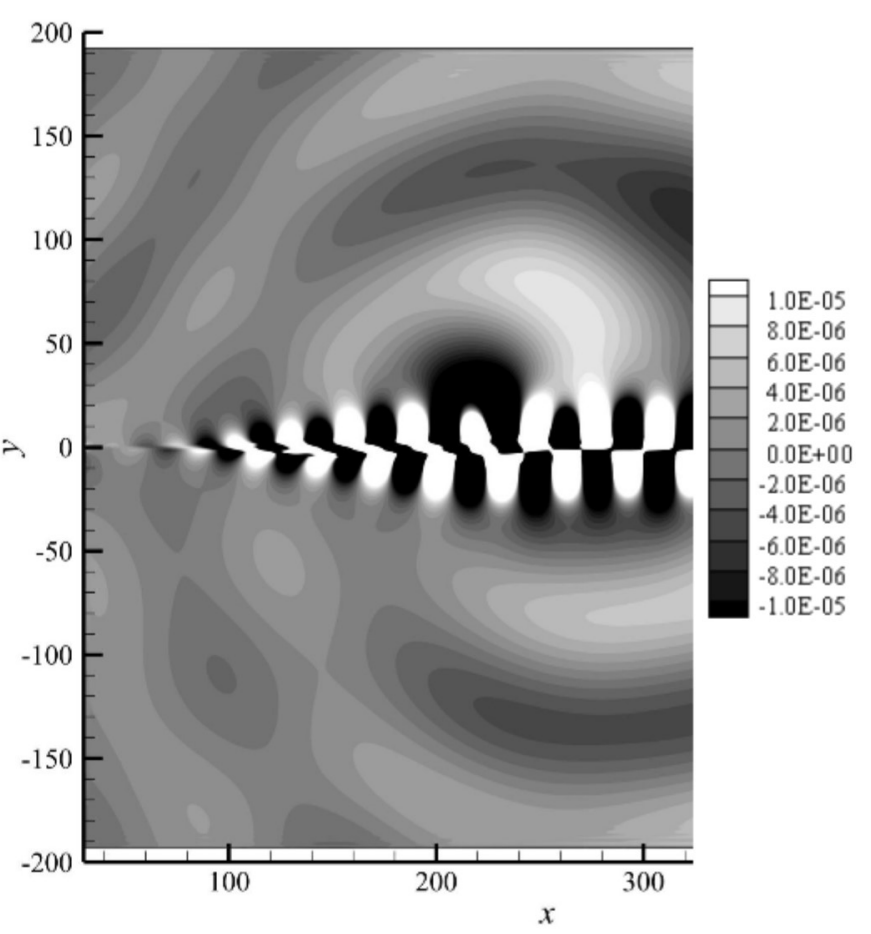

(b)

Fonte: Elaborada pelo autor.

\subsection{Jat os Planares Bidimensionais}

Ainda no processo de validação do código bidimensional, foram simulados dois casos de escoamentos de jatos planares bidimensionais: jatos planares com modos varicoso e sinuoso apresentados por Weder (2012) e também jatos planares para diversos números de Mach apresentados por Reichert e Biringen (2007). Tais comparações e consi derações são agora apresentados.

Jatos planares são escoamentos ci sal hantes típi cos em diversas áreas como combustão, propul são e apl icações ambientais. Também tem crescido o interesse no ruído gerado por esse tipo 
de escoamento para apl icações aeronáuticas. Nesse escoamento uma corrente central se mistura com outra corrente escoando paral elamente com uma velocidade menor ou em repouso. $\mathrm{Na}$ interface de encontro das duas correntes há elevados gradientes das propriedades do escoamento. Essa é uma condição que torna o escoamento instável a perturbações.

O problema aqui examinado agora envolve um jato planar bidimensional não confinado escoando junto com uma corrente externa paral ela. A Figura 37 apresenta um esquema de jato planar bidimensional com suas principais características. A corrente central tem velocidade $U_{j}$ maior do que a velocidade $U$. da corrente externa. Pequenas perturbações são excitadas na entrada do domínio e se amplificam espacial mente em uma região de transição, causando o surgimento de vórtices.

Em todos os casos utilizou-se um domínio computacional bidimensional grande o bastante para permitir o desenvolvimento do jato ao longo da direção longitudinal .

Figura 37 - Esquema de um jato planar bidimensional .

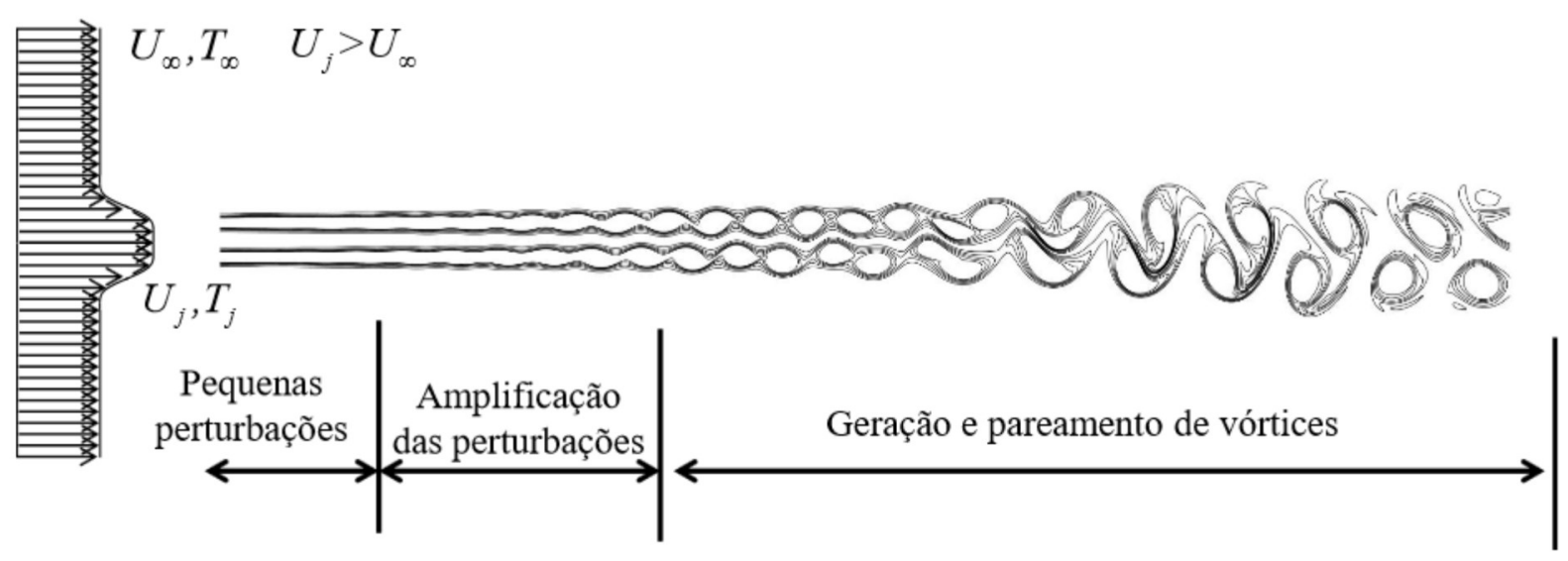

Fonte: Elaborada pelo autor.

\subsubsection{Jatos Planares Bidimensionais - caso apresentado por Weder (2012)}

De acordo com Weder (2012), daqui em diante chamado de "Weder2D”, utilizou-se o seguinte perfil de velocidades:

$$
\mathrm{u}(\mathrm{y})=1+\tanh \frac{\mathrm{R}}{4 \mathrm{q}} \frac{\mathrm{R}}{|\mathrm{y}|}-\frac{|\mathrm{y}|}{\mathrm{R}} \quad ;
$$

onde $\mathrm{R}$ corresponde à metade do comprimento do jato e q à espessura da região de mistura entre o jato e o ambiente externo. Para o perfil de temperatura, baseou-se na rel ação de Crocco- 
Busemann, que pode ser encontrada em White(2005):

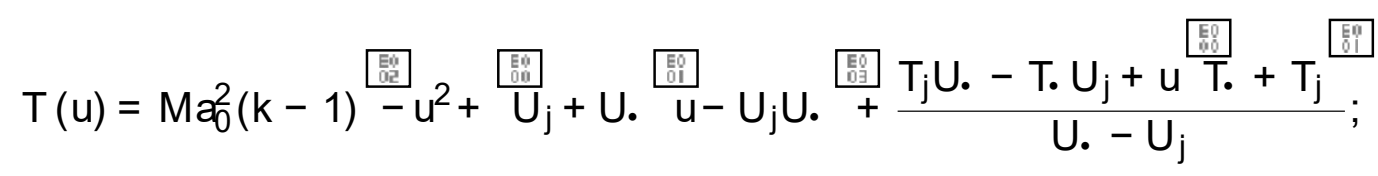

onde $u$ é o perfil de vel ocidade apresentado na Equação 4.22. Nesse caso $U_{j}=1, U .=0$ e $\mathrm{T}_{\mathrm{j}}=\mathrm{T}_{\mathrm{.}}=1$. A densidade é dada por $\mathrm{r}=1=\mathrm{T}$. Os perfis de velocidade e temperatura são apresentados na Figura 38 para $\mathrm{q}=0: 1, \operatorname{Pr}=0 ; 71, \operatorname{Re}=1000$ e $\mathrm{Ma}=0 ; 9$.

Figura 38 - Perfis de (a) velocidade u, (b) temperatura e (c) densidade para o caso Weder2D.

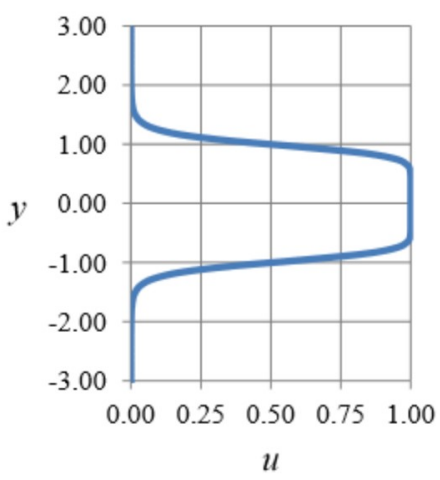

(a)

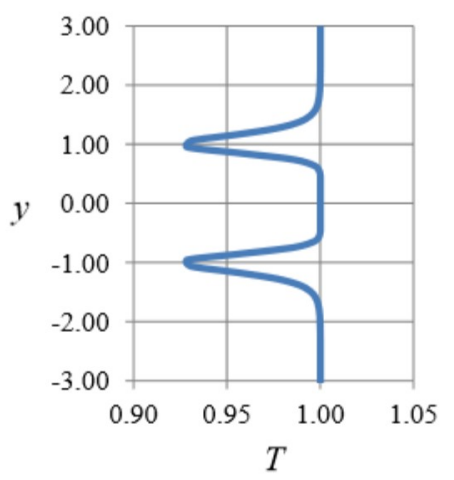

(b)

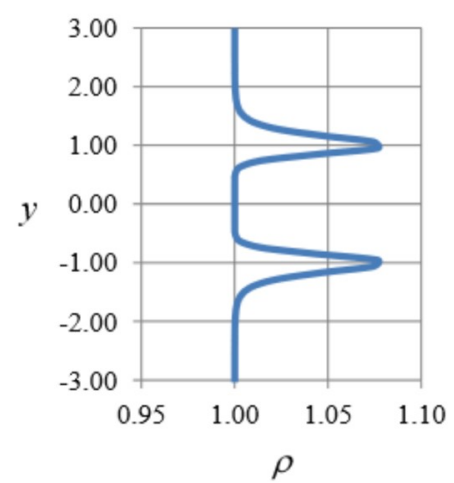

(c)

Fonte: Elaborada pelo autor.

Uma análise LST foi realizada utilizando este perfil de entrada para os casos varicoso e sinuoso, conforme descrito na seção 2.3. A Figura 39 apresenta a taxa de ampl ificação espacial para ambos os casos com boa concordância com os resultados apresentados por Weder (2012). Os valores de máximas taxas de amplificação e correspondentes val ores de frequência são apresentados na Tabela 4.

Tabela 4 - Val ore máximos de taxa de amplificação espacial para os casos si nuoso e varicoso.

\begin{tabular}{|c|c|c|c|}
\hline Modo & $\mathrm{w}$ & $\mathrm{a}_{\mathrm{r}}$ & $\mathrm{a}_{\mathrm{i}}$ \\
\hline sinuoso & 0,9498 & 18,409 & 0,7356 \\
\hline varicoso & 0,9606 & 17,602 & 0,7431 \\
\hline
\end{tabular}

Somente a frequência fundamental foi utilizada para excitar o escoamento em cada caso, com uma amplitude máxima de 0,05. Essa é uma informação não apresentada por Weder (2012) e prejudica a comparação quantitativa entre os dois casos. As ampl itudes e di stribuições de fase das autofunções para essa frequência fundamental são apresentadas na Figura 40.

\section{Parâmetros da simulação}

Nessas si mul ações foi utilizada uma mal ha computacional cartesiana com 1400 x 800 pontos nas direções x e y, respectivamente. Na direção longitudinal a mal ha possui uma região 
Figura 39 - Taxas de amplificação espaciais para os casos (a) sinuoso e (b) varicoso.
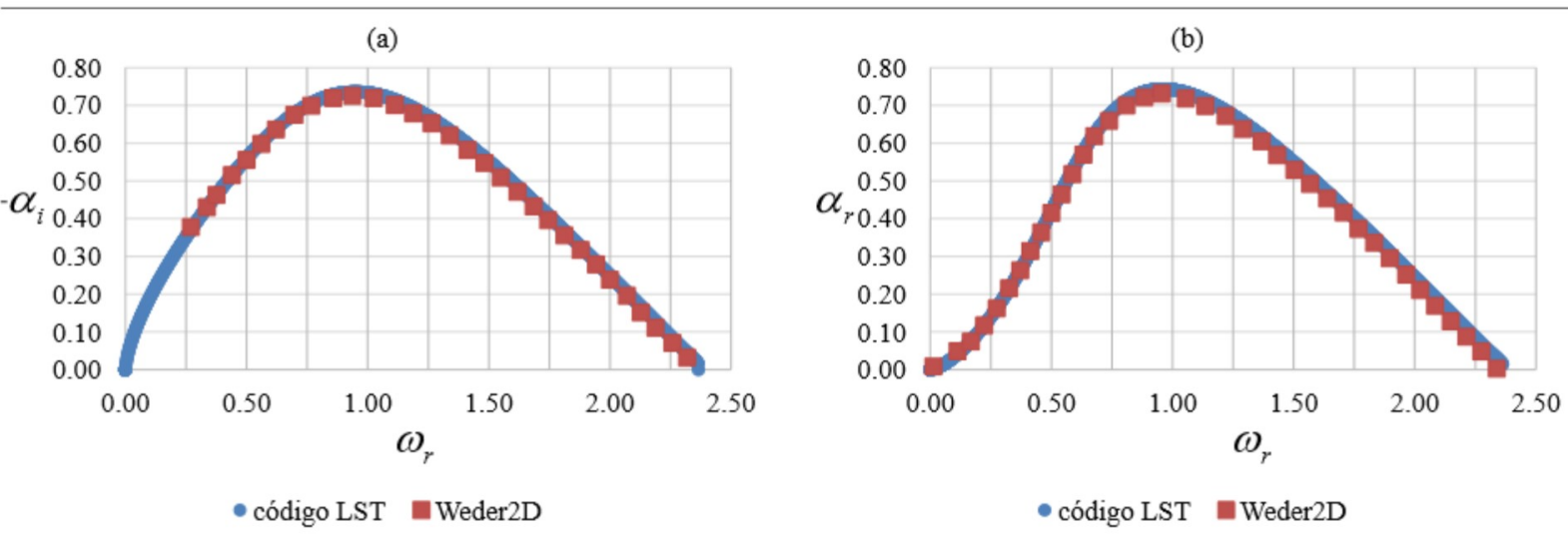

Fonte: Elaborada pelo autor.

de espaçamento uniforme com $\mathrm{Dx}=0$; 025 até $\mathrm{x} \approx 25$ e depois a mal ha é estirada com a uma taxa de aproximadamente $1,0 \%$, formando a zona de amortecimento. Na direção normal a mal ha também possui uma região com espaçamento uniforme $D y=0$; 025 até $y \approx \pm 2 ; 5$ e depois é estirada com a uma taxa de $1,0 \%$ até os contornos superiores. Utilizou-se de decomposição de domínio para sol ução através de processamento paral elo. Foram utilizados 7 el ementos de processamento na direção x e 2 na direção y, total izando 14 elementos de processamento de acordo com o estudo de Speed-up apresentado no Apêndice C.

O passo de tempo escolhido foi $D t=\frac{2 p}{w \cdot n_{p a s s o s}}$, onde $n_{\text {passos }}$ é o número de pontos por onda da frequencia fundamental que serão utilizados. Nesse caso utilizou-se $n_{\text {passos }}=752$, 0 que corresponde a um passo de tempo $\mathrm{Dt} \approx 0 ; 009$. Foram simulados um total de 10 períodos da frequência fundamental para ambos os casos.

Como condi ções de contorno, foram utilizados os perfis de vel oci dade u, temperatura e densi dade apresentados na Figura 38 e introduzidas as perturbações da anál ise LST a cada passo do Runge-Kutta, como no caso apresentado na seção 4.4. Ainda na entrada utilizou-se de condições de contorno características para evitar reflexões na entrada do domínio. Nos contornos superior e inferior da direção normal foi utilizada derivada nula e no contorno final da di reção longitudinal é usada uma combi nação de estiramento da mal ha com fil tro espacial para atenuar as perturbações. 
Figura 40 - Amplitude e di stribuição de fase da perturbação para os casos (a) sinuoso e (b) varicoso.

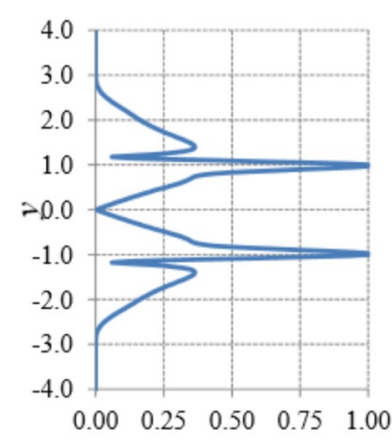

$|\hat{u}|$

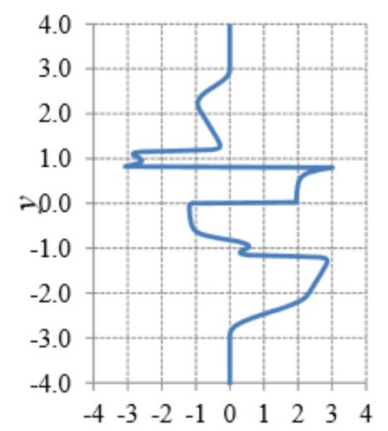

$\Theta_{u}$

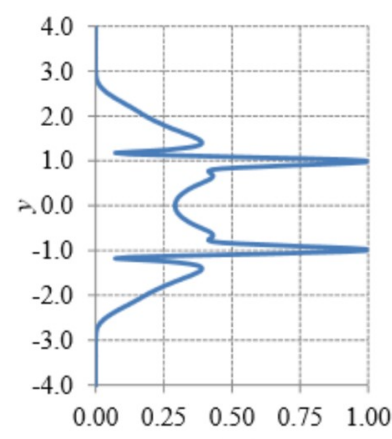

$|\hat{u}|$

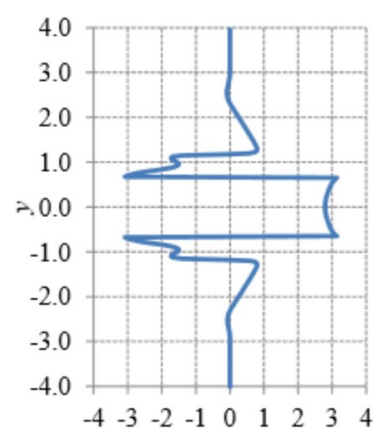

$\Theta_{u}$

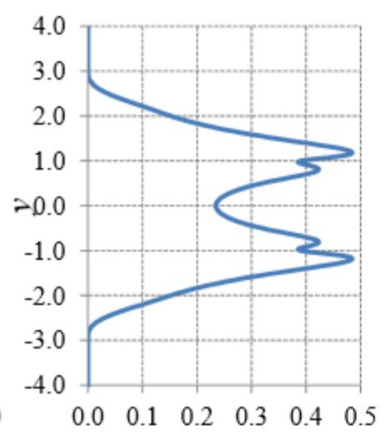

$|\hat{v}|$

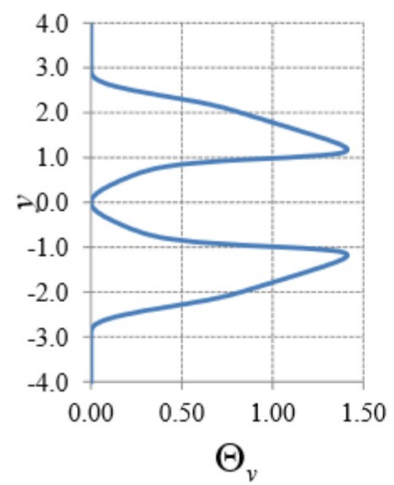

$\Theta_{v}$

(a)

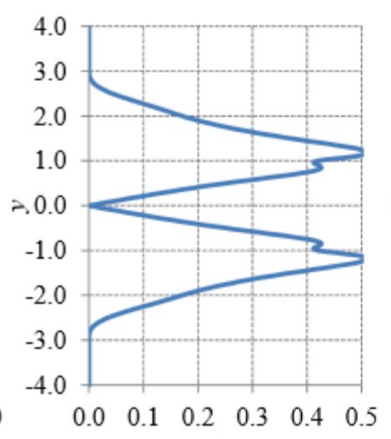

$|\hat{v}|$

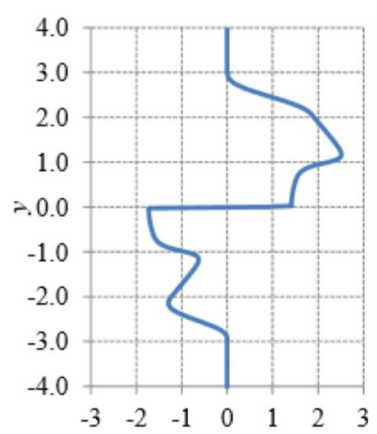

$\Theta_{v}$

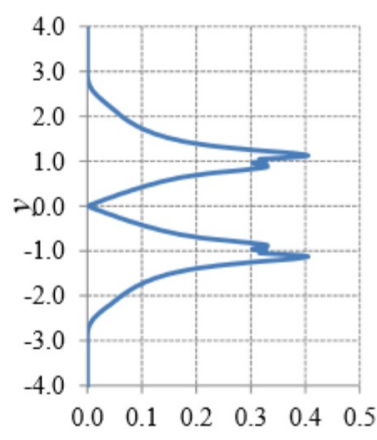

$|\hat{\rho}|$

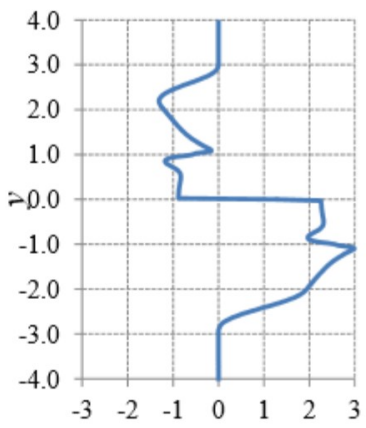

$\Theta_{\rho}$

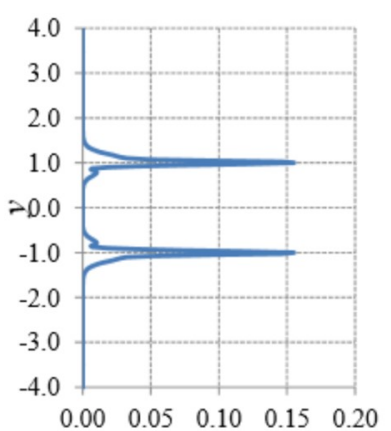

$|\hat{T}|$

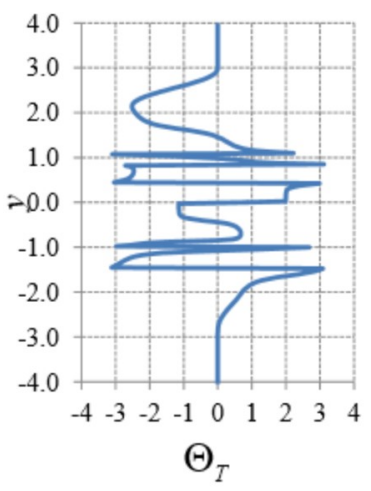

$\Theta_{T}$

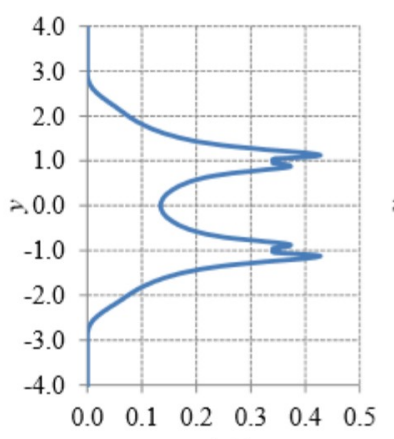

$|\hat{\rho}|$

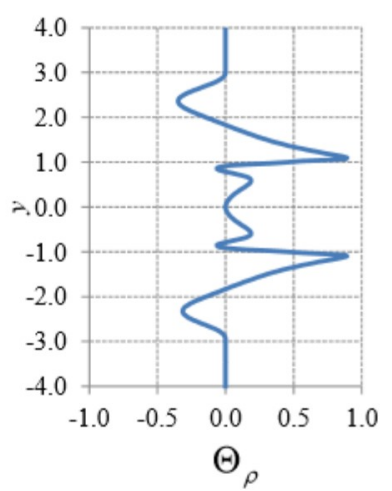

(b)

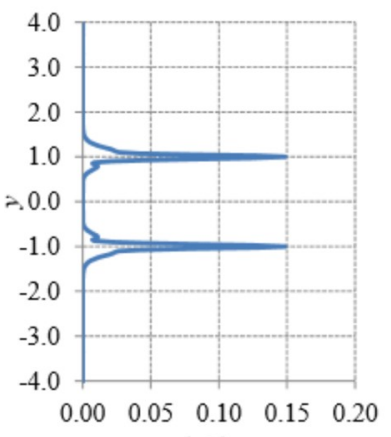

$|\hat{T}|$

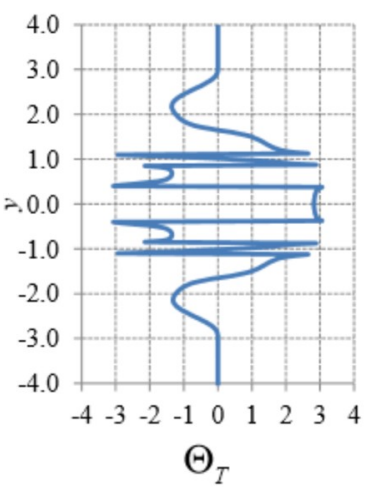

Fonte: Elaborada pelo autor. 


\section{Resultados e Discussões}

A Figura 41 e a Figura 42 mostram a vorti cidade transversal para os casos sinuoso e varicoso, respectivamente. É possível ver a transição e crescimento espacial das perturbações, gerando vórtices com uma configuração si métrica para o modo varicoso e antisi métrica para o modo sinuoso.

Figura 41 - Vorticidade transversal ao final da simul ação para o modo sinuoso. Níveis de contorno de -2,4 até 2,4 com incremento de 0,2 . Linhas sól idas correspondem a valores positivos e tracejadas val ores negativos.

Fonte: Elaborada pelo autor.

Figura 42 - Vorticidade transversal ao final da simulação para o modo varicoso. Níveis de contorno de -2,4 até 2,4 com incremento de 0,2. Linhas sólidas correspondem a valores positivos e tracejadas val ores negativos.

Fonte: Elaborada pelo autor.

Devido a uma possível diferença na amplitude das perturbações introduzidas, mal ha computacional , passo de tempo e outros parâmetros da simulação não informados por Weder 
(2012), não se pode fazer uma comparação quanti tativa di reta com os resul tados apresentados pelo autor. Porém, os modos observados se compararam qual itativamente bem com os apresentados pelo autor, demonstrando que o código está sol ucionando satisfatóriamente escoamento de jatos planares.

\subsubsection{Jatos Planares Bidimensionais - caso apresentado por Reichert e Biringen (2007)}

Para real izar uma comparação com os resultados apresentados por Reichert e Biringen (2007), daqui em diante chamados de "ReichertBiringen2D”, utilizou-se o seguinte perfil de velocidades:

$$
u(y)=\frac{M a_{j}-M a_{\bullet}}{M a_{j}+M a_{\bullet}} \tanh (2 y+q)+1 ;
$$

onde $q=1 ; 98$ e o perfil é refletido de $y=0 . A$ densidade e temperatura são manti dos constantes na entrada como também a pressão de forma que as correntes são isotérmi cas e perfeitamente expandidas. O número de Prandtl $\operatorname{Pr}=0 ; 71$. Os autores utilizaram as equações de Euler na formulação e resolução do problema, onde os efeitos de viscosidade são desprezados. Para se obter efeito semel hante, foi utilizado um número de Reynolds el evado $\operatorname{Re}=10000$, de formas que os termos inerciais fossem muito mai ores do que os termos viscosos.

Nas simulações foram foi adotado o número de Mach do jato. O número de Mach convectivo em função do Mach no jato $\mathrm{Maj}_{\mathrm{j}}$ e do Mach fora do jato Ma. é dado por:

$$
M a_{c}=\frac{M a_{j}-M a_{\bullet}}{2}
$$

Em todos os casos a razão de vel ocidades utilizada é $U_{j}=U .=1 ; 67$. O perfil de velocidade na entrada é apresentado na Figura 43.

Figura 43 - Perfil de velocidade u para o caso ReichertBiringen2D.

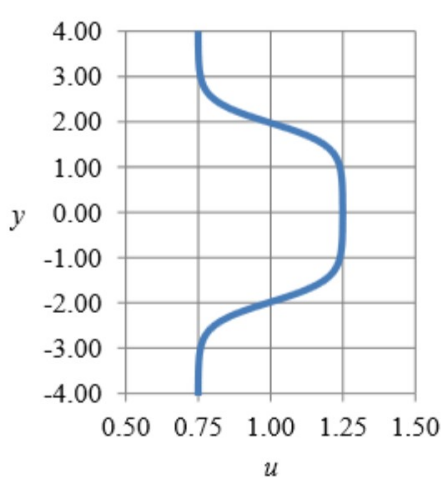

Fonte: Elaborada pelo autor. 
Uma perturbação randômica entre -0,005 e 0,005 foi adicionada às componentes de velocidade u e v em Reichert eBiringen (2007). Entretanto, no presente trabal ho uma anál ise LST foi real izada para cada caso. Para isso, a frequência fundamental foi utilizada para perturbar o escoamento na entrada com uma amplitude máxima de 0,0001 para a componente da velocidade u.

Foram simulados 6 casos, e cada um com perturbações do tipo sinuoso e varicoso. Os números de Mach do jato, da corrente externa e convectivo, bem como os val ores máximos de taxa de ampl ificação para o modo sinuoso são apresentados na Tabela 5. Já para o modo varicoso esses dados estão na Tabela 6.

Tabela 5 - Números de Mach e val ores máximos de taxa de amplificação espacial para os casos ReichertBiringen2D, modo sinuoso.

\begin{tabular}{|c|c|c|c|c|c|c|}
\hline Caso & $\mathrm{Ma}_{\mathrm{j}}$ & $\mathrm{Ma}_{\mathrm{o}}$ & $\mathrm{Ma}$ & $\mathrm{w}_{\mathrm{r}}$ & $\mathrm{a}_{\mathrm{r}}$ & $\mathrm{a}_{\mathrm{i}}$ \\
\hline 1 & 0,25 & 0,15 & 0,05 & 0,8859 & 0,8920 & 0,0966 \\
\hline 2 & 1,05 & 0,63 & 0,21 & 0,8552 & 0,8616 & 0,0908 \\
\hline 3 & 1,50 & 0,90 & 0,30 & 0,8199 & 0,8266 & 0,0849 \\
\hline 4 & 2,00 & 1,20 & 0,40 & 0,7628 & 0,7699 & 0,0767 \\
\hline 5 & 2,50 & 1,50 & 0,50 & 0,6862 & 0,6940 & 0,0674 \\
\hline 6 & 3,00 & 1,80 & 0,60 & 0,5954 & 0,6038 & 0,0581 \\
\hline
\end{tabular}

Tabela 6 - Números de Mach e val ores máximos de taxa de amplificação espacial para os casos ReichertBiringen2D, modo varicoso.

\begin{tabular}{|c|c|c|c|c|c|c|}
\hline Caso & $\mathrm{Ma}_{\mathrm{j}}$ & $\mathrm{Ma}_{\mathrm{a}}$ & $\mathrm{Ma}_{\mathrm{c}}$ & $\mathrm{w}_{\mathrm{r}}$ & $\mathrm{a}_{\mathrm{r}}$ & $\mathrm{a}_{\mathrm{i}}$ \\
\hline 1 & 0,25 & 0,15 & 0,05 & 0,9036 & 0,8980 & 0,0933 \\
\hline 2 & 1,05 & 0,63 & 0,21 & 0,8927 & 0,8875 & 0,0855 \\
\hline 3 & 1,50 & 0,90 & 0,30 & 0,8740 & 0,8690 & 0,0773 \\
\hline 4 & 2,00 & 1,20 & 0,40 & 0,8350 & 0,8301 & 0,0654 \\
\hline 5 & 2,50 & 1,50 & 0,50 & 0,7636 & 0,7586 & 0,0507 \\
\hline 6 & 3,00 & 1,80 & 0,60 & 0,6370 & 0,6311 & 0,0335 \\
\hline
\end{tabular}

O comportamento da taxa de amplificação espacial variando com o número de Mach do jato é apresentado na Figura 44 para o modo sinuoso e na Figura 45 para o modo varicoso. Observa-se que com o aumento do número de Mach há uma dimi nuição no val or máximo da taxa de amplificação, o que deixa o escoamento mais estável. Também há uma di mi nuição da frequência máxima observada para cada val or de Mach.

\section{Parâmetros da simulação}

Nessas si mulações foi utilizada uma mal ha computacional cartesiana com 1400 × 800 pontos nas direções $x$ ey, respectivamente. Na direção longitudinal a mal ha possui uma região de espaçamento uniforme com $\mathrm{Dx}=0 ; 25$ até $\mathrm{x} \approx 250$ e depois a mal ha é estirada com a uma taxa de aproximadamente $1,0 \%$, formando a zona de amortecimento. Na direção normal a mal ha 
Figura 44 - Taxas de amplificação espaciais para os casos ReichertBiringen2D, modo sinuoso.

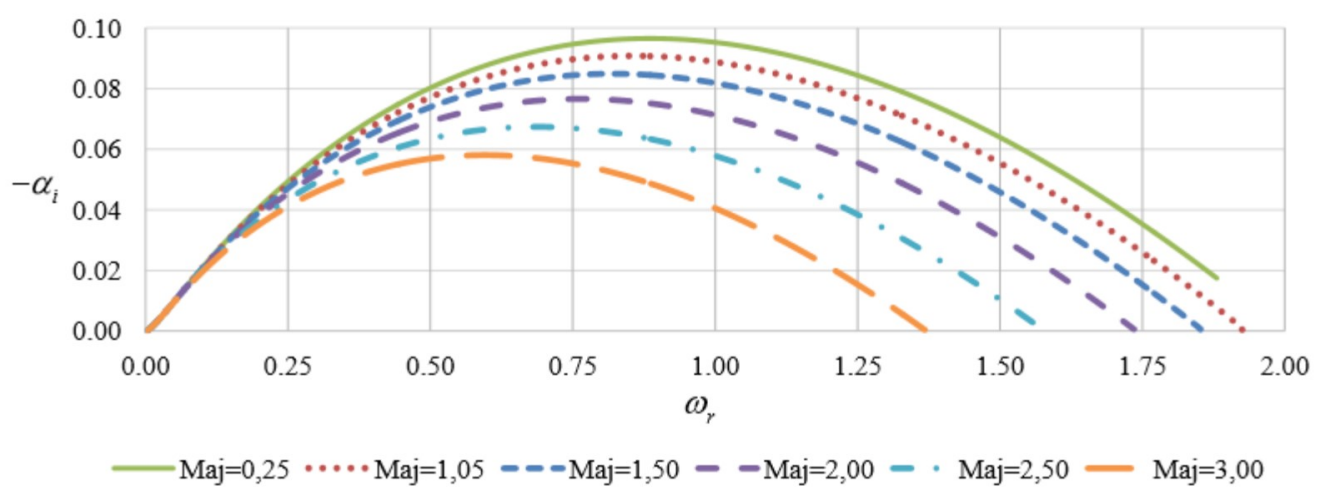

Fonte: Elaborada pelo autor.

Figura 45 - Taxas de amplificação espaciais para os casos ReichertBiringen2D, modo varicoso.

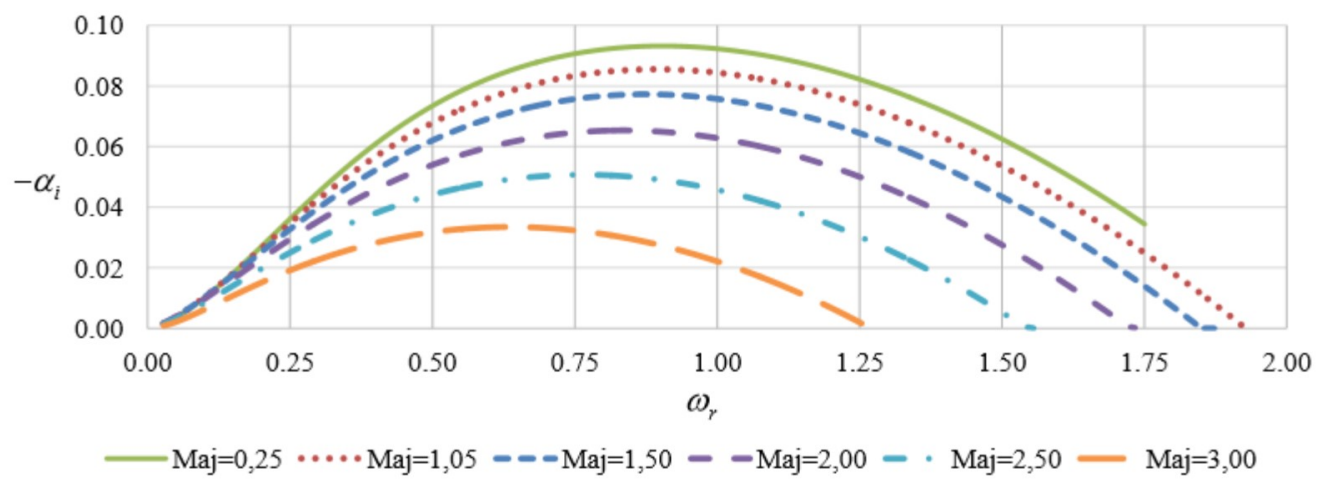

Fonte: Elaborada pelo autor.

também possui uma região com espaçamento uniforme $D y=0 ; 106$ até $y \approx \pm 5 ; 20$ e depois é estirada com a uma taxa de 1,0\% até os contornos superiores. Utilizou-se de decomposição de domínio para sol ução através de processamento paralelo. Foram utilizados 7 el ementos de processamento na direção x e 2 na direção y, total izando 14 elementos de processamento de acordo com o estudo de Speed-up apresentado no A pêndice C.

O passo de tempo escol hido foi $\mathrm{Dt}=\frac{2 p}{\mathrm{w} \cdot n_{\text {passos }}}$, onde $\mathrm{n}_{\text {passos }}$ é o número de pontos por onda da frequencia fundamental que serão utilizados. Nesse caso utilizou-se $n_{\text {passos }}=752$, o que corresponde a um passo de tempo $\mathrm{Dt} \approx 0 ; 009$. Foram simulados um total de 76 períodos da frequência fundamental para ambos os casos, onde os úl timos 8 períodos foram utilizados para análise de dados.

Como condições de contorno, foi utilizado o perfil de velocidade u apresentado na Figura 43 e introduzi das as perturbações a cada passo do Runge-Kutta, como no caso apresentado na seção 4.4. Ainda na entrada utilizou-se de condi ções de contorno características para evitar reflexões na entrada do domínio. Nos contornos superior e inferior da direção normal foi utilizada derivada nula e no contorno final da di reção longitudinal é usada uma combi nação de esti ramento 
da mal ha com filtro espacial para atenuar as perturbações.

\section{Resultados e Discussões}

Segundo Tam (1995), o ef eito mais conhecido da influência do aumento do número de Mach em escoamentos cisal hantes é a redução da taxa de crescimento e redução da mistura. Esse efeito tem grande importância em escoamentos de jatos que envolvem combustão e pode também ajudar no controle de ruído, já que o desenvolvimento da turbulência está associada com o crescimento de instabilidades. A Figura 46 mostra a vorticidade transversal para os casos do modo sinuoso apresentados na Tabela 5, e a Figura 47 para os casos do modo varicoso apresentados na Tabela 6 para $50 \leq x \leq 215$. Primeiramente, é possível notar em todos os casos características semel hantes entre os escoamentos: A partir da entrada há o crescimento espacial das perturbações introduzidas, que transi cionam para gerar estruturas de vórtices a montante. Além do mais, para ambos os modos, é possível verificar que com o aumento do número de Mach há também um aumento da região do núcleo central do jato, "atrasando" a formação dos vórtices e reduzindo seu espal hamento. Val ores mai ores de $\mathrm{Ma}_{\mathrm{j}}$ mostram esteiras de vórtices mais estáveis com menos pareamento, sugerindo menos mistura do escoamento. Comparando os resul tados da Figura 46 com os da Figura 47 nota-se também a diferença na formação dos vórtices, sendo gerados com uma configuração si métrica para o modo varicoso e antisimétrica para o modo sinuoso, como é o esperado para cada caso. 
Figura 46 - Vorticidade transversal ao final da simulação para o modo sinuoso. Níveis de contorno de -0,5 até 0,5. Linhas sóli idas correspondem a val ores positivos e tracejadas val ores negativos.

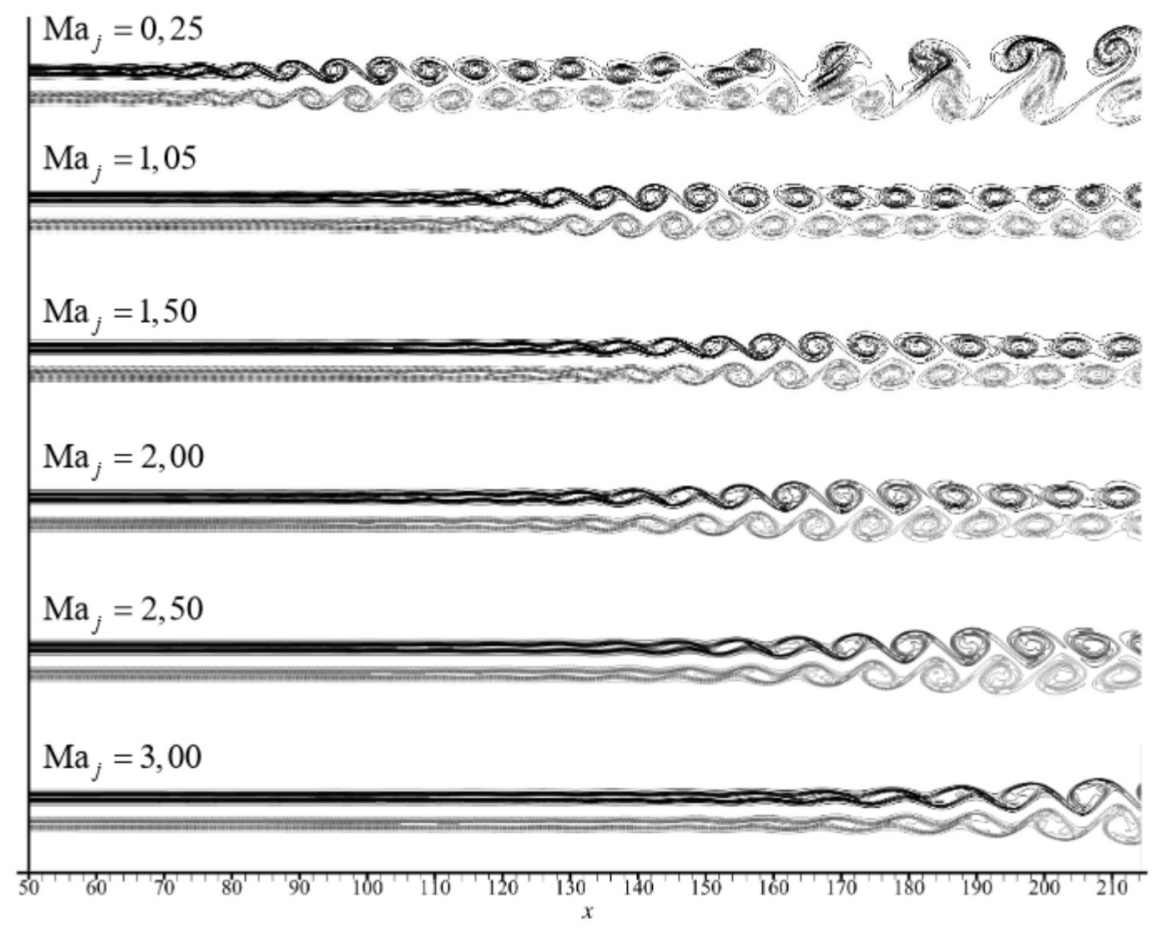

Fonte: Elaborada pelo autor.

Figura 47 - Vorticidade transversal ao final da simulação para o modo varicoso. Níveis de contorno de -0,5 até 0,5. Linhas sólidas correspondem a val ores positivos e tracejadas val ores negativos.

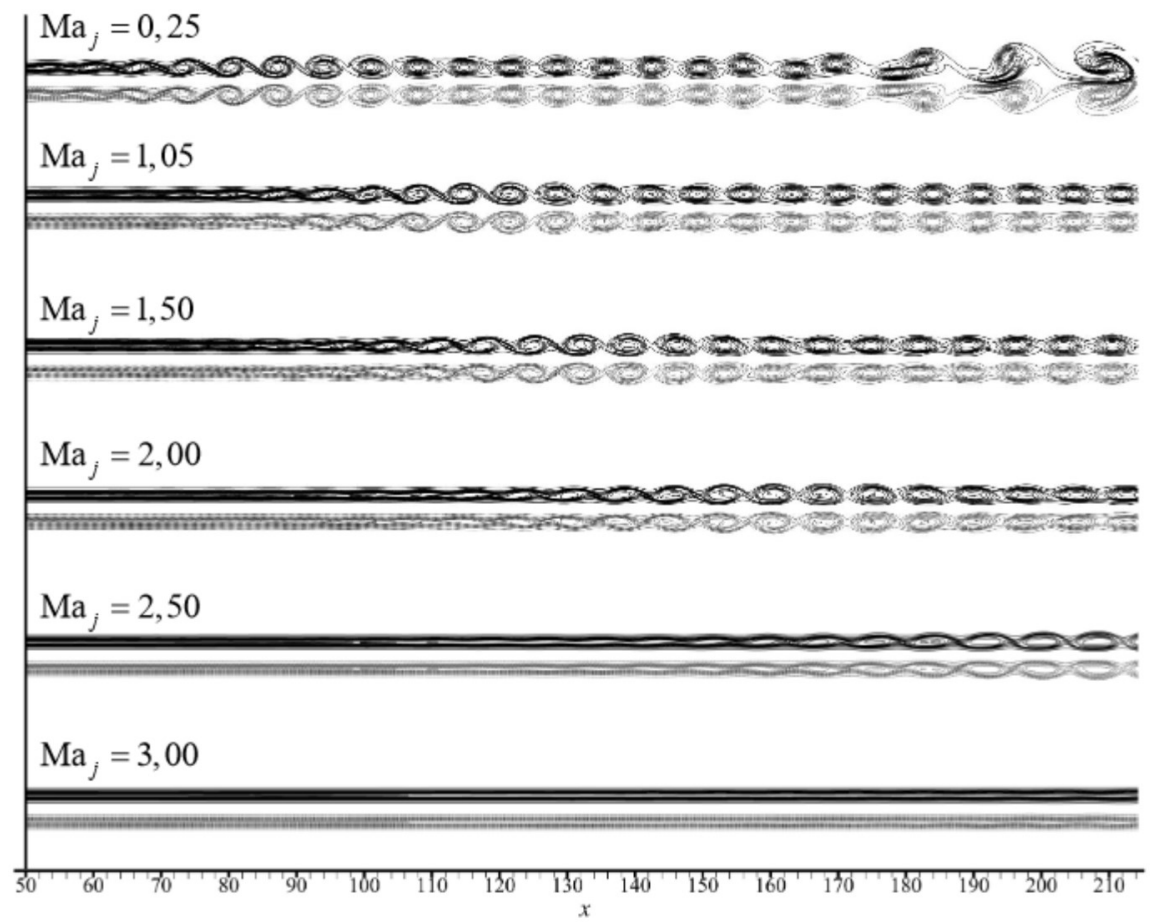

Fonte: Elaborada pelo autor. 
Os val ores da amplitude do máximo val or da velocidade transversal tomada ao longo de y $\left(|v|_{\max }\right)$ para cada ponto x são apresentadas na Figura 48 para o modo si nuoso e na Figura 49 para o modo varicoso, respectivamente. Em ambos os casos é possível verificar uma região inicial de receptividade das perturbações introduzi das na entrada, que crescem aproximadamente linearmente até atingir um patamar máximo. Também observa-se que a posição $x$ em que o val or de $|v|_{\max }$ atinge o patamar superior é postergado ao longo de x com o aumento do número de Mach, mostrando que o escoamento é mais estável com o aumento do número de Mach, conforme demonstrado pela análi ise de LST apresentada na Figura 44 e Figura 45 para os modos sinuoso e varicoso, respectivamente. Por fim, há uma queda brusca na taxa de amplificação correspondendo a uma região onde as perturbações já estão se propagando de forma não linear.

As comparações das taxas de amplificação espacial obtidas com o presente código com as obti das com a anál ise LST também podem ser apresentadas individualmente na Figura 50 e na Figura 51 para os modos sinuoso e varicoso, respectivamente. Mesmo sendo val ores muito sensíveis as taxas de amplificação corresponderam bem com os resultados LST para ambos os modos si nuoso e varicoso. Essa boa comparação mostra que o código é capaz de capturar os fenômenos físi cos previstos por teoria consolidada na área de mecânica dos fluidos, aumentando o grau de verificação e confiabilidade do código numérico.

Devido à diferença na ampl itude das perturbações introduzi das, mal ha computacional , passo de tempo e outros parâmetros da si mul ação não informados por Reichert e Biringen (2007), não se pode fazer uma comparação quantitativa direta com os resultados apresentados pelo autores. Porém, o comportamento da taxa de ampl ificação dos vórtices e dos modos observados são condizentes com o que é reportado na literatura, assim corroborando mais uma vez que o código está sol ucionando sati sfatoriamente esse tipo de escoamento. 
Figura 48 - Amplitude máxima da velocidade normal v ao longo de y para o modo sinuoso.

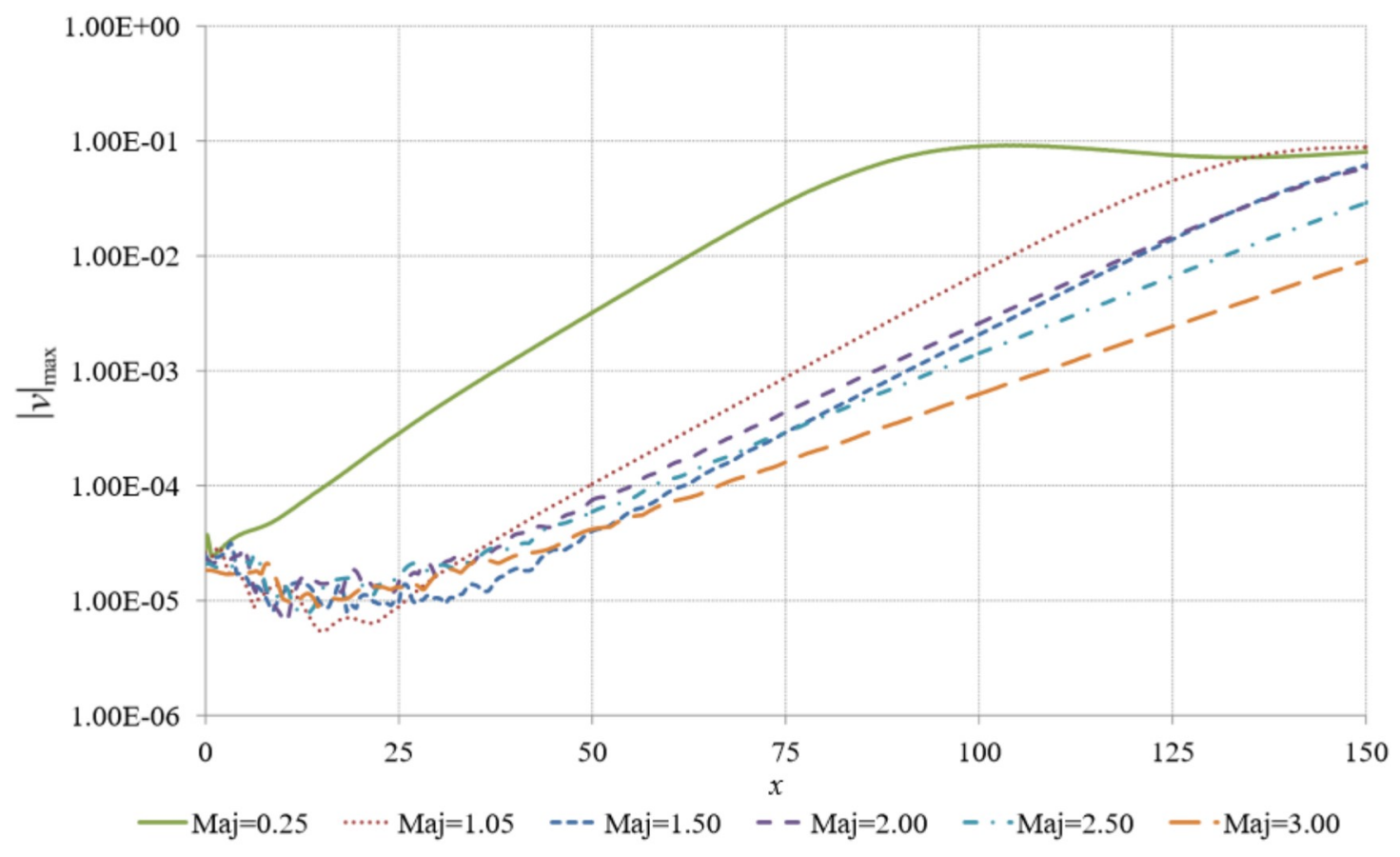

Fonte: Elaborada pelo autor.

Figura 49 - Amplitude máxima da vel ocidade normal v ao longo de y para o modo varicoso.

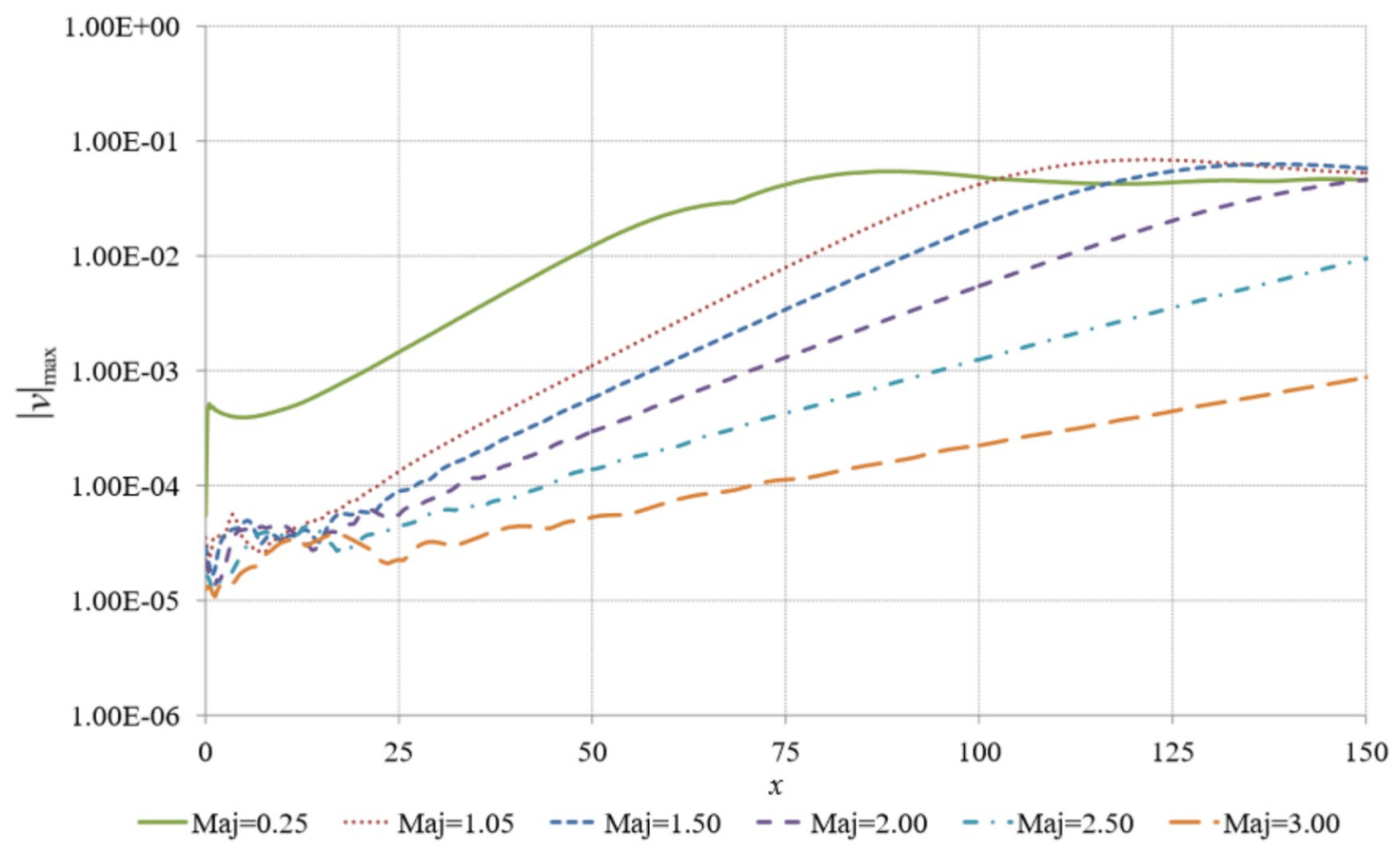

Fonte: Elaborada pelo autor. 
Figura 50 - Máxima amplitude da vel oci dade normal $v$ ao longo da direção y para cada posição $x$, para o modo sinuoso. Linhas sólidas: resultados com o presente código e linhas tracejadas: resul tados obtidos com o código LST.
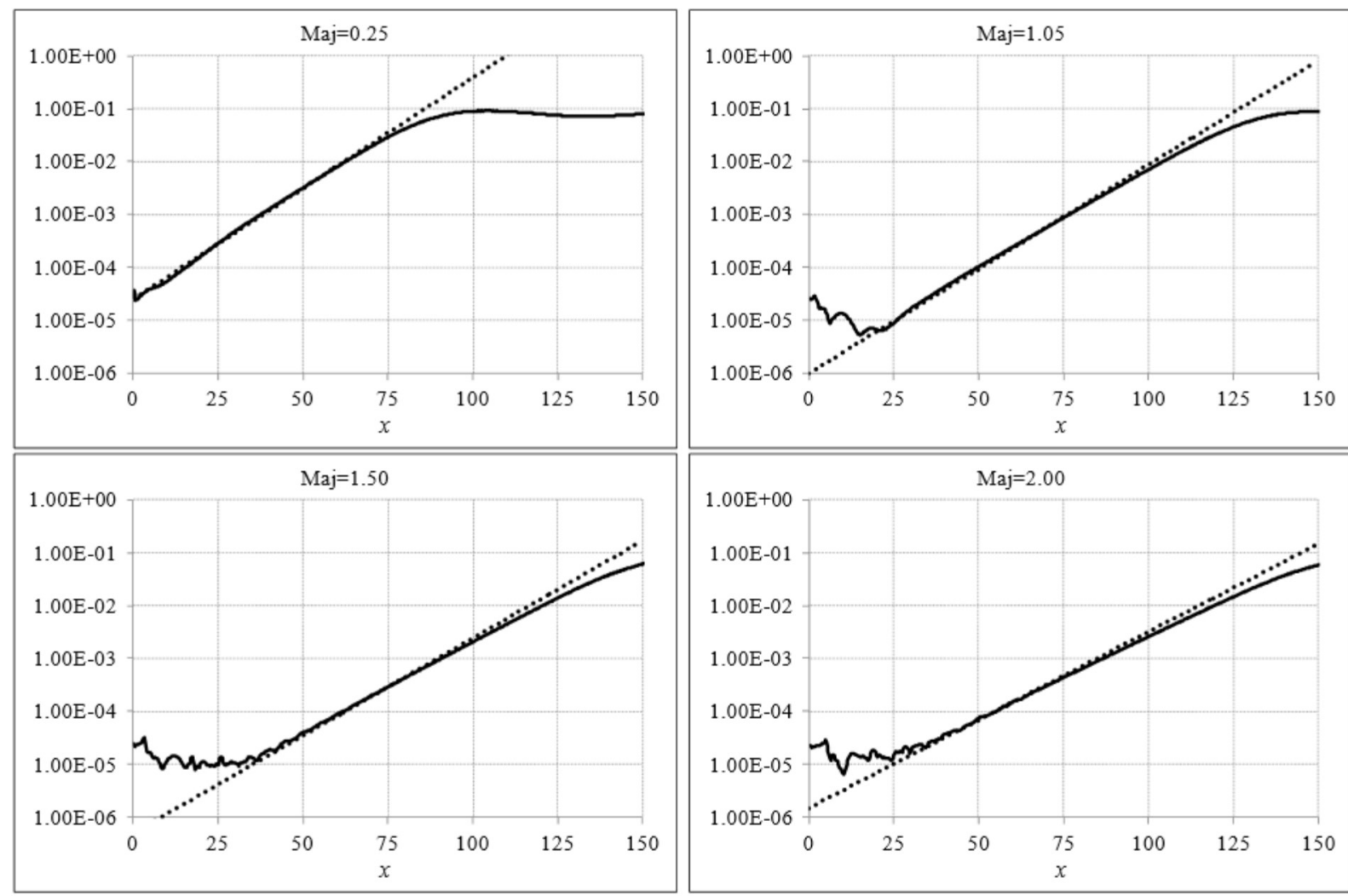

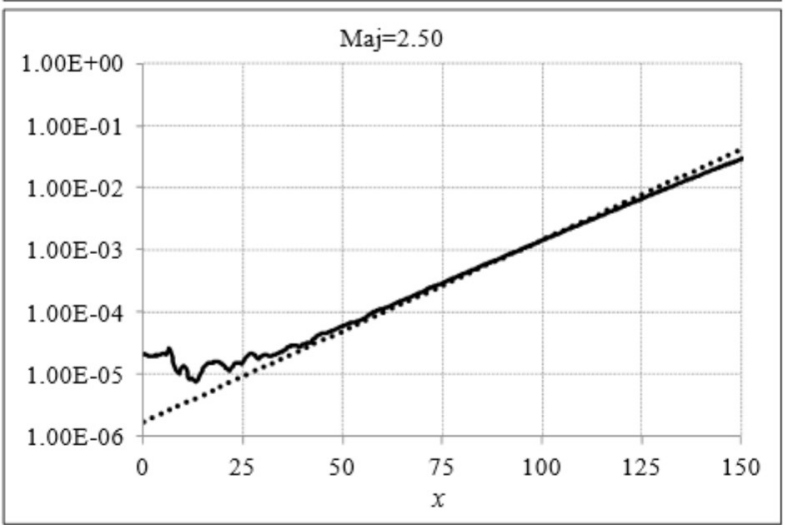

DNS

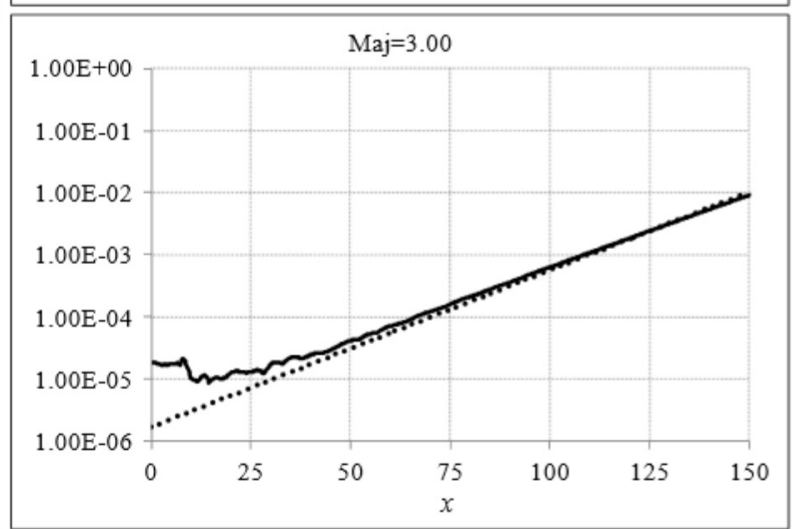

LST

Fonte: Elaborada pelo autor.

Novamente, uma forma de se visual izar a geração e propagação de som no escoamento é através do divergente da velocidade. Foi real izada uma análi ise de Fourier do campo de dilatação. Foram tomados 8 pontos por frequência fundamental ao longo dos 8 últimos períodos simulados, correspondendo a um total 64 pontos disponíveis para fazer a análise de Fourier. Uma subrotina de transformada rápi da de Fourier foi adaptada para real izar essa anál ise.

Da Figura 52 à Figura 57 são apresentados os divergentes de vel ocidades para os dois 
Figura 51 - Máxima amplitude da velocidade normal v ao longo da direção y para cada posição x, para o modo varicoso. Linhas sólidas: resul tados com o presente códi go e linhas tracejadas: resultados obtidos com o código LST.
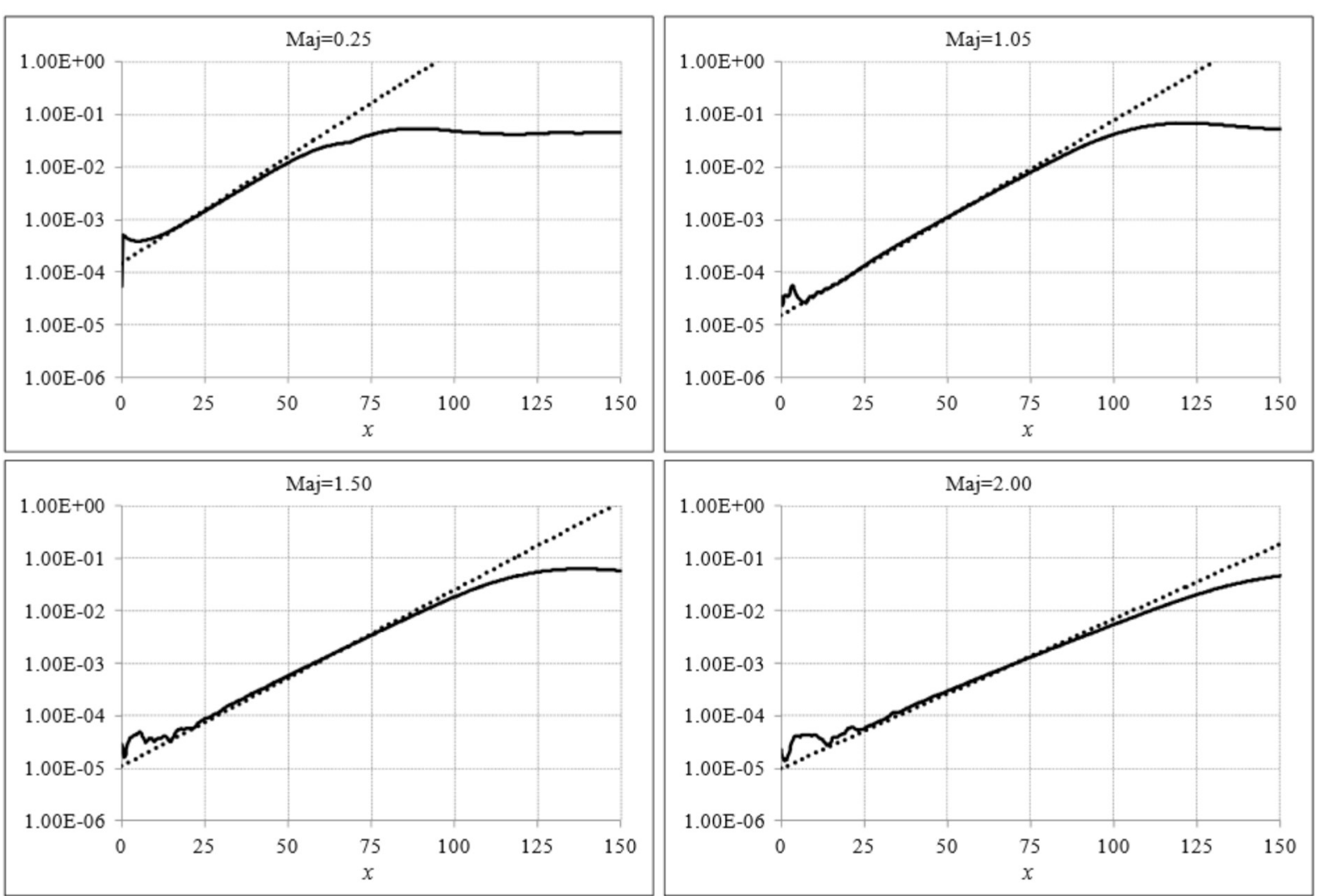

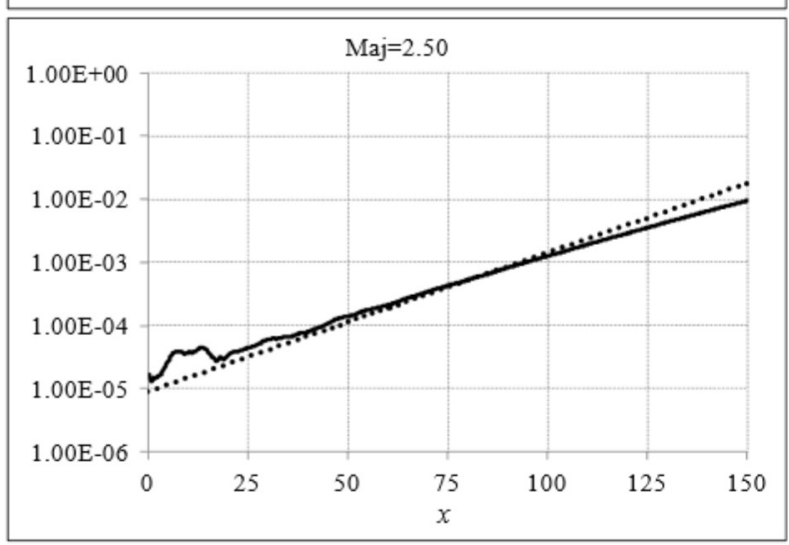

DNS

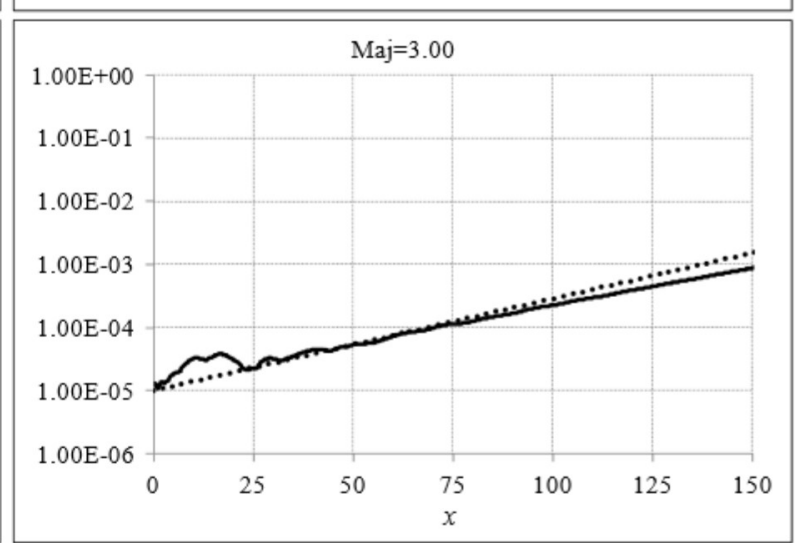

LST

Fonte: Elaborada pelo autor.

modos (sinuoso e varicoso), para os diferentes casos variando $\mathrm{Ma}_{\mathrm{j}}$ e para frequência fundamental w e suas subharmonicas $(w=2, w=4$ e w=8). É possível destacar alguns pontos:

1. Jatos subsônicos $\left(\mathrm{Ma}_{\mathrm{j}}=0 ; 25\right)$

- Frentes de ondas geradas pela introdução de perturbações na entrada se propagam a jusante, deixando o domínio sem produzir reflexão de ondas espúrias para dentro do 
domínio computacional (particularmente percebido para as frequências $w$ e $w=2$ :

- Para a mesma frequência, há uma menor variação da amplitude de - u para o modo sinuoso do que para o modo varicoso

- Para o modo sinuoso, é observado que o pareamento dos vórtices assimétricos criam uma nova fonte de som no final do jato central, o qual não é evidente para os vórtices simétricos do modo varicoso.

2. Jatos supersônicos $\left(\mathrm{Maj}_{\mathbf{j}} \geq 1 ; 05\right)$

- Para a frequência fundamental w, observa-se forte deformação dos frentes de onda originados pela perturbação na do domínio. A deformação ocorre devido à interefência destas ondas com frentes de ondas obl íquas de al ta frequência (particularmente visível para $\mathrm{Maj}_{\mathrm{j}}=1 ; 05 \mathrm{e} 1 ; 50$ ), com ângulo menor para número de Mach mais elevados.

- Para as frequências subharmônicas $w=2$ ew=4, frentes de ondas de al ta frequência são originados na região de saí da, propagando-se à montante na direção oposta ao escoamento.

- Para a frequência subharmônica $w=8$ e para número de $M a c h M_{j} \geq 1 ; 50$, frentes de ondas oblíquas perfeitamente planas ( com ângulo menor para número de Mach mais elevado) propagam-se à montante na direção oposta ao escoamento.

\section{Resumo}

Nesse capítul o foram apresentados primei ramente a metodol ogia de aval iação segundo - Método das Sol uções Manufaturadas e os resul tados obtidos dessa anál ise, mostrando que a versão bidimensional e tridimensional estão livres de erros de implementação pois foram obtidas as ordens formais dos métodos de discretização utilizados. É importante destacar também que obteve-se bons resultados no cál culo do divergente do campo de vel ocidades, que corresponde à propagação de som no escoamento, mostrando que o código é apropriado para apl icação em aeroacústica computacional.

Posteriormente, foram propostos problemas reais de escoamento com resultados publicados em literatura vigente para comparação. $O$ caso da camada de mistura bi dimensional apresentou boa concordância com os resul tados apresentados por Babucke, Kloker e Rist (2008) e com a Teoria de Estabilidade Linear. Já nos casos de jatos planares bidimensionais estendeu-se um pouco mais a avaliação através do estudo de perturbações do modo sinuoso e varicoso, apresentando boas comparações com os resultados apresentados por Weder (2012). Para mai ores investigações desse tipo de escoamento também foram anal isados diversos casos de jatos planares apresentados por Reichert e Biringen (2007), tanto para o modo sinuoso quanto para o modo 
Figura 52 - Divergente da velocidade dos casos sinuoso e varicoso com Maj $=0$; 25 para (a) w; (b) w=2; (c) w=4 e (d) $w=8$.

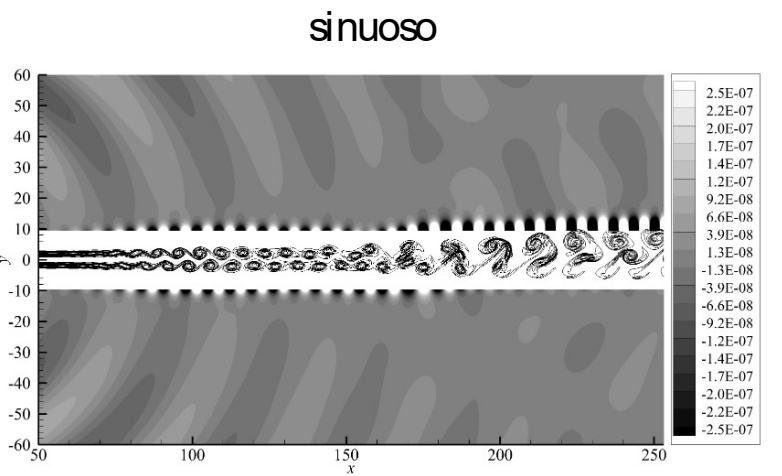

(a.1)

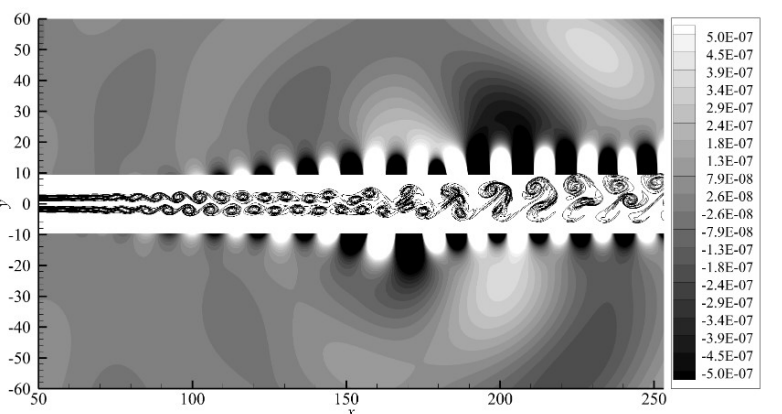

(b.1)

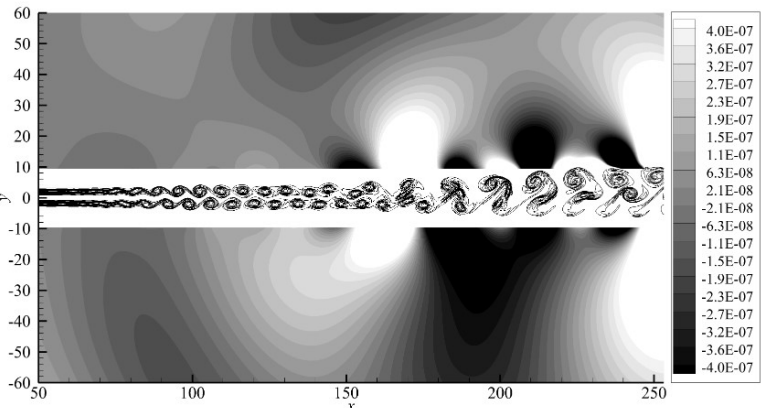

(c.1)

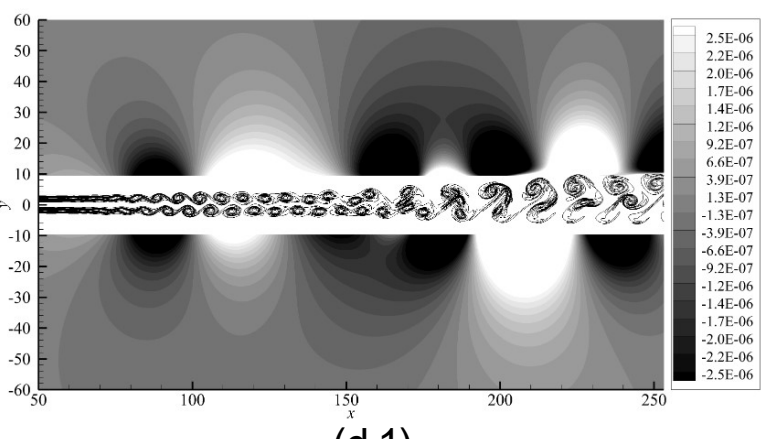

(d.1)

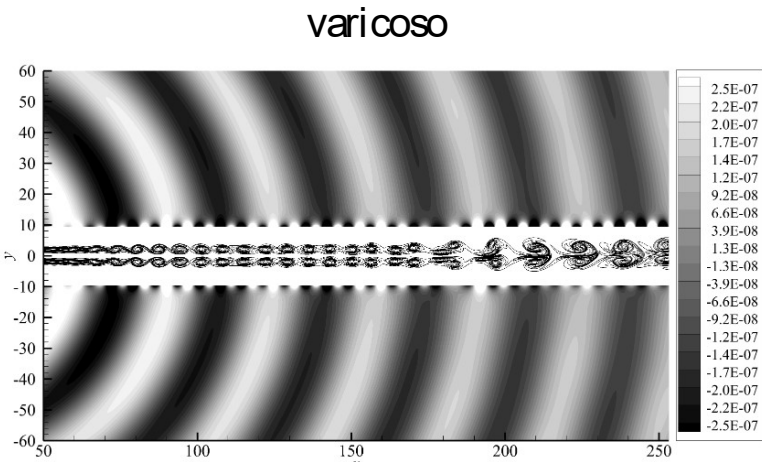

(a.2)

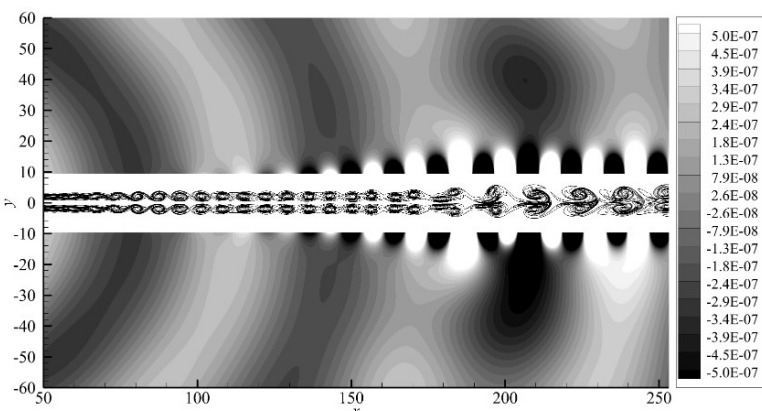

(b.2)

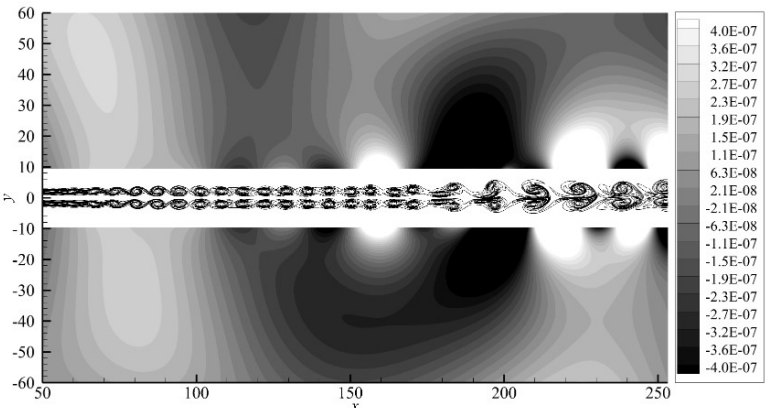

(c.2)

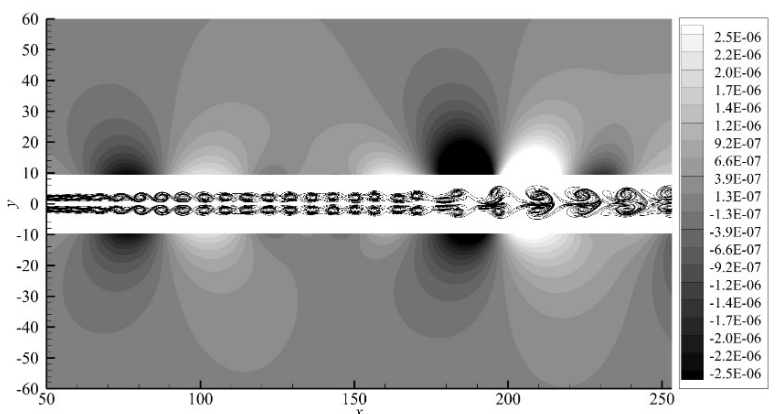

(d.2)

Fonte: Elaborada pelo autor.

varicoso. Boa concordância foi obtida com a Teoria de Estabilidade Linear. Todas essas etapas indicam que o código está sati sfatoriamente verificado e adequado para ser utilizado em anál ises 
Figura 53 - Divergente da velocidade dos casos sinuoso e varicoso com Maj $=1 ; 05$ para (a) w; (b) w=2; (c) w=4 e (d) $w=8$.

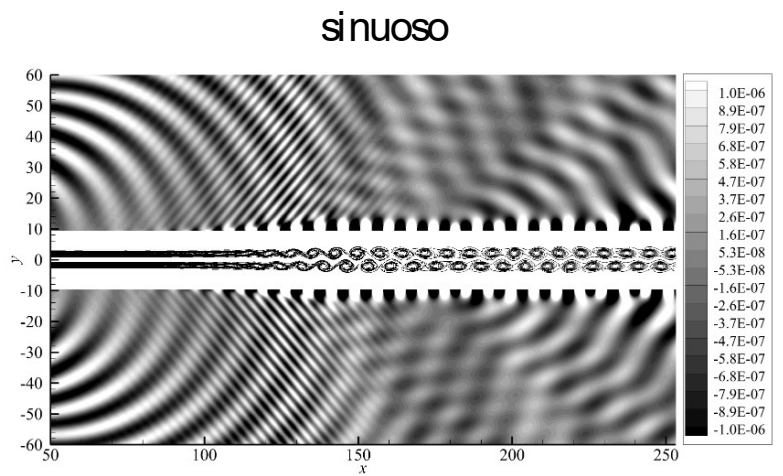

(a.1)

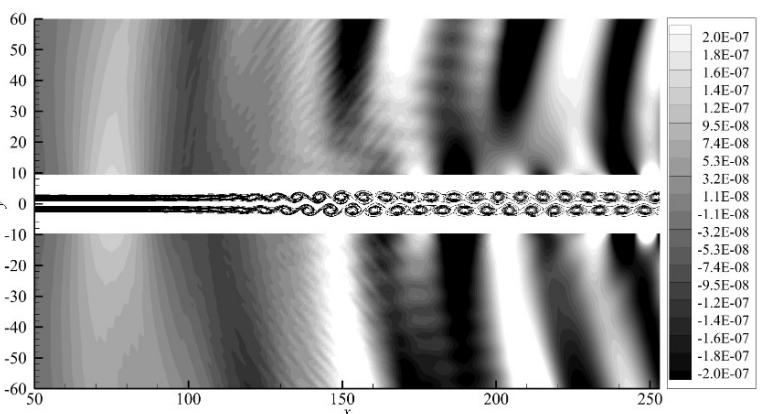

(b.1)

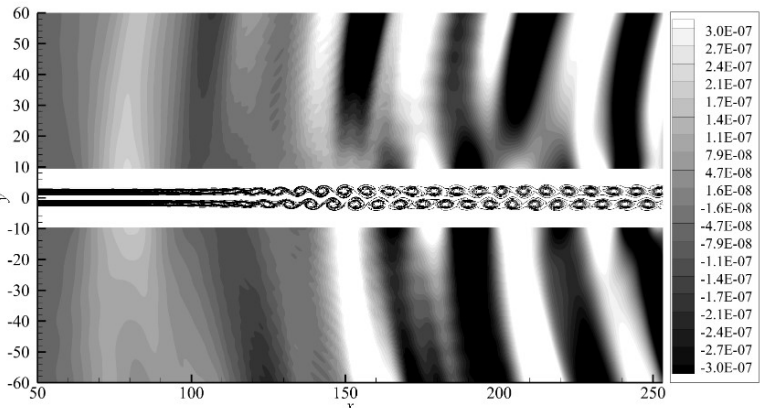

(c.1)

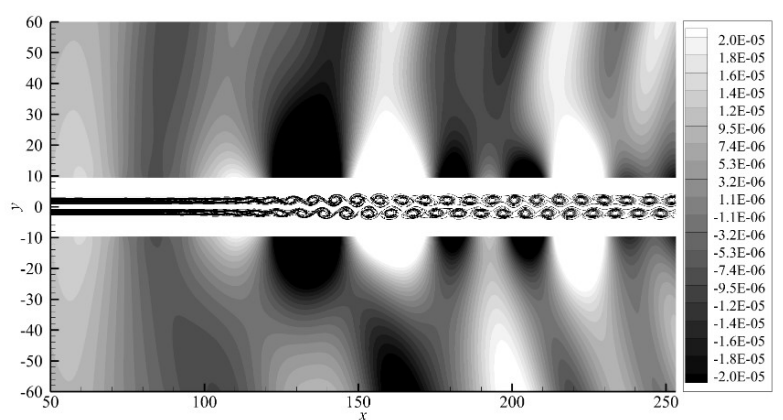

(d.1)

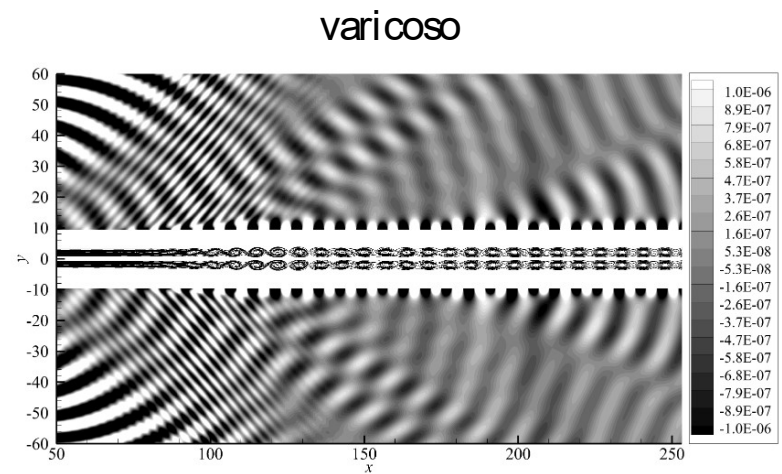

(a.2)

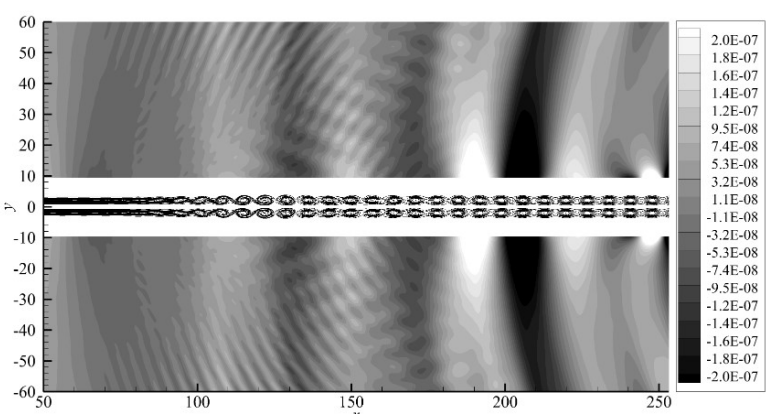

(b.2)

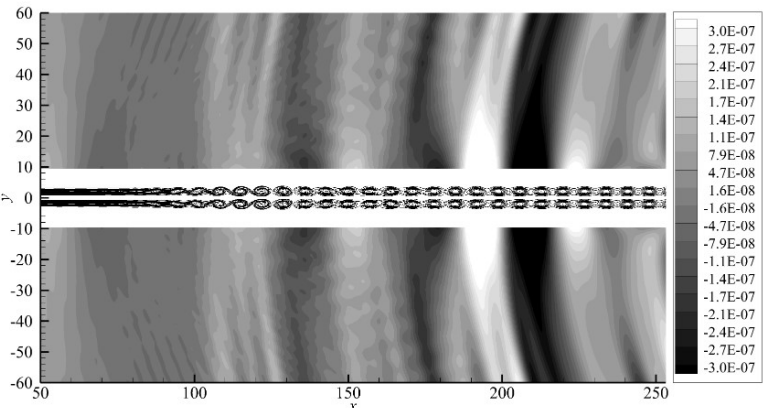

(c.2)

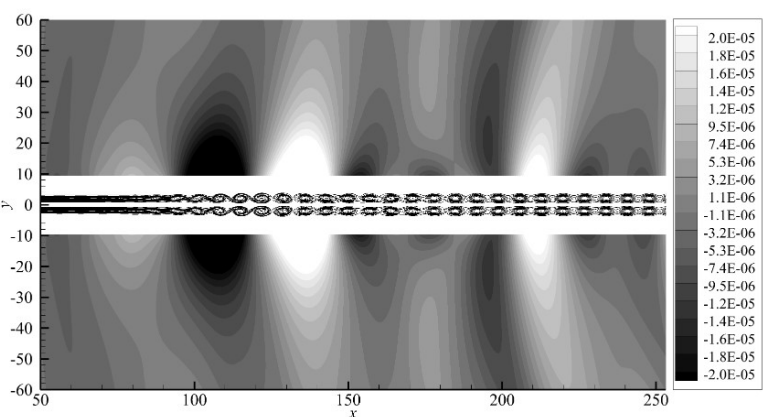

(d.2)

Fonte: Elaborada pelo autor.

de outros problemas de escoamentos para estudo de aeroacústica. 
Figura 54 - Divergente da velocidade dos casos sinuoso e varicoso com $\mathrm{Ma}_{\mathrm{j}}=1 ; 50$ para (a) w; (b) w=2; (c) w=4 e (d) $w=8$.

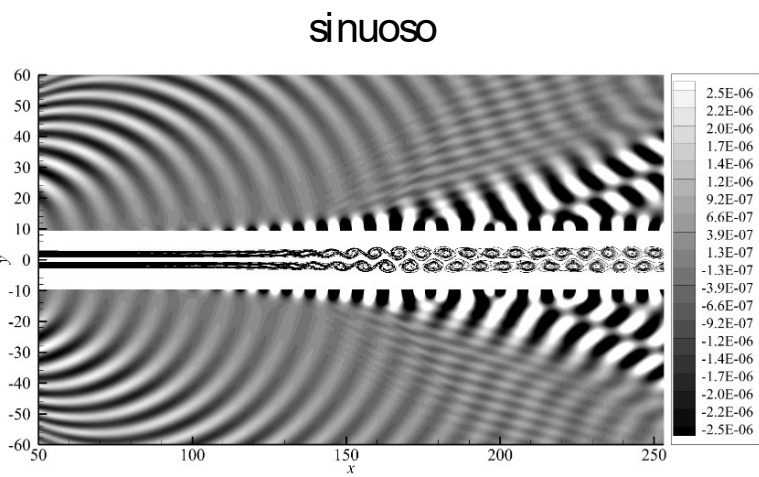

(a.1)

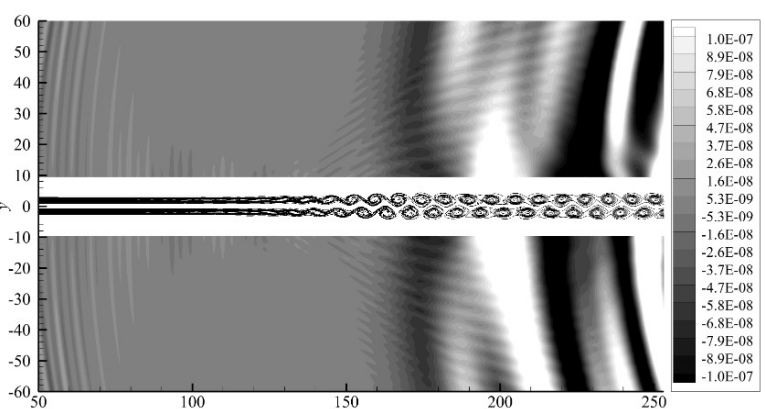

(b.1)

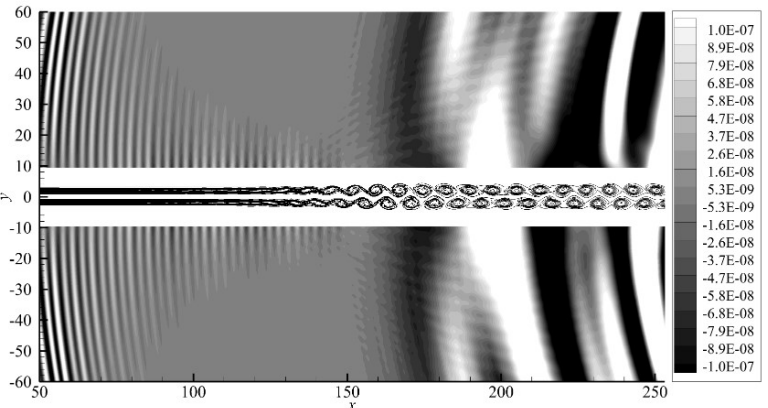

(c.1)

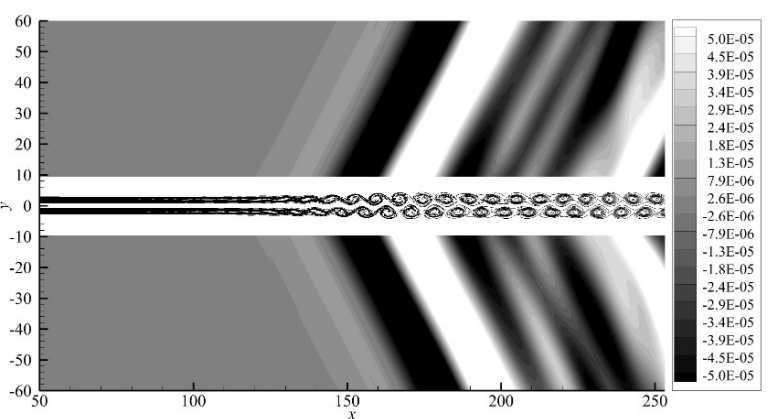

(d.1)

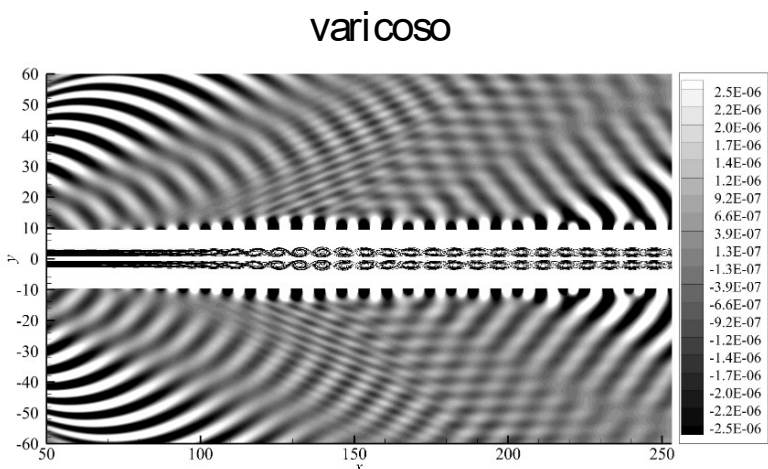

(a.2)

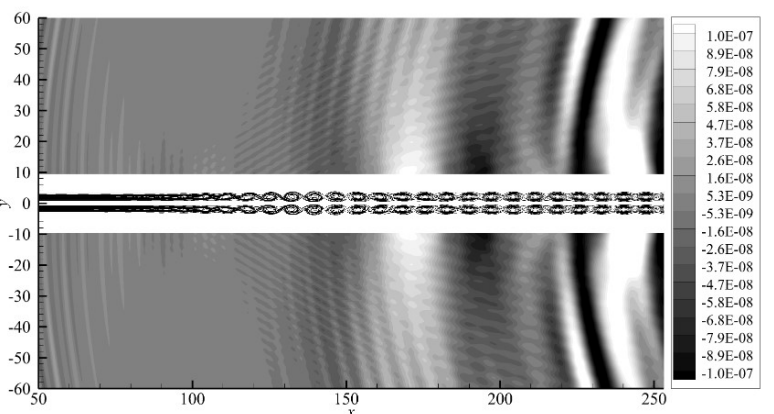

(b.2)

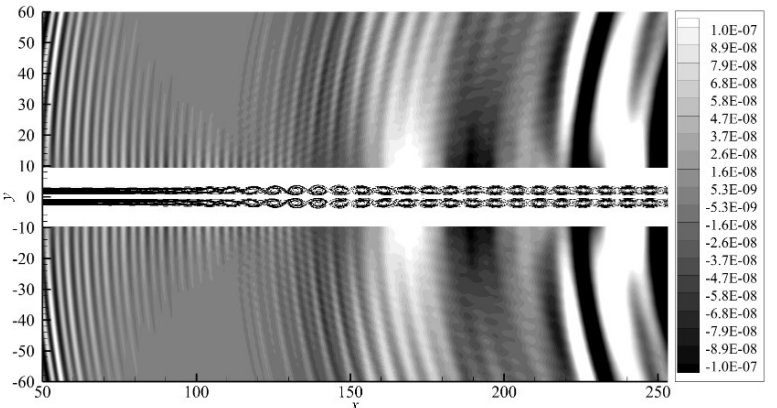

(c.2)

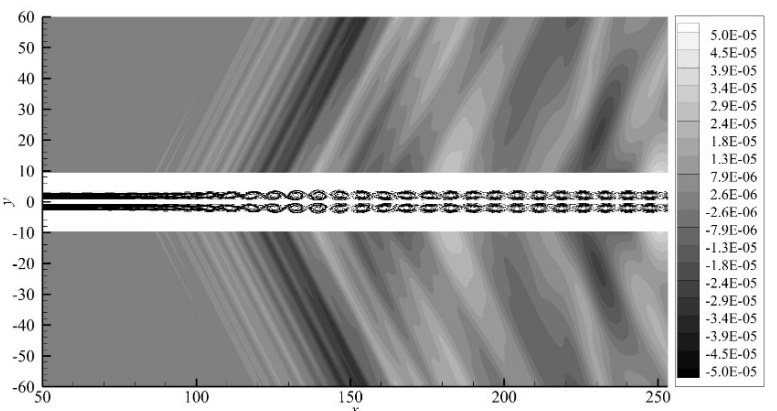

(d.2)

Fonte: Elaborada pelo autor. 
Figura 55 - Divergente da velocidade dos casos sinuoso e varicoso com $\mathrm{Ma}_{\mathrm{j}}=2$ 2; 00 para (a) w; (b) w=2; (c) w=4 e (d) $w=8$.

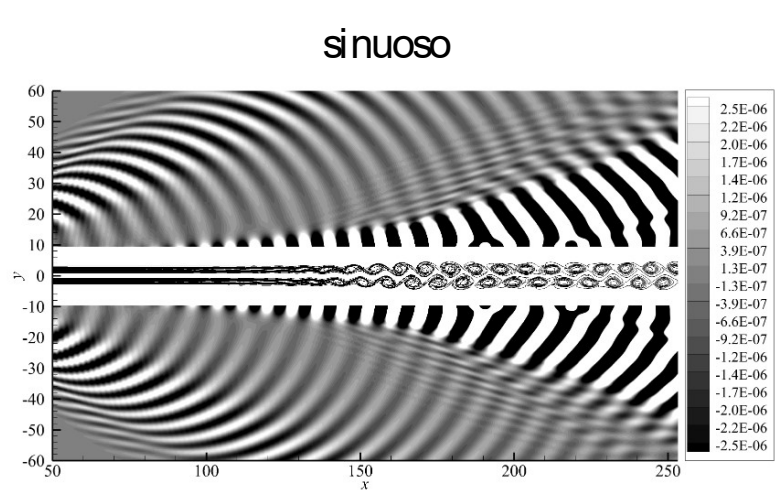

(a.1)

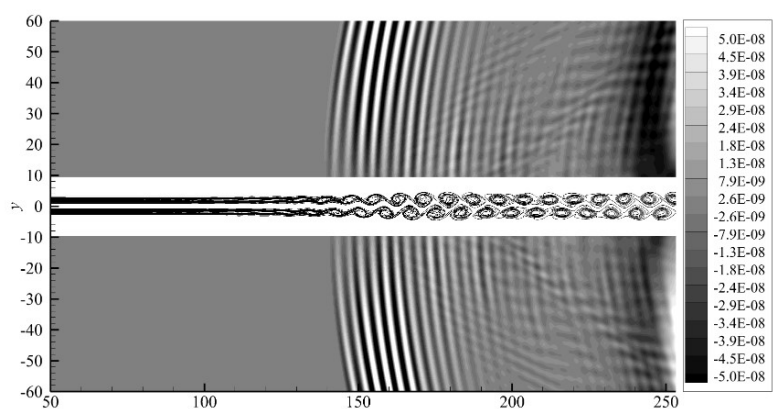

(b.1)

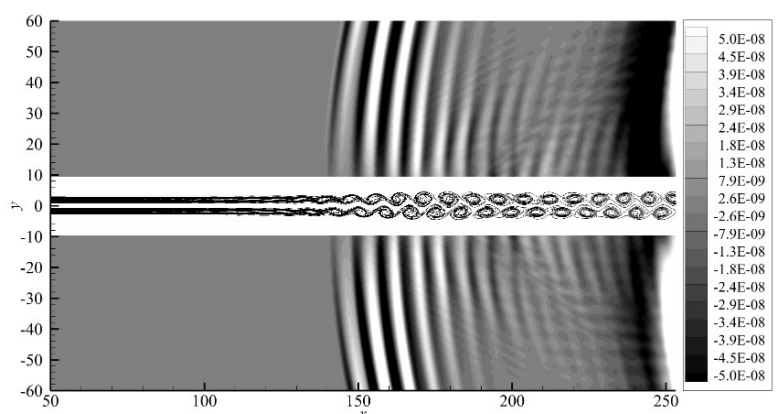

(c.1)

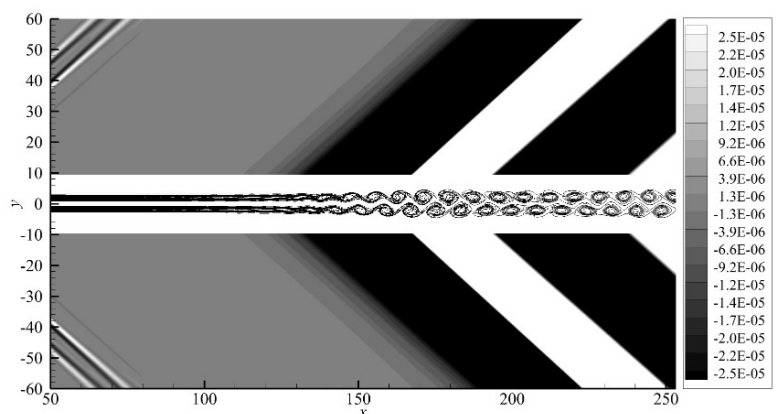

(d.1) varicoso

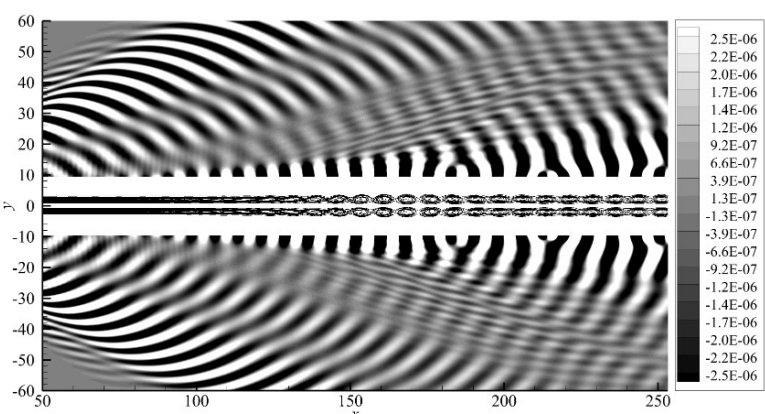

(a.2)

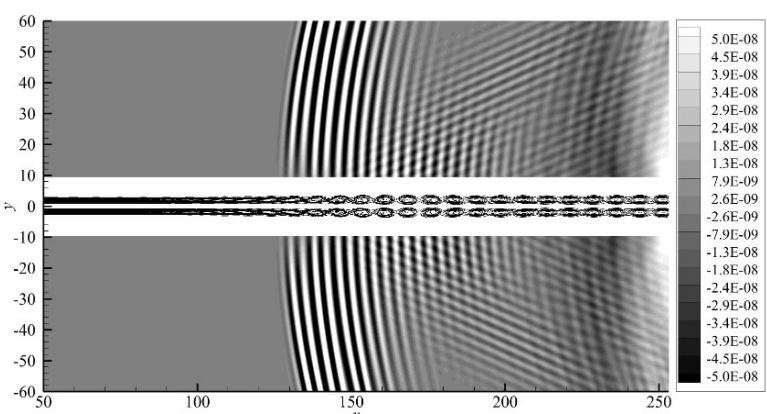

(b.2)

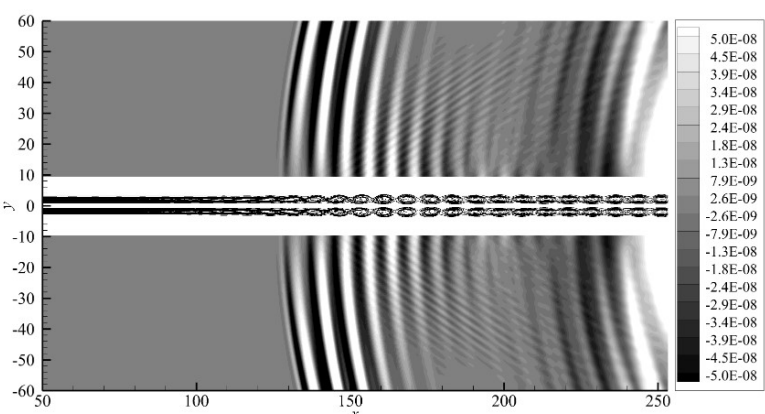

(c.2)

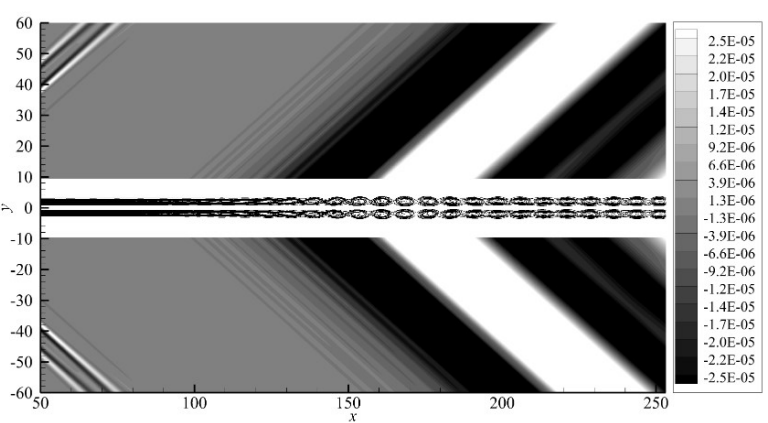

(d.2)

Fonte: Elaborada pelo autor. 
Figura 56 - Divergente da velocidade dos casos sinuoso e varicoso com Maj = 2;50 para (a) w; (b) w=2; (c) w=4 e (d) $w=8$.

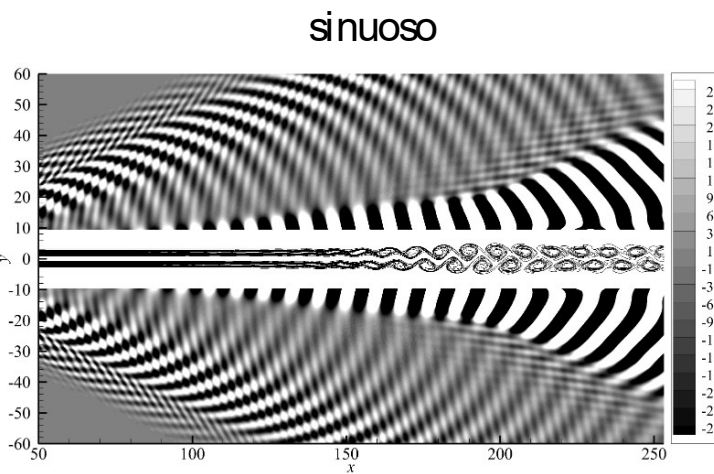

(a.1)

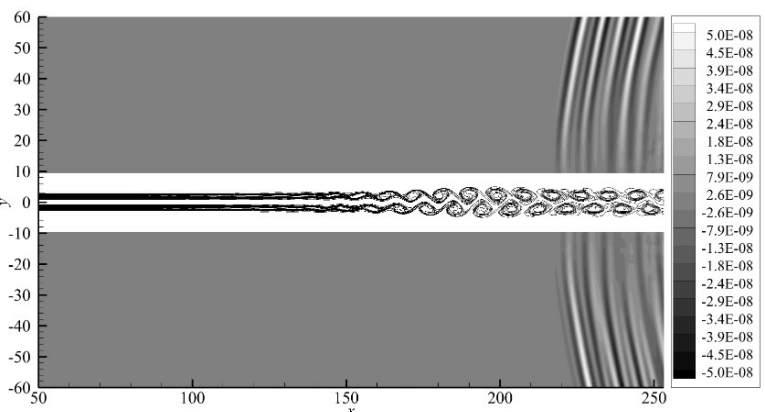

(b.1)

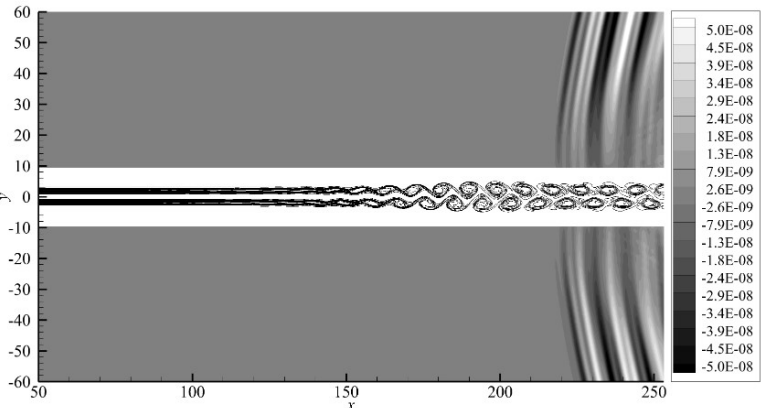

(c.1)

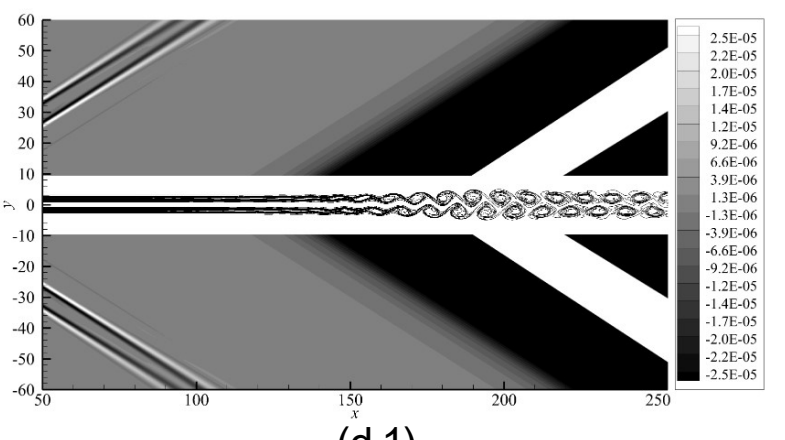

(d.1)

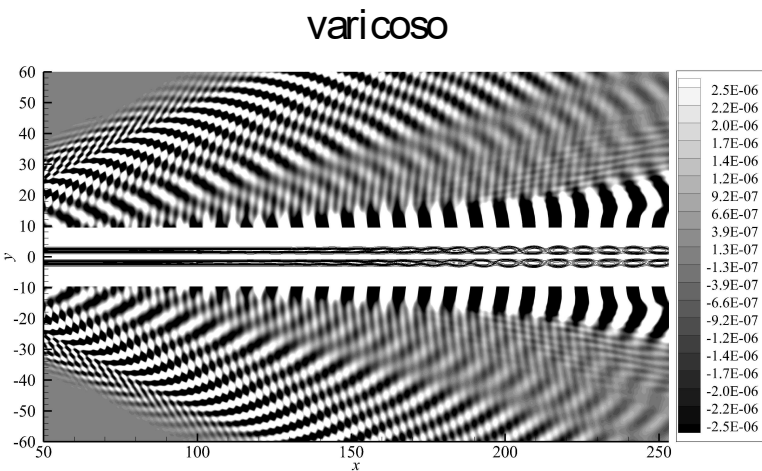

(a.2)

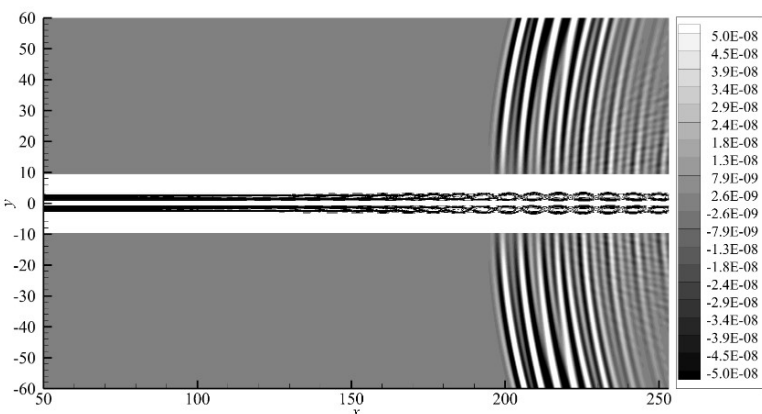

(b.2)

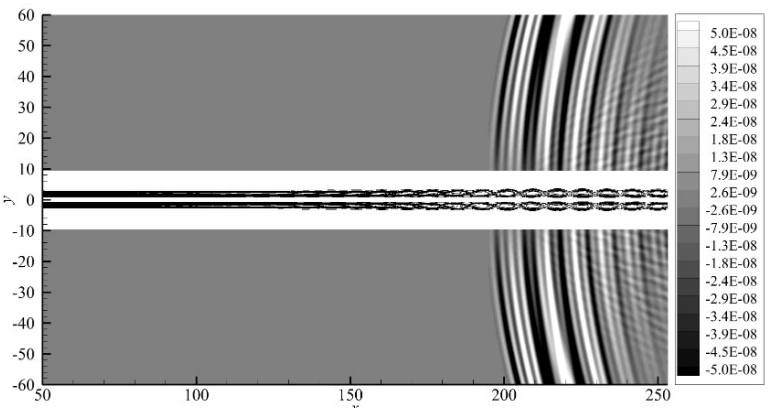

(c.2)

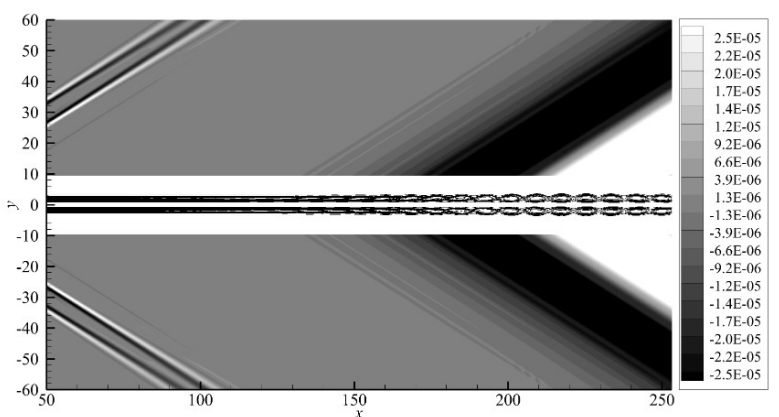

(d.2)

Fonte: Elaborada pelo autor. 
Figura 57 - Divergente da velocidade dos casos sinuoso e varicoso com Maj $=3 ; 00$ para (a) w; (b) w=2; (c) w=4 e (d) $w=8$.

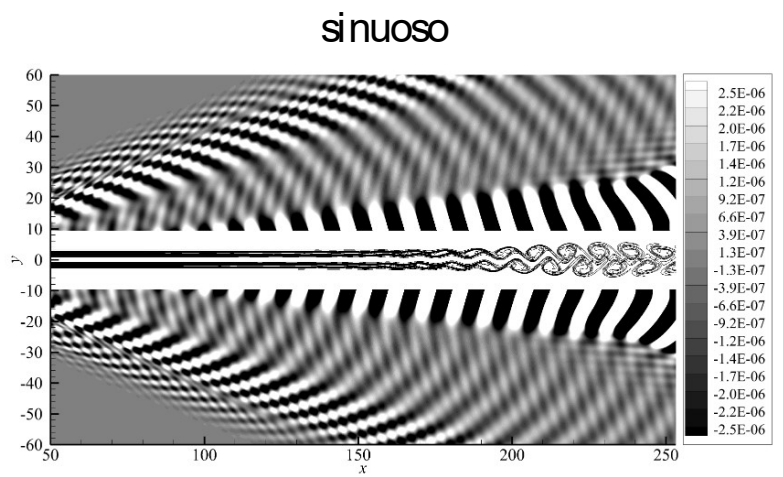

(a.1)

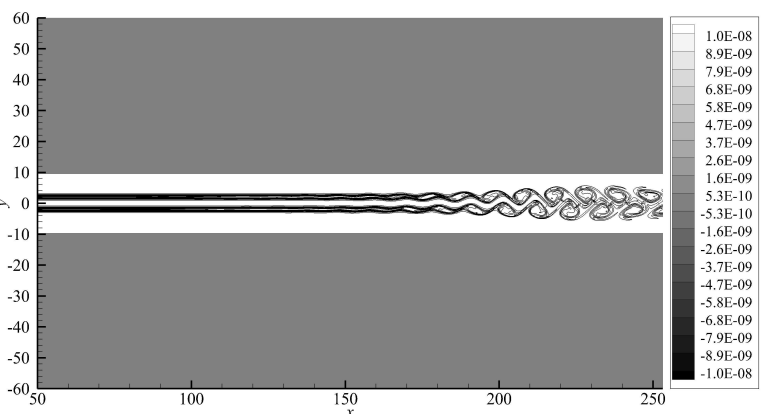

(b.1)

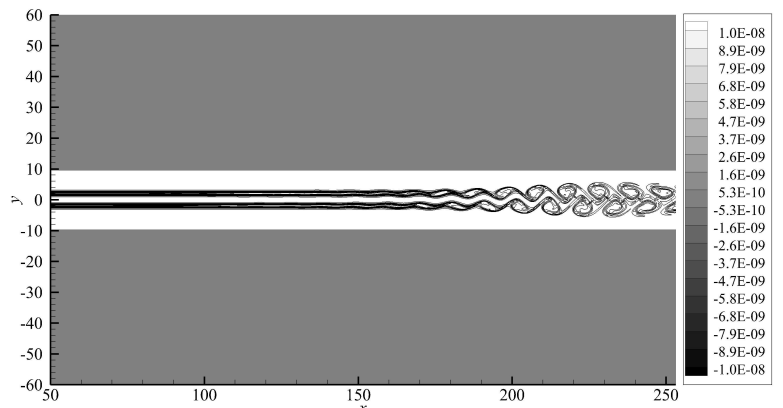

(c.1)

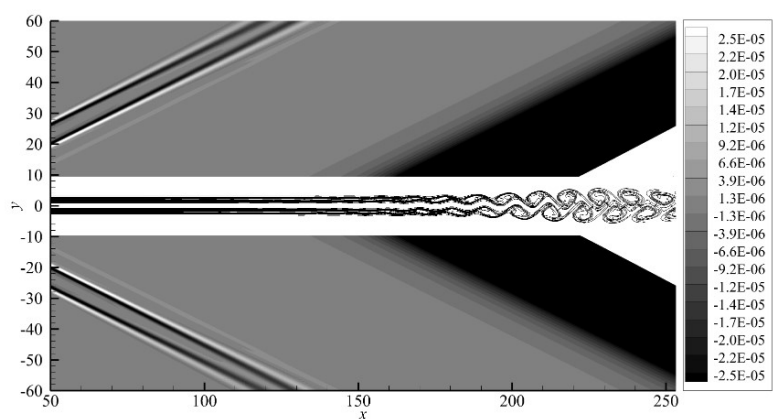

(d.1)

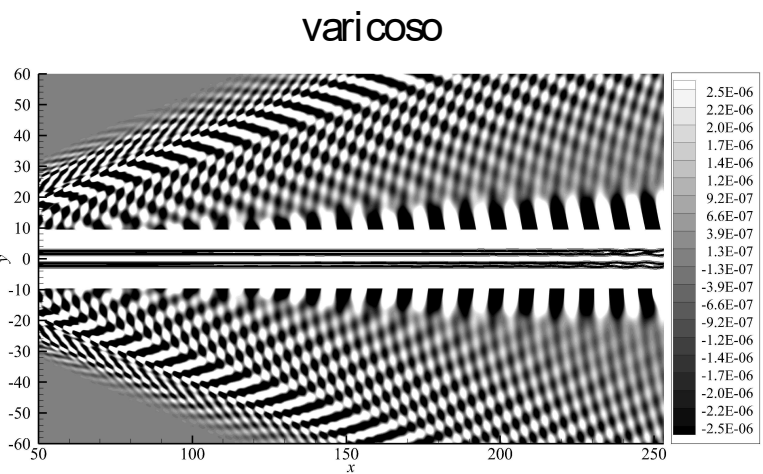

(a.2)

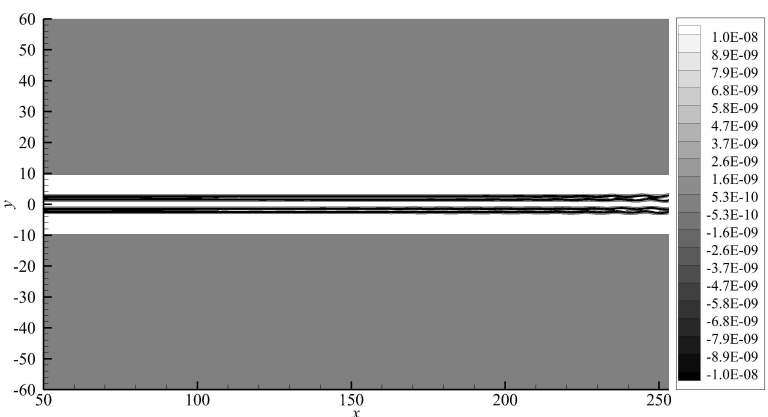

(b.2)

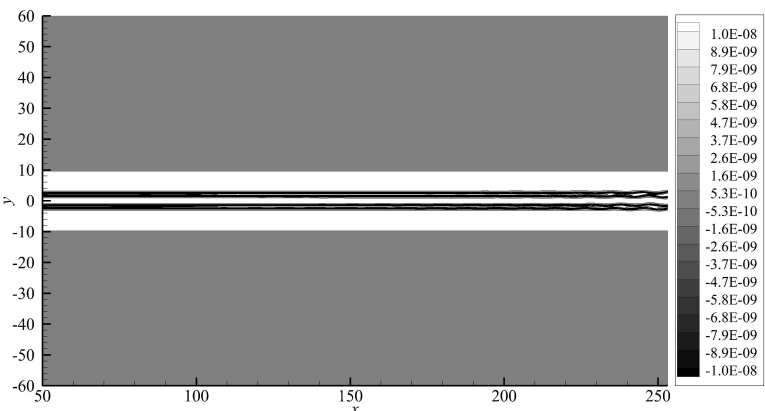

(c.2)

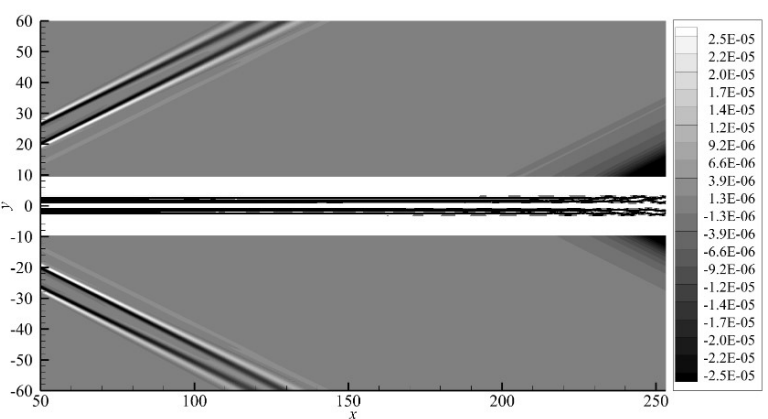

(d.2)

Fonte: Elaborada pel o autor. 
CAPÍTULO

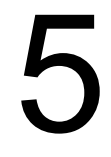

\section{CONCLUSÕES E SUGESTÕES PARA TRABALHOS FUTUROS}

\section{Conclusões}

A predição do som gerado por escoamento, em particular aquele gerado em vál vulas de compressores herméticos de refrigeradores domésticos, foi a principal motivação para real ização desse trabal ho; e que levou ao objetivo de ini ciar o desenvolvimento de um código computacional para simular problemas de aeroacústica. O presente trabal ho apresentou todas as etapas envolvidas na implementação e verificação desse código numérico. Optou-se, para isso, pela utilização de simul ação numérica direta (DNS) onde há ausência de modelagem de turbulência e de anal ogias acústicas, sendo a geração do som e sua propagação cal culados diretamente no código.

Devido às características de problemas acústicos (por exemplo: multiplicidade de escalas e frequências, propagação a longas distâncias), o código possui processamento paral elo com decomposição de domínio para poder simular usando DNS em um tempo factível; esquemas de discretização espaciais e temporais de al ta ordem para mi nimizar ao máximo os fenômenos de dissipação e dispersão das ondas acústicas; e uma série de tratamentos no domínio como filtragem e estiramento da mal ha como também condições de contorno não-reflexivas como intuito de obter uma solução adequada para estudo de aeroacústica.

O Método das Soluções Manufaturadas foi utilizado para avaliar a implementação do código. Um processo formal consiste em executar o programa usando diversas mal has com refinamentos progressivos entre elas e avaliar os erros de discretização e a ordem de precisão da solução. Foi obtida boa concordância nessa etapa mostrando que a versão bidimensi onal e tridimensional estão livres de erros de implementação pois foram obtidas as ordens formais dos métodos de discretização utilizados. É importante destacar também que obteve-se bons 
resultados no cál culo do divergente do campo de velocidades, que corresponde à propagação de som no escoamento, mostrando que o código é apropriado para aplicação em aeroacústica computacional.

Por fim, também foram simulados problemas de escoamentos com resultados publicados em literatura vigente para comparação. $O$ caso da camada de mistura bidimensional apresentou boa concordância com os resultados apresentados por Babucke, Kloker e Rist (2008) e com a Teoria de Estabilidade Linear. Já nos casos de jatos planares bidimensionais estendeu-se um pouco mais a avaliação através do estudo de perturbações do modo sinuoso e varicoso, apresentando boas comparações com os resultados apresentados por Weder (2012). Para mai ores investi gações desse tipo de escoamento também foram anal isados diversos casos de jatos planares apresentados por Reichert e Biringen (2007), tanto para o modo si nuoso quanto para o modo varicoso. Boa concordância foi obtida com a Teoria de Estabilidade Linear. Todas essas etapas demonstram que o código está satisfatoriamente verificado e adequado para ser utilizado em anál ises de outros problemas de escoamentos para estudo de aeroacústica.

\section{Sugestões para Trabalhos Futuros}

São sugestões para trabal hos futuros:

- Implementação de solução de problemas tridimensionais de escoamentos cisal hantes;

- Extensão do código computacional para coordenadas curvilíneas tridimensionais para simulação de jatos planares circunferenciais, buscando resolver escoamentos em difusores radiais como uma primeira aproximação aos escoamentos em vál vul as de compressores de refriegeração

A primorar as anál ises acústicas obtidas a partir dos resultados de simul ação apresentados no presente trabal ho. 


\section{REFERÊNCIAS}

ADAM, Y. Highly accurate compact implicit methods and boundary conditions. Journal of Computational Physics, v. 24, p. 10-22, 1977. Citado na página 55.

ANDERSON, J. D. Computational Fluid Dynamics. [S.I.]: McGraw-Hill, 1995. Citado na página 53.

BABUCKE, A. Direct Numerical Simulation of Noise-Gener ation Mechanisms in the Mixing Layer of a Jet. Tese (Doutorado) - University of Stuttgart, 2009. Citado 8 vezes nas páginas $27,31,50,53,62,63,86$ e 87.

BABUCKE, A.; KLOKER, M.; RIST, U. Dns of a plane mixing layer for the investigation of sound generation mechanisms. Computers and Fluids, v. 37, n. 4, p. $360-368,2008$. Citado 13 vezes nas páginas $16,51,73,87,88,89,91,92,93,94,95,110$ e 118 .

BAILLY, C.; BOGEY, C. Contributions of computational aeroacoustics to jet noise research and prediction. International Journal of Computational Fluid Dynamics, v. 18, n. 6, p. 481-491, 2004. Citado na página 31.

BERANEK, L. L.; VéR, I. L. Noise and Vibration Control Engineering: Principles and Applications. [S.I.]: John Wiley and Sons, 1992. Citado na página 31.

BOERSMA, B. J. Numerical simulation of the noise generated by a low mach number, low reynolds number jet. Fluid Dynamics Research, v. 35, n. 6, p. 425 - 447, 2004 . Citado na página 31.

BOGEY, C.; BAILLY, C. Computation of a high reynol ds number jet and its radiated noise using large eddy simulation based on explicit filtering. Computers and Fluids, v. 35, n. 10, p. $1344-$ 1358, 2006. Citado na página 31.

CEMEAI-ICMC-USP. Cluster Euler . 2016. Disponível em: <http://www.cemeai .icmc.usp.br/ Euler/index.html>. Acesso em: 05/02/2016. Citado na página 49.

COLONIUS, T.; LELE, S. K. Computational aeroacoustics: progress on nonlinear problems of sound generation. Progress in Aerospace Sciences, v. 40, n. 6, p. 345-416, 2004 . Citado 2 vezes nas páginas 36 e 60 .

COLONIUS, T.; LELE, S. K.; MOIN, P. Boundary conditions for di rect computation of aerodynamic sound generation. In: 14th DGLR/AIAA Aer oacoustics Conference. [S.I.: s.n.], 1992. p. 438-447. Citado na página 68.

Sound generation in a mixing layer. Journal of Fluid Mechanics, v. 330, p. 375-409, 1997. Citado 7 vezes nas páginas 16, 51, 73, 87, 91, 92 e 95.

CURLE, N. The influence of solid boundaries upon aerodynamic sound. Proceedings of the Royal Society of L ondon. Series A, Mathematical and Physical Sciences, The Royal Society, v. 231 , n. 1187 , p. pp. 505-514, 1955. Citado na página 34. 
DAINEZI, J. ao H. R. Avaliação de For mação e Remoção de Aliasing em Métodos Espectrais. [S.I.]: FAPESP, ICMC - USP, 2012. Citado na página 58.

EROL, H.; GURDOGAN, A. The noise and vibration characteristics of a reciprocating compressor: Effects of size and profile of discharge port. In: Proceedings of the 2000 International Compressor Engineering Conference at Pur due. Purdue- US: [s.n.], 2000. Citado na página 33.

FAHY, F. Foundations of Engineering Acoustics. [S.I.]: Academic Press, 2003. Citado 2 vezes nas páginas 30 e 31 .

FFOWCSWILLIAMS, J. E.; HAWKINGS, D. L. Sound generation by turbulence and surfaces in arbitrary motion. Philosophical Transactions of the Royal Society of London. Series A, Mathematical and Physical Sciences, The Royal Society, v. 264, n. 1151, p. pp. 321-342, 1969. Citado na página 34 .

FREUND, J. B. Noise sources in a low-reynolds-number turbulent jet at mach 0.9 . Journal of Fluid Mechanics, v. 438, p. 277-305, 2001. Eng. Citado na página 31.

GROPENGIESSER, H. Study on the Stability of Boundary Layers in Compressible Fluids. [S.I.]: S.I., 1970. Citado na página 45.

HIRSH, R. S. Higher order accurate difference solutions of fluid mechanics problems by a compact differencing technique. Journal of Computational Physics, v. 19, n. 1, p. $90-109$, 1975. Citado na página 55.

KINSLER, L. E.; FREY, A. R.; COPPENS, A. B.; SANDERS, J. V. Fundamentals of acoustics. [S.I.]: Wiley, 2000. ISBN 9780471847892. Citado na página 34.

KUNDU, P.; COHEN, I. M. Fluid Mechanics. [S.I.]: Academic Press, 2002. Citado na página 43.

LACERDA, J. F. Simulação Numérica do Escoamento em Vál vulas de Compr essor es Herméticos de Refriger ação usando o Método da Fronteir a I mer sa. Dissertação (Mestrado) Universi dade Estadual Paul ista, 2009. Citado 2 vezes nas páginas 28 e 33.

LELE, S. K. Compact finite difference schemes with spectral-like resolution. Journal of Computational Physics, v. 103, p. 16-42, 1992. Citado 7 vezes nas páginas $54,55,59,60,61,62$ e 68.

LIGHTHILL, M. J. On sound generated aerodynamically. i. general theory. Proceedings of the Royal Society of London. Series A. Mathematical and Physical Sciences, v. 211, n. 1107, p. 564-587, 1952. Citado na página 33.

On sound generated aerodynamically. ii. turbulence as a source of sound. Proceedings of the Royal Society of London. Series A, Mathematical and Physical Sciences, The Royal Society, v. 222, n. 1148, p. pp. 1-32, 1954. Citado na página 33.

LUSK, E.; DOSS, N.; SKJELLUM, A. A high-performance, portable implementation of the mpi message passing interface standard. Par allel Computing, v. 22, p. 789-828, 1996. Citado na página 50.

MAHESH, K. A family of high order finite difference schemes with good spectral resolution. Journal of Computational Physics, v. 145, p. 332-358, 1998. Citado na página 55. 
MARIANI, V. C.; PRATA, A. T.; DESCHAMPS, C. J. Numerical analysis of fluid flow through radial diffusers in the presence of a chamfer in the feeding orifice with a mixed eulerianlagrangian method. Computers and Fluids, v. 39, n. 9, p. 1672 - 1684, 2010. Citado na página 33.

MENDONçA, M. T. Código numérico: Teoria de estabilidade linear. Código numérico gentilmente disponi bilizado pelo Prof. Dr. Márcio T. de Mendonça. 2015. Citado 2 vezes nas páginas 49 e 66.

NBR10152. Níveis de Ruído para Confor to Acústico: Apresentação. Rio de Janeiro: [s.n.], 1987. 4 p. p. Citado na página 27.

NUNES, O. Análise Teórica e Experimental do Campo Sonoro I r radiado por um Compressor Her mético. Dissertação (Mestrado) — Universi dade Estadual de Campinas, 2005. Citado 2 vezes nas páginas 27 e 29 .

OBERKAMPF, W. L.; TRUCANO, T. G. Verification and Validation in Computational Fluid Dynamics. [S.I.]: Sandia National Laboratories, 2002. Citado na página 74.

PRESS, W. H.; FLANNERY, B. P.; TEUKOLSKY, S. A.; VETTERLING, W. T. Numerical recipes in FORTRAN 77: The art of scientific computing. [S.I.]: Cambridge University Press, 1992. Citado 3 vezes nas páginas 55, 57 e 63.

QUIRINO, S. F. Simulação Numérica Direta de Camada Cisalhante Compressível com Fonte de Cal or . Dissertação (Mestrado) — Instituto Nacional de Pesquisas Espaciais - INPE, 2006. Citado na página 43.

REICHERT, R.; BIRINGEN, S. Numerical simulation of compressible plane jets. Mechanics Research Communications, v. 34, n. 3, p. 249 - 259, 2007. Citado 8 vezes nas páginas 25, 74, 95, 101, 102, 106, 110 e 118.

ROACHE, P. Verification and validation in computational science and engineering. Albuquerque, N.M: Hermosa Publishers, 1998. Citado na página 74.

ROGENSKI, J. K. I nfluência do Gr adiente de Pressão na Transição em Escoamentos sobre Superfícies Côncavas. Tese (Doutorado) - ICMC - USP, 2015. Citado na página 43.

ROVARIS, J. a. B.; DESCHAMPS, C. J. Large eddy simulation applied to reciprocating compressors. Journal of the Brazilian Society of Mechanical Sciences and Engineering, scielo, v. 28, p. $208-215,062006$. Citado na página 33.

SALARI, K.; KNUPP, P. Code Verification by the Method of Manufactured Solutions. [S.I.], 2000. Citado 3 vezes nas páginas 74,75 e 76 .

SALEMI, L. Análise deEstabilidadeLinear deCamada deM istura Laminar Compressível Binária. Dissertação (Mestrado) — Instituto Nacional de Pesquisas Espaciais - INPE, 2006. Citado 6 vezes nas páginas 44, 45, 46, 66, 86 e 87.

SANTOS, M. Análise de Filtros Acústicos de Sucção de Compressores na Presença de Escoamento. Dissertação (Mestrado) — Universi dade Federal de Santa Catarina, 2003. Citado na página 30.

SCHLICHTING, H. Boundary-layer theory. 7. ed. New York: McGraw-Hill, 1979. Citado na página 50. 
SILVA, A. R. d.; LENZI, A.; BAARS, E. Controling the noise radiation of hermetic compressors by means of minimization of power flow through discharge pipes using genetic algorithms. In: Proceedings of the 17th International Compressor Engineering Confer ence at Purdue. Purdue- US: [s.n.], 2004. Citado na página 30.

SILVA, H. G.; VILLAR, M. M. Verificação e validação de códigos computacionais. In: 7a Escola de Primavera de Transição e Turbulência-EPTT 2010. [S.I.: s.n.], 2010. Citado 2 vezes nas páginas 74 e 75 .

SILVEIRA, M. Noise and vibration reduction in compressors for commercial applications. In: Proceedings of the 17th International Compressor Engineering Confer ence at Purdue. Purdue- US: [s.n.], 2004. Citado na página 30.

SOEDEL, W. Sound and Vibrations of Positive Displacement Compressors. [S.I.]: CRC Press, 2006. Citado na página 29.

SOUZA, L. F. Numerical eval uation of time integration schemes in a disturbed flow simulation. In: Proceedings of 18th International Congress of Mechanical Engineer . [S.I.: s.n.], 2005. Citado na página 58.

SOUZA, L. F.; MENDONçA, M. T.; MEDEIROS, M. A. F. The advantages of using high-order finite differences schemes in laminar-turbulent transition studies. International Journal for Numerical Methods in Fluids, v. 48, p. 565-582, 2005. Citado na página 55.

SOUZA, M. A.; SOUZA, L. F. Simulação numérica da instabilidade de camada ci sal hante livre bidimensional. In: 5a Escola de Primavera de Transição e Turbulência - EPTT 2006. [S.I.: s.n.], 2006. Citado na página 32.

TAM, C. K. W. Supersonic jet noise. Annual Review of Fluid Mechanics, v. 27, n. 1, p. 17-43, 1995. Citado na página 104.

Jet noise: Since 1952. Theor etical and Computational Fluid Dynamics, Springer Berlin / Heidel berg, v. 10, p. 393-405, 1998. Citado na página 31.

. Computational aeroacoustics: An overview of computational challenges and applications. International Journal of Computational Fluid Dynamics, v. 18, n. 6, p. 547-567, 2004. Citado 3 vezes nas páginas 35, 36 e 59.

TAM, C. K. W.; WEBB, J. C. Dispersion-relation-preserving finite difference schemes for computational acoustics. Journal of Computational Physics, v. 107, n. 2, p. 262 - 281, 1993. Citado 2 vezes nas páginas 54 e 60.

TRELLA, T. J.; SOEDEL, W. On noise generation of air compressor automatic reed valves. In: Proceedings of the 1st International Compressor Engineering Conference at Purdue. Purdue- US: [s.n.], 1972. Citado na página 33.

WANG, M.; FREUND, J. B.; LELE, S. K. Computational prediction of flow-generated sound. Annual Review of Fluid Mechanics, v. 38, n. 1, p. 483-512, 2006. Citado 2 vezes nas páginas 34 e 36.

WEDER, M. Linear Stability and Acoustics of a Subsonic Plane Jet Flow. Dissertação (Mestrado) - ETH Zurich, 2012. C Citado 8 vezes nas pági nas 25, 74, 95, 96, 97, 101, 110 e 118. 
WELLS, V. L.; RENAUT, R. A. Computing aerodynamically generated noise. Annual Review of Fluid Mechanics, v. 29, n. 1, p. 161-199, 1997. Citado na página 36.

WHITE, F. M. Viscous Fluid Flow. [S.I.]: McGraw-Hill, 2005. Citado 2 vezes nas páginas 43 e 97.

WILLIAMSON, J. H. Low-storage Runge-Kutta schemes. Journal of Computational Physics, v. 35 , p. 48-56, 1980. Citado na página 58. 



\section{APÊNDICE}

\section{A}

\section{TERM OS ADICIONAIS NAS EQUAÇÕES GOVERNANTES}

A seguir são apresentados as divisões no cál culo do vetores de fluxo da Equação 2.8 separando em termos em que as $2^{a}$ derivadas são cruzadas e diretas, aproveitando-se das vantagens destacadas na seção 3.4 .

Como exemplo mais detalhado, tomamos a Equação 2.9. É possível reescrevêla da seguinte forma:

$$
F=F_{D 1}+F_{D 2}
$$

onde

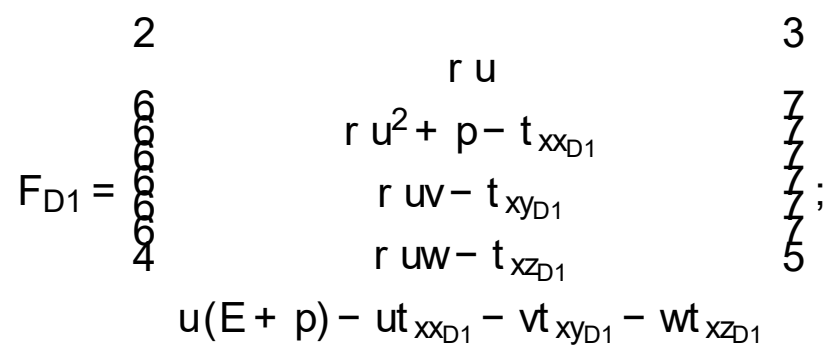

e

$$
F_{D 2}=\begin{array}{ccc}
2 & 0 & 3 \\
6 & -t_{x x_{D 2}} & 3 \\
8 & -t_{x y_{D 2}} & 3 \\
4 & -t_{x z_{D 2}} & 3 \\
q_{x}-u t_{x x_{D 2}}-v t_{x y_{D 2}}-w t_{x z_{D 2}}
\end{array}
$$

Os subscritos “D1" e "D2” consistem em termos que terão $1^{a}$ derivadas e $2^{a}$ derivadas, 
respectivamente. Os termos $\mathrm{D} 1$ geram derivadas cruzadas quando a Equação $\mathrm{A} .1$ é derivada em relação ax, enquanto que os termos $D 2$ geram $2^{a}$ derivadas. $A$ tensão normal $t_{x x}$ e cisal hantes $t_{x y}$ e $t_{x z}$ são também separadas em termos D1 e D2:

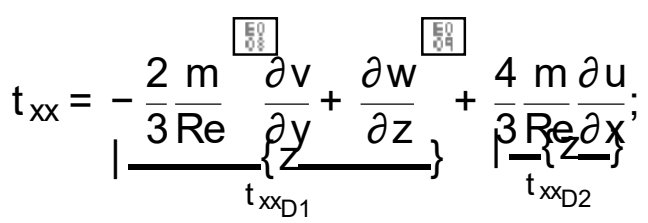

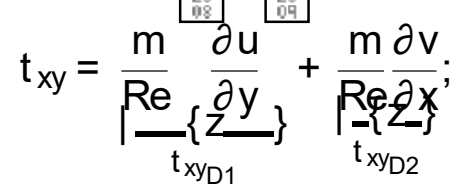

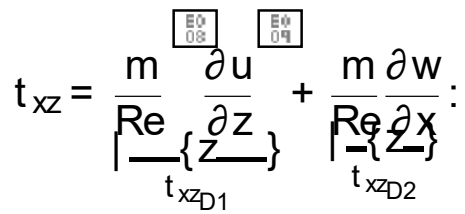

A derivada em relação a $x$ da Equação A.1 é dada por:

$$
\frac{\partial F}{\partial x}=\frac{\partial F_{D 1}}{\partial x}+\frac{\partial F_{D 2}}{\partial x}
$$

Para o cál culo do termo $\frac{\partial F_{D 1}}{\partial x}$ primeiro cal cul a-se cada termo interno e depois aplica-se a derivada ao termo $\mathrm{F}_{\mathrm{D} 1}$. Assim são obtidos os resul tados das derivadas cruzadas. Já o cál cul o do termo $\frac{\partial F_{D 2}}{\partial \mathrm{x}}$ é feito da seguinte forma:

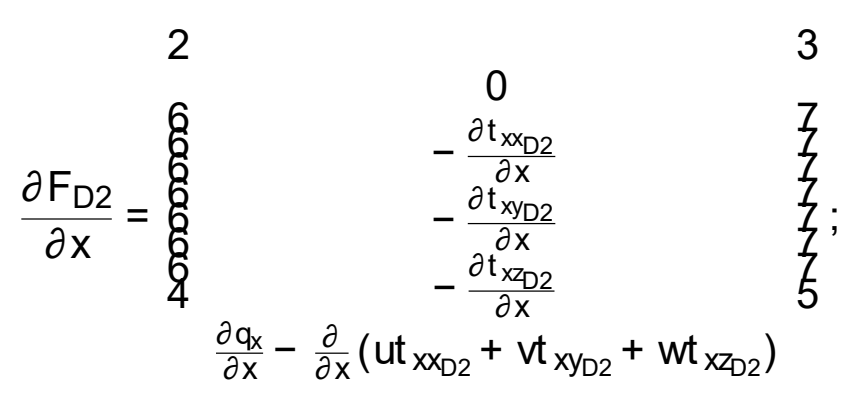

onde

$$
\begin{gathered}
\frac{\partial t_{x_{D 2}}}{\partial x}=\frac{4}{3} \frac{m}{\operatorname{Re}} \frac{\partial^{2} u}{\partial x^{2}} ; \\
\frac{\partial t_{x_{D 2}}}{\partial x}=\frac{m}{\operatorname{Re}} \frac{\partial^{2} v}{\partial x^{2}} ; \\
\frac{\partial t_{x_{D 2}}}{\partial x}=\frac{m}{\operatorname{Re}} \frac{\partial^{2} w}{\partial x^{2}} ; \\
\frac{\partial q_{x}}{\partial x}=\frac{J}{(k-1) \operatorname{RePrMa}^{2}} \cdot \frac{\partial^{2} T}{\partial x^{2}} ;
\end{gathered}
$$


e

$$
\begin{aligned}
& \frac{\partial}{\partial x}\left(u t_{x x_{D 2}}+v t_{x y_{D 2}}+w t_{x z_{D 2}}\right)= \\
& =u \frac{\partial t_{x x_{D 2}}}{\partial x}+t_{x x_{D 2}} \frac{\partial u}{\partial x}+v \frac{\partial t_{x y_{D 2}}}{\partial x}+t_{x y_{D 2}} \frac{\partial v}{\partial x}+w \frac{\partial t_{x z_{D 2}}}{\partial x}+t_{x z_{D 2}} \frac{\partial w}{\partial x}= \\
& =\mathrm{u} \frac{\partial \mathrm{t}_{\mathrm{xx}_{\mathrm{D} 2}}}{\partial \mathrm{x}}+\frac{4}{3} \frac{\mathrm{m}}{\operatorname{Re}} \frac{\partial \mathrm{u}}{\partial \mathrm{x}} \cdot \frac{\partial \mathrm{u}}{\partial \mathrm{x}}+\mathrm{v} \frac{\partial \mathrm{t}_{\mathrm{xy}_{\mathrm{D} 2}}}{\partial \mathrm{x}}+\frac{\mathrm{m}}{\mathrm{Re}} \frac{\partial \mathrm{v}}{\mathrm{R} \mathrm{x}} \cdot \frac{\partial \mathrm{v}}{\partial \mathrm{x}}+\mathrm{w} \frac{\partial \mathrm{t}_{\mathrm{xZ}_{\mathrm{D} 2}}}{\partial \mathrm{x}}+\frac{\mathrm{m}}{\operatorname{Re}} \frac{\partial \mathrm{w}}{\partial \mathrm{x}} \cdot \frac{\partial \mathrm{w}}{\partial \mathrm{x}}= \\
& =u \frac{\partial t_{x x_{D 2}}}{\partial x}+v \frac{\partial t_{x y_{D 2}}}{\partial x}+w \frac{\partial t_{x Z_{D 2}}}{\partial x}+\frac{m}{\operatorname{Re}} \frac{4}{3} \frac{\partial u}{\partial x}+\frac{\partial v}{\partial x}+\frac{\partial w}{\partial x}=
\end{aligned}
$$

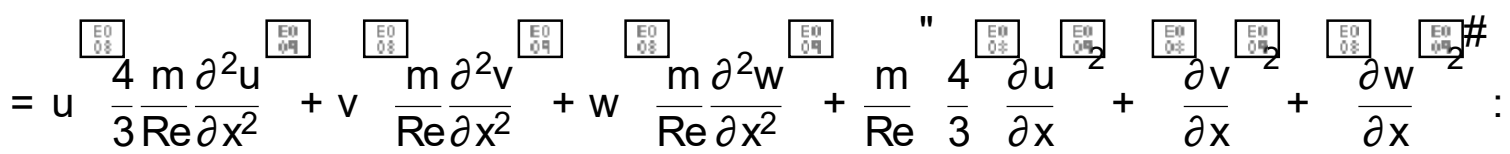

Uma vez cál culado $\frac{\partial F_{D 2}}{\partial x}$, este é somado ao resultado do cál culo do termo $\frac{\partial F_{D 1}}{\partial x}$. Procedimento semel hante é real izado para as variáveis $\mathrm{G}$ eH.

Para a variável G:

$$
\frac{\partial G}{\partial y}=\frac{\partial G_{D 1}}{\partial y}+\frac{\partial G_{D 2}}{\partial y}
$$

onde

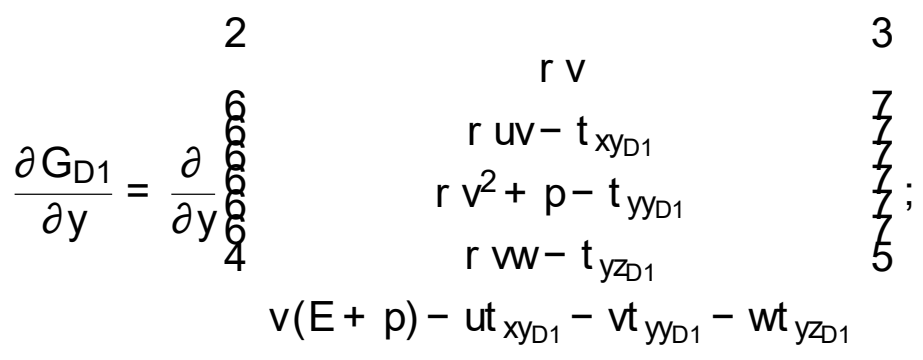

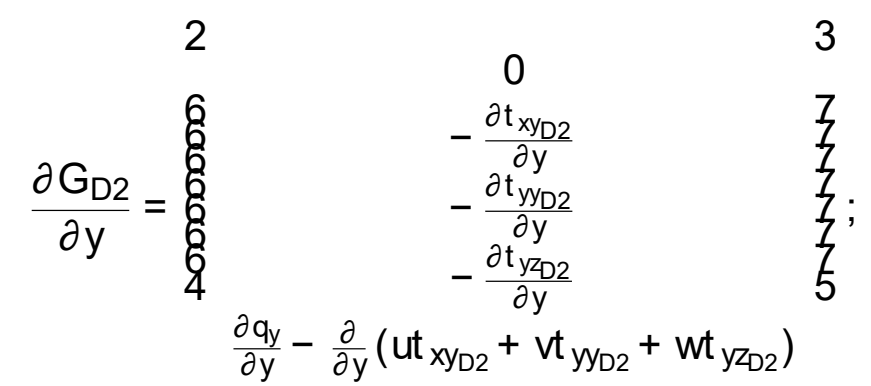

$$
\begin{aligned}
& \frac{\partial \mathrm{t}_{\mathrm{xy}_{\mathrm{D} 2}}}{\partial \mathrm{y}}=\frac{\mathrm{m}}{\operatorname{Re}} \frac{\partial^{2} \mathrm{u}}{\partial \mathrm{y}^{2}} ; \\
& \frac{\partial t_{y_{D 2}}}{\partial y}=\frac{4}{3} \frac{m}{R e} \frac{\partial^{2} v}{\partial y^{2}}
\end{aligned}
$$




$$
\begin{gathered}
\frac{\partial t_{y z D 2}}{\partial y}=\frac{m}{\operatorname{Re}} \frac{\partial^{2} w}{\partial y^{2}} \\
\frac{\partial q_{y}}{\partial y}=\frac{J}{(k-1) \operatorname{RePrMa}^{2}} \cdot \frac{\partial^{2} T}{\partial y^{2}}
\end{gathered}
$$

e

$$
\begin{aligned}
& \frac{\partial}{\partial y}\left(u t_{x y_{D 2}}+v t_{y_{D 2}}+w t_{y_{D} 2}\right)=
\end{aligned}
$$

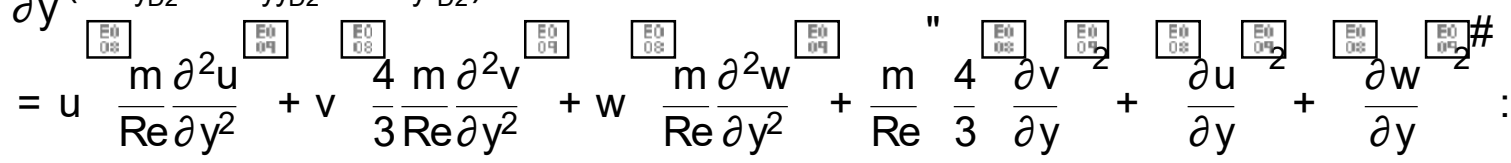

Para a variável $\mathrm{H}$ :

$$
\frac{\partial H}{\partial z}=\frac{\partial H_{D 1}}{\partial z}+\frac{\partial H_{D 2}}{\partial z}
$$

onde

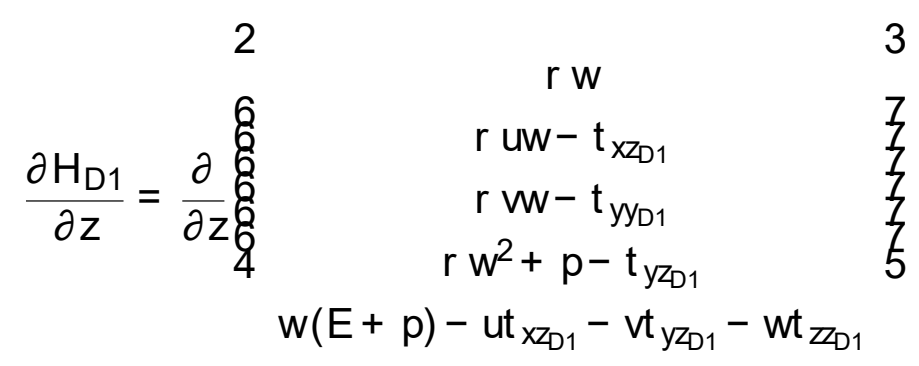

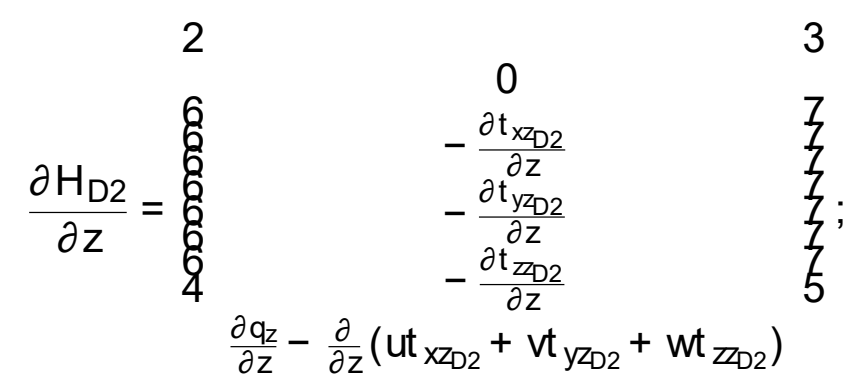

$$
\begin{aligned}
& \frac{\partial t_{x z_{D 2}}}{\partial z}=\frac{m}{\operatorname{Re}} \frac{\partial^{2} u}{\partial z^{2}} \\
& \frac{\partial t_{y z_{D 2}}}{\partial z}=\frac{m}{\operatorname{Re}} \frac{\partial^{2} v}{\partial z^{2}} \\
& \frac{\partial t_{z_{D 2}}}{\partial z}=\frac{4}{3} \frac{m}{\operatorname{Re}} \frac{\partial^{2} w}{\partial z^{2}}
\end{aligned}
$$




$$
\frac{\partial q_{z}}{\partial z}=\frac{J}{(k-1) \operatorname{RePrMa} a^{2}} \cdot \frac{\partial^{2} T}{\partial z^{2}}
$$

e

$$
\begin{aligned}
& \frac{\partial}{\partial z}\left(\mathrm{ut}_{\mathrm{xzD} 2}+\mathrm{vt}_{\mathrm{yzD} 2}+\mathrm{wt}_{\mathrm{z} \mathrm{D} 2}\right)=
\end{aligned}
$$

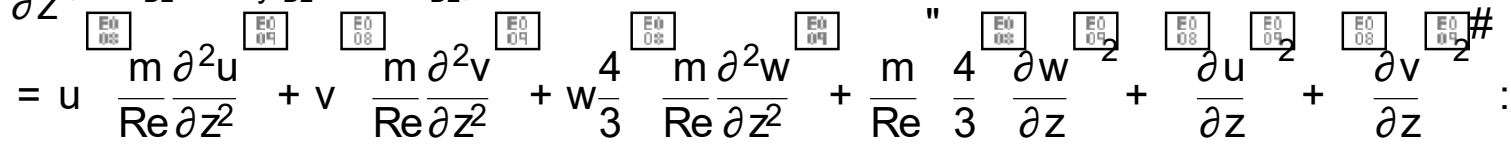





\section{APÊNDICE}

\section{TERMOS FONTES DO MMS}

A seguir são apresentados os termos fontes utilizados para as anál ises MMS bidimensionais (seção 4.2) e tridimensionais (seção 4.3).

\section{B.1 Termos Fontes - M MS 2D}

Figura 58 - Termo fonte para a variável $r$ - MMS 2D.

$\ln [18]=$ FortranForm $[$ Srho $[x, y, t]]$

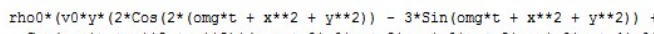

Fonte: Elaborada pelo autor.

Figura 59 - Termo fonte para a variável r u - MMS 2D.

$\ln [19]=$ FortranForm $[S \operatorname{rrhou}[x, y, t]]$

omg*rho $0 * u 0 * \operatorname{Cos}($ omg $* t+x * * 2+y * * 2) *(1.5+\operatorname{Sin}($ omg $t \mathrm{t}+\mathrm{x} * * 2+\mathrm{y} * \star 2))$

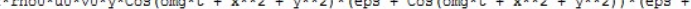

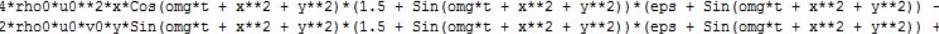

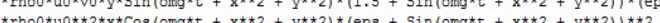

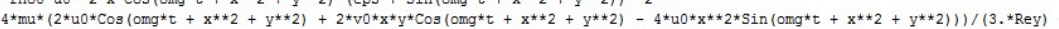

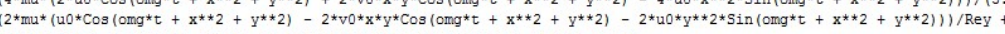

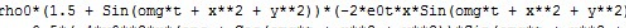

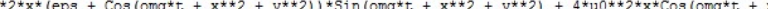

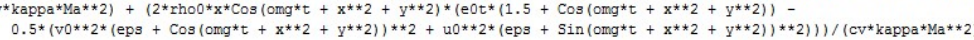

Fonte: Elaborada pelo autor.

\section{B.2 Termos Fontes - M MS 3D}


Figura 60 - Termo fonte para a variável r v - MMS 2D.

$\ln [20]:=$ FortranForm $[$ Srhov $[\mathrm{x}, \mathrm{y}, \mathrm{t}]]$

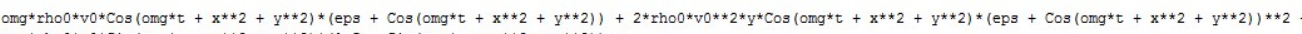

(omg*t $\left.\left.+x^{* * 2}+y^{* * 2}\right)\right) *\left(\right.$ eps $\left.+\operatorname{Sin}\left(o m g * t+x^{* * 2}+y^{* * 2}\right)\right)+$

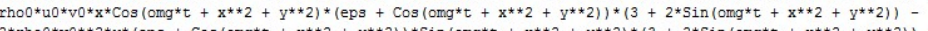

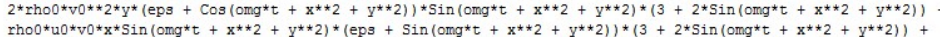

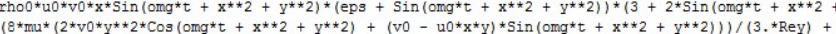

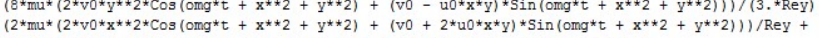

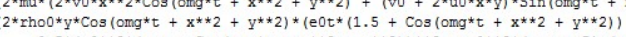

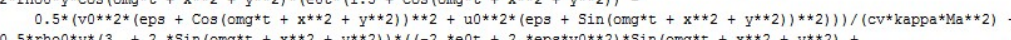

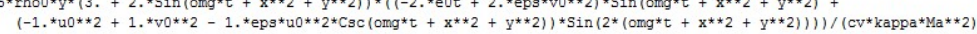

Fonte: Elaborada pelo autor.

Figura 61 - Termo fonte para a variável E - MMS 2D.

In[2]1]= FortranForm [SE $[x, y, t]] / /$ Simplify

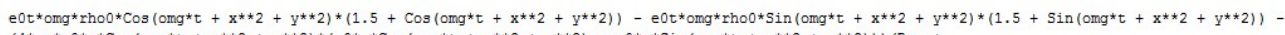

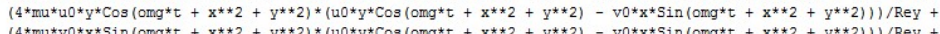

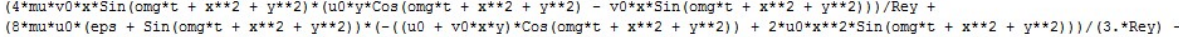

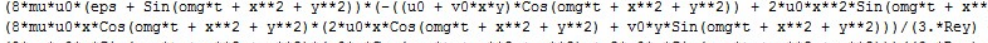

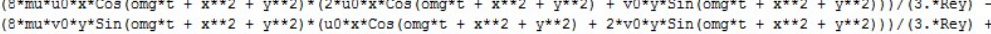

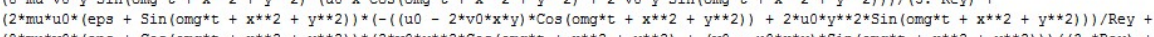

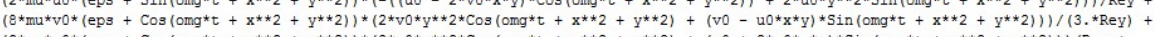

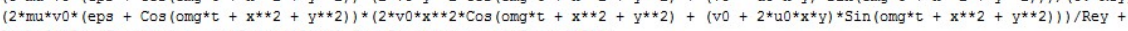

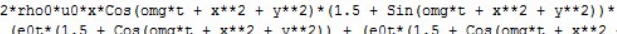

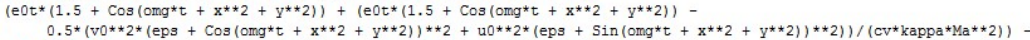

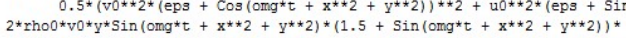

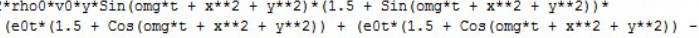

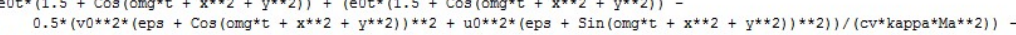

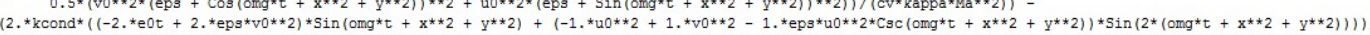

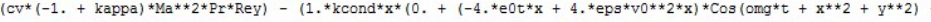

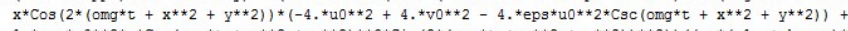

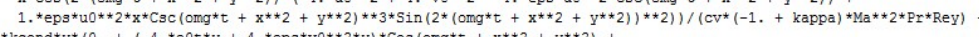

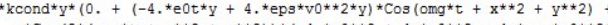

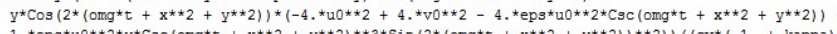

(a)

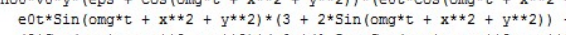

$\left(2 * \operatorname{Cos}\left(\right.\right.$ omg*t $\left.+x^{* * 2}+y^{* * 2}\right) *\left(e 0 t *\left(1.5+\operatorname{Cos}\left(\right.\right.\right.$ omg $\left.\left.* t+x^{* * 2}+y^{* * 2}\right)\right)-$

$0.5 *(\mathrm{v} 0 * * 2 *($ eps
0

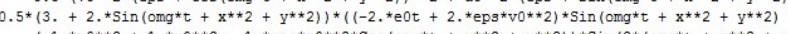

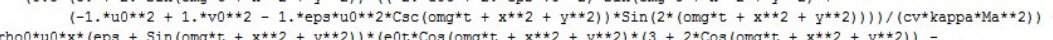

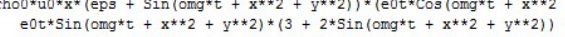

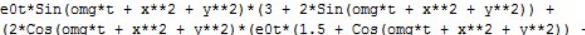

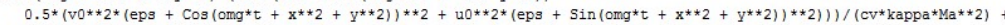

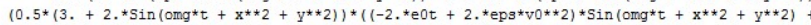

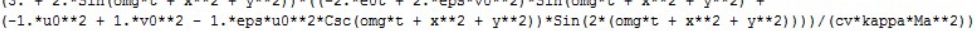

Fonte: Elaborada pelo autor.

Figura 62 - Termo fonte para a variável $r$ - MMS 3D.

[22]- FortranForn [Srho $[x, y, z, t]] / /$ Simplify

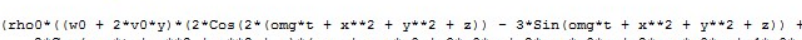

Fonte: Elaborada pelo autor.

Figura 63 - Termo fonte para a variável r u - MMS 3D.

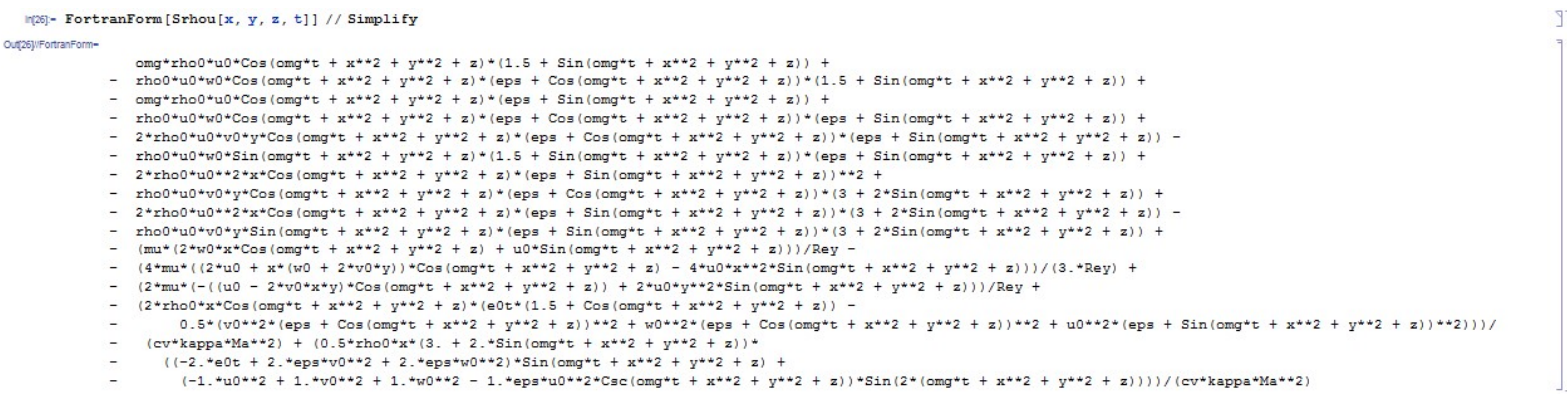

Fonte: Elaborada pelo autor. 
Figura 64 - Termo fonte para a variável r v - MMS 3D.

4[2]- FortranForm [Srhov $[x, y, z, t] 1 / /$ simplis

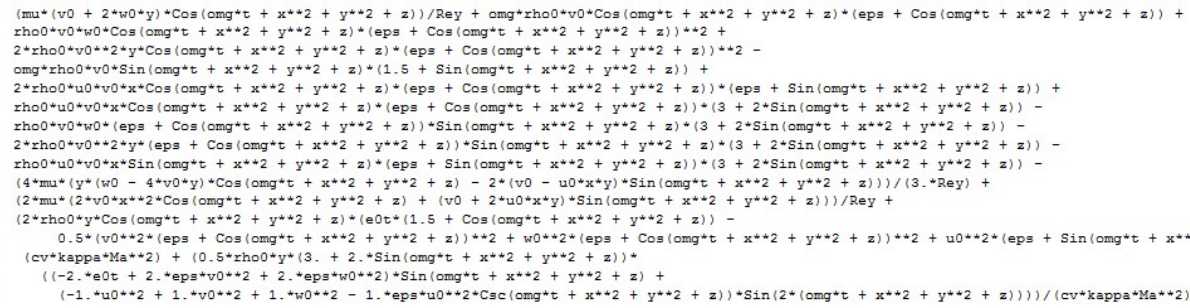

Fonte: Elaborada pelo autor.

Figura 65 - Termo fonte para a variável $\mathrm{r}$ w - MMS 3D.

Wrag- FortranForm [Srhow $[x, y, z, t]] / /$ Simplif $y$

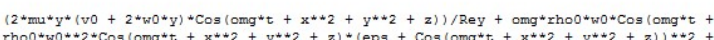

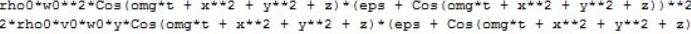

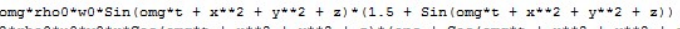

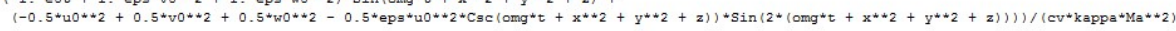

\section{Fonte: Elaborada pelo autor.}


Figura 66 - Termo fonte para a variável E - MMS 3D.

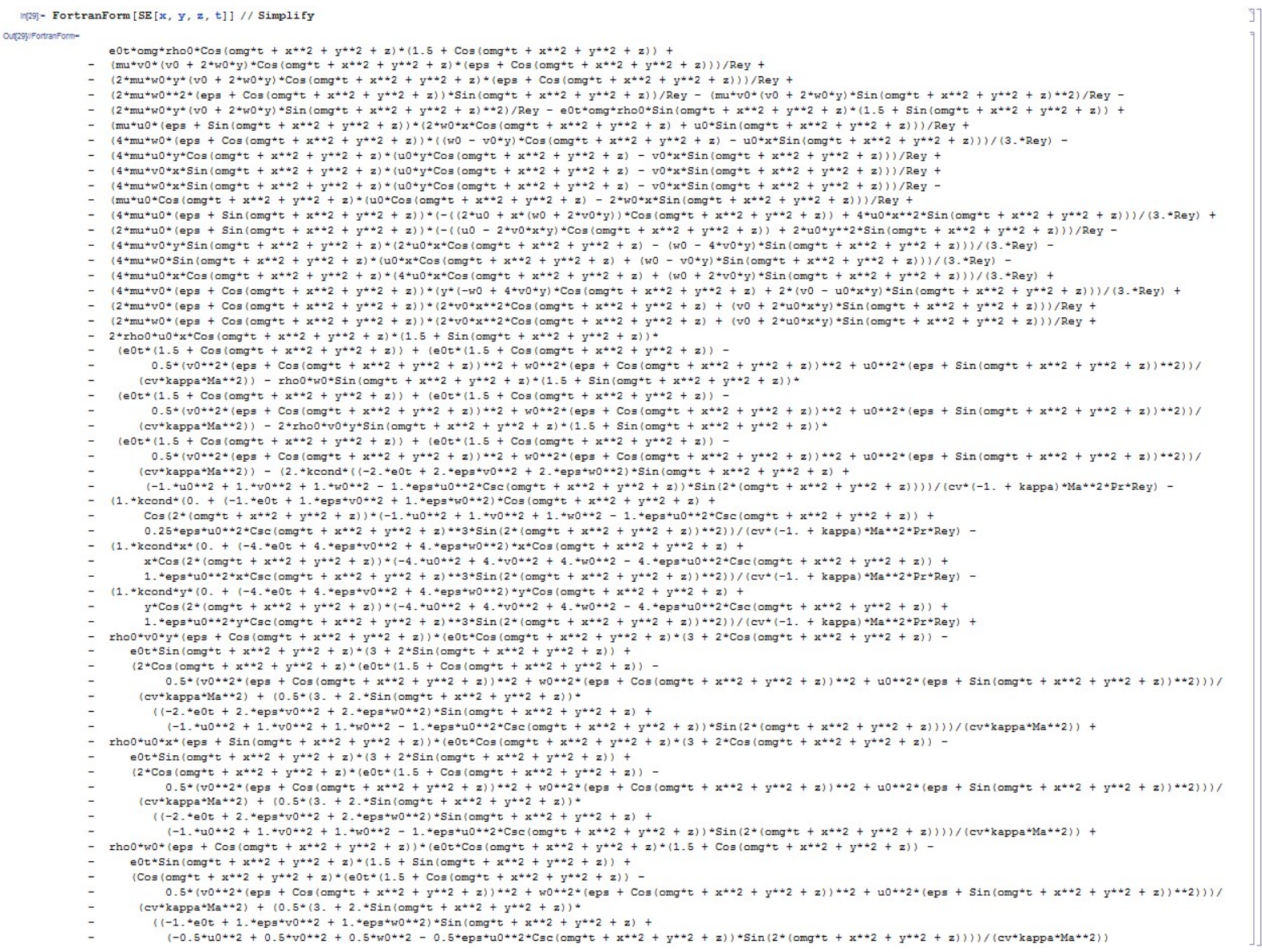

Fonte: Elaborada pelo autor. 


\section{APÊNDICE}

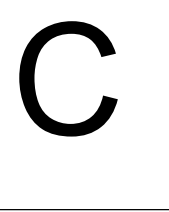

\section{SPEEDUP E EFICIÊNCIA}

Alguma métricas conhecidas de desempenho de compressores são o Speedup e a eficiência.

Speedup pode ser definido como a relação entre o tempo gasto para executar o programa com um único elemento de processamento e o tempo gasto para executar o mesmo programa com $\mathrm{N}$ el ementos de processamento, mostrando o ganho de tempo. Speedup ideal é linear com o aumento do número de elementos de processamento utilizados.

$$
S p=\frac{T_{1}}{T_{N}}
$$

Jáa eficiênciaéa razão entre o Speedup e o número de processadores e indica a proporção do tempo em que os elementos de processamento estão ocupados.

$$
E f=\frac{T_{1}}{N \cdot T_{N}}
$$

No presente trabal ho há decomposição de domínio e um único programa agindo sobre conj untos separados de dados (Single Program Multiple Data - SPMD). No presente caso há a necessidade de se comunicar informações e sincronizar atividades entre os elementos de processamento durante a sol ução. Assi m, o tempo não utilizado real mente nos cál cul os estão sendo despendidos em comunicação e sincronização, o que di minuem o Speedup e a eficiência. Na prática, para cada caso, há um certo ponto em que não se torna mais interessante aumentar o número de el ementos de processamento para se diminuir o tempo computacional.

Na Figura 67 seguir são apresentados os resultados de Speedup e na Figura 68 a eficiência para os casos bidimensionais camada de mistura (seção 4.4), jato planar Weder2D (subseção 4.5.1) e jato planar ReichertBiringen2D (subseção 4.5.2).

Para real ização dos testes apresentados foram si mul ados 100 passos de tempo para todos 
Figura 67 - Speedup para os casos bidimensionais.

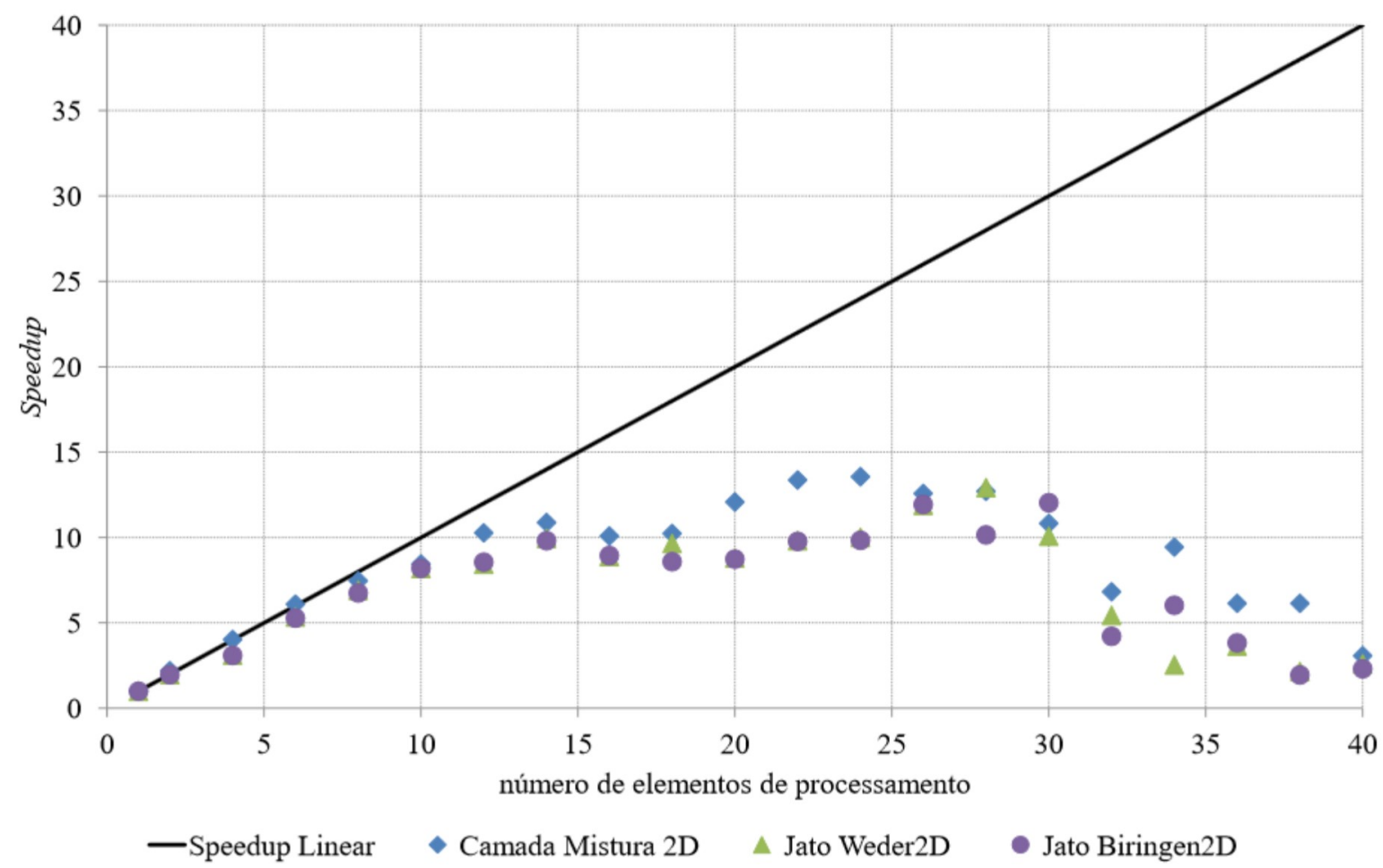

Fonte: Elaborada pelo autor.

os casos e só foram considerados o tempos computacionais para a realização dos cál culos, desconsiderando durante a execução dos códigos os tempos gastos com impressão de resul tados. $\mathrm{Na}$ Figura 69 é mostrado o comportamento do tempo adimensional dado pela razão $T_{N}=T_{1}$. Em todas as si mul ações bidi mensionai s utilizou-se a combi nação com 7 el ementos de processamento para direção x e 2 el ementos para a direção y, total izando 14 elementos de processamento. Os tempos de simul ações são apresentados na Tabela 7 
Figura 68 - Eficiência para os casos bidimensionais.

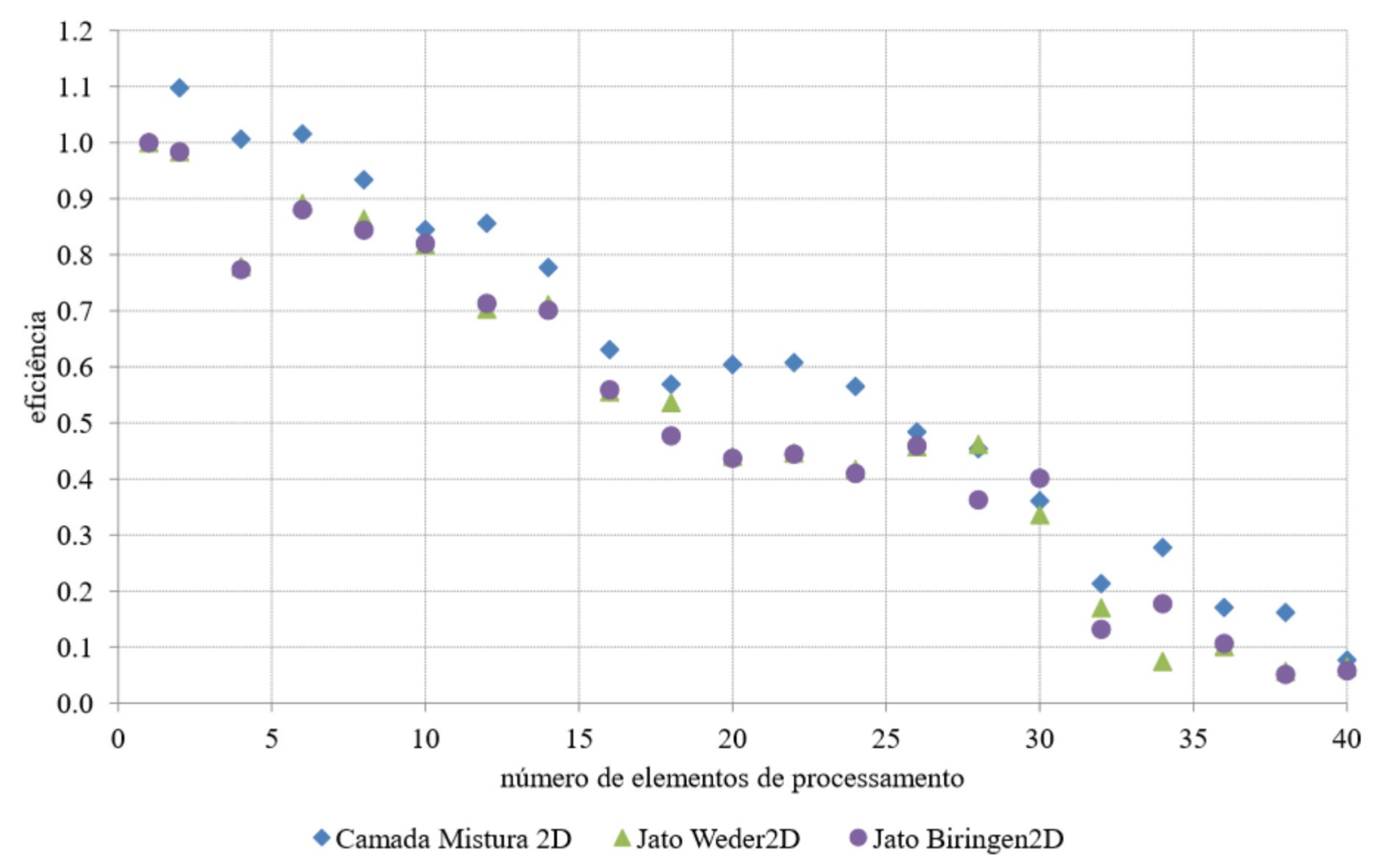

Fonte: Elaborada pelo autor.

Tabela 7 - Parâmetros das si mulações bidimensionais.

\begin{tabular}{|c|c|c|c|}
\hline Caso & $\begin{array}{c}\text { Camada de } \\
\text { Mistura }\end{array}$ & $\begin{array}{c}\text { Jato Planar } \\
\text { Weder2D }\end{array}$ & $\begin{array}{c}\text { Jato Planar } \\
\text { RichertBirin- } \\
\text { gen2D }\end{array}$ \\
\hline Número pontos em $\mathrm{x}$ & 2500 & 1400 & 1400 \\
\hline Número de pontos em y & 850 & 800 & 800 \\
\hline Número total de pontos & 2125000 & 1120000 & 1120000 \\
\hline $\begin{array}{c}\mathrm{N}^{\circ} \text { elementos de } \\
\text { processamento em } \mathrm{x}\end{array}$ & 7 & 7 & 7 \\
\hline $\begin{array}{c}\mathrm{N}^{\circ} \text { elementos de } \\
\text { processamento em y }\end{array}$ & 2 & 2 & 2 \\
\hline $\begin{array}{c}\mathrm{N}^{\circ} \text { elementos de } \\
\text { processamento total }\end{array}$ & 14 & 14 & 14 \\
\hline $\begin{array}{c}\text { Número períodos da } \\
\text { frequênciafundamental }\end{array}$ & 76 & 10 & 76 \\
\hline $\begin{array}{c}\text { No de passos de tempo por } \\
\text { frequênciafundamental }\end{array}$ & 752 & 752 & 752 \\
\hline \begin{tabular}{c} 
Total de passos de tempo \\
\hline Tempo total de simul ação
\end{tabular} & 57152 & 7520 & 57152 \\
\hline
\end{tabular}


Figura 69 - Tempo adimensional para os casos bidimensionais.

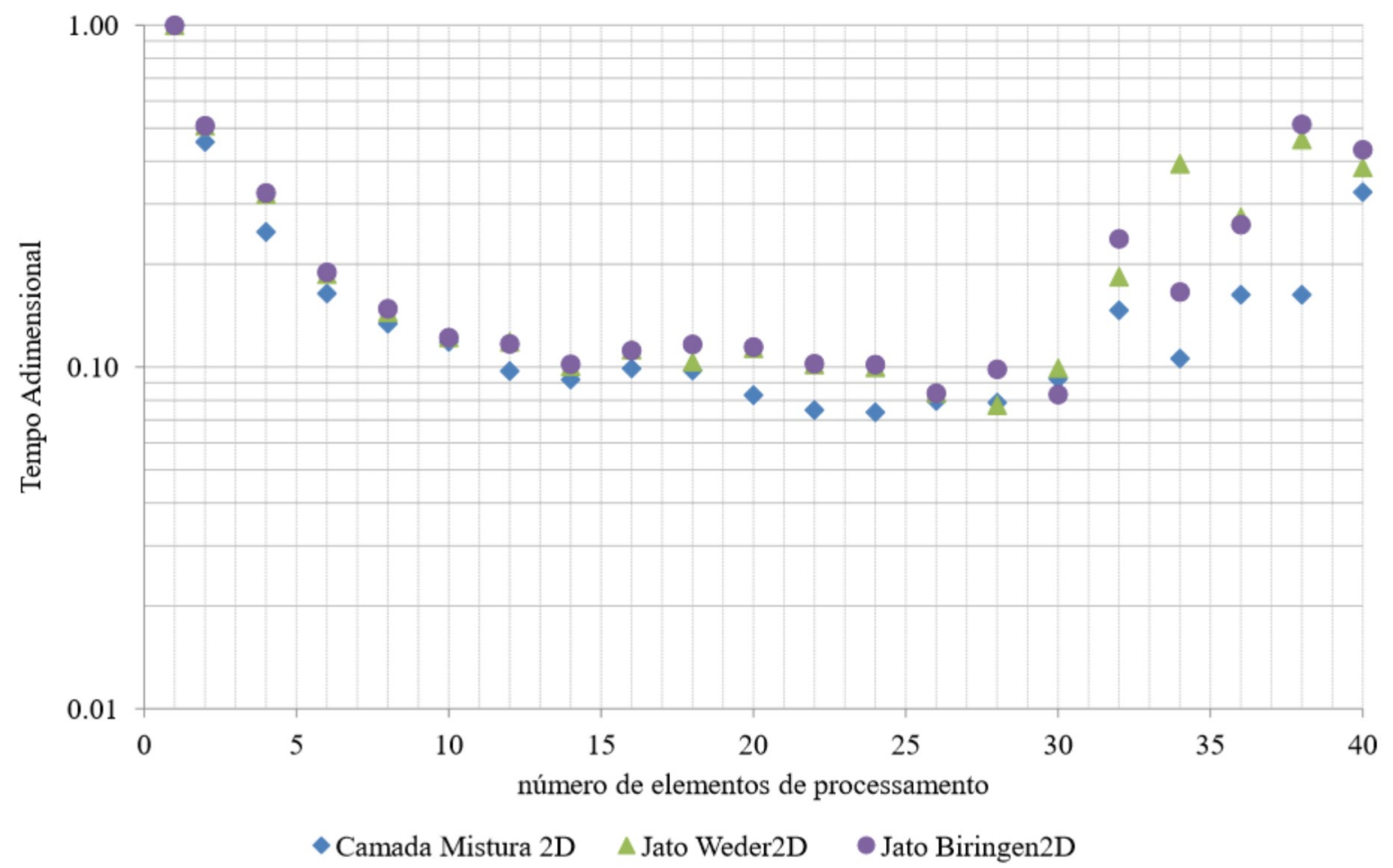

Fonte: Elaborada pel o autor. 